CAMILLA BRUNO DI-NIZO

CITOTAXONOMIA E EVOLUÇÃO CROMOSSÔMICA EM OLIGORYZOMYS (RODENTIA, SIGMODONTINAE)

Dissertação apresentada ao
Programa de Pós-Graduação
Interunidades em Biotecnologia USP/
Instituto Butantan/IPT, para obtenção
do Título de Mestre em Biotecnologia.




\section{CITOTAXONOMIA E EVOLUÇÃO CROMOSSÔMICA EM OLIGORYZOMYS (RODENTIA, SIGMODONTINAE)}

Dissertação apresentada ao Programa de Pós-Graduação Interunidades em Biotecnologia USP/Instituto Butantan/IPT, para obtenção do Título de Mestre em Biotecnologia.

Área de concentração: Biotecnologia

Orientadora: Dra. Maria José de Jesus Silva

Versão original

São Paulo 2013 


\section{DADOS DE CATALOGAÇÃO NA PUBLICAÇÃO (CIP)}

Serviço de Biblioteca e Informação Biomédica do

Instituto de Ciências Biomédicas da Universidade de São Paulo

reprodução não autorizada pelo autor

Di Nizo, Camilla Bruno.

Citotaxonomia e evolução cromossômica em Oligoryzomys (Rodentia, Sigmodontinae) / Camilla Bruno Di Nizo. -- São Paulo, 2013.

Orientador: Profa. Dra. Maria José de Jesus Silva.

Dissertação (Mestrado) - Universidade de São Paulo. Instituto de Ciências Biomédicas. Programa de Pós-Graduação Interunidades em Biotecnologia USP/IPT/Instituto Butantan. Área de concentração:

Biotecnologia. Linha de pesquisa: Estudos citogenéticos em pequenos mamíferos brasileiros.

Versão do título para o inglês: Citotaxonomy and chromosome evolution in Oligoryzomys (Rodentia, Sigmodontinae).

1. Citotaxonomia 2. Citogenética molecular 3. Oligoryzomys 4. Pintura cromossômica 5. Bandamento cromossômico 6. Evolução cromossômica I. Silva, Profa. Dra. Maria José de Jesus II. Universidade de São Paulo. Instituto de Ciências Biomédicas. Programa de Pós-Graduação Interunidades em Biotecnologia USP/IPT/Instituto Butantan III. Título. 
Candidato(a): $\quad$ Camilla Bruno Di Nizo.

Título da Dissertação: $\quad$ Citotaxonomia e evolução cromossômica em Oligoryzomys (Rodentia, Sigmodontinae).

Orientador(a): $\quad$ Profa. Dra. Maria José de Jesus Silva.

A Comissão Julgadora dos trabalhos de Defesa da Dissertação de Mestrado, em sessão pública realizada a ..................................................., considerou
( ) Aprovado(a)
( ) Reprovado(a)

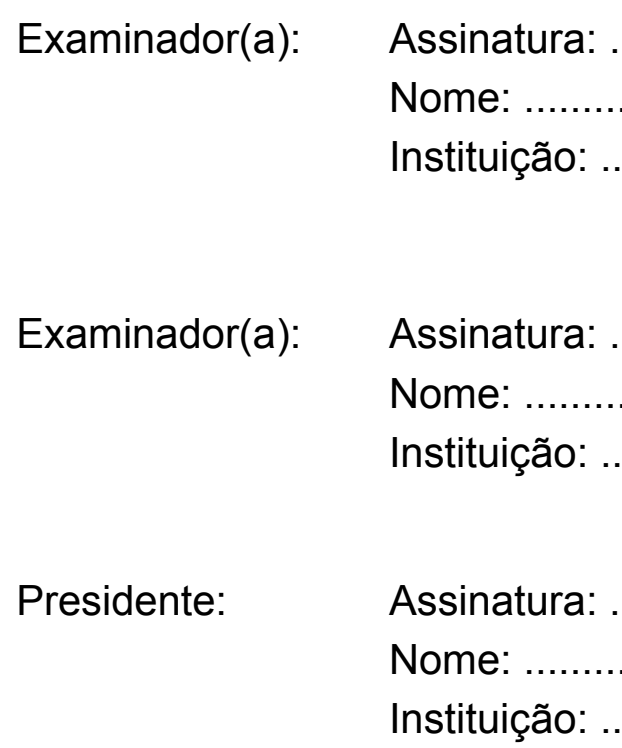




\section{CERTIFICADO}

Certificamos que o Protocolo para uso de animais em experimentação $\mathrm{n}^{\circ}$ 242/05, sobre o projeto intitulado "Estudos citogenéticos e moleculares em pequenos roedores neotropicais", sob a responsabilidade de Maria José de J. Silva está de acordo com os Princípios Éticos na Experimentação Animal adotado pelo Colégio Brasileiro (COBEA) e foi aprovado pela COMISSÃO DE ÉTICA NO USO DE ANIMAIS DO INSTITUTO BUTANTAN (CEUAIB) em reunião de 21/02/2006.

De acordo:

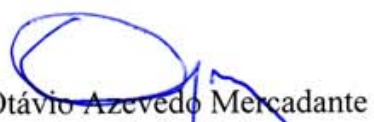

Diretor do Instituto Butantan

São Paulo, 22 de fevereiro de 2006.

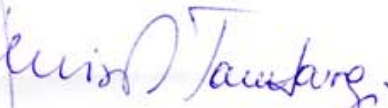

Dra. Denise V. Tambourgi Presidente da CEUAIB 


\section{Secretaria de Estado da Saúde Instituto Butantan www. butantan.gov.br}

\section{Declaração}

Declaro, para os devidos fins, que o projeto de mestrado da aluna CAMILLA BRUNO DI NIZO (Número USP: 7077617), intitulado "Evolução cromossômica no gênero Oligoryzomys (Cricetidae: Sigmodontinae): estudos comparativos por meio de citogenética clássica e pintura cromossômica", foi dispensado da solicitação de um número de licença específico pela Comissão de Ética do Instituto Butantan (CEUAIB), uma vez que tal projeto está inserido no Jovem Pesquisador FAPESP "Estudos citogenéticos e moleculares em pequenos roedores neotropicais", sob minha coordenação, e cujo número de licença autorizado pela CEUAIB é 242/05, emitido em fevereiro de 2006.

São Paulo, 30 de janeiro de 2013

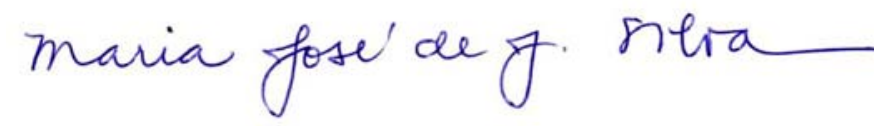

Maria José de J. Silva (orientadora)

Laboratório de Ecologia e Evolução

Instituto Butantan

Av. Dr. Vital Brazil, 1500

São Paulo, SP - Brasil - 05503-000

Tel.: (55)(11) 2627-9812

mariajo@butantan.gov.br

mariajo@usp.br 
Aos meus pais queridos,

Romano e Solange, com muito amor. 


\section{AGRADECIMENTOS}

Gostaria de agradecer às pessoas e entidades que colaboraram para o desenvolvimento deste trabalho.

À Dra. Maria José de Jesus Silva pela orientação, dedicação, conselhos e confiança durante todos esses anos.

À Dra. Karen Ventura por intermediar o contato para minha ida a Cambridge, por me ensinar a trabalhar com as culturas celulares e pelo incentivo.

À Dra. Yatiyo Yonenaga-Yassuda, pelo acesso ao banco de células e pelo exemplo.

À Fundação Coordenação de Aperfeiçoamento de Pessoal de Nível Superior (CAPES) e à Fundação de Amparo à Pesquisa do Estado de São Paulo (FAPESP - Processo: 2010/03432-0) pelo auxílio financeiro.

Ao Dr. Malcolm Ferguson-Smith por me receber em seu laboratório em Cambridge e à Patricia O'Brien pela produção das sondas de Oligoryzomys moojeni.

Ao Dr. Miguel Trefaut Rodrigues e ao seu grupo pelas coletas de grande parte dos exemplares deste trabalho e ao Mauro Teixeira, pelas belas fotos de Oligoryzomys tiradas na Floresta Nacional de Ipanema.

Aos nossos colaboradores, que coletaram o restante da nossa amostra, em especial: Dra. Ana Paula Carmignotto, MSc. Carolina Lima Neves, Raisa Rodarte, Dr. Laerte Viola, Dra. Sandra Favorito, Dra. Adriana Arruda Bueno, Dra. Fernanda Nieri, Dr. Arlei Marcili, Flávio Agapito, Ligia F. de Pina, Dr. Diego Queirolo, Dr. Flávio H. G. Rodrigues, Dr. Mauro Galetti, Dr. Rogério Rossi, Dr. José Carlos Motta-Júnior e Dr. Alexandre U. Christoff.

À Dra. Maria José de Jesus Silva, Dra. Renata Cecília Amaro, Dra. Karen Ventura e MSc. Márcia Laguna pelas preparações citogenéticas de alguns exemplares.

À Dra. Ângela Maria Vianna-Morgante do Instituto de Biociências da USP e aos Doutores Ronaldo Zucatelli e Darci Moraes Barros-Battesti do Instituto Butantan, pela permissão do uso da sala de cultura. 
Aos colegas de laboratório por toda a ajuda e pelos momentos prazerosos: Taís, Karina, Ana, Lorena, Keila, José Patané, Dra. Nancy Oguiura, Dra. Maria José e ao recém-chegado Elkin. Gostaria de fazer um agradecimento especial à Taís, que me acompanha e ajuda desde o comecinho, já que somos as mais antigas do clã Maria José!

A todos os funcionários e amigos do Laboratório de Ecologia e Evolução do Instituto Butantan.

À Dra. Cleusa Nagamachi pela preciosa ajuda e conselhos.

Aos amigos queridos: Marcinha (só você sabe o quanto já me ajudou), Karina (minha companheira de lab e confidente) e aos amigos de graduação, principalmente Mabi, Milena, Maíra, Renato-Crajas, Gabriel e Brunno-Diplas (vocês são muito importantes para mim).

À família Bruno-Di Nizo, por ser minha base e referência.

Aos meus pais, pelo carinho e por sempre me apoiarem em todos os sentidos e à Stella, minha mascote.

Ao Prin, por simplesmente tudo o que representa para mim. 


\section{RESUMO}

DI-NIZO, C. B. Citotaxonomia e evolução cromossômica em Oligoryzomys (Rodentia, Sigmodontinae). 2013. 163 f. Dissertação (Mestrado em Biotecnologia) - Instituto de Ciências Biomédicas, Universidade de São Paulo, São Paulo, 2013.

Os roedores do gênero Oligoryzomys estão distribuídos por toda a região Neotropical. Devido a sua homogeneidade morfológica, há inúmeras controvérsias com relação às entidades taxonômicas do grupo; porém, o cariótipo tem sido uma ferramenta muito valiosa para diagnose das espécies. O objetivo do presente trabalho é caracterizar citogeneticamente as espécies do gênero Oligoryzomys, contribuir para a citotaxonomia, e investigar a evolução cromossômica no gênero. A dissertação está estruturada em quatro partes: no Capítulo 1, será apresentada a revisão bibliográfica sobre a temática do trabalho e o Capítulo 2 tratará de toda a metodologia empregada para o desenvolvimento do mesmo. Os resultados serão apresentados nos Capítulos 3 e 4 . O Capítulo 3 abordará os resultados obtidos empregando as técnicas de citogenética clássica, a partir das quais foram analisados 117 exemplares pertencentes às espécies: $O$. flavescens $(2 \mathrm{n}=64-66, \mathrm{NF}=66)$, O. fornesi $(2 \mathrm{n}=62, \mathrm{NF}=64)$, O. microtis $(2 \mathrm{n}=64, \mathrm{NF}=64)$, O. moojeni $(2 \mathrm{n}=70, \mathrm{NF}=72)$, O. nigripes $(2 \mathrm{n}=62, \mathrm{NF}=78-$ $82)$, O. stramineus $(2 \mathrm{n}=52, \mathrm{NF}=68)$ e Oligoryzomys sp. A $(2 \mathrm{n}=70, \mathrm{NF}=72)$. As seis primeiras possuem cariótipos espécie-específicos e, dessa forma, reiteramos a importância da informação citogenética para a citotaxonomia do grupo. No Capítulo 4, serão mostrados os dados de pintura cromossômica realizados em cinco espécies de Oligoryzomys a partir de sondas cromossômicas de $O$. moojeni, uma das espécies com maior número diplóide do gênero. A pintura cromossômica comparativa (ZooFISH) revelou hibridação em 29 segmentos autossômicos em $O$. fornesi; 30 em O. microtis; 31 em O. nigripes; e $32 \mathrm{em} O$. rupestris e Oligoryzomys sp. 2. Os resultados mostraram uma extensa reorganização genômica na evolução cromossômica do gênero, decorrente de fissões, fusões em tandem, rearranjos Robertsonianos e perda/inativação, ganho/ativação ou reposicionamento de centrômero.

Palavras-chave: Oligoryzomys. Citotaxonomia. Evolução cromossômica. Pintura Cromossômica. 


\begin{abstract}
DI-NIZO, C. B. Citotaxonomy and chromosome evolution in Oligoryzomys (Rodentia, Sigmodontinae). 2013. 163 p. Masters thesis (Biotechnology) - Instituto de Ciências Biomédicas, Universidade de São Paulo, São Paulo, 2013.

Pygmy rice rats of the genus Oligoryzomys are widespread in the Neotropical region. Taxonomy controversies are common in the genus due to its morphological homogeneity. Therefore, cytogenetic has been a useful tool to diagnose species. The aim of this work is to characterize cytogenetically the species of the genus Oligoryzomys, contributing to citotaxonomy, and to investigate the chromosomal evolution of the genus. This Master thesis consists in four chapters: in Chapter 1, a brief introduction of the subject is presented and Chapter 2 has the methodology used throughout this work. The results obtained are presented separately in Chapters 3 and 4 . In Chapter 3, we show the results of classical cytogenetics techniques. A total of 117 individuals were cytogenetically analysed, and they belong to the following species: $O$. flavescens $(2 n=64$ 66, $\mathrm{FN}=66)$, O. fornesi $(2 \mathrm{n}=62, \mathrm{FN}=64)$, O. microtis $(2 \mathrm{n}=64, \mathrm{FN}=64), 0$. moojeni $(2 \mathrm{n}=70, \mathrm{FN}=72), 0$. nigripes $(2 \mathrm{n}=62, \mathrm{FN}=78-82)$, O. stramineus $(2 n=52, F N=68)$, and Oligoryzomys sp. A $(2 n=70, F N=72)$. The first six species possess species-specific karyotypes, and therefore we emphasize the importance of cytogenetic studies for citotaxonomy. Finally, in Chapter 4 we report the results obtained by chromosome painting in five Oligoryzomys species, with whole chromosomes probes of 0 . moojeni. Comparative chromosome painting (Zoo-FISH) hybridized to 29 segments on metaphases of $O$. fornesi, 30 on 0 . microtis, 31 on 0 . nigripes, and 32 on 0 . rupestris and Oligoryzomys sp. 2. The results showed an extensive genomic reshuffling, due to fissions, tandem and Robertsonian fusions, loss/inactivation, gain/activation or repositioning of centromeres.
\end{abstract}

Keywords: Oligoryzomys. Citotaxonomy. Chromosome evolution. Chromosome Painting. 
CAPÍTULO 1 - INTRODUÇÃO GERAL ................................................. 14

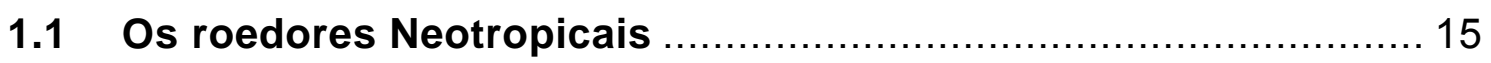

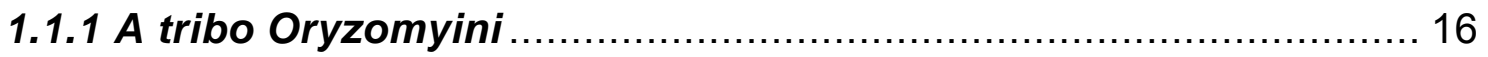

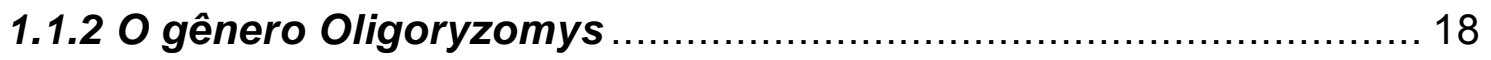

1.1.2.1 Estudos de filogenia molecular em Oligoryzomys ................. 22

1.1.2.2 Estudos citogenéticos em Oligoryzomys …........................ 27

1.2 Relevância da citogenética molecular .......................................... 30

1.2.1 FISH com sondas teloméricas (TTAGGG) $n$

1.2.2 FISH com sondas cromossômicas (Pintura Cromossômica)........ 32

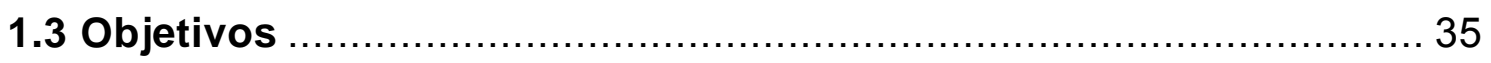

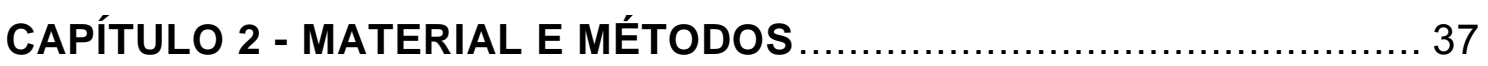

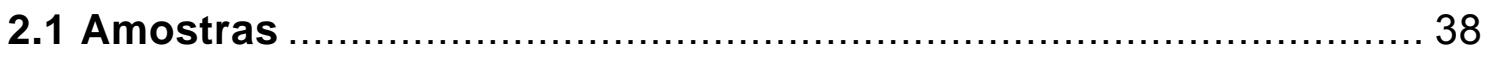

2.1.1 Amostra referente ao Capítulo 3: "Estudos de citogenética convencional e hibridação in situ fluorescente com sondas teloméricas em Oligoryzomys (Rodentia, Sigmodontinae): importância dos cariótipos espécie-específicos para a citotaxonomia" ......................... 38

2.1.2 Amostra referente ao Capítulo 4: "Pintura cromossômica comparativa (Zoo-FISH) em Oligoryzomys (Sigmodontinae, Rodentia): homologias e rearranjos envolvidos na diferenciação cariotípica de

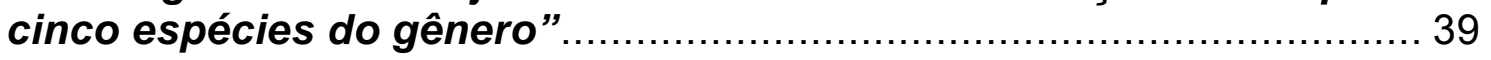

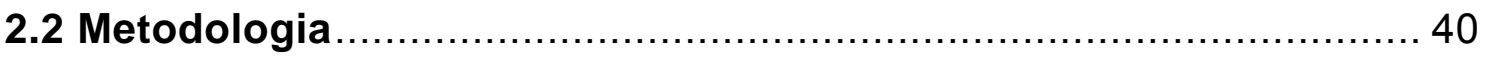

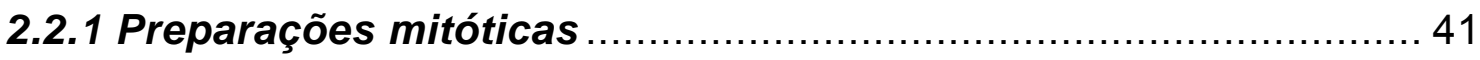

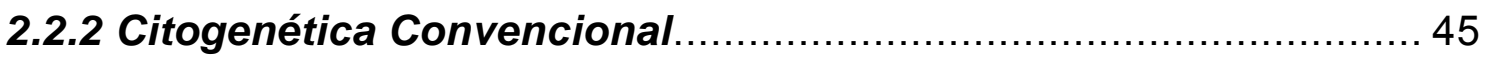

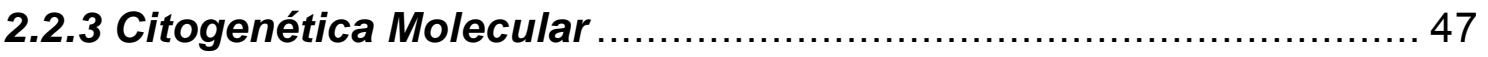

CAPÍTULO 3 - Estudos de citogenética convencional e hibridação in situ fluorescente com sondas teloméricas em Oligoryzomys (Rodentia, Sigmodontinae): importância dos cariótipos espécie-específicos para a

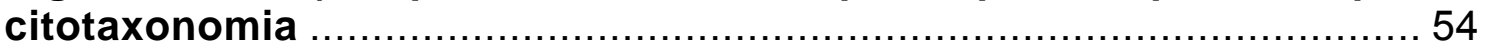

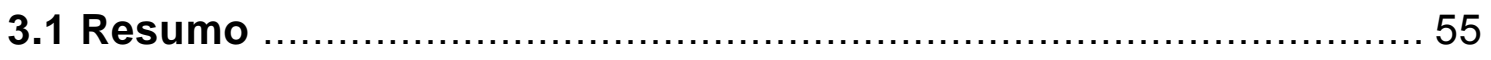

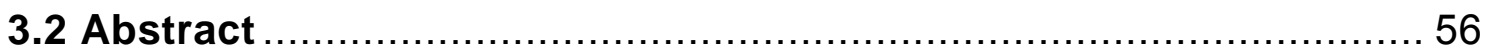

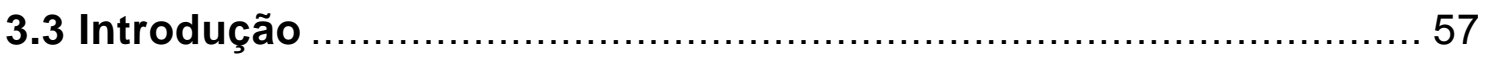




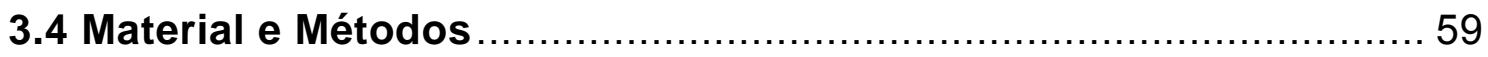

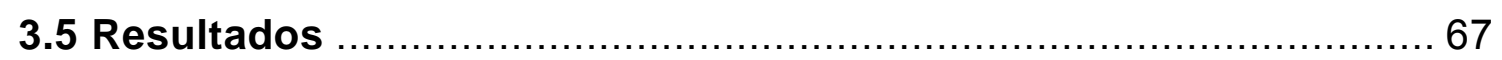

3.5.1 Oligoryzomys flavescens $(2 n=64-66, N F=66) \ldots \ldots \ldots \ldots \ldots \ldots \ldots \ldots 6$

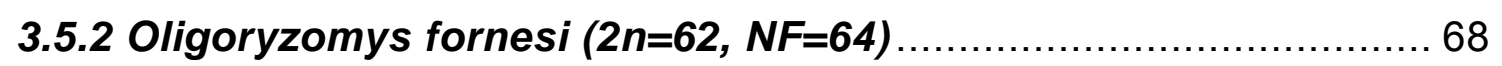

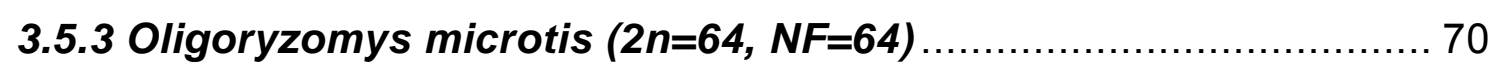

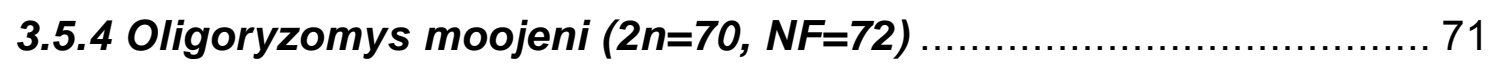

3.5.5 Oligoryzomys nigripes $(2 n=62, N F=78-82) \ldots \ldots \ldots \ldots \ldots \ldots \ldots \ldots . \ldots \ldots$

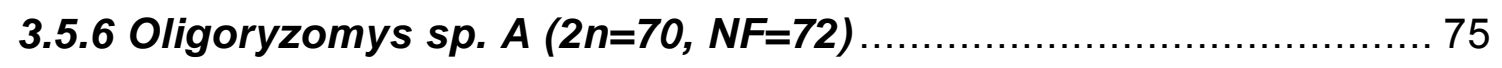

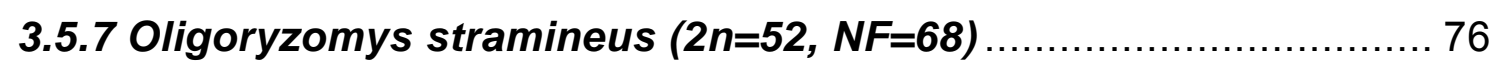

3.5.8 Comparação dos cariótipos através do padrão de bandas G ...... 77

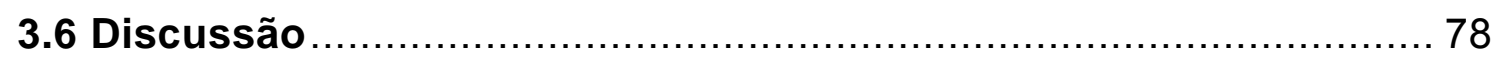

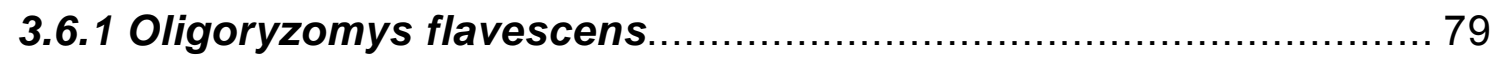

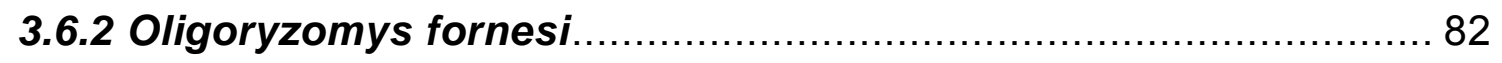

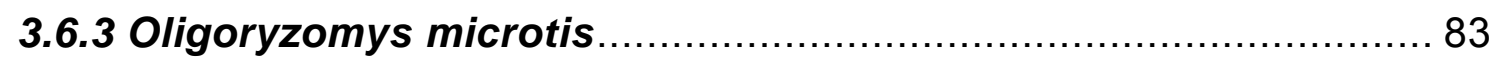

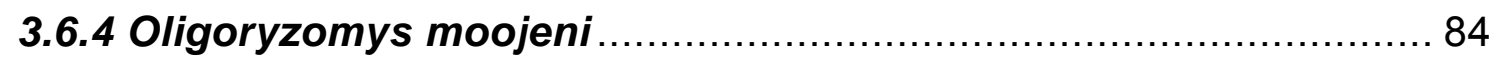

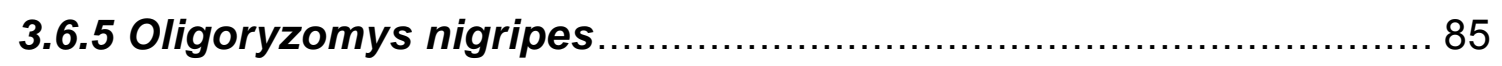

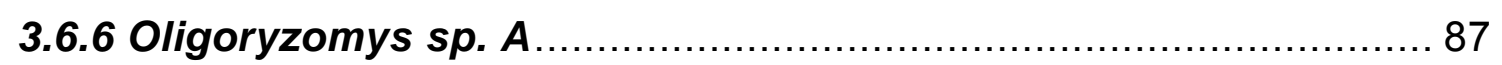

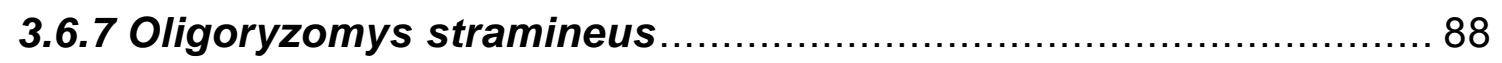

3.6.8 Polimorfismos de cromossomos sexuais em Oligoryzomys ....... 89

3.6.9 Regiões Organizadoras de Nucléolo (RONs) ......................... 91

3.6.10 Comparação dos cariótipos das espécies de Oligoryzomys ..... 92

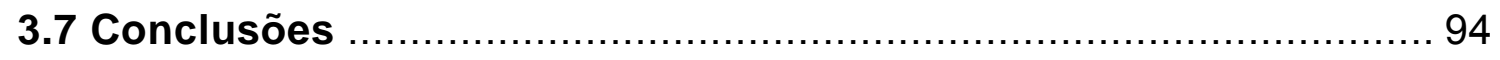

CAPÍTULO 4 - Pintura cromossômica comparativa (Zoo-FISH) em Oligoryzomys (Rodentia, Sigmodontinae): homologias e rearranjos envolvidos na diferenciação cariotípica de cinco espécies do gênero. 112

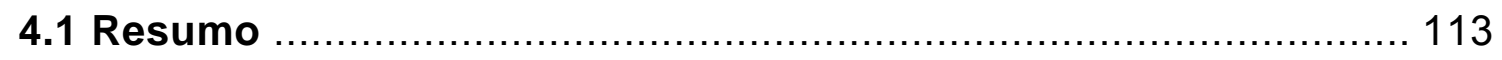

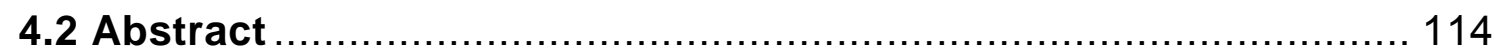

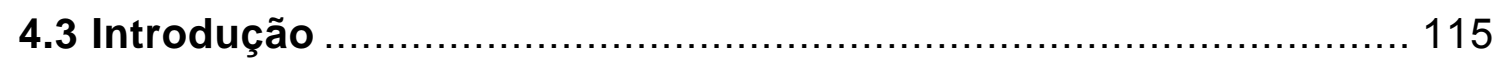

4.4 Material e Métodos .............................................................. 117 
4.5.1 Citometria de fluxo de Oligoryzomys moojeni $(2 n=70, N F=72) . .118$ 4.5.2 Pintura cromossômica com as sondas OMO Xa $\mathrm{e} X \mathrm{Xb}$ de $\mathrm{O}$. moojeni em 0 . flavescens $(2 n=66, N F=66)$.

4.5.3 Pintura cromossômica com sondas de 0 . moojeni em 0 . fornesi $(2 n=62, N F=64)$

4.5.4 Pintura cromossômica com sondas de 0 . moojeni em 0 . microtis $(2 n=64, N F=64)$ 120

4.5.5 Pintura cromossômica com sondas de 0 . moojeni em 0 . nigripes $(2 n=62, N F=81)$ 120

4.5.6 Pintura cromossômica com sondas de 0 . moojeni em 0 . rupestris $(2 n=46, N F=52)$

4.5.7 Pintura cromossômica com sondas de 0 . moojeni em

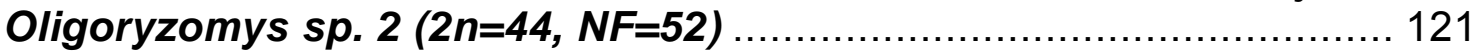

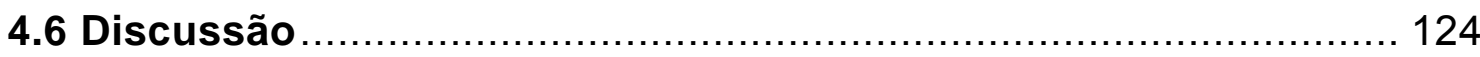

4.6.1 Sondas que permaneceram íntegras ............................. 125

4.6.2 Sondas que se mostraram rearranjadas e os mecanismos responsáveis por esses rearranjos.

4.6.3 Associações específicas encontradas a partir da pintura cromossômica e a redução do número diplóide em 0 . rupestris e

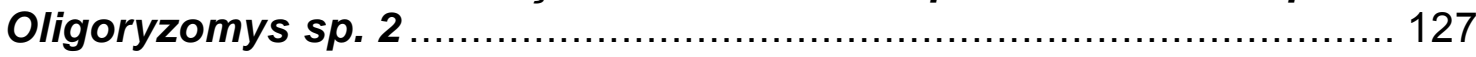

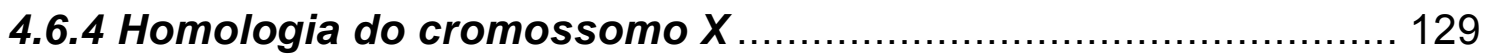

4.6.5 Pintura cromossômica e a evolução cariotípica em Oligoryzomys.................................................................... 130

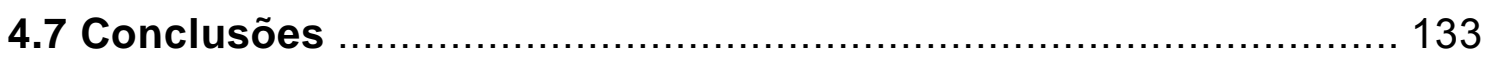

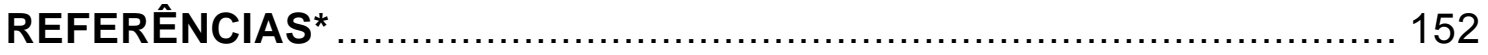


CAPÍTULO 1 INTRODUÇÃO GERAL 


\subsection{Os roedores Neotropicais}

A ordem Rodentia é a mais abundante e diversificada entre os mamíferos, representando cerca de $42 \%$ das espécies viventes, e estima-se que aproximadamente 2277 espécies façam parte deste grupo (MUSSER; CARLETON, 2005). Seus representantes estão amplamente distribuídos por quase todos os continentes e habitam diferentes tipos de ambientes, tais como: desertos, florestas, montanhas, pântanos, pradarias, savanas e rios e possuem hábitos noturnos ou crepusculares (CARLETON, 1984; NOWAK, 1991).

Em decorrência da grande diversidade alcançada por seus representantes e da distribuição cosmopolita, há muitas divergências entre diferentes autores em relação à taxonomia do grupo, de modo que a classificação dos roedores é incerta tanto em níveis taxonômicos elevados quanto ao nível específico (MUSSER; CARLETON, 2005; WEKSLER, 1996; WOOD, 1958).

A família Cricetidae, uma das 33 famílias da ordem Rodentia, é composta por seis subfamílias, dentre as quais está a subfamília Sigmodontinae, com representantes principalmente distribuídos na região Neotropical (MUSSER; CARLETON, 2005).

Considera-se que os sigmodontíneos sejam altamente diversificados e tiveram uma rápida irradiação pela região Neotropical (STEPPAN; ADKINS; ANDERSON, 2004). Essa subfamília tem sido alvo de estudos tanto com dados morfológicos (HOOPER; MUSSER, 1964; REIG, 1980, 1984; WEKSLER, 1996) quanto com moleculares (D’ELÍA, 2003; D’ELÍA et al., 2006; SMITH; PATTON, 1999; WEKSLER; PERCEQUILLO; VOSS, 2006), mas problemas taxonômicos ainda persistem.

A subfamília Sigmodontinae foi subdividida formalmente em tribos; tanto o número de tribos quanto os seus componentes também variam muito, de acordo com diferentes autores (D'ELÍA et al., 2007; MUSSER; CARLETON, 2005; REIG, 1986; SMITH; PATTON, 1999). A discrepância no número de tribos e gêneros (Tabela 1.1) é decorrente do aumento no número de estudos morfológicos, moleculares e citogenéticos, assim como maiores esforços e ampliação das metodologias de coletas, que levaram à descrição de novas espécies, validação de outras, elevação de subgêneros à categoria de gêneros e esclarecimento de 
algumas relações de parentesco (D’ELÍA et al., 2007; MUSSER; CARLETON, 2005; WEKSLER, 2003).

Tabela 1.1 - Classificação tribal dos roedores sigmodontíneos, de acordo com Musser e Carleton (2005) e Reig (1984), com base em caracteres morfológicos, e D’Elía et al. (2007), com base em morfologia e sistemática molecular.

\begin{tabular}{l|l|l}
\hline Reig (1984) & Musser e Carleton (2005) & D'Elía et al. (2007) \\
\hline Akodontini (10) & Akodontini (19) & Abrotrichini (5) \\
Ichthyomyini (4) & Ichthyomyini (5) $_{*}{ }^{*}$ Akodontini (14) \\
Oryzomyini (13) & Oryzomyini (18) & Ichthyomyini (5) \\
Phyllotini (14) & Phyllotini (14) & Oryzomyini (26) \\
Scapteromyini (3) & Reithrodontini (3) & Phyllotini (10) \\
Sigmodontini (2) & Sigmodontini (1) & Reithrodontini (1) \\
Wiedomyini (1) & Thomasomyini (4) & Sigmodontini (1) \\
Incertae sedis (4) & Wiedomyini (1) & Thomasomyini (5) \\
& Incertae sedis (8) & Wiedomyini (1) \\
& & Incertae sedis (11) \\
\hline
\end{tabular}

Os números entre parênteses representam o número de gêneros de cada tribo. *Indica a tribo à qual pertence o gênero Oligoryzomys, foco deste trabalho.

\subsubsection{A tribo Oryzomyini}

A tribo Oryzomyini é a mais diversa da subfamília Sigmodontinae e a ampla diversidade está refletida em variações morfológicas, ecológicas e cromossômicas (GARDNER; PATTON, 1976; SILVA, 1994; WEKSLER; PERCEQUILLO, 2011; WEKSLER; PERCEQUILLO; VOSS, 2006). Além disso, é a tribo que possui o maior número de táxons, contando com aproximadamente 114 espécies (WEKSLER; PERCEQUILLO, 2011).

Há muitas divergências entre os autores em relação aos gêneros e subgêneros da tribo Oryzomyini. Na revisão mais recente, Musser e Carleton (2005) agruparam 18 gêneros nessa tribo (Tabela 1.2).

O gênero Oryzomys, por exemplo, foi considerado o mais diverso dentre os orizominos, e chegou a ser composto por quase metade das espécies de Oryzomyini (MUSSER; CARLETON, 1993; REIG, 1984). Os atuais gêneros Melanomys, Microryzomys, Nesoryzomys, Oecomys e Oligoryzomys já foram considerados subgêneros de Oryzomys e posteriormente elevados à categoria de gênero após 
análises morfológicas, cromossômicas e moleculares (BONVICINO; MOREIRA, 2001; CARLETON; MUSSER, 1984, 1989; MYERS; LUNDRIGAN; TUCKER, 1995; SMITH; PATTON, 1999). Segundo Musser e Carleton (2005), Oryzomys seria um grupo polifilético, composto por 43 espécies reunidas em "grupos".

Mais recentemente, na tentativa de estabelecer o monofiletismo de Oryzomys, Weksler, Percequillo e Voss (2006), com base em estudos morfológicos e moleculares, nomearam 10 novos gêneros, todos anteriormente referidos como Oryzomys. Assim, de acordo com essa nova classificação, o gênero Oryzomys ficou restrito ao "grupo palustris" e, consequentemente, o número de gêneros na tribo subiu para 28 (Tabela 1.2).

Posteriormente, Percequillo, Weksler e Costa (2011) descreveram um novo gênero para Oryzomyini, endêmico da Floresta Atlântica, denominado Drymoreomys. Mais recentemente, Pine, Timm e Weksler (2012) elevaram a espécie Sigmodontomys aphrastus à categoria de gênero, sendo esse novo gênero denominado Tanyuromys e, portanto, Oryzomyini passou a ser composta por 30 gêneros (Tabela 1.2).

Tabela 1.2 - Gêneros atuais que compõem a Tribo Oryzomyini

\begin{tabular}{|c|c|}
\hline Autores & Gêneros \\
\hline $\begin{array}{l}\text { Musser e Carleton } \\
(2005)\end{array}$ & $\begin{array}{l}\text { Amphinectomys, Handleyomys, Holochilus, } \\
\text { Lundomys, Megalomys, Melanomys, } \\
\text { Microakodontomys, Microryzomys, Neacomys, } \\
\text { Nectomys, Nesoryzomys, Noronhomys, Oecomys, } \\
\text { Oligoryzomys, Oryzomys, Pseudoryzomys, } \\
\text { Sigmodontomys e Zygodontomys }\end{array}$ \\
\hline $\begin{array}{l}\text { Weksler, Percequillo e } \\
\text { Voss (2006) }\end{array}$ & $\begin{array}{l}\text { Amphinectomys, Handleyomys, Holochilus, } \\
\text { Lundomys, Megalomys, Melanomys, Microryzomys, } \\
\text { Neacomys, Nectomys, Nesoryzomys, Noronhomys, } \\
\text { Oecomys, Oligoryzomys, Oryzomys, } \\
\text { Pseudoryzomys, Sigmodontomys, Zygodontomys, } \\
\text { Scolomys, Aegialomys }{ }^{*} \text {, Cerradomys } \\
\text { Eremoryzomys }^{*}, \text { Euryoryzomys }{ }^{*}, \text { Hylaeamys }{ }^{*}, \\
\text { Mindomys }{ }^{*}, \text { Nephelomys }^{*}, \text { Oreoryzomys }^{*}, \\
\text { Sooretamys }^{*} \text { e Transandinomys }\end{array}$ \\
\hline $\begin{array}{l}\text { Percequillo, Weksler e } \\
\text { Costa (2011) }\end{array}$ & $\begin{array}{l}\text { Todos os considerados por Weksler, Percequillo e } \\
\text { Voss }(2006)+\text { Drymoreomys }\end{array}$ \\
\hline $\begin{array}{l}\text { Pine, Timm e Weksler } \\
\text { (2012) }\end{array}$ & Todos os anteriores + Tanyuromys \\
\hline
\end{tabular}

O gênero Oligoryzomys aparece em destaque (sublinhado) e $\left(^{*}\right)$ indica os gêneros nomeados por Weksler, Percequillo e Voss (2006), anteriormente referidos como Oryzomys. 


\subsubsection{O gênero Oligoryzomys}

Os representantes do gênero Oligoryzomys possuem hábitos noturnos, são terrestres e alimentam-se de sementes, insetos e frutas (EMMONS; FEER, 1997). Popularmente, são chamados de "ratos do arroz", pois podem ser encontrados frequentemente nos arrozais. São morfologicamente semelhantes e trata-se do gênero mais especioso dentro da Tribo Oryzomyini (MUSSER; CARLETON, 2005; WEKSLER; PERCEQUILLO, 2011).

O gênero está amplamente distribuído pela região Neotropical, do México até o extremo sul da Argentina e Chile (MUSSER; CARLETON, 2005). Além disso, ocupa diferentes tipos de habitats, desde as elevadas altitudes dos Andes até as costas Pacífica e Atlântica e todos os tipos de biomas, como Caatinga, Cerrado, Floresta Atlântica, Amazônia, Chaco e Pampas (EMMONS; FEER, 1997). Algumas espécies são, inclusive, endêmicas de certos biomas, enquanto outras possuem distribuições mais abrangentes (BONVICINO; WEKSLER, 1998; PARESQUE, 2010; WEKSLER; BONVICINO, 2005).

O número de espécies do gênero é muito controverso, principalmente pelo fato de seus representantes apresentarem morfologia externa extremamente semelhante.

Musser e Carleton (2005) reconheceram 18 espécies (O. andinus, $O$. arenalis, $\mathrm{O}$. brendae, $\mathrm{O}$. chacoensis, $\mathrm{O}$. delticola, O. destructor, O. eliurus, $\mathrm{O}$. flavescens, 0 . fornesi, 0 . fulvescens, 0 . griseolus, 0 . longicaudatus, 0. magellanicus, O. microtis, O. nigripes, O. stramineus, O. vegetus e O. victus). Entretanto, esse número está subestimado, pois, nos últimos anos, diversos trabalhos sobre o gênero foram publicados com descrições de espécies novas, cariótipos novos e validações de espécies anteriormente consideradas sinônimas. Além disso, duas espécies reconhecidas por Musser e Carleton (2005) foram sinonimizadas a O. nigripes: O. delticola e O. eliurus (BONVICINO; WEKSLER, 1998; PARESQUE, 2004; WEKSLER; BONVICINO, 2005).

Dessa forma, compilando os dados da literatura, o gênero Oligoryzomys é composto atualmente por 22 espécies formalmente descritas (Tabela 1.3); destas, 11 ocorrem no Brasil: O. chacoensis, O. flavescens, O. fornesi, O. fulvescens, 0 . messorius, $O$. microtis, $O$. moojeni, O. nigripes, O. rupestris, $O$. stramineus e O. utiaritensis (AGRELLOS et al., 2012; ANDRADES-MIRANDA et 
al., 2001; MIRANDA et al., 2008; MUSSER; CARLETON, 2005; PARESQUE, 2004, 2010; PARESQUE et al., 2007; SILVA; YONENAGA-YASSUDA, 1997; WEKSLER; BONVICINO, 2005). 
Tabela 1.3 - Compilação dos dados cariotípicos de Oligoryzomys: espécie, número diplóide (2n) e número fundamental (NF), sinonímias, localidade e referências.

(continua)

\begin{tabular}{|c|c|c|c|c|c|}
\hline Espécie & $2 n$ & NF & Referido como & Localidade & Referência \\
\hline O. andinus & 60 & 70 & & Peru e Bolívia & 1 \\
\hline O. arenalis & - & - & & Costas áridas e semiáridas do Peru & 2 \\
\hline O. chacoensis & 58 & 74 & & $\begin{array}{l}\text { Mato Grosso e Mato Grosso do Sul - Brasil (Cerrado e } \\
\text { Chaco), Paraguai }\end{array}$ & 3,4 \\
\hline O. costaricensis & 54 & 68 & O. fulvescens & Costa Rica & 1 \\
\hline O. flavescens & $64-68$ & $66-72$ & & $\begin{array}{l}\text { Sul da Bahia ao Rio Grande do Sul - Brasil (Pampas, } \\
\text { Mata Atlântica, Cerrado), Argentina, Bolívia, Uruguai }\end{array}$ & $5,6,7$ \\
\hline O. fornesi & 62 & 64-66 & O. eliurus & $\begin{array}{l}\text { Bahia, Goiás, Minas Gerais, Pernambuco, Paraíba - } \\
\text { Brasil (Cerrado e Caatinga), Paraguai }\end{array}$ & 7,8 \\
\hline O. fulvescens & 60 & 72,74 & & Região norte do Brasil, Guianas, Equador & 9,10 \\
\hline O. griseolus & - & - & & Venezuela e Colômbia & 2 \\
\hline O. microtis & 64 & 64,66 & O. longicaudatus (var. 2) & Brasil e Peru (Amazônia) & $1,12,13,{ }^{*}$ \\
\hline O. moojeni & 70 & $\begin{array}{l}72,74 \\
76\end{array}$ & Oligoryzomys sp. & $\begin{array}{l}\text { Goiás, Minas Gerais, Tocantins - Brasil (endêmica do } \\
\text { Cerrado) }\end{array}$ & $7,14,15, *$ \\
\hline O. nigripes & 61,62 & $78-82$ & O. delticola, O. eliurus & $\begin{array}{l}\text { Pernambuco ao Rio Grande do Sul, estendendo-se a } \\
\text { Minas Gerais - Brasil (Mata Atlântica, Cerrado) }\end{array}$ & 16,17 \\
\hline O. rupestris & 46 & 52 & Oligoryzomys sp. 1 & Endêmico em campo rupestre (Cerrado) & 15,18 \\
\hline
\end{tabular}


Tabela 1.3 - Compilação dos dados cariotípicos de Oligoryzomys: espécie, número diplóide (2n) e número fundamental (NF), sinonímias, localidade e referências.

(conclusão)

\begin{tabular}{|c|c|c|c|c|c|}
\hline Espécie & $2 n$ & NF & Referido como & Localidade & Referência \\
\hline O. stramineus & 52 & $68-70$ & & $\begin{array}{l}\text { Goiás, Minas Gerais, Paraíba, Pernambuco, Piauí, } \\
\text { Ceará - Brasil (Cerrado e Caatinga) }\end{array}$ & $4,8,19$ \\
\hline O. utiaritensis & 72 & 76 & O. nigripes & $\begin{array}{l}\text { Mato Grosso e Pará - Brasil (transição Cerrado- } \\
\text { Amazônia) }\end{array}$ & 20 \\
\hline O. vegetus & 54 & 68 & & Panamá & 2 \\
\hline O. victus & - & - & & São Vicente - Antilhas (Localidade tipo) & 2 \\
\hline Oligoryzomys sp. 2 & 44,45 & 552,53 & Oligoryzomys sp. 2 & Serra do Cipó, Minas Gerais - Brasil (Localidade tipo) & 18 \\
\hline Oligoryzomys sp. A & 70 & 72 & & Apiacás, Mato Grosso - Brasil (Amazônia) & * \\
\hline Oligoryzomys sp. B & 66 & 74 & O. microtis & Amapá - Brasil (Amazônia) & 7 \\
\hline
\end{tabular}

*Presente trabalho; 1. Gardner e Patton (1976); 2. Musser e Carleton (2005); 3. Myers e Carleton (1981); 4. Bonvicino e Geise (2006); 5. Espinosa e Reig (1991); 6. Sbalqueiro et al. (1991); 7. Andrades-Miranda et al. (2001); 8. Bonvicino e Weksler (1998); 9. Haiduk, Bickham e Schmidly (1979); 10. Paresque (2004); 11. Gallardo e Patterson (1985); 12. Aniskin e Volobouev (1999); 13. Patton, Da Silva e Malcolm (2000); 14. Lima, Bonvicino e Kasahara (2003); 15. Weksler e Bonvicino (2005); 16. Almeida e Yonenaga-Yassuda (1991); 17. Paresque et al. (2007); 18. Silva e Yonenaga-Yassuda (1997); 19. Fernandes, D'Andrea e Bonvicino (2012); 20. Agrellos et al. (2012). 
No Brasil, as espécies estão distribuídas da seguinte forma: $O$. chacoensis no noroeste do estado de Mato Grosso do Sul e sudoeste de Mato Grosso; O. flavescens, do sul da Bahia ao Rio Grande do Sul; O. fornesi, norte de Minas Gerais, Goiás, Bahia, oeste de Pernambuco e Distrito Federal; O. fulvescens, norte do Pará e Amapá, Roraima e nordeste do Amazonas; O. messorius, Roraima; O. microtis distribui-se nos estados do Acre, Rondônia, sul do Pará e do Amazonas e norte de Mato Grosso; O. moojeni, sul do Tocantins, norte de Goiás e noroeste de Minas Gerais; $O$. nigripes ocorre do estado de Pernambuco ao norte do Rio Grande do Sul, em Minas Gerais e no Distrito Federal; O. rupestris encontrado em altitudes elevadas nos estados da Bahia e Goiás; O. stramineus, norte de Minas Gerais, nordeste de Goiás, sudeste do Piauí, Ceará, Pernambuco e Paraíba; e O. utiaritensis ocorre em Mato Grosso e no Pará (AGRELLOS et al., 2012; BONVICINO; OLIVEIRA; D'ANDREA, 2008; FERNANDES; D'ANDREA; BONVICINO, 2012; MUSSER; CARLETON, 2005; SILVA; YONENAGA-YASSUDA, 1997).

Com relação ao status de conservação de Oligoryzomys, segundo a IUCN (2012), O. victus é considerada extinta e as espécies $O$. brendae, $O$. moojeni e O. rupestris são deficientes em dados.

Nos últimos anos, estudos multidisciplinares envolvendo ecologia, morfologia, citogenética e filogenia molecular aumentaram consideravelmente, de modo que novas informações vêm sendo adicionadas para o gênero. Ainda assim, o número de espécies válidas, suas relações e seus limites de distribuição continuam pouco claros.

\subsubsection{Estudos de filogenia molecular em Oligoryzomys}

Durante muito tempo, Oligoryzomys foi considerado subgênero do antigo gênero Oryzomys. Carleton e Musser (1989) propuseram que Oligoryzomys fosse elevado à categoria de gênero pleno, de acordo com características morfológicas específicas que esse grupo compartilha.

Após o trabalho de Myers, Lundrigan e Tucker (1995), Oligoryzomys foi efetivamente considerado gênero pleno, devido ao monofiletismo 
observado a partir da reconstrução filogenética obtida empregando sequências gênicas aliadas a estudos morfológicos.

A partir dos anos 2000, surgiram outros trabalhos abordando a filogenia do grupo, com dados morfológicos, alozimas e marcadores moleculares (AGRELLOS et al., 2012; GONZALEZ-ITTIG et al., 2010; MIRANDA et al., 2008; PALMA et al., 2010; PERINI et al., 2004; WEKSLER; PERCEQUILLO; VOSS, 2006). Em todos esses trabalhos, o monofiletismo do grupo foi recuperado; no entanto, as relações de parentesco entre as espécies permanecem controversas. Ainda assim, algumas congruências filogenéticas foram encontradas por mais de um autor em diferentes análises. Agrellos et al. (2012), Gonzalez-Ittig et al. (2010), Miranda et al. (2008) e Palma et al. (2010), por exemplo, recuperaram O. microtis como grupo irmão das demais espécies do gênero. Além disso, O. nigripes foi recuperado como grupo irmão de O. stramineus (AGRELLOS et al., 2012; GONZALEZ-ITTIG et al., 2010; MIRANDA et al., 2008).

Gonzalez-Ittig et al. (2010) e Paresque (2010) propuseram que $O$. flavescens deve ser um complexo de espécies, pois os exemplares do Brasil e da Argentina não agrupam com os O. flavescens da Bolívia.

Miranda et al. (2008), a partir de análises baseadas em sequências do gene citocromo- $b$, obtiveram as relações filogenéticas de Oligoryzomys arranjadas em um padrão de ocupação da América do Sul, de acordo com um gradiente norte-sul (Figura 1.1). Nesta análise, O. microtis, de origem amazônica, foi recuperada como irmã das demais espécies. Embora os autores ressaltem a formação de dois grupos, "Pampa-Andino" e "Amazônia-Cerrado", este último não pode ser considerado monofilético, pois as espécies da Amazônia e Cerrado não formam um clado. Apenas as espécies que ocorrem nos Pampas e nos Andes compõem o clado mais derivado na análise, que justificaria a ocupação em direção ao sul da América do Sul.

Mais recentemente, Agrellos et al. (2012) apresentaram uma filogenia molecular para o gênero, na qual um maior número de táxons foi utilizado e sete novas espécies foram incluídas na amostra, tornando a informação mais robusta e abrangente, quando comparada ao trabalho de Miranda et al. (2008). O. microtis também foi recuperada como irmã das demais 
espécies e as relações entre o clado "Pampa-Andino" foram igualmente recuperadas. Entretanto, este clado não foi recuperado como o mais derivado da filogenia, uma vez que a inclusão de novos dados modificou consideravelmente as relações entre as demais espécies. Assim, não foi observado um padrão entre os clados e os biomas que as espécies ocupam. Neste mesmo trabalho, O. utiaritensis foi revalidada e mostrou-se irmã de O. moojeni (Figura 1.2).

Neste contexto, fica clara a necessidade de desenvolvimento de mais estudos de inferência filogenética envolvendo todas as espécies do gênero e outros marcadores moleculares para a melhor compreensão das relações filogenéticas do grupo. 
Figura 1.1 - Filogenia molecular, baseada em sequências do gene citocromo-b, para o gênero Oligoryzomys.

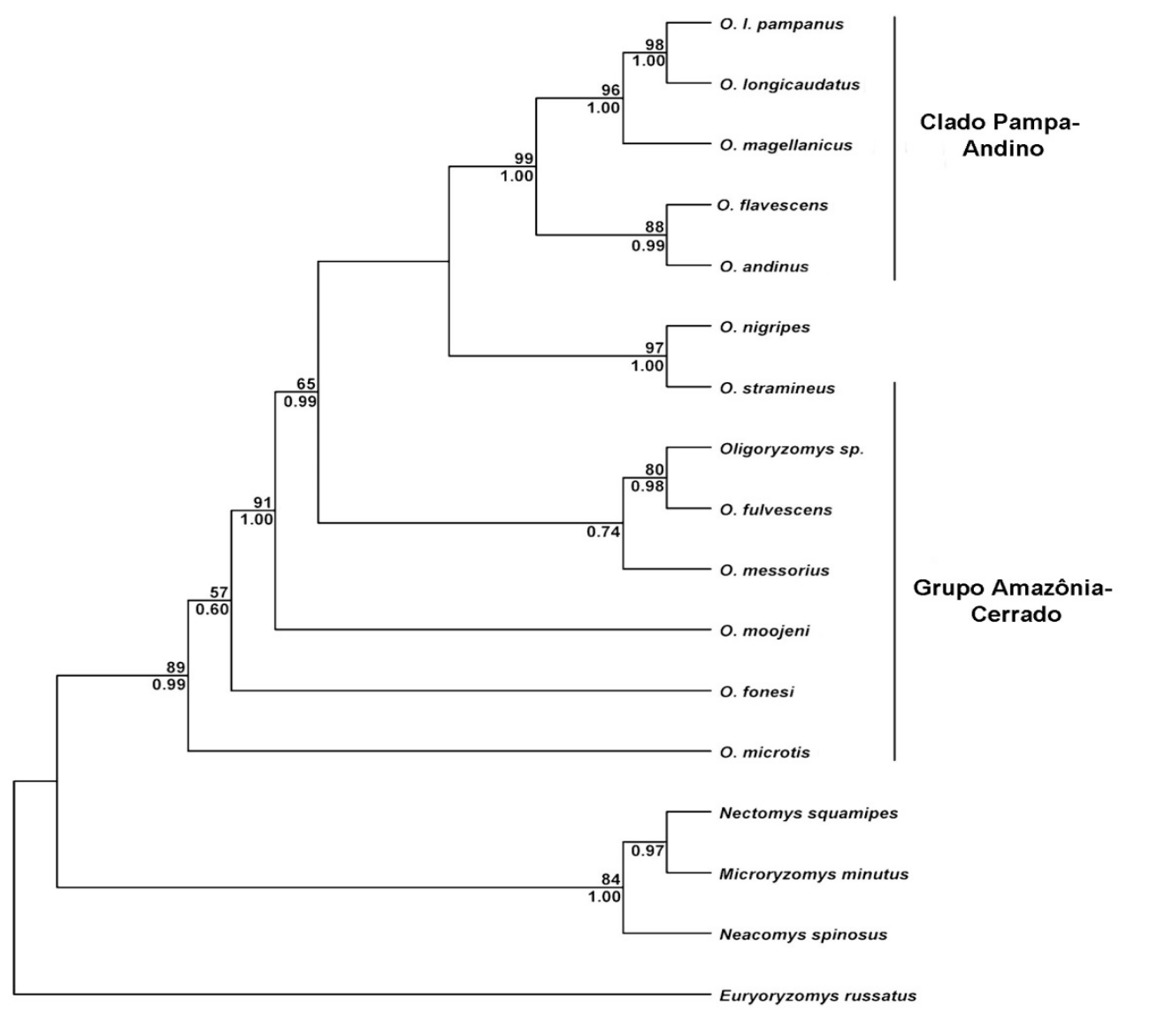

Fonte: Miranda et al. (2008), com modificações. 
Figura 1.2 - Filogenia molecular, baseada em sequências do gene citocromo- $b$, para o gênero Oligoryzomys.

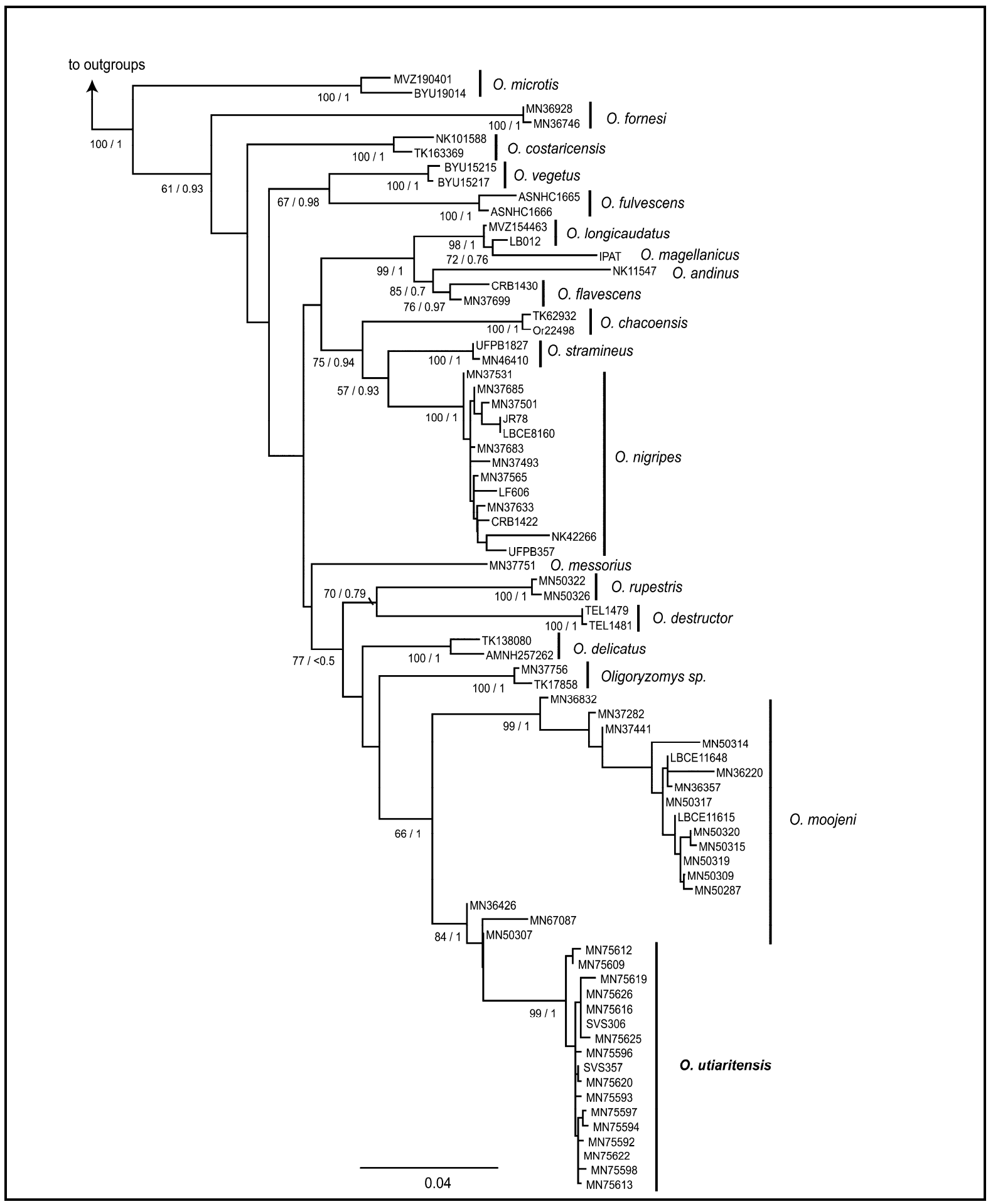

Fonte: Agrellos et al. (2012), com modificações. 


\subsubsection{Estudos citogenéticos em Oligoryzomys}

O gênero Oligoryzomys apresenta grande variabilidade cariotípica e os números diplóides geralmente são elevados, podendo variar de $2 n=44$ a $2 n=72$ (AGRELLOS et al., 2012; ANDRADES-MIRANDA et al., 2001; SILVA; YONENAGA-YASSUDA, 1997).

De acordo com Paresque (2010), existem mais de 30 formas cariotípicas descritas para Oligoryzomys e, segundo Silva (1999), na literatura são encontrados casos em que diferentes cariótipos foram relacionados à mesma entidade taxonômica ou diferentes espécies apresentam o mesmo cariótipo.

Um dos exemplos de maiores discrepâncias ocorre em $O$. longicaudatus, o qual tem seu nome e distribuição geográfica envolvidos em grande controvérsia. Gardner e Patton (1976) descreveram quatro formas cariotípicas para esta espécie, provenientes do Peru e Venezuela, que mais tarde foram relacionadas a outros nomes (Tabela 1.3). De acordo com Belmar-Lucero et al. (2009), Gallardo e Patterson (1985) e Palma et al. (2005), caracteres citogenéticos, morfológicos e moleculares mostram que O. longicaudatus tem seus limites de distribuição no Chile e Argentina.

Primeiramente, com base em morfologia, foram descritas três subespécies para Oligoryzomys longicaudatus: $O$. longicaudatus longicaudatus, O. longicaudatus phillipi e O. longicaudatus magellanicus (OSGOOD, 1943). Muitos anos mais tarde, análises citogenéticas mostraram a presença de dois cariótipos distintos, sendo $2 n=56$ para O. I. longicaudatus e O. I. phillipi e $2 \mathrm{n}=54$ para O. I. magellanicus (GALLARDO; PATTERSON, 1985). Cerca de cinco anos depois, Gallardo e Palma (1990) demonstraram que as subespécies $O$. I. longicaudatus e O. I. phillipi são morfologicamente uniformes e as sinonimizaram a $O$. longicaudatus. Além disso, os autores elevaram a subespécie $O$. longicaudatus magellanicus ao nível específico, sendo chamada de $O$. magellanicus.

Sbalqueiro et al. (1991) estudaram citogeneticamente diferentes populações de $O$. flavescens e encontraram três números diplóides distintos: $2 n=64,65$ e 66 . Tal variação foi decorrente da presença de um ou dois cromossomos acrocêntricos pequenos em alguns indivíduos, 
interpretados como cromossomos supernumerários (Bs). Estudos citogenéticos mais recentes indicaram que $O$. flavescens pode ter de 0 a 4 cromossomos supernumerários (ANDRADES-MIRANDA et al., 2001; PARESQUE, 2004).

Aniskin e Volobouev (1999) fizeram análises comparativas de bandas C e G nos cariótipos de O. microtis e O. flavescens coletados na Bolívia e estabeleceram que o primeiro possui $2 n=64, N F=66$, e que $O$. flavescens apresenta $2 \mathrm{n}=64,65,66$ e NF=66-68.

De fato, o cariótipo com $2 \mathrm{n}=64, \mathrm{NF}=66$, tem sido relacionado a $O$. microtis (BONVICINO; GEISE, 2006; PATTON; DA SILVA; MALCOLM, 2000; WEKSLER; BONVICINO, 2005). Entretanto, Andrades-Miranda et al. (2001) descreveram um cariótipo com $2 n=66, N F=74$, para exemplares coletados no Amapá e correlacionaram-no à mesma espécie. Mais recentemente, Miranda et al. (2008) realizaram análises filogenéticas com alguns marcadores moleculares e verificaram que tais indivíduos com $2 n=66, N F=74$, poderiam representar outra espécie ainda não descrita (Oligoryzomys sp. B, Tabela 1.3), pois não agruparam com indivíduos identificados como O. microtis na filogenia.

A validade de algumas espécies também tem sido questionada. Por exemplo, O. messorius foi considerada sinônimo júnior de O. fulvescens, mas os dados cariotípicos e moleculares mostraram que se trata de uma espécie válida (ANDRADES-MIRANDA et al., 2001; MIRANDA et al., 2008).

Em outro exemplo da grande confusão existente no gênero Oligoryzomys, os limites morfológicos e cariotípicos de $O$. destructor precisam ser estabelecidos, pois, de acordo com Paresque (2010), esta espécie foi recuperada no mesmo clado de $O$. microtis na filogenia molecular.

Paresque et al. (2007) detectaram mais de 40 composições cariotípicas distintas para $O$. nigripes $(2 n=62, N F=78-82)$, cuja elevada diversidade cariotípica foi relacionada a inversões pericêntricas nos pares autossômicos 2, 3, 4 e 8 e variações na morfologia dos cromossomos sexuais, posicionando $O$. nigripes como uma das espécies que possui mais polimorfismos entre os roedores Neotropicais. 
Essas características de O. nigripes, adicionadas à sua ampla distribuição, levaram a inúmeras controvérsias na literatura. Exemplo disso ocorreu durante muito tempo, envolvendo $O$. nigripes e $O$. delticola, pois ambas apresentavam morfologia externa e cariótipos idênticos $(2 n=62$, $\mathrm{NF}=78-82$ ). Bonvicino e Weksler (1998) consideraram essas espécies sinônimas; Paresque (2004) e Silva (1999) confirmaram a interpretação de Bonvicino e Weksler (1998), já que comparações citogenéticas revelavam o mesmo padrão de bandas e rearranjos envolvendo os mesmos pares cromossômicos. Francès e D'Elía (2006) propuseram que ambos os táxons são sinônimos por serem indistinguíveis por dados de morfologia craniana.

Há controvérsias também em relação à Oligoryzomys eliurus, que, de acordo com semelhanças morfológicas, foi considerada sinônimo júnior de O. nigripes (BONVICINO; WEKSLER, 1998). Entretanto, Andrades-Miranda et al. (2001) descreveram cariótipos diferentes para essas duas espécies, atribuindo $2 n=62, N F=64-66$, a $O$. eliurus e 2n=62, NF=78-82, a $O$. nigripes, ambos coletados em regiões do Cerrado. Já Bonvicino e Geise (2006), Bonvicino e Weksler (1998), Myers e Carleton (1981) e Paresque (2004) correlacionaram o cariótipo com 2n=62 e NF=64 a O. fornesi.

Silva e Yonenaga-Yassuda (1997) descreveram dois cariótipos inéditos para o gênero: Oligoryzomys sp. $1(2 \mathrm{n}=46, \mathrm{NF}=52)$ e Oligoryzomys sp. $2(2 n=44,45, \quad N F=52,53)$ e realizaram estudos de evolução cromossômica, com base em bandas C, G, localização das Ag-RONs e FISH telomérica. A associação de tais dados indicou que fusão cêntrica é o evento responsável pela diferenciação dos números diplóides dessas duas espécies novas de Oligoryzomys.

Weksler e Bonvicino (2005) publicaram uma revisão taxonômica de Oligoryzomys do Cerrado brasileiro e descreveram duas novas espécies endêmicas deste bioma: Oligoryzomys moojeni $(2 \mathrm{n}=70, \quad \mathrm{NF}=74)$ e Oligoryzomys rupestris $(2 n=46, N F=52)$, sendo esse último cariótipo idêntico ao de Oligoryzomys sp. 1 descrito previamente por Silva e Yonenaga-Yassuda (1997).

Mais recentemente, Oligoryzomys utiaritensis (anteriormente considerada sinônimo júnior de O. nigripes) foi revalidada por Agrellos et al. (2012). Segundo os autores, estudos morfológicos, morfométricos, 
filogenéticos e cariotípicos mostraram claramente que ambas as espécies são entidades taxonômicas distintas. De fato, com relação ao cariótipo, $O$. nigripes possui $2 \mathrm{n}=62, \mathrm{NF}=78-82$, enquanto $O$. utiaritensis apresenta $2 \mathrm{n}=72, \mathrm{NF}=76$, o maior número diplóide descrito para o gênero. Além disso, O. nigripes está distribuído ao longo da Mata Atlântica e regiões de transição de Cerrado e $O$. utiaritensis, em regiões de Cerrado e Floresta Amazônica.

Conforme apresentado anteriormente, estudos citogenéticos em Oligoryzomys claramente representam uma ferramenta valiosa para a diagnose das espécies. Além disso, o gênero é um modelo para estudo de evolução cromossômica, pois apresenta diversos tipos de rearranjos e variabilidade intra e interespecífica (PARESQUE, 2004, 2010).

\subsection{Relevância da citogenética molecular}

A "Citogenética molecular" passou a ser rotineiramente aplicada com o desenvolvimento da tecnologia de hibridação in situ. A partir de então, foi possível a localização de sequências específicas de ácidos nucléicos nos cromossomos, garantindo a associação dos dados moleculares sobre sequências de DNA com informações cromossômicas (SCHWARZACHER; HESLOP-HARRISON, 2000).

A técnica se baseia na desnaturação do DNA-alvo, presente nos cromossomos metafásicos ou interfásicos, e na aplicação de sequências complementares isoladas de DNA ou RNA (sondas) que se ligam ao sítio exato onde a sequência ocorre naturalmente (GUERRA, 2005).

Nos primeiros protocolos de hibridação, que foram desenvolvidos ainda no final da década de 1960 , as sondas eram marcadas com isótopos radioativos. Com o estabelecimento de novas tecnologias, a marcação isotópica foi substituída gradativamente por marcação com outras moléculas, como por exemplo, os fluorocromos e, portanto, a técnica de hibridação passou a ser chamada de FISH (do inglês: fluorescence in situ hybridization) (SCHWARZACHER; HESLOP-HARRISON, 2000; VIEGAS-PEQUIGNOT et al., 1989). 
Diversos tipos de sondas podem ser utilizadas, tais como: (i) sondas de sequências únicas ou de poucas cópias, úteis em mapeamento, localização e ordenamento de sequências de DNA ou genes nos cromossomos; (ii) sondas de DNA repetitivo disperso, que são sequências repetitivas dispersas ao longo dos cromossomos e marcam uniformemente todo o genoma; (iii) sondas genômicas, constituídas por um grande número de sequências únicas e repetitivas, que marcam todos os cromossomos igualmente; (iv) sondas cromossômicas, um conjunto de sequências gênicas ou não-gênicas de um determinado cromossomo que pode ser reunido para formar uma sonda capaz de "pintar" apenas aquele cromossomo; (v) sondas de sequências repetitivas organizadas em tandem: o DNA ribossômico, centromérico e o telomérico, por exemplo, que têm sido amplamente empregados em diversos tipos de estudos (GUERRA, 2005).

As sondas cromossomo-específicas levaram ao desenvolvimento da técnica de pintura cromossômica, que permite corar simultaneamente cada cromossomo ou pedaços dele em cores diferentes (seção 1.2.2).

\subsubsection{FISH com sondas teloméricas (TTAGGG)}

Os telômeros são estruturas formadas por proteínas e DNA, localizados nas extremidades dos cromossomos, que impedem a fusão com outros cromossomos e os protegem da degradação (ZAKIAN, 1995).

Experimentos de FISH com a sequência (TTAGGG) ${ }_{n}$ de telômeros, realizados em diversas espécies de vertebrados, mostraram a presença da sequência em posições teloméricas e não-teloméricas (estas últimas denominadas também sequências teloméricas intersticiais ou ITS - do inglês interstitial telomeric sequences). Essa sequência é extremamente conservada entre diferentes grupos e, por isso, é considerada uma sonda importante para estudos de evolução cromossômica (MEYNE et al., 1990).

Enquanto a hibridação exclusivamente telomérica implica se tratar da região do telômero funcional, a origem e função das repetições (TTAGGG) n nos sítios não-teloméricos ainda são contraditórias.

Em alguns casos, sítios não-teloméricos de (TTAGGG) $)_{n}$ podem representar sequências remanescentes de telômeros, resultantes de 
rearranjos cromossômicos, tais como inversões, fusões cêntricas e fusões em tandem ocorridos durante a evolução cariotípica de muitos vertebrados (ANDRADES-MIRANDA et al., 2002; LEE; SASI; LIN, 1993; MEYNE et al., 1990; RUIZ-HERRERA et al., 2002). Porém, essa condição parece não ser universal, uma vez que foram localizadas ITS em cromossomos de cariótipos que não sofreram variações numéricas ou estruturais (WILEY et al., 1992) e localizadas próximas ou dentro de blocos de heterocromatina constitutiva (METCALF; ELDRIDGE; JOHNSTON, 2004; MEYNE et al., 1990; PAGNOZZI; SILVA; YONENAGA-YASSUDA, 2000).

Estudos das localizações das sequências teloméricas têm sido realizados em diferentes espécies de vertebrados e têm demonstrado que há uma variedade de mecanismos que podem levar ao surgimento de (TTAGGG) $)_{n}$ em sítios intersticiais; entre eles: (i) as ITS seriam derivadas de cromossomos envolvidos em rearranjos durante a evolução cariotípica e representariam sequências remanescentes nos cromossomos recémformados; (ii) poderiam ser resultantes da amplificação de sequências (TTAGGG) ; (iii) resultariam de permuta, transposição e trocas desiguais de cromátides irmãs; (iv) introdução de sequências teloméricas pela enzima telomerase; e (v) integração de segmentos extracromossômicos ou transposons com sequências teloméricas (MEYNE et al., 1990; RUIZHERRERA et al., 2008; WILEY et al., 1992).

Assim, não há um consenso em relação à presença ou ausência de ITS e rearranjos cromossômicos, de modo que diferentes mecanismos podem estar ocorrendo nos diversos grupos de vertebrados estudados (SILVA, 1999).

\subsubsection{FISH com sondas cromossômicas (Pintura Cromossômica)}

Quando a hibridação in situ fluorescente é realizada com sondas derivadas de cromossomos inteiros ou pedaços cromossômicos, é denominada "Pintura cromossômica" (FERGUSON-SMITH; YANG; O'BRIEN, 1998). Caso as sondas cromossômicas de uma espécie sejam utilizadas para hibridar cromossomos de outra espécie, a técnica passa a 
ser chamada de "Pintura cromossômica comparativa" ou Zoo-FISH (CHOWDHARY; RAUDSEPP, 2001).

As sondas cromossômicas podem ser obtidas por microdissecção ou citometria de fluxo. No caso da citometria de fluxo, os cromossomos são separados por tamanho e razão AT/CG, a partir de um gráfico denominado cariótipo de fluxo (ver Figura 4.1, Capítulo 4).

O cariótipo de fluxo é característico para cada espécie e pequenas variações dentro da mesma espécie são normalmente resultantes de diferentes quantidades de DNA repetitivo dos indivíduos (FERGUSONSMITH; YANG; O'BRIEN, 1998).

A Zoo-FISH é capaz de detectar sintenias entre espécies diferentes. Dessa forma, pode ocorrer hibridação em apenas um cromossomo, indicando que todo o cromossomo é conservado; ou, em outros casos, muitos cromossomos ou partes deles são pintados, indicando que vários rearranjos cromossômicos ocorreram durante a divergência das espécies. Geralmente, espécies mais relacionadas exibem menor número de rearranjos do que espécies distantes (FERGUSON-SMITH; YANG; O'BRIEN, 1998).

As homologias detectadas pela pintura cromossômica são úteis para - mapeamento genético das espécies, para estudos de evolução cromossômica, determinando, assim, os rearranjos que ocorreram durante a evolução. Entretanto, tal técnica não permite a detecção de rearranjos intra-cromossômicos e também não é bem sucedida quando aplicada entre grupos de animais filogeneticamente distantes. Apesar dessas limitações, a pintura é capaz de determinar linhas de descendência entre diversas espécies (FERGUSON-SMITH; TRIFONOV, 2007).

A pintura cromossômica comparativa se iniciou com hibridações de sondas humanas em outros primatas (MORESCALCHI et al., 1997; RICHARD; LOMBARD; DUTRILLAUX, 1996; WIENBERG et al., 1990). Posteriormente, as sondas cromossômicas humanas foram hibridadas em outras ordens de mamíferos, permitindo o reconhecimento de sequências de DNA conservadas e revelando que grandes blocos de DNA têm sido transmitidos sem grandes alterações durante a evolução da classe 
Mammalia (FERGUSON-SMITH; TRIFONOV, 2007; FERGUSON-SMITH; YANG; O'BRIEN, 1998; SCHERTHAN et al., 1994).

À medida que as novas tecnologias foram avançando, foi possível a obtenção de sondas cromossômicas de qualquer espécie de vertebrado que dispõe de cultura celular (FERGUSON-SMITH; YANG; O'BRIEN, 1998; YANG; GRAPHODATSKY, 2009). Entretanto, a maioria dos trabalhos de pintura cromossômica envolve sondas cromossômicas obtidas de espécies de mamíferos, de modo que experimentos de Zoo-FISH com sondas de outros vertebrados (aves, répteis e principalmente anfíbios) ainda são muito escassos na literatura (DOBIGNY; YANG, 2008).

Com relação aos roedores, análises com sondas humanas em representantes não pertencentes à superfamília Muroidea, como os Sciuridae (esquilos), mostraram um cariótipo altamente conservado, que retém muitas sintenias ancestrais (RICHARD et al., 2003). Em contrapartida, os roedores da superfamília Muroidea possuem cariótipos muito rearranjados, de tal modo que dados de pintura cromossômica com sondas de espécies muito distantes podem ser de difícil interpretação. Por isso, sondas do roedor Mus musculus (superfamília Muroidea, família Muridae) foram utilizadas para serem hibridadas em lâminas de roedores muróideos (HASS; SBALQUEIRO; MULLER, 2008; ROMANENKO et al., 2006).

Hass, Sbalqueiro e Muller (2008), utilizando tais sondas, verificaram 27 regiões de homologia com 10 cromossomos de cinco espécies de roedores sul-americanos: Akodon cursor, A. montensis, A. paranaensis, A. serrensis e Oligoryzomys flavescens, mostrando conservação evolutiva dos cromossomos 1, 4, 6, 7, 11, 14, 15, 18, 19 e X. Contudo, como as famílias Muridae e Cricetidae possuem $o$ ancestral comum que divergiu provavelmente há cerca de 31,1 milhões de anos, a hibridação de $M$. musculus em cricetídeos pode não ser tão esclarecedora (SWIER et al., 2009).

Diante disso, Swier et al. (2009) isolaram sondas cromossômicas da espécie Sigmodon hispidus (família Cricetidae, subfamília Sigmodontinae) para hibridar em outras nove espécies do mesmo gênero, com o objetivo de 
determinar as mudanças cariotípicas ocorridas entre as espécies de Sigmodon. Assim, sugeriram um possível cariótipo ancestral para o gênero.

Outro estudo recente, que utilizou sondas espécie-específicas de roedores da subfamília Sigmodontinae, foi realizado por Ventura et al. (2009). Os autores compararam os cariótipos de quatro espécies de Akodon e os resultados revelaram homologia completa entre os complementos de Akodon sp. n. $(2 \mathrm{n}=10), A$. cursor $(2 \mathrm{n}=15)$, A. montensis $(2 \mathrm{n}=24)$ e $A$. paranaensis $(2 n=44)$, evidenciando inúmeros rearranjos cromossômicos entre as espécies. A pintura mostrou oito segmentos sintênicos compartilhados entre A. montensis, A. cursor e Akodon sp. n., cinco associações exclusivas para $A$. cursor e seis para Akodon sp. n. Foi detectada também homologia quase completa dos cromossomos $X$ e até mesmo do $\mathrm{Y}$, indicando que tais espécies passaram por um processo recente de intensa diferenciação autossômica, no qual a homologia total dos cromossomos sexuais foi conservada, excetuando na espécie Akodon sp. n.

Os roedores neotropicais possuem grande variabilidade cariotípica e são modelos úteis para investigação de evolução cromossômica utilizando pintura cromossômica comparativa. Além de auxiliar na compreensão dos rearranjos que ocorreram durante a evolução das espécies, a pintura cromossômica detecta homologias que podem ser usadas para construção de mapas citogenéticos (PIECZARKA; NAGAMACHI, 2005).

\subsection{Objetivos}

O presente trabalho tem como objetivo realizar estudos citogenéticos e de evolução cromossômica em roedores do gênero Oligoryzomys, visando a contribuir para a citotaxonomia, melhor compreensão da história evolutiva do grupo e dos processos envolvidos na diferenciação cariotípica das espécies.

Especificamente, pretende-se:

* Caracterizar o número e a morfologia dos cromossomos dos espécimes e, para isso, serão empregadas técnicas de coloração convencional, obtenção de padrões de bandas C, G e localização das Ag- 
RONs (regiões organizadoras de nucléolos), para que os cariótipos sejam comparados entre os indivíduos da mesma espécie e entre espécies do mesmo gênero;

* Determinar a localização específica de sequências teloméricas e realizar experimentos de pintura cromossômica com sondas específicas, utilizando metodologias de hibridação in situ fluorescente, para traçar estudos comparativos e de evolução cromossômica, com descrição dos possíveis mecanismos envolvidos na diferenciação cariotípica do grupo. 
CAPÍTULO 2 MATERIAL E MÉTODOS 


\subsection{Amostras}

O material utilizado neste trabalho é proveniente de campanhas de coleta, com armadilhas de queda (pitfall) ou Sherman, realizadas por membros do Laboratório de Ecologia e Evolução (LEEV - Instituto Butantan) e por colaboradores com seus grupos de pesquisa: Dr. Miguel T. Rodrigues (IB-USP), Dra. Ana Paula Carmignotto (UFSCar campus Sorocaba), Dr. Mauro Galetti (UNESP campus Rio Claro), Dra. Sandra Favorito, Dra. Renata Pardini (IB-USP), Dra. Adriana Bueno (SMA-SP), Dra. Darci M. Barros-Battesti (Instituto Butantan), Flávio Agapito (Seband), Dr. Rogério V. Rossi (UFMT), Dr. José Carlos Motta Jr. (IB-USP), Dr. Alexandre U. Christoff (Universidade Luterana do Brasil), Dr. Pedro L. B. da Rocha (UFBA) e Dr. Diego Queirolo (Universidad de la Republica - Uruguai).

\subsubsection{Amostra referente ao Capítulo 3: "Estudos de citogenética convencional e hibridação in situ fluorescente com sondas teloméricas em Oligoryzomys (Rodentia, Sigmodontinae): importância dos cariótipos espécie-específicos para a citotaxonomia"}

Foram analisados citogeneticamente 117 indivíduos pertencentes a sete espécies de Oligoryzomys: $O$. flavescens (16), O. fornesi (7), $O$. microtis (4), O. moojeni (4), O. nigripes (83), Oligoryzomys sp. A (1) e 0. stramineus (2) (Tabela 3.2 - Capítulo 3).

Os exemplares foram coletados em 28 localidades, oito estados do Brasil: Apiacás, Aripuanã e Vila Rica, no estado de Mato Grosso; UruçuíUna, Piauí; Peixe, Tocantins; Minaçu e Parque Nacional das Emas, Goiás; Camacan, na Bahia; Caxambu, Jequitinhonha e Serra da Canastra, Minas Gerais; Biritiba-Mirim, Buri, Caieiras, Caraguatatuba, Cotia, Floresta Nacional de Ipanema, Guará, Juquitiba, Luís Antônio, Parque Estadual Carlos Botelho, Parque Estadual da Serra do Mar (núcleo Santa Virgínia), Piedade, Pindamonhangaba, Pinhalzinho, São Bernardo do Campo e São Joaquim da Barra, em São Paulo; e Esmeralda, no estado do Rio Grande do Sul. 
As preparações citogenéticas dos exemplares provenientes de Caieiras, Caraguatatuba, Cotia, Floresta Nacional de Ipanema, Guará, Parque Estadual Carlos Botelho, Parque Estadual da Serra do Mar e São Joaquim da Barra (São Paulo) foram obtidas no Laboratório de Ecologia e Evolução (LEEV - Instituto Butantan) ou em campo, em um laboratório montado provisoriamente (Figura 2.1). O restante da amostra conta com preparações que foram realizadas em campo pela Dra. Maria José de Jesus Silva, Dra. Renata Cecília Amaro e Dra. Karen Ventura (Tabela 3.2).

A análise desse material foi iniciada durante a iniciação científica da aluna, de abril de 2008 a novembro de 2009, (FAPESP: 2008/00493-9) sendo dada continuidade durante o mestrado (FAPESP: 2010/03432-0).

\subsubsection{Amostra referente ao Capítulo 4: "Pintura cromossômica comparativa (Zoo-FISH) em Oligoryzomys (Sigmodontinae, Rodentia): homologias e rearranjos envolvidos na diferenciação cariotípica de cinco espécies do gênero"}

Para os experimentos de pintura cromossômica do Capítulo 4, deu-se preferência aos exemplares cujas culturas de células estavam disponíveis, pois as hibridações em metáfases de medula óssea e baço não mostraram resultados satisfatórios.

Foram descongeladas culturas de fibroblastos provenientes do Banco de Células do Laboratório de Citogenética de Vertebrados (IBUSP), cujas biópsias e/ou cultura celular primária foram obtidas pela Dra. Maria José de Jesus Silva, durante o período de seu doutorado e pós-doutorado no IBUSP, sob orientação da Dra. Yatiyo Yonenaga-Yassuda.

Os exemplares são provenientes das seguintes localidades: Fazenda Intervales e Floresta Nacional de Ipanema (São Paulo), Peixe (Tocantins), Aripuanã (Mato Grosso), Minaçu (Goiás), Serra do Cipó (Minas Gerais) e Pico das Almas (Bahia) (Tabela 4.1 - Capítulo 4).

A pintura cromossômica foi realizada nas espécies $O$. flavescens, $O$. fornesi, O. microtis, O. moojeni (exemplares analisados por citogenética clássica no Capítulo 3 do presente trabalho), O. nigripes (exemplar analisado em Silva, 1994) e O. rupestris e Oligoryzomys sp. 2 (exemplares 
cujos cariótipos foram descritos por Silva e Yonenaga-Yassuda, 1997) (Tabela 4.1 - Capítulo 4).

Figura 2.1 - Laboratório provisório montado na Floresta Nacional de Ipanema para realização de preparações citogenéticas, metodologias de captura e foto de exemplar utilizado neste trabalho.
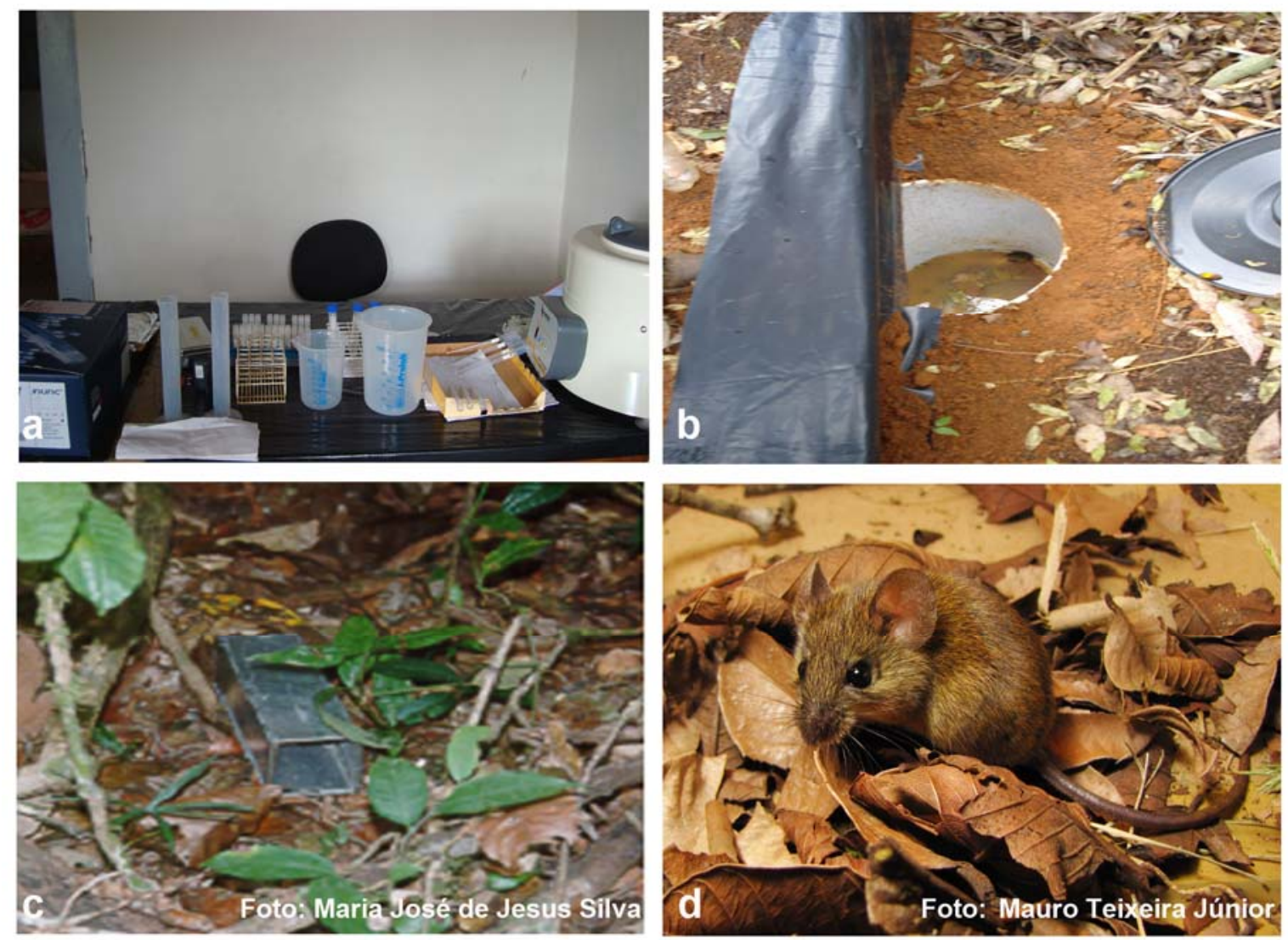

(a) Laboratório montado provisoriamente para realização de preparações citogenéticas no campo; (b) Armadilha de queda (pitfall); (c) Armadilha tipo Sherman; (d) Oligoryzomys flavescens coletado na Floresta Nacional de Ipanema (SP).

\subsection{Metodologia}

A eutanásia foi realizada de acordo com os "Princípios éticos na experimentação animal" (CARPENTER; MASHIMA; RUPIPER, 1996) e licença da Comissão de Ética para uso de Animais do Instituto Butantan (CEUAIB) $n^{\circ} 242 / 05$. 


\subsubsection{Preparações mitóticas}

a. Preparação in vivo de medula óssea e baço, segundo Ford e Hamerton (1956), Silva (1994) e Yonenaga (1972), com modificações:

1. Aproximadamente 24 horas antes da preparação cromossômica, injetar subcutaneamente, na proporção de $1 \mathrm{~mL}$ para cada $100 \mathrm{~g}$ do animal, uma solução preparada com $2 \mathrm{~g}$ de fermento biológico e $5 \mathrm{~g}$ de açúcar, dissolvidos em $25 \mathrm{~mL}$ de água destilada, para estimular divisões celulares.

2. Cerca de 30 minutos antes do sacrifício, injetar subcutaneamente colchicina $0,1 \%(0,5 \mathrm{~mL}$ para cada $100 \mathrm{~g}$ do animal).

3. Fazer uma pequena incisão na região ventral, retirar os fêmures, limpar e cortar as epífises. Em seguida, retirar o baço. Colocá-los em uma placa de Petri contendo de 3 a $5 \mathrm{~mL}$ de solução balanceada de Hanks. As preparações de baço e medula poderiam ser processadas separadamente; porém, para Oligoryzomys, por serem animais muito pequenos, optou-se por juntar o material para otimizar resultados.

4. Com a ajuda de uma seringa com agulha, lavar sucessivas vezes o canal ósseo e o baço, até retirar todo o material.

5. Transferir o material para um tubo de centrífuga e centrifugar por 10 minutos a $1200 \mathrm{rpm}$.

6. Desprezar o sobrenadante e adicionar $7 \mathrm{~mL}$ de solução hipotônica $(\mathrm{KCl}$ 0,075 M). Incubar por cerca de 20 minutos em banho-maria a $37^{\circ} \mathrm{C}$.

7. Retirar do banho, adicionar 6 gotas de fixador (3:1 metanol-ácido acético) e ressuspender delicadamente. Deixar 10 minutos a temperatura ambiente.

8. Acrescentar $3 \mathrm{~mL}$ de fixador, homogeneizar vagarosamente e deixar por 10 minutos a temperatura ambiente. Centrifugar a 1200 rpm durante 10 minutos.

9. Desprezar o sobrenadante e adicionar $7 \mathrm{~mL}$ de fixador. Homogeneizar, ressuspendendo a solução com uma pipeta de $3 \mathrm{~mL}$, por cerca de 100 vezes. 
10. Centrifugar novamente e desprezar o sobrenadante.

11. Repetir mais duas lavagens, trocando o fixador em cada uma delas, ressuspendendo por cerca de 100 vezes.

12. Após a última centrifugação, desprezar o sobrenadante e adicionar fixador suficiente para que o material não fique muito concentrado.

13. Pingar 1 ou 2 gotas da suspensão celular em lâminas histológicas limpas, previamente estocadas em etanol, e observar ao microscópio em contraste de fase. Caso seja necessário, diluir o material.

Durante a preparação cromossômica, retirar tecidos (fígado e músculo) do animal para análise molecular. Os tecidos estão sendo mantidos no banco de tecidos do nosso laboratório (LEEV - Instituto Butantan).

b. Preparação in vitro de cultura de fibroblastos, segundo Freshney (1986) e Silva (1994), com modificações:

Obtenção das biópsias

1. Iniciar a assepsia da extremidade da região (orelha), utilizando algodões embebidos com acetona, etanol $70 \%$, éter e Merfene (solução desinfetante contendo $0,05 \mathrm{~g}$ de borato de fenilmercúrio, 50 $\mathrm{mL}$ de etanol $95 \%$ e $100 \mathrm{~mL}$ de água deionizada). Descartar o algodão após cada limpeza. Repetir esta operação sucessivas vezes.

2. Cortar a extremidade com tesouras e pinças esterilizadas. Após a biópsia, passar mercúrio-cromo na região cortada do animal, a fim de evitar posteriores infecções.

3. Colocar o tecido cortado em um frasco contendo $5 \mathrm{~mL}$ de Dulbecco's Modified Eagle's Medium (DMEM) com $20 \%$ de soro bovino fetal.

4. Deixar na geladeira a $4{ }^{\circ} \mathrm{C}$ por 24 horas.

Plantio da cultura

1. Após o procedimento anterior, cortar a biópsia em pequenos fragmentos em uma placa de Petri estéril contendo $5 \mathrm{~mL}$ de meio de cultura completo (DMEM com $20 \%$ de soro bovino fetal e $50 \mu \mathrm{g}$ de neomicina). 
2. Umedecer uma das paredes de um frasco de cultura com soro bovino fetal.

3. Transferir os fragmentos da placa de Petri para o frasco de cultura, depositando-os sobre a parede já umedecida.

4. Na parede oposta do frasco, adicionar $2 \mathrm{~mL}$ de meio (DMEM) completo e deixá-lo em repouso durante 30 minutos em estufa a $37^{\circ} \mathrm{C}$.

5. Virar o frasco cuidadosamente, de modo que os fragmentos entrem em contato com o meio de cultura, e deixá-lo na estufa $37^{\circ} \mathrm{C}$ por 3 dias.

6. Observar em microscópio invertido. Quando as células começarem a proliferar, adicionar mais $3 \mathrm{~mL}$ de meio de cultura. À medida que a proliferação celular ocorrer, toda a superfície do frasco de cultura ficará coberta pelas células, formando uma monocamada. Quando este estágio for atingido, as células sofrerão inibição por contato e o processo de divisão será interrompido. Neste instante, deve-se proceder à tripsinização para divisão das células em dois frascos de cultura.

\section{Tripsinização}

1. Desprezar o meio de cultura e adicionar $2 \mathrm{~mL}$ de solução de Hanks. Movimentar delicadamente a garrafa por cerca de 20 vezes.

2. Colocar no frasco de cultura de 1 a $3 \mathrm{~mL}$ de tripsina.

3. Observar ao microscópio invertido. Quando as células começarem a se desprender, desprezar imediatamente a solução de tripsina.

4. Adicionar $3 \mathrm{~mL}$ de meio completo (DMEM com $20 \%$ de soro bovino fetal) e bater com forte impacto nas paredes laterais do frasco para que as células se soltem totalmente da superfície. Observar o processo ao microscópio invertido.

5. Transferir $1,5 \mathrm{~mL}$ de meio de cultura para outro frasco e completar ambos os frascos com meio de cultura (DMEM com 20\% de soro bovino fetal).

6. Manter os frascos em estufa a $37^{\circ} \mathrm{C}$ e fazer acompanhamento diário.

7. Após novo crescimento celular, pode-se colher o material para análise cromossômica ou armazená-lo em nitrogênio líquido. 
Colheita do material para análise cromossômica

1. Verificar no microscópio invertido se as células estão em pico de divisão e adicionar colchicina na concentração de $0,1 \mu \mathrm{g} / \mathrm{mL}$.

2. Incubar a garrafa por 30 a 40 minutos na estufa a $37^{\circ} \mathrm{C}$.

3. Bater com vigor na parede da garrafa e observar ao microscópio invertido se as células em divisão se desprenderam.

4. Transferir todo o material do frasco de cultura para o tubo de centrífuga e centrifugar a $1200 \mathrm{rpm}$ por 8 minutos.

5. Retirar o sobrenadante e desprezá-lo.

6. Adicionar $10 \mathrm{~mL}$ de solução hipotônica $(\mathrm{KCl} 0,075 \mathrm{M})$, homogeneizar a solução e deixar cerca de 8 minutos em banho-maria a $37^{\circ} \mathrm{C}$. Acrescentar $1 \mathrm{~mL}$ de fixador gelado (3:1 metanol-ácido acético), homogeneizar a solução e centrifugar durante 10 minutos a $1200 \mathrm{rpm}$.

7. Desprezar o sobrenadante, adicionar $10 \mathrm{~mL}$ de fixador e ressuspender várias vezes para desprender o material.

8. Centrifugar a $1200 \mathrm{rpm}$ durante 10 minutos. Fazer 2 lavagens sucessivas.

9. Pingar 1 ou 2 gotas da suspensão celular em lâminas limpas, previamente estocadas em etanol.

\section{Congelamento das células}

1. Retirar o meio de cultura e lavar a garrafa com $2 \mathrm{~mL}$ de solução de Hanks. Agitar o frasco por cerca de 20 vezes e desprezar a solução.

2. Acrescentar $2 \mathrm{~mL}$ de tripsina e observar ao microscópio invertido se as células estão se desprendendo da parede da garrafa. Desprezar a tripsina.

3. Adicionar $2 \mathrm{~mL}$ de meio de cultura (DMEM com $20 \%$ de soro bovino fetal), bater com vigor na parede da garrafa e observar ao microscópio invertido se as células se desprenderam.

4. Em um tubo de centrífuga, adicionar $2 \mathrm{~mL}$ de uma solução preparada com meio (DMEM) $70 \%$, soro bovino fetal $20 \%$ e DMSO (dimetilsulfóxido) $10 \%$. 
5. Transferir o material da garrafa para o tubo de centrífuga e, em seguida, para os frascos criogênicos com capacidade de 1,5 ou 1,8 $\mathrm{mL}$, devidamente etiquetados.

6. Colocar os frascos criogênicos no gelo por cerca de 10 minutos.

7. Deixá-los overnight no freezer $\left(-4^{\circ} \mathrm{C}\right)$. No dia seguinte, transferí-los para o tanque de nitrogênio líquido à temperatura de $-196{ }^{\circ} \mathrm{C}$. Anotar exatamente a posição que os frascos foram depositados.

Descongelamento de células

1. Retirar os frascos criogênicos do tanque de nitrogênio líquido e colocálos em banho-maria a $37^{\circ} \mathrm{C}$.

2. Passar um algodão embebido em álcool $70 \%$ nos frascos criogênicos antes de abrí-los.

3. Transferir o material para um tubo de centrífuga com tampa, contendo $1,5 \mathrm{~mL}$ de meio de cultura (DMEM com $20 \%$ de soro bovino fetal).

4. Centrifugar a $1000 \mathrm{rpm}$ por 7 minutos. Desprezar o sobrenadante.

5. Adicionar 1,5 $\mathrm{mL}$ de meio de cultura completo e homogeneizar.

6. Transferir a solução para um frasco de cultura e acrescentar $3,5 \mathrm{~mL}$ de meio completo. Caso haja necessidade, adicionar $0,5 \mathrm{~mL}$ de AmnioMax C-100 (Gibco, Invitrogen, Paisley, Reino Unido).

7. Colocar em estufa a $37^{\circ} \mathrm{C}$ e acompanhar o crescimento da cultura.

\subsubsection{Citogenética Convencional}

\section{a. Coloração convencional:}

1. Hidrolisar as lâminas em $\mathrm{HCl} 1 \mathrm{~N}$ em banho-maria a $60{ }^{\circ} \mathrm{C}$ durante 7 minutos.

2. Lavar em água destilada.

3. Corar por 7 minutos com uma solução de Giemsa (Merck S.A., Rio de Janeiro, R.J., Brasil), preparada com $1 \mathrm{~mL}$ de corante para $30 \mathrm{~mL}$ de tampão fosfato (pH 6,8).

4. Lavar em água destilada e secar. 


\section{b. Bandamento C (CBG), segundo Sumner (1972), com modificações:}

1. Hidrolisar as lâminas em $\mathrm{HCl} 0,2 \mathrm{~N}$ durante 30 minutos a temperatura ambiente.

2. Lavar em água destilada e deixar secar.

3. Mergulhar as lâminas em hidróxido de bário octahidratado $5 \%$ a $60^{\circ} \mathrm{C}$, durante 30 a 40 segundos, aproximadamente.

4. Imediatamente em seguida, lavá-las em água destilada e passar rapidamente em $\mathrm{HCl} 1 \mathrm{~N}$ a $60{ }^{\circ} \mathrm{C}$.

5. Lavar em água destilada e deixar secar.

6. Incubar em $2 \times S S C(p H ~ 7,0)$ a $60{ }^{\circ} \mathrm{C}$ durante 15 minutos. Após esse período, retirar e levar em água destilada.

7. Corar com solução de Giemsa preparada com $1 \mathrm{~mL}$ de corante para 20 $\mathrm{mL}$ de solução tampão fosfato $(\mathrm{pH} 6,8)$ durante 30 minutos.

8. Lavar em água destilada e secar.

As soluções de hidróxido de bário octahidratado e 2xSSC podem ser utilizadas por até uma semana.

\section{c. Bandamento G (GTG), segundo Seabright (1971), com modificações:}

1. Retirar as lâminas do freezer de 3 a 5 dias antes do experimento ou incubá-las na estufa a $65{ }^{\circ} \mathrm{C}$ por 1 hora, para envelhecer o material.

2. Hidrolisar a lâmina por 15 minutos em $2 x S S C$ a $60^{\circ} \mathrm{C}$.

3. Lavar em água destilada e deixar secar.

4. Preparar, em banho-maria a $37^{\circ} \mathrm{C}$, uma solução de tripsina $(0,02 \mathrm{~g} \mathrm{em}$ $75 \mathrm{~mL}$ tampão fosfato $\mathrm{pH} 6,8$ ). Homogeneizar bem.

5. Mergulhar as lâminas nesta solução fazendo movimentos para frente e para trás, durante 8 a 10 segundos.

6. Lavar em água destilada imediatamente após o processo anterior para interromper a ação da tripsina.

7. Corar durante 7 minutos com solução de Giemsa preparada com $1 \mathrm{~mL}$ do corante para $30 \mathrm{~mL}$ de solução tampão fosfato $(\mathrm{pH} 6,8)$.

8. Lavar em água destilada e secar.

Descartar a solução de tripsina depois de cada experimento. 
d. Coloração das Regiões Organizadoras de Nucléolos (RONs), segundo Howell e Black (1980):

1. Hidrolisar as lâminas em $\mathrm{HCl}(1 \mathrm{~N})$ a $60^{\circ} \mathrm{C}$ por 7 minutos.

2. Lavar em água destilada e deixar secar.

3. Pingar sobre o material da lâmina uma gota de solução coloidal reveladora ( $1 \mathrm{~g}$ de gelatina para microbiologia em $50 \mathrm{~mL}$ de água destilada com $0,5 \mathrm{~mL}$ de ácido fórmico) e duas gotas da solução de nitrato de prata $50 \%$ ( $1 \mathrm{~g}$ de $\mathrm{AgNO}_{3}$ para $2 \mathrm{~mL}$ de água destilada).

4. Cobrir com lamínula e incubar por 3 a 4 minutos em câmara úmida a $60{ }^{\circ} \mathrm{C}$.

5. Lavar em água destilada através de jatos com a pisseta para retirar a lamínula e corar durante 30 segundos com solução de Giemsa preparada com $1 \mathrm{~mL}$ de corante para $50 \mathrm{~mL}$ de tampão fosfato.

6. Lavar em água destilada e deixar secar.

\section{e. Análises microscópicas:}

Para o estabelecimento do número diplóide e número de braços de cromossomos autossômicos (NF), foram analisadas aproximadamente 30 metáfases de cada indivíduo. As melhores metáfases foram fotografadas no microscópio Axioskop 40 (Zeiss) com objetiva de imersão 100x e optovar de 1,25x, no programa AxionVision 4.6.3 Zeiss.

Os cariótipos foram montados de acordo com a literatura, levando-se em consideração a morfologia e tamanho dos cromossomos. Para o estabelecimento do número de organizadores nucleolares, no mínimo 20 células foram analisadas e, em seguida, foram verificadas a média, a moda e o número de associações observadas.

\subsubsection{Citogenética Molecular}

Antes de iniciar o procedimento, selecionar as lâminas que contenham alto índice mitótico e cromossomos distendidos. Delimitar a região com lápis diamante para localização imediata da área que contém o material. 
a. Hibridação in situ fluorescente (FISH) com sondas teloméricas:

Foi utilizado o kit Telomere PNA FISH/FITC (DAKO, Denmark A/S, Glostrup, Dinamarca), Catálogo No. 5325, com modificações nos procedimentos descritos pelo fabricante. Foi adicionado lodeto de Propídio na solução de montagem para visualização dos cromossomos, pois o programa de captura de imagem não faz a sobreposição das imagens fotografadas nos filtros usados para visualizar DAPI e FITC. Adicionalmente, foi alterado o tempo e a temperatura da solução de lavagem (Wash solution), com o objetivo de garantir melhor integridade dos cromossomos e das marcações.

Preparo dos reagentes e materiais

- Tampão TBS

Dissolver o conteúdo de um pacote de TBS em $1 \mathrm{~L}$ de água destilada. Esta solução pode ser estocada por 6 meses a $4{ }^{\circ} \mathrm{C}$. Para cada experimento, são necessários $500 \mathrm{~mL}$ de TBS.

- Formaldeído $3.7 \%$ em TBS

Diluir 1 volume de formaldeído $37 \%$ em 9 volumes de TBS (solução 1:10). Usar a solução a temperatura ambiente. Preparar uma solução nova a cada experimento.

- Solução de pré-tratamento

Diluir o volume do vidro $\mathrm{n}^{\circ} 1$ em TBS $(40 \mu \mathrm{L}$ da solução de prétratamento em $80 \mathrm{~mL}$ de TBS) e usar a temperatura ambiente. Preparar uma solução a cada novo experimento.

- Solução de enxágue (Rinse solution)

Diluir os $20 \mathrm{~mL}$ do vidro $\mathrm{n}^{\circ} 3 \mathrm{em} 980 \mathrm{~mL}$ de água pura. Esta solução pode ser estocada por 6 meses a $4{ }^{\circ} \mathrm{C}$. Utilizar $80 \mathrm{~mL}$ desta solução a cada experimento. 
- Solução de lavagem (Wash solution)

Diluir os $20 \mathrm{~mL}$ do vidro $\mathrm{n}^{\circ} 4 \mathrm{em} 980 \mathrm{~mL}$ de água pura. Esta solução pode ser estocada por seis meses a $4{ }^{\circ} \mathrm{C}$ após a diluição. Começar cada experimento pré-aquecendo $80 \mathrm{~mL}$ desta solução a $55^{\circ} \mathrm{C}$.

- Montagem da lâmina

Para a montagem da lâmina, deve-se preparar uma solução de DAPI $(2 \mu \mathrm{L}, 1 \mu \mathrm{L} / \mathrm{mL})+$ lodeto de propídeo $(1 \mu \mathrm{L}, 0,5 \mu \mathrm{L} / \mathrm{mL})$ em reagente antifade Vectashield - Vector (1 mL).

\section{Procedimento}

1. Mergulhar as lâminas no TBS 1 por 2 minutos.

2. Passar as lâminas para o formaldeído $3.7 \%$ por 2 minutos exatamente.

3. Lavar no TBS 1 por 5 minutos

4. Lavar no TBS 2 por 5 minutos.

5. Passar as lâminas para a solução de pré-tratamento e deixá-las por 10 minutos.

6. Lavar no TBS 3 por 5 minutos

7. Lavar no TBS 4 por 5 minutos.

8. Passar as lâminas por uma série de etanol $70 \%, 85 \%$ e $96 \%$, durante 2 minutos cada.

9. Deixar as lâminas secarem em posição vertical por cerca de 5 minutos.

10. Adicionar $10 \mu \mathrm{L}$ da sonda na área previamente delimitada da lâmina.

11. Cobrir com lamínula $18 \times 18 \mathrm{~mm}$.

12. Colocar as lâminas em uma estufa a $80^{\circ} \mathrm{C}$ por 3 minutos.

13. Transferir as lâminas para uma câmara escura, a temperatura ambiente. Aguardar o processo de hibridação ocorrer por no mínimo 30 minutos.

14. Mergulhar as lâminas na solução de Rinse para lavagem e retirada das lamínulas, por aproximadamente 1 minuto.

15. Mergulhar as lâminas na solução de lavagem Wash a $55{ }^{\circ} \mathrm{C}$ por 2 minutos. 
16. Passar as lâminas por uma série de etanol $70 \%, 85 \%$ e $96 \%$, durante 2 minutos cada.

17. Deixar as lâminas secarem em posição vertical por cerca de 5 minutos.

18. Aplicar $20 \mu \mathrm{L}$ da solução de montagem e cobrir com lamínula de $24 \mathrm{x}$ $50 \mathrm{~mm}$.

19. Deixar as lâminas descansarem por 15 minutos (ou mais) no escuro antes de proceder à análise.

20. Analisar em fotomicroscópio de fluorescência, com filtro para DAPI e filtro para FITC.

b. Hibridação in situ fluorescente (FISH) com sondas cromossômicas Pintura cromossômica:

Isolamento dos cromossomos - segundo Yang et al., 1995; Yang et al., 2009

1. Adicionar colchicina na concentração de $0,1 \mu \mathrm{g} / \mathrm{mL}$ aos frascos de cultura de fibroblastos com aproximadamente $80 \%$ de confluência.

2. Incubar a $37^{\circ} \mathrm{C}$ por 5 horas.

3. Agitar e centrifugar as células por 5 minutos em $400 \mathrm{~g}$ [1100 rpm].

4. Ressuspender o pellet em $5 \mathrm{~mL}$ de tampão hipotônico $(75 \mathrm{mM} \mathrm{KCl}, 0,2$ $\mathrm{mM}$ espermina, $0,5 \mathrm{mM}$ espermidina) e deixar por 15 minutos à temperatura ambiente.

5. Centrifugar a $400 \mathrm{~g}$ [1100 rpm] por 5 minutos.

6. Ressuspender 0 pellet em $500 \mu \mathrm{L}$ de tampão de poliamina [concentrações $15 \mathrm{mM}$ Tris metilamina, 0,2 $\mathrm{mM}$ espermina, 0,5 mM espermidina, $2 \mathrm{mM}$ EDTA, 0,5 mM EGTA, $80 \mathrm{mM} \mathrm{KCl}, 20 \mathrm{mM} \mathrm{NaCl}, 14$ mM $\beta$-mercaptoetanol, 0,25\% Triton-X 100 (Sigma-Aldrich Brasil LTDA, São Paulo, S.P., Brasil), pH 7.2] e deixar no gelo por 10 minutos.

7. Agitar no vórtex por 10-15 segundos.

8. Corar os cromossomos com $40 \mu \mathrm{L} / \mathrm{mL}$ de cromomicina $\mathrm{A} 3,2 \mathrm{mM}$ $\mathrm{MgSO}_{4}$ e $2 \mu \mathrm{L} / \mathrm{mL}$ de Hoeschst 33258 e incubar por pelo menos 2 horas. 
9. Cerca de 10 minutos antes da análise do fluxo, adicionar sulfito de sódio e citrato de sódio, nas concentrações finais de 10 e $25 \mathrm{mM}$, respectivamente.

A separação dos cromossomos foi feita em citômetro de fluxo DualLaser Cell Sorter Mo-Flow System. Aproximadamente 400 cromossomos são separados para cada pico registrado, diretamente em tubos individuais de $500 \mu \mathrm{L}$ para $\mathrm{PCR}$, contendo $300 \mu \mathrm{L}$ de água destilada.

Preparação das sondas cromossomo-específicas - segundo Telenius et al., 1992

Para obtenção das sondas, foram realizadas duas amplificações por DOP-PCR (reação em cadeia da polimerase com primers degenerados). A primeira amplificação ocorreu sob as seguintes condições:

\begin{tabular}{l|l}
\hline Reagentes & Volume \\
\hline $\mathrm{ddH}_{2} \mathrm{O}$ & $28,2 \mu \mathrm{L}$ \\
\hline Tampão 5x & $10 \mu \mathrm{l}$ \\
\hline $\begin{array}{l}\text { Tampão detergente W1 (éter } \\
\text { polioexietileno W-1 0,05\%) }\end{array}$ & $2,5 \mu \mathrm{L}$ \\
\hline dNTPs $(250 \mu \mathrm{M})$ & $4 \mu \mathrm{L}$ \\
\hline Primer 6MW $(4 \mu \mathrm{M})^{*}$ & $5 \mu \mathrm{l}$ \\
\hline Taq polimerase 5 $\mathrm{U} / \mu \mathrm{L}$ & $0,3 \mu \mathrm{l}$ \\
\hline Total & $50 \mu \mathrm{l}$ \\
\hline
\end{tabular}

Regime de temperaturas: $94{ }^{\circ} \mathrm{C}$ por 9 minutos; 9 ciclos de $94{ }^{\circ} \mathrm{C}$ por 1 minuto; $30{ }^{\circ} \mathrm{C}$ por 1,5 segundos; transição a $0,23{ }^{\circ} \mathrm{C}$ por segundo até a temperatura de $72{ }^{\circ} \mathrm{C}$ durante 3 minutos; 30 ciclos de $94{ }^{\circ} \mathrm{C}$ por 1 minuto; $62{ }^{\circ} \mathrm{C}$ por um minuto; $72{ }^{\circ} \mathrm{C}$ por 3 minutos e extensão final de $72{ }^{\circ} \mathrm{C}$ por 10 minutos.

\section{*Primer 6MW: (5' CCG ACT CGA GNN NNN NAT GTG G 3')}

Para a segunda amplificação por DOP-PCR:

Utilizar $1 \mu \mathrm{L}$ do produto primário amplificado adicionado a $2,5 \mu \mathrm{L}$ de biotina-16-dUTP ou FITC-12-dUTP e realizar uma segunda reação de PCR, diminuindo a concentração de dNTP para $125 \mu \mathrm{M}$. Realizar apenas 25 ciclos de amplificação. Os outros parâmetros e condições são idênticos aos descritos anteriormente. 
Hibridação in situ fluorescente - segundo Ventura et al., 2009; Yang et al., 1995

Pingar uma gota da suspensão de metáfases fixadas em uma lâmina estocada em etanol absoluto. Verificar ao microscópio a qualidade e o índice de metáfases.

\section{Hibridação}

1. Incubar a lâmina pela série de etanol em temperatura ambiente:

a. Duas vezes em etanol $70 \%$ por 2 minutos

b. Duas vezes em etanol $90 \%$ por 2 minutos

c. Uma vez em etanol $100 \%$ por 4 minutos

d. Deixar secar.

2. Incubar a lâmina na estufa a $65^{\circ} \mathrm{C}$ por 1 hora.

3. Preparar as sondas adicionando $1 \mu \mathrm{l}$ de produto de PCR secundário marcado com fluorocromo a $12 \mu \mathrm{l}$ de tampão de hibridação (25 mL de

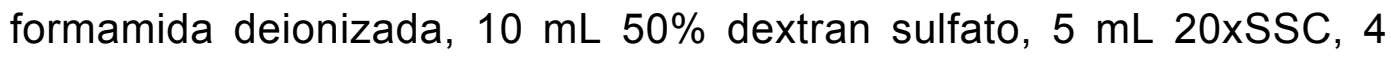
$\mathrm{mL}$ 0,5 M fosfato de sódio $\mathrm{pH} 7$ e $1 \mathrm{~mL} 50 \mathrm{X}$ de solução de Denhardt), centrifugar rapidamente, aquecer a $75^{\circ} \mathrm{C}$ por 10 minutos e manter a 37 ${ }^{\circ} \mathrm{C}$ (pre-annealing).

4. Passar as lâminas em solução composta por $70 \%$ de formamida em 2xSSC, por 2 minutos, a $65{ }^{\circ} \mathrm{C}$, para desnaturar o DNA dos cromossomos. Esse tempo e temperatura podem variar em diferentes espécies.

5. Mergulhar as lâminas em etanol gelado $70 \%$ por 4 minutos.

6. Repetir a série de álcool em temperatura ambiente:

a. Duas vezes em etanol $70 \%$ por 2 minutos

b. Duas vezes em etanol $90 \%$ por 2 minutos

c. Uma vez em etanol $100 \%$ por 4 minutos

d. Deixar secar.

7. Aplicar $13 \mu \mathrm{L}$ da sonda fluorescente desnaturada mantida a $37^{\circ} \mathrm{C}$.

8. Cobrir com lamínulas $22 \times 22 \mathrm{~mm}$.

9. Deixar em câmara úmida com água destilada a $37^{\circ} \mathrm{C}$ por uma ou duas noites. 


\section{Detecção}

1. Incubar as lâminas a $42{ }^{\circ} \mathrm{C}$ por 5 minutos em solução composta por $50 \%$ de formamida em 2xSSC. Repetir o processo em uma nova cuba coplin.

2. Incubar as lâminas a $42{ }^{\circ} \mathrm{C}$ por 5 minutos em 2xSSC. Repetir o processo mais uma vez.

3. Incubar por 4 minutos em detergente $(100 \mathrm{~mL}$ de $20 x S S C, 400 \mathrm{~mL}$ de água e $250 \mu \mathrm{L}$ de Triton-X 100).

4. Para as sondas marcadas com biotina, detectar com Avidina-FITC ou Avidina-Cy3 (escolher de acordo com o filtro do microscópio disponível) e incubar a $37{ }^{\circ} \mathrm{C}$, por pelo menos 20 minutos.

5. Lavar as lâminas três vezes por 3 minutos em solução detergente.

6. Corar com solução de montagem, conforme descrita na seção 2.2.3.a.

As metáfases foram fotografadas no microscópio Axioskop 40 (Zeiss) com objetiva de imersão $100 x$ e optovar de $1,25 x$, no programa AxionVision 4.6.3 Zeiss ou no microscópio Zeiss Axiphot, programa Isis Metasystems, com filtros para DAPI, FITC e Cy3. 
CAPÍTULO 3 -

Estudos de citogenética convencional e hibridação in situ fluorescente com sondas teloméricas em Oligoryzomys (Rodentia, Sigmodontinae): importância dos cariótipos espécie-específicos para a citotaxonomia 


\subsection{Resumo}

Os roedores do gênero Oligoryzomys estão distribuídos por toda a região Neotropical, do México até o sul da Argentina. Devido a sua homogeneidade morfológica, há inúmeras controvérsias com relação às entidades taxonômicas do grupo. O cariótipo tem sido uma ferramenta muito utilizada para diagnose das espécies, uma vez que o gênero apresenta cariótipos espécie-específicos. O objetivo do presente trabalho é caracterizar citogeneticamente as espécies do gênero Oligoryzomys e contribuir para a citotaxonomia do grupo. Foram analisados 117 indivíduos, coletados em 28 localidades, sendo oito estados brasileiros, pertencentes às espécies: $O$. flavescens $(2 \mathrm{n}=64,65$ e $66, \mathrm{NF}=66), \mathrm{O}$. fornesi $(2 n=62, N F=64)$, O. microtis $(2 n=64, N F=64)$, O. moojeni $(2 n=70, N F=72)$, O. nigripes $(2 n=62, N F=78-82)$, Oligoryzomys sp. A $(2 n=70, N F=72)$ e $O$. stramineus $(2 \mathrm{n}=52, \quad \mathrm{NF}=68)$. Foram encontrados heteromorfismos e polimorfismos de autossomos e cromossomos sexuais e presença de cromossomos supernumerários. A FISH com sondas teloméricas mostrou marcações exclusivamente nos telômeros de todas as espécies. Das sete espécies analisadas, seis apresentam cariótipos espécie-específicos ( $O$. flavescens, O. fornesi, O. microtis, O. moojeni, O. nigripes e O. stramineus). Novas formas cariotípicas estão sendo descritas para O. microtis e O. moojeni, assim como uma forma inédita para o par 8 (homomórfica acrocêntrico) e um caso de mosaicismo $(\mathrm{X} / \mathrm{XX})$ em $O$. nigripes. Com base nos resultados, reiteramos a importância dos estudos citogenéticos para a citotaxonomia do grupo.

Palavras-chave: Oligoryzomys. Cariótipos espécie-específicos. Bandamento cromossômico. Citotaxonomia. 


\subsection{Abstract}

Pygmy rice rats of the genus Oligoryzomys are distributed throughout the Neotropical region, from Mexico to South Argentina. Because of their morphological similarity, the taxonomy of the species is controversial. Cytogenetic approaches have been useful to clarify the taxonomy of this complex group, since they present species-specific karyotypes. The goal of this work is to characterize cytogenetically species of the genus Oligoryzomys and contribute to cytotaxonomy. Cytogenetic analyses were carried out on 117 individuals from 28 localities, eight states of Brazil: O. flavescens $(2 \mathrm{n}=64,65$ and $66, \mathrm{FN}=66), 0$. fornesi $(2 \mathrm{n}=62, \mathrm{FN}=64)$, O. microtis $(2 \mathrm{n}=64, \mathrm{FN}=64)$, O. moojeni $(2 \mathrm{n}=70, \mathrm{FN}=72)$, O. nigripes $(2 \mathrm{n}=62, \mathrm{FN}=78-82)$, Oligoryzomys sp. $\mathrm{A}(2 \mathrm{n}=70, \mathrm{FN}=72)$ and 0 . stramineus $(2 \mathrm{n}=52, \mathrm{FN}=68)$. Autosomal and sex chromosome polymorphisms as well as supernumerary chromosomes were observed. FISH with telomeric probes showed signals exclusively at the telomeres. From the seven species studies in this work, six species presented species-specific karyotypes (O. flavescens, $O$. fornesi, O. microtis, O. moojeni, O. nigripes and O. stramineus). Two new fundamental numbers are being described for 0 . microtis and 0 . moojeni. We also report for the first time one individual of $O$. nigripes with homomorphic acrocentric pair 8 and another with mosaicism $(X / X X)$. Thereby we emphasize and reinforce the importance of karyological studies for this group of small rodents.

Keywords: Oligoryzomys. Species-specific karyotypes. Chromosome banding. Cytotaxonomy. 


\subsection{Introdução}

Os roedores do gênero Oligoryzomys distribuem-se do México ao sul do Chile e Argentina e ocupam os mais diversos tipos de biomas (MUSSER; CARLETON, 2005). Inicialmente, eram considerados subgênero de Oryzomys, mas foram elevados à categoria de gênero pleno devido às características morfológicas específicas que o grupo compartilha e ao monofiletismo encontrado a partir de sequências gênicas (CARLETON; MUSSER, 1989; MYERS; LUNDRIGAN; TUCKER, 1995).

Dentre as características mais marcantes, os representantes do gênero são morfologicamente homogêneos, de pequeno porte, cauda mais longa que o tamanho do corpo e pés desenvolvidos (CARLETON; MUSSER, 1989; PARESQUE, 2010). Possuem hábitos noturnos ou crepusculares e alimentam-se de sementes, frutos e insetos (EMMONS; FEER, 1997).

Carleton e Musser (1989) reconheceram 15 espécies para o gênero, organizadas em cinco grupos, com base em características morfológicas: (1) "O. nigripes", (2) "O. flavescens", (3) “O. fulvescens", (4) “O. microtis" e (5) "O. andinus". Mais tarde, Weksler e Bonvicino (2005) descreveram duas novas espécies e propuseram alterações nesses grupos, também com base em características morfológicas, incluindo um novo grupo: "O. rupestris". Recentemente, Paresque (2010), por meio de estudos de filogenia molecular, também modificou a composição desses grupos, reconhecendo 22 espécies (Tabela 3.1).

O número de espécies do gênero varia de acordo com diferentes autores e vários nomes específicos permanecem instáveis na taxonomia do grupo (ANDRADES-MIRANDA et al., 2001; MUSSER; CARLETON, 2005; PARESQUE, 2010; WEKSLER; BONVICINO, 2005). Diante desse problema, estudos citogenéticos têm se mostrado uma ferramenta valiosa para diagnose das espécies, uma vez que a maioria possui cariótipo espécie-específico.

Além disso, o gênero apresenta número diplóide predominantemente elevado, que varia de 44 a 72 (AGRELLOS et al., 2012; ANDRADES-MIRANDA et al., 2001; SILVA; YONENAGA-YASSUDA, 1997), e exibe alta variabilidade cariotípica, com exemplos de rearranjos do tipo fusão, inversão pericêntrica, polimorfismos de cromossomos sexuais e presença de supernumerários 
(ALMEIDA; YONENAGA-YASSUDA, 1991; PARESQUE et al., 2007; SBALQUEIRO et al., 1991; SILVA; YONENAGA-YASSUDA, 1997).

O objetivo deste capítulo é caracterizar citogeneticamente as espécies do gênero Oligoryzomys, estabelecer os padrões de bandas C, G, localização das regiões organizadoras de nucléolo (RONs) e de sequências teloméricas, utilizando $\mathrm{FISH}$, investigar a ocorrência de rearranjos cromossômicos intraespecíficos, comparar as informações obtidas com os dados da literatura e contribuir para a citotaxonomia do grupo.

Tabela 3.1 - Comparação da composição dos grupos de espécies do gênero Oligoryzomys propostos por Carleton e Musser (1989), Weksler e Bonvicino (2005) e Paresque (2010), respectivamente.

\begin{tabular}{|c|c|c|c|}
\hline Grupos & $\begin{array}{l}\text { Carleton e Musser } \\
(1989)\end{array}$ & $\begin{array}{l}\text { Weksler e Bonvicino } \\
(2005)\end{array}$ & Paresque (2010) \\
\hline \multirow[t]{4}{*}{ nigripes } & O. nigripes & O. nigripes & O. nigripes \\
\hline & O. eliurus ${ }^{c}$ & O. stramineus & O. aff. nigripes \\
\hline & O. destructor & O. destructor & O. stramineus \\
\hline & $\begin{array}{l}\text { O. longicaudatus } \\
\text { O. delticola } \\
\end{array}$ & $\begin{array}{l}\text { O. longicaudatus } \\
\text { O. magellanicus }\end{array}$ & O. chacoensis \\
\hline \multirow[t]{4}{*}{ flavescens $^{a}$} & O. flavescens & O. flavescens & O. flavescens \\
\hline & Oligoryzomys sp. A & O. microtis & O. aff. flavescens \\
\hline & Oligoryzomys sp. B & O. fornesi & O. longicaudatus \\
\hline & Oligoryzomys sp. C & O. moojeni & \\
\hline \multirow[t]{3}{*}{ fulvescens } & O. fulvescens & O. fulvescens & O. fulvescens \\
\hline & O. arenalis & O. f. costaricensis & O. vegetus \\
\hline & O. vegetus & O.f. fulvescens & \\
\hline \multirow[t]{2}{*}{ microtis } & O. microtis & & O. microtis \\
\hline & & & $\begin{array}{l}\text { O. aff. microtis } \\
\text { O. fornesi }\end{array}$ \\
\hline \multirow[t]{2}{*}{ andinus } & O. andinus & O. andinus & O. andinus \\
\hline & O. chacoensis & O. chacoensis & O. aff. andinus \\
\hline \multirow[t]{7}{*}{ rupestris $^{b}$} & & O. rupestris & O. rupestris \\
\hline & & & O. messorius \\
\hline & & & O. moojeni \\
\hline & & & Oligoryzomys sp. A \\
\hline & & & Oligoryzomys sp. B \\
\hline & & & Oligoryzomys sp. C \\
\hline & & & $\begin{array}{l}\text { Oligoryzomys sp. D } \\
\text { Oligoryzomys sp. E }\end{array}$ \\
\hline
\end{tabular}

aparesque (2010) sugere o nome grupo Iongicaudatus; ${ }^{b}$ Paresque (2010) sugere a utilização do nome grupo messorius; 'Espécies sinonimizadas a $O$. nigripes. 


\subsection{Material e Métodos}

Foram analisados citogeneticamente 117 indivíduos do gênero Oligoryzomys, pertencentes às espécies O. flavescens, O. fornesi, O. microtis, O. moojeni, O. nigripes, Oligoryzomys sp. A e O. stramineus, coletados em 28 localidades de oito estados do Brasil: Bahia, Goiás, Mato Grosso, Minas Gerais, Piauí, Rio Grande do Sul, São Paulo e Tocantins (Tabela 3.2, Figura 3.1).

É importante ressaltar que a espécie Oligoryzomys sp. A não foi descrita formalmente e está sendo denominada assim neste trabalho a fim de não ser confundida com a espécie Oligoryzomys sp. 2, analisada no Capítulo 4. Este indivíduo não corresponde à mesma espécie descrita por Carleton e Musser (1989) e Paresque (2010).

Os espécimes foram depositados no Museu de Zoologia da Universidade de São Paulo (MZUSP) ou na Coleção Mastozoológica da Universidade Federal do Espírito Santo (UFES) e os indivíduos que já possuem número de tombo disponível, estão indicados na Tabela 3.2.

As preparações cromossômicas foram obtidas in vivo de células da medula óssea e baço, segundo Ford e Hamerton (1956), com modificações, ou in vitro de cultura de fibroblastos, segundo Freshney (1986), com modificações. Os padrões de bandamento cromossômico (CBG e GTG) e a coloração das regiões organizadoras de nucléolo (Ag-RONs) foram efetuados de acordo com Sumner (1972), Seabright (1971) e Howell e Black (1980), respectivamente.

A hibridação in situ fluorescente (FISH) com sequências teloméricas $(\text { TTAGGG) })_{\mathrm{n}}$ foi realizada utilizando o kit Telomere PNA FISH/FITC (DAKO, Catálogo No. 5325), de acordo com o protocolo fornecido pelo fabricante, com modificações (seção 2.2.3). As metáfases foram analisadas no microscópio Axioskop 40 (Zeiss), equipado com filtros para FITC, e fotografadas no programa AxionVision 4.6.3 Zeiss.

O Equilíbrio de Hardy-Weinberg foi avaliado, empregando o teste do quiquadrado apenas nos exemplares provenientes da Floresta Nacional de Ipanema $(\mathrm{SP})$, cuja amostra é maior.

Os cariótipos foram montados de acordo com a literatura, exceto no caso de Oligoryzomys sp. A, cujo cariótipo está sendo descrito pela primeira vez. 
Os cromossomos sexuais das espécies 0 . flavescens, 0 . fornesi, $O$. microtis, 0 . moojeni e $O$. nigripes foram medidos no programa Image $\mathrm{J}$ versão 1.46 (RASBAND, 2011), segundo índices descritos por Levan, Fredga e Sandberg (1964). Os cromossomos sexuais de O. nigripes foram classificados de acordo com Paresque et al. (2007), e para o restante das espécies, as classificações estão sendo determinadas no presente trabalho. 
Tabela 3.2 - Relação dos exemplares de Oligoryzomys analisados, com número de laboratório, número de campo ou número de tombo (quando disponível), número diplóide $(2 n)$, número fundamental $(N F)$, sexo ( $M=$ macho, $F=f e ̂ m e a)$, procedência e coordenadas.

(continua)

\begin{tabular}{|c|c|c|c|c|c|c|c|}
\hline Espécie & Código & $\mathrm{N}^{\circ}$ de campo/Museu & $2 n$ & NF & Sexo & Procedência & Coordenadas \\
\hline \multirow[t]{11}{*}{ O. flavescens } & CIT 1774 & UNIBAN 2094 & 65 & $66^{*}$ & $\mathrm{M}$ & Biritiba-Mirim, SP & $23^{\circ} 47^{\prime} \mathrm{S} ; 46^{\circ} 03^{\prime} \mathrm{O}$ \\
\hline & CIT 1854 & MZUSP 30945 & 64 & 66 & $M$ & Buri, SP & $23^{\circ} 47^{\prime} \mathrm{S} ; 48^{\circ} 35^{\prime} \mathrm{O}$ \\
\hline & CIT 1894 & MZUSP 31007 & 64 & 66 & $\mathrm{M}$ & & \\
\hline & ROD 87 & CA-40 & 64 & 66 & M & Caieiras, SP & $23^{\circ} 20^{\prime} \mathrm{S} ; 46^{\circ} 46^{\prime} \mathrm{O}$ \\
\hline & ROD 123 & CLM02 & 66 & $66^{*}$ & $\mathrm{~F}$ & Caraguatatuba, SP & $23^{\circ} 37^{\prime} \mathrm{S} ; 51^{\circ} 27^{\prime} \mathrm{O}$ \\
\hline & ROD 18 & APC 1705 & 65 & $66^{*}$ & $\mathrm{M}$ & Floresta Nacional Ipanema, SP & $23^{\circ} 25^{\prime} \mathrm{S} ; 47^{\circ} 35^{\prime} \mathrm{O}$ \\
\hline & ROD 21 & APC 1779 & 66 & $66^{*}$ & M & & \\
\hline & ROD 24 & APC 1782 & 64 & 66 & $\mathrm{~F}$ & & \\
\hline & ROD 26 & APC 1785 & 64 & 66 & $\mathrm{~F}$ & & \\
\hline & ROD 59 & APC 1860 & 64 & 66 & $\mathrm{M}$ & & \\
\hline & ROD 238 & APC 2165 & 65 & $66^{*}$ & $\mathrm{~F}$ & & \\
\hline \multirow[t]{5}{*}{ O. fornesi } & CIT 747 & MZUSP 29535 & 62 & 64 & $\mathrm{~F}$ & Vila Rica, MT & $9^{\circ} 54^{\prime} \mathrm{S} ; 51^{\circ} 12^{\prime} \mathrm{O}$ \\
\hline & CIT 749 & APC327 & 62 & 64 & $\mathrm{~F}$ & & \\
\hline & ROD 289 & $\mathrm{PCH} 3826$ & 62 & 64 & M & Guará, SP & $20^{\circ} 48^{\prime} \mathrm{S} ; 47^{\circ} 48^{\prime} \mathrm{O}$ \\
\hline & CIT 962 & & 62 & 64 & $\mathrm{M}$ & Luís Antônio, SP & $21^{\circ} 35^{\prime} \mathrm{S} ; 47^{\circ} 47^{\prime} \mathrm{O}$ \\
\hline & CIT 1089 & APC565 & 62 & 64 & $\mathrm{M}$ & Parque Nacional das Emas, GO & $18^{\circ} 4^{\prime \prime S} ; 52^{\circ} 55^{\prime} \mathrm{O}$ \\
\hline
\end{tabular}


Tabela 3.2 - Relação dos exemplares de Oligoryzomys analisados, com número de laboratório, número de campo ou número de tombo (quando disponível), número diplóide $(2 n)$, número fundamental $(N F)$, sexo ( $M=$ macho, $F=f e ̂ m e a)$, procedência e coordenadas.

\begin{tabular}{|c|c|c|c|c|c|c|c|}
\hline Espécie & Código & $\mathrm{N}^{\circ}$ de campo/Museu & $2 n$ & NF & Sexo & Procedência & Coordenadas \\
\hline \multirow{2}{*}{ O. fornesi } & CIT 1477 & APC839 & 62 & 64 & M & Peixe, TO & $12^{\circ} 1^{\prime} \mathrm{S} ; 48^{\circ} 32^{\prime} \mathrm{O}$ \\
\hline & CIT 1490 & APC 808 & 62 & 64 & $\mathrm{M}$ & & \\
\hline \multirow[t]{3}{*}{ O. microtis } & CIT 683 & APC216 & 64 & 64 & $\mathrm{~F}$ & Aripuanã, MT & $10^{\circ} 10^{\prime} \mathrm{S} ; 59^{\circ} 27^{\prime} \mathrm{O}$ \\
\hline & CIT 695 & APC239 & 64 & 64 & $\mathrm{~F}$ & & \\
\hline & CIT 696 & MZUSP 29534 & 64 & 64 & $M$ & & \\
\hline \multirow{3}{*}{ O. moojeni } & CIT 2040 & SAMA 92 & 70 & 72 & $\mathrm{~F}$ & & \\
\hline & CIT 2041 & SAMA 93 & 70 & 72 & $\mathrm{M}$ & & \\
\hline & CIT 1480 & APC 853 & 70 & 72 & $\mathrm{M}$ & Peixe, TO & $12^{\circ} 1 ' \mathrm{~S} ; 48^{\circ} 32^{\prime} \mathrm{O}$ \\
\hline \multirow[t]{7}{*}{ O. nigripes } & CIT 1744 & UNIBAN 2014 & 62 & 80 & $M$ & Biritiba-Mirim, SP & $23^{\circ} 47^{\prime} \mathrm{S} ; 46^{\circ} 03^{\prime} \mathrm{O}$ \\
\hline & CIT 1746 & UNIBAN 2016 & 62 & 82 & $M$ & & \\
\hline & CIT 2004 & UNIBAN 2361 & 62 & 81 & $\mathrm{~F}$ & & \\
\hline & CIT 2020 & UNIBAN 2488 & 62 & 81 & $\mathrm{M}$ & & \\
\hline & CIT 1857 & MZUSP 30952 & 62 & 82 & $M$ & Buri, SP & $23^{\circ} 47^{\prime} \mathrm{S} ; 48^{\circ} 35^{\prime} \mathrm{O}$ \\
\hline & CIT 1861 & MZUSP 30958 & 62 & 80 & $\mathrm{~F}$ & & \\
\hline & CIT 1862 & MZUSP 30959 & 62 & 82 & $M$ & & \\
\hline
\end{tabular}


Tabela 3.2 - Relação dos exemplares de Oligoryzomys analisados, com número de laboratório, número de campo ou número de tombo (quando disponível), número diplóide $(2 n)$, número fundamental $(N F)$, sexo ( $M=$ macho, $F=f e ̂ m e a)$, procedência e coordenadas.

\begin{tabular}{|c|c|c|c|c|c|c|c|}
\hline Espécie & Código & $\mathrm{N}^{\circ}$ de campo/Museu & $2 n$ & NF & Sexo & Procedência & Coordenadas \\
\hline \multirow[t]{16}{*}{ O. nigripes } & CIT 1869 & MZUSP 30975 & 62 & 82 & M & & \\
\hline & CIT 1870 & MZUSP 30974 & 62 & 80 & M & & \\
\hline & CIT 1878 & MZUSP 30991 & 62 & 82 & $F$ & Buri, SP & $23^{\circ} 47^{\prime} \mathrm{S} ; 48^{\circ} 35^{\prime} \mathrm{O}$ \\
\hline & CIT 1895 & MZUSP 31011 & 62 & 81 & $F$ & & \\
\hline & CIT 1898 & MZUSP 31032 & 62 & 81 & M & & \\
\hline & CIT 1903 & MZUSP 31044 & 62 & 82 & M & & \\
\hline & ROD 201 & MG 12 & 62 & 82 & $\mathrm{~F}$ & Cotia, SP & $23^{\circ} 35^{\prime} \mathrm{S} ; 52^{\circ} 58^{\prime} \mathrm{O}$ \\
\hline & ROD 226 & VV43 & 62 & 81 & $\mathrm{~F}$ & & \\
\hline & ROD 278 & MG 23 & 62 & 81 & $\mathrm{~F}$ & & \\
\hline & ROD 16 & APC1709 & 62 & 82 & $M$ & Floresta Nacional Ipanema, SP & $23^{\circ} 25^{\prime} \mathrm{S} ; 47^{\circ} 35^{\prime} \mathrm{O}$ \\
\hline & ROD 17 & APC 1707 & 62 & 81 & $F$ & & \\
\hline & ROD 46 & APC 1837 & 62 & 82 & M & & \\
\hline & ROD 50 & APC 1846 & 62 & 80 & $F$ & & \\
\hline & ROD 52 & APC 1850 & 62 & 82 & $M$ & & \\
\hline & ROD 53 & APC 1853 & 62 & 82 & $\mathrm{~F}$ & & \\
\hline & ROD 54 & APC 1854 & 62 & 82 & $\mathrm{~F}$ & & \\
\hline
\end{tabular}


Tabela 3.2 - Relação dos exemplares de Oligoryzomys analisados, com número de laboratório, número de campo ou número de tombo (quando disponível), número diplóide $(2 n)$, número fundamental $(N F)$, sexo ( $M=$ macho, $F=f e ̂ m e a)$, procedência e coordenadas.

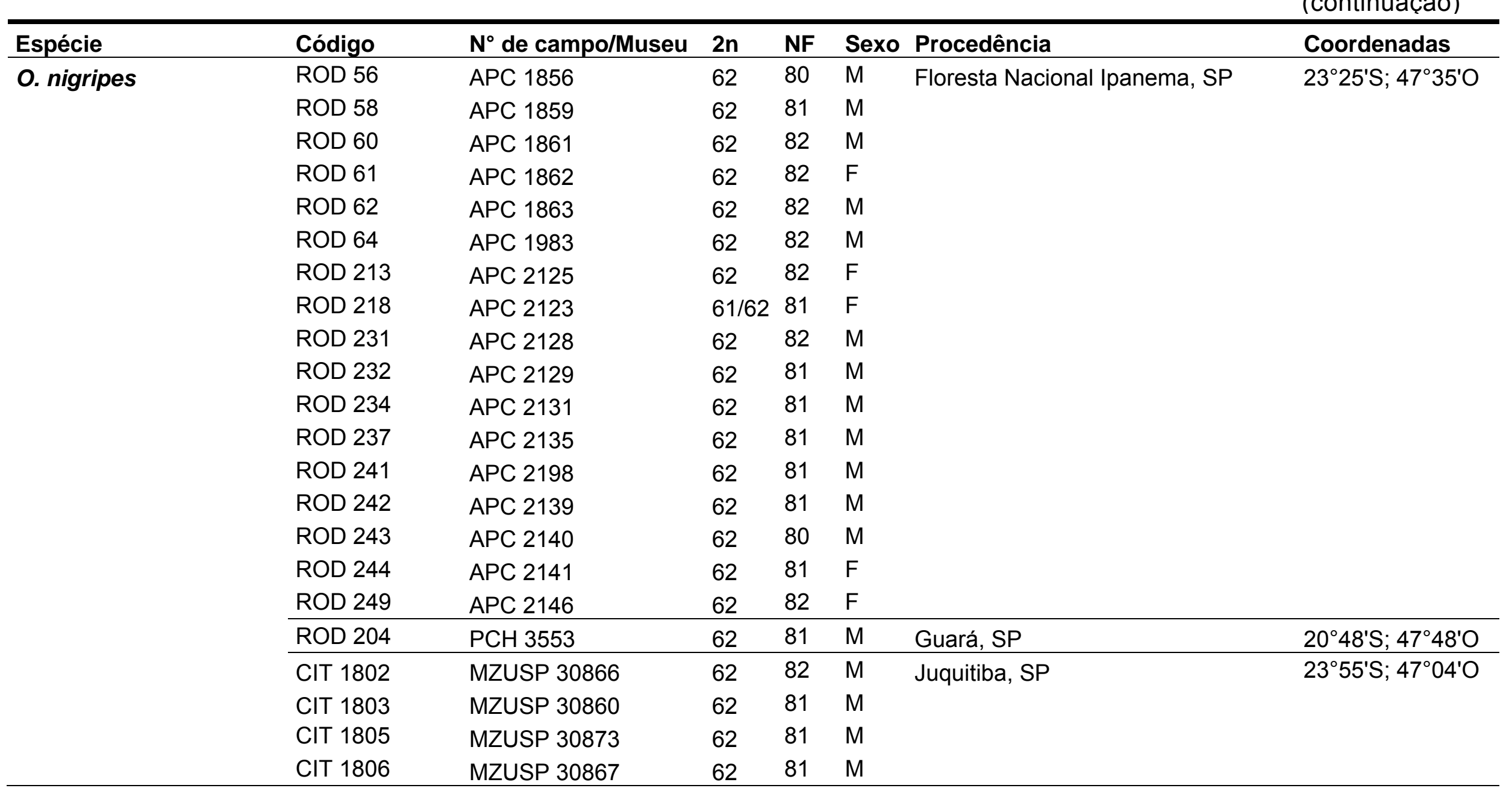


Tabela 3.2 - Relação dos exemplares de Oligoryzomys analisados, com número de laboratório, número de campo ou número

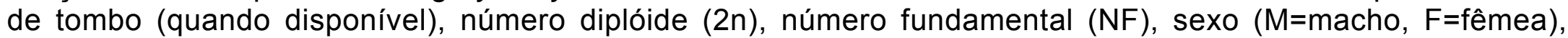
procedência e coordenadas.

(continuação)

\begin{tabular}{|c|c|c|c|c|c|c|c|}
\hline Espécie & Código & $\mathrm{N}^{\circ}$ de campo/Museu & $2 n$ & NF & Sexo & Procedência & Coordenadas \\
\hline \multirow[t]{15}{*}{ O. nigripes } & CIT 1811 & MZUSP 30882 & 62 & 82 & $\mathrm{M}$ & Juquitiba, SP & $23^{\circ} 55^{\prime} \mathrm{S} ; 47^{\circ} 04^{\prime} \mathrm{O}$ \\
\hline & CIT 1813 & MZUSP 30888 & 62 & 79 & $\mathrm{~F}$ & & \\
\hline & CIT 1816 & MZUSP 30886 & 62 & 81 & $M$ & & \\
\hline & CIT 1822 & MZUSP 30896 & 62 & 80 & $\mathrm{M}$ & & \\
\hline & CIT 964 & & 62 & 81 & $\mathrm{~F}$ & Luís Antônio, SP & $21^{\circ} 35^{\prime} \mathrm{S} ; 47^{\circ} 47^{\prime} \mathrm{O}$ \\
\hline & ROD 34 & OLISVPJB32 & 62 & 80 & $M$ & & \\
\hline & ROD 35 & UFES2275 & 62 & 81 & M & & \\
\hline & ROD 36 & UFES2276 & 62 & 80 & M & & \\
\hline & ROD 76 & UFES2277 & 62 & 81 & $\mathrm{~F}$ & & \\
\hline & ROD 77 & UFES2278 & 62 & 80 & $\mathrm{~F}$ & & \\
\hline & CIT 1851 & M0283 & 62 & 81 & $\mathrm{~F}$ & & \\
\hline & CIT 360 & & 62 & 80 & $\mathrm{~F}$ & Pindamonhangaba, SP & $22^{\circ} 55^{\prime} \mathrm{S} ; 45^{\circ} 27^{\prime} \mathrm{O}$ \\
\hline & CIT 1039 & & 62 & 82 & $\mathrm{~F}$ & Pinhalzinho, SP & $22^{\circ} 46^{\prime} \mathrm{S} ; 45^{\circ} 35^{\prime} \mathrm{O}$ \\
\hline & CIT 1044 & & 62 & 81 & $\mathrm{M}$ & & \\
\hline & CIT 1645 & ITM-0068 & 62 & 80 & $\mathrm{~F}$ & São Bernardo do Campo, SP & $23^{\circ} 69^{\prime} \mathrm{S} ; 46^{\circ} 56^{\prime} \mathrm{O}$ \\
\hline
\end{tabular}


Tabela 3.2 - Relação dos exemplares de Oligoryzomys analisados, com número de laboratório, número de campo ou número de tombo (quando disponível), número diplóide $(2 n)$, número fundamental $(N F)$, sexo ( $M=$ macho, $F=f e ̂ m e a)$, procedência e coordenadas.

(conclusão)

\begin{tabular}{|c|c|c|c|c|c|c|c|}
\hline Espécie & Código & $\mathrm{N}^{\circ}$ de campo/Museu & $2 n$ & NF & Sexo & Procedência & Coordenadas \\
\hline \multirow{6}{*}{ O. nigripes } & ROD 229 & PCH 3622 & 62 & 81 & M & São Joaquim da Barra, SP & $20^{\circ} 34^{\prime} \mathrm{S} ; 47^{\circ} 51^{\prime} \mathrm{O}$ \\
\hline & ROD 272 & $\mathrm{PCH} 3724$ & 62 & 81 & M & & \\
\hline & ROD 273 & $\mathrm{PCH} 3725$ & 62 & 80 & $\mathrm{~F}$ & & \\
\hline & CIT 352 & & 62 & 82 & $\mathrm{~F}$ & Caxambu, MG & $21^{\circ} 58^{\prime} \mathrm{S}, 44^{\circ} 55^{\prime} \mathrm{O}$ \\
\hline & CIT 1043 & DQM007 & 62 & 81 & $\mathrm{M}$ & Serra da Canastra, MG & $20^{\circ} 18^{\prime} \mathrm{S} ; 46^{\circ} 35^{\prime} \mathrm{O}$ \\
\hline & ROD 68 & MTR15862 & 62 & 78 & $\mathrm{~F}$ & Camacan, BA & $15^{\circ} 23^{\prime} \mathrm{S} ; 39^{\circ} 39^{\prime} \mathrm{O}$ \\
\hline \multirow[t]{2}{*}{ O. stramineus } & CIT 1705 & & 52 & 68 & $M$ & Uruçuí-Una, PI & $8^{\circ} 52^{\prime} \mathrm{S} ; 44^{\circ} 58^{\prime} \mathrm{O}$ \\
\hline & ROD 141 & MTR17413 & 52 & 68 & $\mathrm{~F}$ & Jequitinhonha, MG & $16^{\circ} 26^{\prime} \mathrm{S} ; 41^{\circ} 0^{\prime} \mathrm{O}$ \\
\hline Total & 117 (67M, 50F) & & & & & & \\
\hline
\end{tabular}




\subsection{Resultados}

\subsubsection{Oligoryzomys flavescens $(2 n=64-66, N F=66)$}

Foram analisados 16 indivíduos (onze machos e cinco fêmeas) provenientes de Biritiba-Mirim, Buri, Caieiras, Caraguatatuba, Floresta Nacional de Ipanema e Guará (SP) e Esmeralda (RS) (Figura 3.1, Tabela 3.2).

\section{Descrição do cariótipo}

Os animais apresentaram $2 n=64,65$ e 66 e NF=66 (Tabela 3.2), sendo o cariótipo com 2n=64 composto por 1 par acrocêntrico grande (par 1, o maior do complemento), 28 pares de cromossomos acrocêntricos com variação gradual de tamanho (pares 2 a 29) e dois pares de cromossomos metacêntricos pequenos (pares 30 e 31) (Figura 3.2). A variação no número diplóide observada em oito dos 16 exemplares analisados ocorreu devido à presença de 1 ou 2 cromossomos supernumerários (Bs) puntiformes. $O X$ é submetacêntrico $(\mathrm{Xa})$ ou subtelocêntrico $(\mathrm{Xb})$, com tamanho intermediário entre os pares autossômicos 1 e 2, e o Y mostrou-se submetacêntrico de tamanho pequeno. Em coloração convencional, foi possível a identificação dos pares autossômicos 1, 30, 31, dos cromossomos Bs e das duas formas do X (Figura 3.2).

A presença dos cromossomos $B s$ e a variação observada nos cromossomos sexuais de 11 exemplares, cuja banda $C$ foi obtida, levaram à obtenção de seis composições cariotípicas diferentes para O. flavescens (Tabela 3.3).

\section{Coloração diferencial}

O padrão de bandas $C$ mostrou heterocromatina constitutiva nas regiões pericentroméricas de todos os autossomos. $O$ braço curto e a região pericentromérica do $X$ são heterocromáticos e $\circ \mathrm{Y}$ mostra banda $C$ positiva na região distal do braço longo. Além disso, os cromossomos Bs não apresentaram marcação conspícua (Figura 3.3). 
O padrão de bandas $G$ possibilitou a identificação e emparelhamento de quase todos os pares de homólogos. Não foi detectado padrão nos cromossomos Bs. $\mathrm{O} X$ apresentou duas bandas escuras na região mediana do braço longo, evidenciando um padrão típico do cromossomo $X$ de mamíferos, além de uma banda $G$ positiva no braço curto (Figura 3.4). Não foi observado um padrão de bandas $\mathrm{G}$ definido no cromossomo $\mathrm{Y}$.

A coloração das regiões organizadoras de nucléolo não foi obtida para esta espécie e a FISH com sondas teloméricas mostrou sinais exclusivos na região do telômero de todos os cromossomos, inclusive no supernumerário (Figura 3.5).

Tabela 3.3 - Citótipos encontrados para O. flavescens, nos quais $\mathrm{Xa}=$ submetacêntrico grande; $\mathrm{Xb}=$ subtelocêntrico grande; $\mathrm{Y}=$ submetacêntrico pequeno.

\begin{tabular}{cccclll}
\hline Citótipos & 2n & NF & B & Par sexual & \multicolumn{1}{c}{ Código } & Procedência \\
\hline $\mathbf{1}$ & 64 & 66 & 0 & XaXa & ROD 24; ROD 26 & a \\
\hline $\mathbf{2}$ & 64 & 66 & 0 & XaY & $\begin{array}{l}\text { ROD 19; ROD 59; } \\
\text { ROD 292 }\end{array}$ & a, b \\
\hline $\mathbf{3}$ & 65 & 66 & 1 & XaXb & ROD 238 & a \\
\hline $\mathbf{4}$ & 65 & 66 & 1 & XaY & ROD 18; ROD 20 & a \\
\hline $\mathbf{5}$ & 66 & 66 & 2 & XaXa & ROD 123 & $\mathrm{c}$ \\
\hline $\mathbf{6}$ & 66 & 66 & 2 & XaY & CIT 941; ROD 21 & d, a \\
\hline
\end{tabular}

B (cromossomo supernumerário). Procedência: (a) Floresta Nacional de Ipanema; (b) Guará; (c) Caraguatatuba, todas as localidades em SP e (d) Esmeralda, RS.

\subsubsection{Oligoryzomys fornesi $(2 n=62, N F=64)$}

Sete indivíduos (cinco machos e duas fêmeas) provenientes de cinco localidades (Figura 3.1), sendo quatro estados brasileiros (Parque Nacional das Emas, GO; Vila Rica, MT; Peixe, TO; Luís Antônio e Guará, SP) foram analisados citogeneticamente (Tabela 3.2).

\section{Descrição do cariótipo}

O cariótipo apresentou $2 n=62, N F=64$, sendo o par 1 acrocêntrico grande (o maior do complemento), os pares 2 a 28 são acrocêntricos, com variação 
gradual de tamanho; o par 29 é submetacêntrico médio e o par 30, metacêntrico pequeno (Figura 3.6). Foram observadas variações tanto no cromossomo $X$ quanto no $\mathrm{Y}$. O X mostrou-se de duas formas: subtelocêntrico grande (Xa) ou acrocêntrico grande $(\mathrm{Xb})$ e $\mathrm{O} Y$, subtelocêntrico pequeno ( $\mathrm{Ya}$ ) ou submetacêntrico médio (Yb) (Figuras 3.6 e 3.7). Devido à variação encontrada nos cromossomos sexuais, foram encontradas três formas cariotípicas diferentes nos sete exemplares estudados (Tabela 3.4).

\section{Coloração diferencial}

O bandamento $\mathrm{C}$ revelou blocos de heterocromatina constitutiva nas regiões pericentroméricas dos autossomos, sendo a marcação no par 1 muito sutil em comparação com os outros pares (Figura 3.7). O X subtelocêntrico (Xa) apresentou heterocromatina constitutiva na região pericentromérica, estendendose para região proximal do braço curto e do braço longo, além de duas bandas intersticiais no braço longo. O bandamento $C$ no cromossomo $X$ acrocêntrico $(\mathrm{Xb})$ não foi obtido. Ambas as formas de $\mathrm{Y}$ apresentaram heterocromatina na região distal do braço longo (Figura 3.7).

O bandamento $G$ permitiu a identificação e o emparelhamento de quase todos os homólogos (Figura 3.8).

A técnica de Ag-RON evidenciou marcações terminais múltiplas em cromossomos acrocêntricos pequenos, que não puderam ser identificados. Foram analisadas 20 metáfases e ocorreu variação de três a seis cromossomos portadores de RONs, sendo a média 4,15 e a moda 4; foram observadas até 12 associações entre dois cromossomos (dado não mostrado).

A FISH com sondas teloméricas evidenciou marcação nos telômeros de todos os cromossomos (dado não mostrado). 
Tabela 3.4 - Citótipos encontrados para O. fornesi, onde $\mathrm{Xa}=$ subtelocêntrico grande; $\mathrm{Xb}=$ acrocêntrico grande; $\mathrm{Ya}=$ subtelocêntrico pequeno e $\mathrm{Yb}=$ submetacêntrico médio.

\begin{tabular}{ccclll}
\hline Citótipos & $\mathbf{2 n}$ & NF & Par sexual & Exemplares & Procedência \\
\hline $\mathbf{1}$ & 62 & 64 & XaXb & CIT 747; CIT 749 & Vila Rica (MT) \\
\hline $\mathbf{2}$ & 62 & 64 & XaYa & CIT 962; & Luís Antônio (SP); \\
& & & & CIT1477; CIT1490 & Peixe (TO) \\
\hline $\mathbf{3}$ & 62 & 64 & XaYb & CIT 1089; ROD 289 & Parque Nac. Emas \\
& & & & & $($ GO); Guará (SP) \\
\hline
\end{tabular}

\subsubsection{Oligoryzomys microtis $(2 n=64, N F=64)$}

Foram analisados quatro indivíduos (três fêmeas e um macho) provenientes de Aripuanã (MT) (Figura 3.1), que apresentaram 2n=64 e NF=64 (Tabela 3.2).

\section{Descrição do cariótipo}

O cariótipo é constituído pelo par 1, um acrocêntrico grande, sendo destacadamente o maior do complemento; do par 2 ao 30, os cromossomos são acrocêntricos com variação gradual de tamanho, e o par 31 é submetacêntrico pequeno (Figura 3.9). O cromossomo $X$ apresentou-se subtelocêntrico grande (Xa) ou acrocêntrico grande $(\mathrm{Xb})$. O cromossomo $\mathrm{Y}$ do único macho mostrou-se subtelocêntrico pequeno. A partir dos quatro exemplares analisados, foi possível reconhecer três formas cariotípicas diferentes, devido à variação encontrada nos cromossomos sexuais (Tabela 3.5).

\section{Coloração diferencial}

O padrão de bandas $\mathrm{C}$ mostrou heterocromatina constitutiva na região pericentromérica de todos os cromossomos, evidenciando que o par 31 é constituído por cromossomos de dois braços. O X subtelocêntrico (Xa) apresentou heterocromatina constitutiva na região pericentromérica, estendendose à região proximal do braço curto e o $X$ acrocêntrico $(X b)$, apenas na região pericentromérica. O Y mostrou-se heterocromático no braço longo (Figura 3.10). 
O bandamento $G$ possibilitou o emparelhamento correto dos homólogos, exceto no caso dos cromossomos de menor tamanho. Além disso, o X, em suas duas formas, mostrou as duas bandas escuras características na região mediana do braço longo (Figura 3.11) e o Y não mostrou um padrão peculiar (dado não mostrado).

As RONs foram múltiplas e as marcações ocorreram na região terminal de cromossomos acrocêntricos de tamanho médio a pequeno, que não puderam ser identificados (dado não mostrado). As marcações variaram de três a seis, sendo a média 4,7 e a moda 4. Foram observadas até nove associações entre dois cromossomos e uma entre três cromossomos.

Após a FISH com sondas teloméricas, foram observadas marcações na região dos telômeros de todos os cromossomos (Figura 3.12).

Tabela 3.5 - Citótipos encontrados para O. microtis, onde $\mathrm{Xa}=$ subtelocêntrico grande; $\mathrm{Xb}=$ acrocêntrico grande e $\mathrm{Y}=$ subtelocêntrico pequeno.

\begin{tabular}{ccclll}
\hline Citótipos & 2n & NF & Par sexual & Exemplares & Procedência \\
\hline $\mathbf{1}$ & 64 & 64 & XaXa & CIT 683; CIT 695 & Aripuanã (MT) \\
\hline $\mathbf{2}$ & 64 & 64 & XaXb & CIT 702 & Aripuanã (MT) \\
\hline $\mathbf{3}$ & 64 & 64 & XbY & CIT 696 & Aripuanã (MT) \\
\hline
\end{tabular}

\subsubsection{Oligoryzomys moojeni $(2 n=70, N F=72)$}

Quatro exemplares (duas fêmeas e dois macho), provenientes de Minaçu (GO) e Peixe (TO) (Figura 3.1), foram analisados citogeneticamente e apresentaram 2n=70, NF=72 (Tabela 3.2).

\section{Descrição do cariótipo}

O cariótipo é composto por 32 pares acrocêntricos (pares 1 a 32), sendo o primeiro par muito maior que o restante, que decrescem gradualmente de tamanho e dois pares metacêntricos pequenos (pares 33 e 34). O X mostrou-se polimórfico, devido a diferenças no tamanho do braço curto, de modo que um deles foi considerado submetacêntrico (Xa) e o outro, subtelocêntrico (Xb) 
(Figura 3.13). O Y também apresentou variação entre os dois machos da amostra, sendo um acrocêntrico médio (Ya) e o outro, submetacêntrico médio (Yb), ambos de tamanho semelhante aos pares 7 e 8, de modo que o Ya só pode ser reconhecido após o bandamento $C$ (Figura 3.14). As análises nos quatro exemplares de O. moojeni revelaram três citótipos diferentes (Tabela 3.6).

\section{Coloração diferencial}

O padrão de bandas $C$ evidenciou blocos heterocromáticos na região pericentromérica dos autossomos, na região distal do par 11, no braço curto e na região proximal de ambas as formas do $\mathrm{X}(\mathrm{Xa}$ e $\mathrm{Xb})$ e na região distal do braço longo dos dois cromossomos $Y$ ( $Y a$ e $Y b)$ (Figura 3.14).

A banda $G$ permitiu o emparelhamento dos homólogos e, além disso, mostrou duas bandas escuras na região mediana do braço longo dos cromossomos $X$ (Figura 3.15). Não foi obtida banda $G$ dos exemplares machos.

As Ag-RONs foram múltiplas, localizadas em cromossomos acrocêntricos, que não puderam ser identificados (Figura 3.16). Nas 21 células analisadas, as marcações variaram de 5 a 9 , sendo a média 6,9 e a moda 7. Associações entre os cromossomos portadores de RONs foram observadas, sendo mais frequentes aquelas entre dois cromossomos (22 associações no total).

A FISH com sondas teloméricas mostrou sinais apenas na região dos telômeros (dado não mostrado).

Tabela 3.6 - Citótipos encontrados para $O$. moojeni, onde $X a=$ submetacêntrico grande; $\mathrm{Xb}=$ subtelocêntrico grande; $\mathrm{Ya}=$ acrocêntrico médio e $\mathrm{Yb}=$ submetacêntrico médio.

\begin{tabular}{ccclll}
\hline Citótipos & 2n & NF & Par sexual & Exemplares & Procedência \\
\hline $\mathbf{1}$ & 70 & 72 & XaXb & CIT 2039; CIT 2040 & Minaçu (GO) \\
\hline $\mathbf{2}$ & 70 & 72 & XbYa & CIT 2041 & Minaçu (GO) \\
\hline $\mathbf{3}$ & 70 & 72 & XbYb & CIT 1480 & Peixe (TO) \\
\hline
\end{tabular}




\subsubsection{Oligoryzomys nigripes $(2 n=62, N F=78-82)$}

Foram analisados 83 indivíduos (46 machos e 37 fêmeas), provenientes de 18 localidades: Biritiba-Mirim, Buri, Caieiras, Cotia, Floresta Nacional de Ipanema, Guará, Juquitiba, Luís Antônio, Parque Estadual Carlos Botelho, Parque Estadual da Serra do Mar (núcleo Santa Virgínia), Piedade, Pindamonhangaba, Pinhalzinho, São Bernardo do Campo e São Joaquim da Barra (SP), Caxambu e Serra da Canastra (MG) e Camacan (BA) (Figura 3.1), que apresentaram 2n=62 e NF=78-82 (Tabela 3.2).

\section{Descrição do cariótipo}

O cariótipo em coloração comum mostrou-se da seguinte forma: o par 1 é um subtelocêntrico grande; duas formas distintas para o par 2 foram encontradas: submetacêntrico grande (2SM) ou acrocêntrico grande (2A); o par 3 , mostrou-se homomórfico acrocêntrico (3A), homomórfico metacêntrico (3M) ou heteromórfico, com um cromossomo acrocêntrico e um metacêntrico $(3 \mathrm{H})$; também foi observado um exemplar com heteromorfismo no par 8 , o qual mostrou-se acrocêntrico médio $(8 \mathrm{~A})$. Há, ainda, sete pares metacêntricos/submetacêntricos (pares 4 a 7 e 9 a 11) e 19 pares acrocêntricos (pares 12 a 30), que decrescem gradativamente de médios a pequenos (Figura 3.17). Uma fêmea apresentou mosaicismo $2 n=61, X / 62, X X$, sendo que $46 \%$ das 50 células analisadas mostraram número diplóide igual a 61 , com ausência de um dos cromossomos $\mathrm{X}$.

$O$ cromossomo $X$ mostrou-se submetacêntrico grande $(X a)$, subtelocêntrico grande $(\mathrm{Xb})$ ou metacêntrico grande $(\mathrm{Xc})$ e $\circ \mathrm{Y}$ também apresentou variação em sua morfologia, podendo ser metacêntrico médio (Ya), submetacêtrico pequeno $(\mathrm{Yb})$ ou submetacêntrico médio $(\mathrm{Yc})$, segundo morfologias definidas em Paresque et al. (2007) (Figura 3.17 e 3.18). Os cromossomos sexuais só puderam ser identificados após bandamento $\mathrm{C}$.

Devido a essa alta variabilidade nos autossomos e cromossomos sexuais, nos 27 exemplares da amostra cuja banda $C$ foi obtida, foram observadas 15 composições cariotípicas diferentes (Tabela 3.7). 


\section{Coloração diferencial}

O padrão de bandas C evidenciou pequenas quantidades de heterocromatina constitutiva na região pericentromérica de todos os autossomos e alguns indivíduos mostraram marcação na região distal no braço longo do par 21 (dado não mostrado).

O cromossomo $X$ apresentou-se fortemente heterocromático no braço curto e o cromossomo $\mathrm{Y}$ foi C-positivo em um dos braços ou no cromossomo inteiro, dependendo da atividade de ação do bário. Os cromossomos sexuais de O. nigripes podem ser identificados apenas após o bandamento $\mathrm{C}$, pois apresentam padrão heterocromático característico. Apesar de a técnica ter sido aplicada em todos os 83 exemplares, resultado positivo foi obtido apenas em 27 (provavelmente devido à idade das lâminas) e somente os cromossomos sexuais dos indivíduos cuja banda $\mathrm{C}$ foi obtida foram medidos e classificados (Figura 3.18, Tabela 3.7).

O padrão de bandas $G$ possibilitou a identificação correta dos pares de homólogos, inclusive daqueles envolvidos em rearranjos do tipo inversão pericêntrica (par 3). Além disso, o cromossomo $X$ apresentou duas bandas escuras no braço longo e uma no braço curto, enquanto que no cromossomo $Y$ inteiro não foi identificado um padrão definido (Figura 3.19).

A técnica de Ag-RON realizada em três indivíduos (sendo dois com o par $3 \mathrm{H}$ e um com o par $3 \mathrm{M}$ ) evidenciou marcações terminais múltiplas no braço curto de cromossomos acrocêntricos pequenos, que variaram de 2 a 8 , e foram observadas associações entre dois e três cromossomos (dado não mostrado).

Apesar de terem sido realizadas hibridações com sondas teloméricas em exemplares $2 \mathrm{~A}, 3 \mathrm{M}, 3 \mathrm{H}, 3 \mathrm{~A}$ e $8 \mathrm{~A}$, resultado positivo foi obtido somente nos exemplares que possuíam o par $3 \mathrm{~A}$ e $3 \mathrm{H}$. Foram detectados sinais de hibridação da sequência (TTAGGG) na região telomérica de todos os cromossomos (Figura 3.20). 
Tabela 3.7 - Citótipos encontrados para 0 . nigripes, nos quais $\mathrm{Xa}=$ submetacêntrico grande; $\mathrm{Xb}=$ subtelocêntrico grande; $\mathrm{Xc}=$ metacêntrico grande; $\mathrm{Ya}=$ metacêntrico médio; $\mathrm{Yb}=$ submetacêntrico pequeno e $Y_{c}=$ submetacêntrico médio.

\begin{tabular}{|c|c|c|c|c|c|c|c|c|}
\hline Citótipos & $2 n$ & NF & Par 2 & Par 3 & Par 8 & Par sexual & Código & Procedência \\
\hline 1 & 62 & 78 & A & A & $\mathrm{M}$ & $\mathrm{XbXb}$ & ROD 68 & a \\
\hline 2 & 62 & 79 & SM & $\mathrm{H}$ & A & $\mathrm{XaXa}$ & CIT 1813 & $b$ \\
\hline 3 & 62 & 80 & SM & A & M & XaXc & $\begin{array}{l}\text { ROD } 77 ; \\
\text { ROD } 273\end{array}$ & $c, d$ \\
\hline 4 & 62 & 80 & SM & A & $M$ & XaYc & ROD 36 & c \\
\hline 5 & 62 & 81 & SM & $\mathrm{H}$ & $\mathrm{M}$ & XaXa & $\begin{array}{l}\text { ROD 25; } \\
\text { ROD } 79 ; \\
\text { ROD 164; } \\
\text { ROD } 226 \\
\end{array}$ & $e, c, f, g$ \\
\hline 6 & 62 & 81 & SM & $\mathrm{H}$ & $\mathrm{M}$ & $X c X c$ & ROD 76 & c \\
\hline 7 & 62 & 81 & SM & $\mathrm{H}$ & $\mathrm{M}$ & XaYa & $\begin{array}{l}\text { ROD 35; } \\
\text { ROD } 272\end{array}$ & $c, d$ \\
\hline 8 & 62 & 81 & SM & $\mathrm{H}$ & M & $\mathrm{XcYc}$ & $\begin{array}{l}\text { CIT 1803; } \\
\text { ROD } 58\end{array}$ & $b, e$ \\
\hline 9 & 62 & 81 & SM & $\mathrm{H}$ & M & XcYa & $\begin{array}{l}\text { CIT 1805; } \\
\text { CIT 1806 }\end{array}$ & b \\
\hline 10 & 62 & 82 & SM & $\mathrm{M}$ & $M$ & $\mathrm{XaXa}$ & $\begin{array}{l}\text { ROD 23; } \\
\text { ROD 53; } \\
\text { ROD 54; } \\
\text { ROD } 61\end{array}$ & e \\
\hline 11 & 62 & 82 & SM & $\mathrm{M}$ & $\mathrm{M}$ & $\mathrm{XaXc}$ & ROD 213 & $\mathrm{e}$ \\
\hline 12 & 62 & 82 & SM & $\mathrm{M}$ & M & $\mathrm{XaYb}$ & ROD 85 & $\mathrm{~h}$ \\
\hline 13 & 62 & 82 & SM & $M$ & $\mathrm{M}$ & $\mathrm{XaYc}$ & $\begin{array}{l}\text { ROD 22; } \\
\text { ROD 60; } \\
\text { ROD 64 }\end{array}$ & $\mathrm{e}$ \\
\hline 14 & 62 & 82 & SM & $\mathrm{M}$ & $\mathrm{M}$ & XcYa & CIT 1811 & $\mathrm{~b}$ \\
\hline 15 & $61 / 62$ & 81 & SM & $\mathrm{H}$ & $\mathrm{M}$ & $\mathrm{Xa} / \mathrm{XaXb}$ & ROD 218 & e \\
\hline
\end{tabular}

Cromossomos sexuais classificados de acordo com Paresque et al. (2007). SM, A e H referem-se às diferentes formas encontradas nos pares 2, 3 e 8 de 0 . nigripes. SM: submetacêntrico; $\mathrm{A}$ : acrocêntrico e $\mathrm{H}$ : heteromórfico, sendo um cromossomo metacêntrico e outro acrocêntrico. Procedência: (a) Camacan, BA; (b) Juquitiba, SP; (c) Parque Estadual da Serra do Mar, núcleo Santa Virgínia, SP; (d) São Joaquim da Barra, SP; (e) Floresta Nacional de Ipanema, SP; (f) Parque Estadual Carlos Botelho, SP; (g) Cotia, SP; (h) Caieiras, SP.

\subsubsection{Oligoryzomys sp. $A(2 n=70, N F=72)$}

Um exemplar, proveniente de Apiacás (MT) (Figura 3.1), foi analisado e apresentou $2 \mathrm{n}=70$ e NF=72 (Tabela 3.2). 


\section{Descrição do cariótipo}

O cariótipo mostrou que os pares 1 e 33 são heteromórficos, sendo o par 1 composto por um cromossomo subtelocêntrico grande e o outro acrocêntrico grande e o par 33, composto por um cromossomo subtmetacêntrico de tamanho médio e outro acrocêntrico médio. O restante do cariótipo possui 31 pares acrocêntricos (pares 2 a 32) e um par meta/submetacêntrico pequeno (par 34) (Figura 3.21).

\section{Coloração diferencial}

$O$ padrão de bandas $C$ mostrou pequenos blocos de heterocromatina constitutiva na região centromérica dos autossomos, no braço curto do $X$ e no braço longo do $Y$ (Figura 3.21).

Não foi possível obtenção de bandas G, RONs e FISH telomérica neste exemplar.

\subsubsection{Oligoryzomys stramineus $(2 n=52, N F=68)$}

Dois exemplares, uma fêmea proveniente de Jequitinhonha (MG) e um macho de Uruçuí-Una (PI) (Figura 3.1), foram analisados e apresentaram 2n=52, $\mathrm{NF}=68$ (Tabela 3.2 ).

\section{Descrição do cariótipo}

O cariótipo é composto por nove pares de cromossomos de dois braços e 16 pares acrocêntricos. $O$ cromossomo $X$ é um submetacêntrico médio, e o $Y$, metacêntrico pequeno. $\mathrm{Na}$ fêmea, foi observado um heteromorfismo de $X$ caracterizado por uma sutil diferença no tamanho do braço curto de um dos cromossomos, designado como $\mathrm{X}^{+}$(Figura 3.22).

\section{Coloração diferencial}

A banda $C$ evidenciou blocos de heterocromatina constitutiva na região pericentromérica dos autossomos, no braço curto do cromossomo $\mathrm{X}$ e ao longo de todo o cromossomo $Y$ (Figura 3.23). O cromossomo $Y$ só pode ser 
identificado após a técnica de banda $C$, pois possui o mesmo tamanho e morfologia que os pares 4 e 5 .

O padrão de bandas $G$ possibilitou a identificação dos pares de homólogos. Além disso, o cromossomo $X$ apresentou duas bandas escuras no braço longo (Figura 3.24).

Não foi possível a obtenção de RON nessa espécie.

A FISH com sondas teloméricas evidenciou marcação nos telômeros de todos os cromossomos (dado não mostrado).

\subsubsection{Comparação dos cariótipos através do padrão de bandas G}

O padrão de bandas $\mathrm{G}$ dos exemplares de O. flavescens (OFL), O. fornesi (OFO), O. microtis (OMI), O. moojeni (OMO), O. nigripes (ONI) e O. stramineus (OST) (deste trabalho) e de O. rupestris (ORU) (Oligoryzomys sp. 1) e Oligoryzomys sp. 2 (OSP), retirados de Silva e Yonenaga-Yassuda, 1997, foram comparados entre si para estabelecimento das homologias entre os pares cromossômicos (Figura 3.25).

Para facilitar a leitura, neste trabalho, as regiões de mesma composição genética tanto da mesma espécie quanto de espécies diferentes estão sendo denominadas de "homólogas".

O único cromossomo/ braço cromossômico que se mostrou homólogo nas oito espécies foi o par 1 inteiro das espécies OFL, OFO, OMI, OMO, ONI; o par 2 de OST e o braço longo do par 3 de ORU e OSP (Figura 3.25a).

Além disso, pode ser inferida homologia entre outros dois cromossomos autossômicos nas espécies $O$. flavescens, O. fornesi, O. microtis, O. moojeni, $O$. nigripes e O. stramineus: (i) OFL 2, OFO 2, OMI 2, OMO 2, ONI 2 e OST 10 (Figura 3.25b); e (ii) OFL 3, OFO 3, OMI 3, OMO 3, ONI 3 e OST 1 (Figura 3.25c).

Os outros autossomos não puderam ser comparados, pois são muito pequenos e o padrão de bandas não estava adequado para a comparação entre as diferentes espécies. 


\subsection{Discussão}

Das 11 espécies de Oligoryzomys que ocorrem no Brasil, seis foram abordadas neste trabalho: $O$. flavescens, O. fornesi, O. microtis, O. moojeni, $O$. nigripes e O. stramineus. Além disso, há um indivíduo cujo cariótipo $(2 n=70$, $\mathrm{NF}=72$ ) está sendo apresentado pela primeira vez na literatura e, até o momento, não pode ser relacionado a nenhuma outra espécie descrita de Oligoryzomys, totalizando sete espécies estudadas.

Dessas sete espécies, seis possuem cariótipos espécie-específicos que podem ser usados como dignóstico citotaxonômico: O. flavescens, O. fornesi, $O$. microtis, O. moojeni, O. nigripes e O. stramineus. Mesmo que o O. moojeni tenha o mesmo número diplóide e fundamental que o descrito para Oligoryzomys sp. A, apenas a primeira está sendo considerada uma espécie portadora de cariótipo espécie-específico, pois possui um cariótipo peculiar, já descrito na literatura por diversos autores, e distinto de Oligoryzomys sp. A (Figuras 3.13 e 3.21).

$\mathrm{Na}$ literatura, das 22 espécies descritas formalmente, 16 (72,7\%) possuem cariótipos espécie-específicos, o que mostra a importância da citogenética na caracterização desses táxons: $O$. andinus $(2 n=60, N F=70), O$. chacoensis $(2 n=58, N F=74)$, O. delicatus $(2 n=62, N F=74,76)$, O. destructor $(2 n=60, N F=76)$, O. flavescens $(2 n=64-68, N F=66-72)$, O. fornesi $(2 n=62, N F=62)$, O. fulvescens $(2 \mathrm{n}=60, \mathrm{NF}=72,74)$, O. longicaudatus $(2 \mathrm{n}=56, \mathrm{NF}=66)$, O. magellanicus $(2 \mathrm{n}=56$, $\mathrm{NF}=66)$, O. messorius $(2 \mathrm{n}=56, \mathrm{NF}=58)$, O. microtis $(2 \mathrm{n}=64, \mathrm{NF}=64,66), O$. moojeni $(2 \mathrm{n}=70, \mathrm{NF}=72,74,76)$, O. nigripes $(2 \mathrm{n}=61,62, \mathrm{NF}=78-82)$, O. rupestris $(2 n=46, N F=52)$, O. stramineus $(2 n=52, N F=68-70)$ e O. utiaritensis $(2 n=72$, $\mathrm{NF}=76)$ (Tabela 1.3 - Capítulo 1).

A Tabela 1.3 mostra uma compilação dos dados cariotípicos descritos até o momento para Oligoryzomys. Pode-se perceber que o número de espécies reconhecidas para o gênero é menor do que o número de cariótipos descritos na literatura e não há dados citogenéticos para quatro espécies válidas: $O$. arenalis, O. brendae, O. griseolus, O. victus.

De um total de 117 indivíduos estudados, 83 (70,9\%) pertencem à espécie O. nigripes. O elevado número de exemplares dessa espécie na amostra é 
devido ao fato de as coletas serem mais frequentes em áreas de Floresta Atlântica, principalmente no estado de São Paulo. Além disso, O. nigripes está amplamente distribuída pelo Brasil e é considerada uma espécie generalista, podendo ocorrer em fragmentos florestais degradados pela ação antrópica (VIEIRA, 2003).

Ao observar a distribuição de Oligoryzomys no Brasil, nota-se que na região central do país há poucos registros de ocorrência do gênero. É provável que haja uma lacuna amostral nessa região. Pode-se notar também que nas regiões onde há maiores esforços amostrais (costa do Brasil, estendendo-se à região do interior até Minas Gerais), há maior ocorrência de espécies simpátricas.

O presente trabalho reitera a importância dos levantamentos faunísticos para maior conhecimento das espécies e para descrição de novos táxons, pois novos esforços de coleta com frequência resultam em descrições de novas espécies ou até gêneros, como por exemplo, o gênero Drymoreomys (Tribo Oryzomyini), que foi descrito recentemente e é endêmico da Floresta Atlântica (PERCEQUILLO; WEKSLER; COSTA, 2011).

Segundo Chiarello et al. (2008), o número de exemplares coletados é insuficiente para o real conhecimento das espécies de mamíferos do Brasil, já que a maior parte do território nacional foi pouco explorada. Além disso, dados sobre ocorrência, vulnerabilidade e abundância das espécies são essenciais para traçar estratégias de conservação (DE VIVO et al., 2011).

\subsubsection{Oligoryzomys flavescens}

O cariótipo apresentado neste trabalho para O. flavescens é idêntico ao descrito por Aniskin e Volobouev (1999) e Sbalqueiro et al. (1991).

O. flavescens ocorre no Paraguai, Argentina, Uruguai e Brasil (BONVICINO; OLIVEIRA; D'ANDREA, 2008; MUSSER; CARLETON, 2005). No Brasil, a espécie apresenta distribuição na região dos Pampas, florestas de galerias do Cerrado e Mata Atlântica, desde o Rio Grande do Sul até o sul da Bahia, de modo que os dados apresentados neste trabalho corroboram a 
distribuição descrita por Bonvicino, Oliveira e D’Andrea (2008). Além disso, O. flavescens ocorre em simpatria com O. nigripes nas localidades de Biritiba-Mirim, Buri, Caieiras e Floresta Nacional de Ipanema (SP), que são áreas de Floresta Atlântica ou transição entre Floresta Atlântica e Cerrado, e com O. fornesi e $O$. nigripes em Guará (SP), também uma área de transição entre Cerrado e Mata Atlântica.

A variação encontrada no número diplóide $(2 n=64-66)$ é decorrente da presença de um ou dois cromossomos supernumerários puntiformes, cuja morfologia não pode ser definida, em decorrência do tamanho pequeno. Oito dos 16 indivíduos analisados neste trabalho apresentaram cromossomos $B$ (sendo quatro com $1 \mathrm{~B}$ e quatro com $2 \mathrm{Bs}$ ).

Bonvicino e Geise (2006) descreveram um cariótipo para O. flavescens no qual o cromossomo B possuía dois braços. Entretanto, a morfologia desse cromossomo extra de dois braços é semelhante à do cromossomo $Y$ apresentado por Aniskin e Volobouev (1999), Sbalqueiro et al. (1991) e no presente trabalho.

Estudos realizados em $O$. flavescens mostraram que os supernumerários são metacêntricos nos indivíduos provenientes do Uruguai (BRUM-ZORRILLA; FRONZA; WAINBERG, 1988), e acrocêntricos nos indivíduos do Brasil (SBALQUEIRO et al., 1991). Outra diferença observada é a ausência de indivíduos provenientes daqueles países com número diplóide igual a 65 .

As análises de banda $C$ nos exemplares da amostra não evidenciaram padrão heterocromático nos $\mathrm{Bs}$, quando comparados às bandas $\mathrm{C}$ pericentroméricas dos demais cromossomos do complemento. Segundo Camacho (2005) e Vujosevic e Blagojevic (2004), geralmente os cromossomos extras são compostos por heterocromatina, sendo, portanto, sua coloração bem evidenciada pela banda $C$. Contudo, inúmeros exemplos têm sido descritos, nos quais a marcação C-positiva não ocorre ou ocorre fracamente (KASAHARA, 2009). Além disso, o fato de esses cromossomos serem puntiformes dificulta a constatação exata do bandamento.

As bandas $G$ também não evidenciaram um padrão peculiar nos cromossomos supernumerários da amostra. De acordo com Kasahara (2009), o 
bandamento $\mathrm{G}$ tem mostrado pouca ou nenhuma diferenciação ao longo dos Bs, embora Silva e Yonenaga-Yassuda (1998) tenham verificado um padrão conspícuo de bandas $G$ nas três diferentes formas de cromossomos $B$ do roedor orizomino Nectomys.

A hibridação in situ fluorescente foi realizada em um exemplar que possuía um cromossomo supernumerário e foram observadas marcações restritas aos telômeros. Alguns estudos revelaram sinais intersticiais teloméricos em cromossomos supernumerários, como por exemplo, nos roedores do gênero Nectomys (SILVA; YONENAGA-YASSUDA, 1998), porém não foi o caso para $O$. flavescens.

Os cromossomos Bs são cromossomos extras, que aparecem em algumas espécies causando variação no seu número diplóide. São considerados dispensáveis, por não estarem presentes em todos os indivíduos da população, porém possuem ampla ocorrência em diversos grupos de animais e plantas, estando presentes em aproximadamente 15\% das espécies de eucariotos (CAMACHO, 2005; TRIFONOV et al., 2010). Além disso, apresentam variação interpopulacional e até mesmo entre diferentes tecidos (JONES; REES, 1982).

Esses cromossomos têm sido alvo de extensa investigação, pois representam um elemento intrigante do ponto de vista citogenético. Possuem comportamento meiótico irregular, com formação de univalentes, mesmo quando a espécie apresenta dois Bs idênticos; não sofrem recombinação com os cromossomos A e possuem herança não-mendeliana (CAMACHO, 2005; JONES; REES, 1982).

Embora haja consenso de que os Bs não promovam alterações fenotípicas e nem alteram a adaptabilidade dos indivíduos (JONES; REES, 1982), alguns trabalhos mais recentes mostram a presença de DNA ribossômico ou elementos transponíveis nesses cromossomos (CAMACHO, 2005; PEPPERS; WIGGINS; BAKER, 1997; STITOU et al., 2000; TRIFONOV et al., 2010).

Cerca de 55 espécies de mamíferos apresentam Bs (VUJOSEVIC; BLAGOJEVIC, 2004) e, entre elas, estão nove roedores brasileiros: Akodon montensis, Blarinomys breviceps, Holochilus brasiliensis, Nectomys rattus, Nectomys squamipes, Sooretamys angouya, Proechimys sp. 2, Trinomys iheringi 
e Oligoryzomys flavescens (SILVA; YONENAGA-YASSUDA, 2004; VENTURA et al., 2012).

A partir dos dados apresentados e da compilação dos cariótipos da literatura, concluímos que O. flavescens $(2 n=64,65,66$; NF=66) possui cariótipo espécie-específico, útil em sua diagnose, uma vez que ocorre em simpatria com O. nigripes $(2 \mathrm{n}=62 ; \mathrm{NF}=78-82)$ e 0 . fornesi $(2 \mathrm{n}=62 ; \mathrm{NF}=62)$ (BONVICINO; OLIVEIRA; D'ANDREA, 2008; presente trabalho).

\subsubsection{Oligoryzomys fornesi}

Sete indivíduos foram analisados e apresentaram $2 n=62, N F=64$. Tais eexemplares foram coletados em áreas de Cerrado, transição de Mata Atlântica e Cerrado e Amazônia-Cerrado. O cariótipo apresentado neste trabalho é espécie-específico e similar ao descrito para animais identificados como Oligoryzomys fornesi por Bonvicino e Geise (2006), Bonvicino e Weksler (1998) e Paresque (2004).

Segundo Bonvicino e Weksler (1998), O. fornesi é uma espécie endêmica do Cerrado e Caatinga e distribui-se pelos estados de Minas Gerais, Goiás, Bahia e oeste de Pernambuco. O exemplar proveniente do Parque Nacional das Emas (GO) corrobora essa distribuição. No entanto, os exemplares coletados em Guará e Luís Antônio (SP), Vila Rica (MT) e Peixe (TO), apesar de serem áreas de transição de Cerrado, estão fora dos limites de distribuição designados anteriormente para $O$. fornesi, de modo que a distribuição para esta espécie estava subestimada. Além disso, observou-se que $O$. fornesi ocorre em simpatria com O. nigripes em Luís Antônio (SP), com O. flavescens e O. nigripes em Guará (SP) e com O. moojeni em Peixe (TO).

Andrades-Miranda et al. (2001) atribuíram o cariótipo $(2 n=62, N F=64-66)$ a O. eliurus. Contudo, essa espécie foi considerada sinônimo-júnior de $O$. nigripes por Myers e Carleton (1981) e Weksler e Bonvicino (2005).

Bonvicino e Weksler (1998) correlacionaram o cariótipo $2 n=62$, NF=64, a O. fornesi e $2 n=64-66, N F=66-68$, a 0 . flavescens e afirmaram que ambas as espécies possuem, além de cariótipos, morfologias diferentes. 


\subsubsection{Oligoryzomys microtis}

Nos quatro indivíduos provenientes de Aripuanã (MT), região de Floresta Amazônica, foram encontrados cariótipos com número diplóide e número fundamental iguais a 64. Segundo Bonvicino, Oliveira e D'Andrea (2008) e Musser e Carleton (2005), a espécie O. microtis é endêmica da Amazônia.

O cariótipo apresentado neste trabalho é semelhante ao descrito para $O$. microtis por Aniskin e Volobouev (1999), Gardner e Patton (1976) e Patton, Da Silva e Malcolm (2000), exceto pela presença de um grande par acrocêntrico no presente trabalho (par 1), que equivale a um grande metacêntrico nos trabalhos desses autores (par 1). É provável que essa diferença seja decorrente de um rearranjo do tipo inversão pericêntrica, que é a segunda classe mais frequente de rearranjos cromossômicos descritos em roedores (ROMANENKO; VOLOBOUEV, 2012). Entretanto, essa hipótese só poderia ser confirmada após comparações do padrão de bandas $G$, que não foi possível, pois nossa amostra não conta com exemplares de $\mathrm{NF}=66$.

Maiores detalhes sobre inversões pericêntricas serão abordados na seção 3.6.5, onde discutiremos os resultados obtidos em O. nigripes, espécie na qual as inversões pericentricas foram descritas em quatro pares autossômicos (ALMEIDA; YONENAGA-YASSUDA, 1991; PARESQUE et al., 2007; SILVA, 1994).

Andrades-Miranda et al. (2001), descreveram um cariótipo para $O$. microtis, com $2 n=66$ e NF=74, proveniente de Tartarugalzinho (AP), região de Floresta Amazônica, diferente do apresentado no presente trabalho e na literatura. Os autores descreveram cinco pares de cromossomos pequenos com dois braços e um par de cromossomos a mais do que o exemplar da presente amostra. Mais tarde, Miranda et al. (2008) demonstraram que esses indivíduos com $2 \mathrm{n}=66, \mathrm{NF}=74$ pertencem a outra entidade taxonômica ainda não descrita, distinta de $O$. microtis, que na Tabela 1.3 foram chamados de Oligoryzomys sp. B.

Os dados moleculares obtidos paralelamente em nosso laboratório indicam que os exemplares CIT 683, CIT 695, CIT 696 e CIT 702 fazem parte de 
um clado composto por O. microtis (SILVA, comunicação pessoal). Além disso, esses exemplares possuem caracteres morfológicos semelhantes à $O$. microtis (CARMIGNOTTO, comunicação pessoal).

Com a compilação dos dados da localidade em que foram coletados (Floresta Amazônica), a similaridade do presente cariótipo com aquele descrito na literatura e os resultados preliminares de sistemática molecular e morfologia, sugerimos que esses exemplares devam pertencer a 0 . microtis, com um rearranjo do tipo inversão pericêntrica no par 1 , sendo o cariótipo $2 n=64, N F=64$, 66 espécie-específico.

Maiores esforços amostrais na região Amazônica seriam importantes para que a hipótese da existência de polimorfismo de inversão pericêntrica em $O$. microtis seja confirmada e para investigar a ocorrência de populações que possuem o par 1 heterozigoto.

\subsubsection{Oligoryzomys moojeni}

O cariótipo apresentado neste trabalho é similar ao descrito para $O$. moojeni por Agrellos et al. (2012); Andrades-Miranda et al. (2001); Lima, Bonvicino e Kasahara (2003) e Weksler e Bonvicino (2005), no qual há predominância de cromossomos acrocêntricos e três ou quatro pares de dois braços, sendo este cariótipo considerado espécie-específico.

No presente trabalho, no entanto, foram observados apenas dois pares metacêntricos. Essa diferença pode ser decorrente de eventos de inversões pericêntricas nos pares de menor tamanho e isso só poderia ser confirmado por meio de comparação de bandas $\mathrm{G}$ entre os exemplares com NF=72 (presente trabalho) e aqueles com NF=74 e 76 (ANDRADES-MIRANDA et al., 2001, LIMA; BONVICINO; KASAHARA., 2003; WEKSLER; BONVICINO, 2005). Isso não foi possível devido ao padrão de bandas G, que não estava adequado para a comparação, em decorrência do pequeno tamanho dos pares envolvidos no rearranjo.

Os exemplares estudados neste trabalho são provenientes de Minaçu (GO) e Peixe (TO), corroborando a distribuição e endemismo de O. moojeni, em 
região de Cerrado brasileiro (BONVICINO; OLIVEIRA; D'ANDREA. 2008; WEKSLER; BONVICINO, 2005). Além disso, esta espécie ocorre em simpatria com O. fornesi em Peixe (TO).

\subsubsection{Oligoryzomys nigripes}

Do ponto de vista taxonômico, até a decada de 2000 ocorreram algumas confusões na identificação dessa espécie: cariótipos idênticos aos de O. nigripes foram relacionados a $O$. delticola e $O$. eliurus. Porém, tais espécies foram consideradas sinônimo-júnior de O. nigripes, de acordo com similaridades morfológicas e padrão de bandamento cromossômico (BONVICINO; WEKSLER, 1998; FRANCÈS; D’ELÍA, 2006; PARESQUE et al., 2007). Dessa forma, atualmente, o cariótipo de $O$. nigripes é considerado espécie-específico.

A diferença observada no número fundamental (78-82) é decorrente de variações na morfologia dos pares 2,3 e 8.

Dos 83 indivíduos estudados no presente trabalho, 32 (38,55\%) apresentaram o par 3M, 18 (21,68\%) apresentaram 3A e $33(39,76 \%)$ foram $3 \mathrm{H}$. Além disso, dois exemplares mostraram o par 2A e apenas um exemplar possuia o par 8A. De acordo com Paresque et al. (2007) e Silva (1994), a variação no par 3 é a mais frequente e está amplamente distribuída pelo território brasileiro.

O padrão de bandas $G$ permitiu constatar que tal diferença no par 3 é resultante de inversão pericêntrica, corroborando os dados previamente descritos por Almeida e Yonenaga-Yassuda (1991); Paresque (2004); Paresque et al. (2007) e Silva (1994).

Não foi possível a obtenção de bandas $G$ nos exemplares com variação no par 2 e 8; porém, de acordo com a literatura, esse heteromorfismo também é decorrente de inversões pericêntricas (PARESQUE et al., 2007). Almeida e Yonenaga-Yassuda (1991) e Paresque et al. (2007) descreveram o par 8 de duas formas: homomórfico metacêntrico $(8 \mathrm{M})$ ou heteromórfico metacêntrico/acrocêntrico $(\mathrm{H})$. Entretanto, em um único exemplar deste trabalho, proveniente de Juquitiba (SP), este par mostrou-se homomórfico acrocêntrico, sendo esta uma forma inédita na literatura (8A). 
Além disso, na literatura, foram descritos também casos de polimorfismos originados por inversões pericêntricas envolvendo o par 4 (ALMEIDA; YONENAGA-YASSUDA, 1991; PARESQUE, 2004).

O Equilíbrio de Hardy-Weinberg para a variação no par 3 foi testado apenas na amostra proveniente da Floresta Nacional de Ipanema (SP) e foi encontrado o qui-quadrado de 0,43 (sendo o grau de liberdade igual a 1), indicando que nenhum desvio significativo foi encontrado, de forma que os cruzamentos devem estar ocorrendo ao acaso nesta população.

No presente trabalho, considerando os polimorfismos encontrados nos pares autossômicos 2, 3 e 8 e nos cromossomos sexuais, foram encontradas 15 variantes cariotípicas para $O$. nigripes. Este número, no entanto, está subestimado, uma vez que o padrão de bandas $C$ só foi obtido em 27 dos 83 exemplares da amostra e por isso, apenas os cromossomos sexuais desses 27 indivíduos puderam ser identificados e classificados (Tabela 3.7).

De acordo com Paresque et al. (2007), considerando todas as combinações de polimorfismos envolvendo os pares 2 (2A ou $2 \mathrm{M}), 3$ (3A, 3H ou 3M), 4 (4A, 4H ou 4M), 8 (8H ou 8M), X (Xa, Xb ou Xc) e Y (Ya, Yb, Yc ou Yd), poder-se-ia encontrar um total de 432 variantes cariológicas diferentes para $O$. nigripes. Se considerarmos a nova forma do par 8 (8A) descrita neste trabalho, seria esperado encontrar 648 cariótipos diferentes para esta espécie.

Apesar do conhecimento teórico de que as inversões geram gametas com duplicações e deficiências e, portanto, podem causar uma menor adaptabilidade dos heterozigotos, outros estudos têm demonstrado que as inversões pericêntricas desempenham um papel relevante na especiação, à medida que se fixam nas populações (PATTON, 2004; RIESEBERG, 2001; RIESEBERG; LIVINGSTONE, 2003).

Inversão pericêntrica é um exemplo de rearranjo que já foi descrito para vários gêneros da família Cricetidae, tais como Akodon, Thaptomys, Cerradomys, entre tantos outros (ALMEIDA; YONENAGA-YASSUDA, 1985; FAGUNDES; CHRISTOFF; YONENAGA-YASSUDA, 1998; VENTURA et al., 2004), incluindo O. nigripes (ALMEIDA; YONENAGA-YASSUDA, 1991; PARESQUE et al., 2007; SILVA, 1994), cujos polimorfismos observados em 
vários pares de autossomos, descritos no presente trabalho, corroboram esta afirmação.

Estudos meióticos de complexo sinaptonêmico em Akodon cursor, que possui $2 n=14,15$ e 16 e é uma espécie portadora de vários rearranjos cromossômicos do tipo inversão pericêntrica, demonstraram que ajustes sinápticos, associados à supressão do crossing-over nos segmentos invertidos, devem ser os mecanismos que permitem o emparelhamento e a segregação apropriada em indivíduos heterozigotos (FAGUNDES; CHRISTOFF; YONENAGA-YASSUDA, 1998). Alguns mecanismos genéticos parecem ser responsáveis pela superação dos erros meióticos em indivíduos heterozigotos, como a ocorrência de heterossinapse e a baixa frequência de quiasmas entre os segmentos invertidos (FAGUNDES, 1997).

Bonvicino, D'Andrea e Borodin (2001) analisaram o comportamento meiótico do par 3 em heterozigotos de diferentes populações de $O$. nigripes. Os dados indicaram sinapse não-homóloga e supressão do crossing-over na região invertida dos heterozigotos. Assim, as inversões pericêntricas não parecem resultar em desvantagem seletiva aos heterozigotos.

Os exemplares da amostra deste trabalho distribuem-se em áreas de Floresta Atlântica e em áreas de transição de Cerrado. Esses dados estão de acordo com a distribuição de $O$. nigripes descrita na literatura (BONVICINO; OLIVEIRA; D'ANDREA, 2008). Além disso, O. nigripes ocorre em simpatria com O. flavescens em Biritiba-Mirim, Caieiras, Buri (Floresta Atlântica) e FLONA de Ipanema (transição de Mata Atlântica e Cerrado) (SP), com O. fornesi em Luís Antônio (SP) e com O. fornesi e O. flavescens em Guará (SP), ambas áreas de transição de Floresta Atlântica e Cerrado.

\subsubsection{Oligoryzomys sp. A}

Um único exemplar (CIT 447, denominado Oligoryzomys sp. A) foi capturado em uma área de Floresta Amazônica. Foi observado o mesmo número diplóide e fundamental descrito para a espécie O. moojeni deste trabalho, endêmica de Cerrado. 
Entretanto, o cariótipo deste indivíduo mostrou-se diferente de O. moojeni pela presença de dois pares heteromórficos: subtelocêntrico/acrocêntrico (par 1) e submetacêntrico/acrocêntrico (par 33). Além disso, o par 1 de O. moojeni é destacadamente o maior par do complemento, enquanto que, em Oligoryzomys sp. A, o par 1 é sutilmente maior que o par 2.

Embora não tenha sido obtido um padrão de bandas $G$ adequado neste exemplar, poder-se-ia aventar que o rearranjo envolvido na diferenciação cariotípica dessas duas espécies foi decorrente de um evento de translocação entre o braço curto de um cromossomo do par 33 (par de dois braços) e um cromossomo acrocêntrico do par 1 ou a dois eventos de inversão pericêntrica isolados nesses dois pares (1 e 33).

Outras duas espécies de Oligoryzomys ocorrem na Amazônia: O. microtis $(2 n=64, N F=64,66)$ e 0 . utiaritensis $(2 n=72, N F=76)$. Entretanto, os dados morfológicos indicam que o CIT 447 é semelhante à $O$. moojeni e distinto de $O$. utiaritensis (CARMIGNOTTO, comunicação pessoal). Embora sejam necessárias maiores análises morfológicas e moleculares, é provável que este exemplar seja uma nova entidade taxonômica ainda não descrita.

\subsubsection{Oligoryzomys stramineus}

Dois exemplares, um de Jequitinhonha (MG), área de contato Mata Atlântica/Caatinga, e outro de Uruçuí-Una (PI), região de Cerrado, mostraram cariótipo idêntico ao descrito por Andrades-Miranda et al. (2001) e Weksler e Bonvicino (2005) para O. stramineus, sendo considerado espécie-específico. Além disso, estes últimos autores encontraram uma variação no NF dessa espécie (de 68 a 70) devido a uma inversão em um par acrocêntrico pequeno.

As localidades em que os exemplares foram coletados corroboram com a distribuição descrita em Bonvicino, Oliveira e D’Andrea (2008) e Weksler e Bonvicino (2005). 


\subsubsection{Polimorfismos de cromossomos sexuais em Oligoryzomys}

$\mathrm{Na}$ literatura, polimorfismos de cromossomos sexuais em Oligoryzomys foram descritos em: O. flavescens (SBALQUEIRO et al., 2001), O. fulvescens (HAIDUK; BICKHAM; SCHIMIDLY, 1979), O. Iongicaudatus (GALLARDO; GONZÁLEZ, 1977), O. magellanicus (GALLARDO; PALMA, 1990), O. microtis (ANISKIN; VOLOBOUEV, 1991), O. nigripes (ALMEIDA; YONENAGA-YASSUDA, 1991; PARESQUE et al., 2007) e Oligoryzomys sp. 2 (SILVA; YONENAGAYASSUDA, 1997).

No presente trabalho, das sete espécies estudadas, seis $(O$. flavescens, O. fornesi, O. microtis, O. moojeni, O. nigripes e O. stramineus) mostraram variação no cromossomo $\mathrm{X}$, e três ( $O$. fornesi, $O$. moojeni e $O$. nigripes) apresentaram variação no $\mathrm{Y}$.

$\mathrm{O}$ baixo número de exemplares machos de $O$. microtis e $O$. stramineus na amostra pode ter mascarado a variabilidade do cromossomo $Y$ nessas espécies.

É importante ressaltar que o bandamento $C$ é extremamente necessário na caracterização dos cromossomos sexuais de Oligoryzomys, uma vez que estes cromossomos são morfologicamente semelhantes aos autossômicos e somente o padrão heterocromático característico é capaz de evidenciá-los.

Com relação a $O$. flavescens, neste trabalho, foi encontrada uma única forma para o $\mathrm{Y}$ e variações no cromossomo $\mathrm{X}$, devido à adição/deleção de heterocromatina constitutiva. Sbalqueiro et al. (1991) encontraram variações nos cromossomos $\mathrm{Y}$, podendo ser submetacêntrico, metacêntrico, acrocêntrico ou subtelocêntrico.

Em O. fornesi, foram observadas duas formas para o cromossomo $\mathrm{X} e$ duas para o $Y$. Com base no padrão de bandas $C$, foi possível constatar que 0 heteromorfismo encontrado no cromossomo $X$ é devido à adição/deleção de heterocromatina constitutiva e, no cromossomo $Y$, a uma inversão pericêntrica, uma vez que esses cromossomos possuem o mesmo tamanho e mostraram-se C-positivos no braço longo.

Já para O. microtis, foram encontradas duas formas para o $\mathrm{X}$ que também foram relacionadas a adição/deleção de heterocromatina constitutiva. Aniskin e 
Volobouev (1999) descreveram variações no cromossomo X de O. microtis, mas não correlacionaram tais variações a nenhum tipo de rearranjo.

Em O. moojeni, as fêmeas mostraram o X polimórfico, devido a diferenças no tamanho do braço curto. O padrão de bandas $\mathrm{C}$ mostrou que o polimorfismo do $\mathrm{X}$ é decorrente de adição/deleção de heterocromatina constitutiva. Foram observadas também duas formas para o cromossomo $\mathrm{Y}$; entretanto, a heterocromatina constitutiva foi localizada na região distal do braço longo de ambas as formas, indicando que essa variação é causada por inversão pericêntrica, uma vez que ambos os $Y$ possuem o mesmo tamanho.

Em O. nigripes, foram encontradas três formas de $X$ e três de $Y$. Na literatura, foram identificadas três formas diferentes para o cromossomo $X$ (Xa, $\mathrm{Xb}$ e $\mathrm{Xc}$ ) e quatro formas para o $\mathrm{Y}$ (Ya, Yb, Yc e Yd) (ALMEIDA; YONENAGAYASSUDA, 1991; PARESQUE et al., 2007). Essa variação foi correlacionada à deleção/adição de heterocromatina constitutiva.

Uma fêmea de O. nigripes, foi considerada mosaico por apresentar $2 n=61$, X/62,XX. O mosaicisco pode ter sido gerado por uma não-disjunção ou atraso anafásico do cromossomo $\mathrm{X}$ durante as primeiras divisões celulares pószigóticas.

Nas fêmeas de mamíferos, a perda de um cromossomo $X$ pode ser tolerada devido aos mecanismos de compensação de dose (Lyonização), na qual um dos cromossomos $X$ da fêmea é inativado. Kasahara e Yonenaga-Yassuda (1983) reportaram um caso de mosaicismo em uma fêmea do roedor Necromys lasiurus $(2 n=33, X / 34, X X)$. Paresque et al. (2007) encontraram um indivíduo de O. nigripes com monossomia do cromossomo $X$ em todas as células, o que foi explicado por uma não-disjunção meiótica nos gametas de um dos parentais.

Oligoryzomys stramineus mostrou uma sutil variação no tamanho do braço curto do cromossomo $X$ da única fêmea analisada e estes cromossomos foram identificados como $\mathrm{X}^{+} \mathrm{X}$. Esta sutil variação pode estar relacionada ao processo de inativação de um dos cromossomos $X$ da fêmea, podendo levar a diferenças na condensação desses cromossomos.

Silva e Yonenaga-Yassuda (1997) descreveram variação nos cromossomos $X$ de Oligoryzomys sp. 2, sendo que duas formas foram 
encontradas: subtelocêntrica (Xa) e acrocêntrica $(X b)$ e essa diferença foi relacionada a inversão pericêntrica, pois esses cromossomos eram do mesmo tamanho. Neste mesmo trabalho, os autores descreveram pela primeira vez o cariótipo de 0 . rupestris (na época, Oligoryzomys sp. 1), mas, ao contrário de Oligoryzomys sp. 2, não houve variação nos cromossomos sexuais.

$\mathrm{Na}$ tribo Oryzomyini, polimorfismos de cromossomos sexuais parecem ser muito comuns, pois já foram descritos para várias espécies: Cerradomys subflavus (SVARTMAN; ALMEIDA, 1992), Euryoryzomys russatus (SILVA, 1994), Nectomys squamipes (SILVA; YONENAGA-YASSUDA, 1998), Nephelomys albigularis (antigo Oryzomys albigularis) (AGUILERA; PÉREZ-ZAPATA; MARTINO, 1995), entre outras.

As variações na quantidade de heterocromatina constitutiva são uma classe de rearranjos que não parece ter envolvimento direto no processo de especiação (KING, 1993; ROMANENKO; VOLOBOUEV, 2012).

O aumento de abordagens citogenéticas nas diferentes espécies do grupo e em vários exemplares pode contribuir para que novos polimorfismos de cromossomos sexuais sejam descritos.

\subsubsection{Regiões Organizadoras de Nucléolo (RONs)}

As RONs foram obtidas para: O. fornesi, O. microtis, O. moojeni e 0. nigripes e as marcações foram múltiplas e localizadas na região terminal de cromossomos acrocêntricos pequenos. Em O. nigripes, não foi observado aumento ou diminuição aparente no número de RONs entre os indivíduos com diferentes formas do par 3, uma vez que as regiões organizadoras de nucléolo não se localizam nesses pares.

Andrades-Miranda et al. (2001) encontraram de 2 a 5 pares cromossômicos portadores de RON em O. moojeni, 1 a 3 pares em 0 . fornesi (chamado de O. eliurus) e dois pares em O. microtis. Silva (1994) observou variação de 1 a 12 RONs em 0 . nigripes.

No presente trabalho, as RONs não se mostraram informativas, uma vez que ocorreram em pares acrocêntricos, impossíveis de serem identificados por 
esse tipo de coloração. Em contrapartida, as RONs, em conjunto com outras técnicas citogenéticas, ajudaram na identificação de um rearranjo Robertsoniano entre O. rupestris e Oligoryzomys sp. 2 (SILVA; YONENAGA-YASSUDA, 1997).

Nos mamíferos, é frequente a ocorrência de RONs múltiplas, de modo que essa técnica é bastante útil apenas quando é possível a correlação precisa dos pares portadores de organizadores nucleolares, como é o caso dos roedores Akodon montensis (FAGUNDES, 1997), Chaetomys subspinosus (VILELA et al., 2009), Sciurus aestuans ingrami (FAGUNDES et al., 2003) e Trinomys iheringi (YONENAGA-YASSUDA et al., 1985) e de algumas espécies de marsupiais sulamericanos (PEREIRA et al., 2008; SVARTMAN, 2009).

Em outros vertebrados, as RONs aparecem em um único par cromossômico, podendo ser considerada um marcador citotaxonômico, por exemplo, em peixes (SCACCHETTI et al., 2011), lagartos (PELLEGRINO; RODRIGUES; YONENAGA-YASSUDA, 1999) e anfíbios (PAIVA et al., 2010), dentre diversos outros exemplos.

A técnica mais utilizada para localizar as regiões organizadoras de nucléolo é a impregnação por nitrato de prata; porém, apesar de ser uma técnica simples e de fácil aplicação, só revela as RONs que estavam ativas na intérfase anterior, pois cora as proteínas ácidas nucleolares. A hibridação in situ fluorescente com sondas de DNA ribossômico tem sido muito empregada nos últimos anos, uma vez que evidencia cistrons ribossomais, sendo um marcador citológico mais preciso para a caracterização cariotípica das espécies.

\subsubsection{Comparação dos cariótipos das espécies de Oligoryzomys}

Os cariótipos das espécies de Oligoryzomys apresentam predominância de cromossomos acrocêntricos, mesmo nas espécies $O$. nigripes e $O$. stramineus, que possuem número fundamental elevado.

Oligoryzomys nigripes, por exemplo, possui 11 pares de cromossomos com dois braços e 19 pares acrocêntricos. Além disso, é a espécie que possui maior variabilidade cariotípica e seu cariótipo é um dos mais estudados entre as espécies do gênero, em decorrência de sua ampla distribuição e facilidade de 
coleta. Em contrapartida, os cariótipos das outras espécies aqui apresentados mostram até dois cromossomos meta/submetacêntricos e não mais do que isso.

Além disso, em O. flavescens, O. fornesi, O. microtis e O. moojeni, o par 1 apresentou-se destacadamente o maior par do cariótipo, enquanto que em $O$. nigripes, Oligoryzomys sp. A e O. stramineus, o par 1 é pouco maior que o par 2.

A comparação dos padrões de bandas $G$ mostrou que um único cromossomo/braço cromossômico possui homologia completa nas oito espécies: OFL, OFO, OMI, OMO, ONI, OST, ORU e OSP, indicando ainda, que houve um evento de fusão/fissão nas duas últimas espécies, gerando o par ORU/OSP 3 de dois braços (Figura 3.25a). Além disso, pode ser inferida a ocorrência de inversões pericêntricas envolvendo os pares: OFL 1, OFO 1, OMI 1, OMO 1 (acrocêntricos), ONI 1 e OST 2 (subtelocêntrico e submetacêntrico, respectivamente) (Figura 3.25a); OFL 2, OFO 2, OMI 2, OMO 2, OST 10 (acrocêntricos) e ONI (submetacêntrico em maior frequência na população) (Figura 3.25b); OFL 3, OFO 3, OMI 3, OMO 3 (acrocêntricos), ONI 3 (que pode ser encontrado de três formas na população: metacêntrico, acrocêntrico e heteromórfico) e OST 1 (metacêntrico) (Figura 3.25c).

A comparação dos padrões de bandamento $G$ tem sido um indicador de homologia cromossômica confiável, exceto em caso de comparação de espécies filogeneticamente distantes ou envolvidas em rápida evolução cromossômica. Assim, a comparação das homologias tornou-se mais fidedigna após 0 surgimento das técnicas de citogenética molecular (GRAPHODATSKY; TRIFONOV; STANYON, 2011).

Pela comparação dos cariótipos de Oligoryzomys deste trabalho e da literatura, juntamente com os dados de pintura cromossômica que serão apresentados no Capítulo 4, pode-se dizer que se trata de um dos gêneros com maior número de rearranjos inter e intra-específicos de roedores Neotropicais.

Apesar disso, as hibridações in situ fluorescente com sequências teloméricas evidenciaram marcação exclusivamente nos telômeros em todas as espécies estudadas. Alguns trabalhos descreveram a presença de sítios teloméricos intersticiais (ITS) em espécies que apresentam variações cromossômicas, e tais ITS podem representar, entre outras hipóteses, 
remanescentes de rearranjos cromossômicos que ocorreram durante a evolução cariotípica (ANDRADES-MIRANDA et al., 2002; LEE; SASI; LIN, 1993; MEYNE et al., 1990; VENTURA et al., 2004, 2012). A ausência dessas sequências em espécies que possuem grande variabilidade cariotípica, comprovada pelas técnicas de citogenética comum, pode ser explicada pela eliminação das mesmas durante as quebras e posterior reorganização cromossômica no processo evolutivo do grupo (RUIZ-HERRERA et al., 2008).

No Capítulo 4, será discutida, com base em pintura cromossômica, a evolução cariotípica de cinco espécies estudadas, com o auxílio da citogenética convencional apresentada neste capítulo.

\subsection{Conclusões}

1) As análises citogenéticas em 117 exemplares do gênero Oligoryzomys revelaram O. flavescens $(2 \mathrm{n}=64,65,66, \mathrm{NF}=66)$, O. fornesi $(2 \mathrm{n}=62, \mathrm{NF}=64), 0$. microtis $(2 \mathrm{n}=64, \mathrm{NF}=64)$, O. moojeni $(2 \mathrm{n}=70, \mathrm{NF}=72)$, O. nigripes $(2 \mathrm{n}=62$, $N F=78-82)$, Oligoryzomys sp. A $(2 n=70, N F=72)$ e 0. stramineus $(2 n=52, N F=68)$ e novos números fundamentais foram descritos para 0 . microtis $(\mathrm{NF}=64)$ e 0 . moojeni (NF=72).

2) O. flavescens, O. fornesi, O. microtis, O. moojeni, O. nigripes e 0. stramineus apresentam cariótipos espécie-específicos, úteis para a citotaxonomia do gênero.

3) Um novo cariótipo está sendo descrito para Oligoryzomys sp. A, com $2 \mathrm{n}=70, \mathrm{NF}=72$.

4) Uma nova forma para o par 8 (homomórfica acrocêntrica) de 0 . nigripes foi observada, assim como um caso de mosaicismo $(2 n=61, X / 62, X X)$.

5) O. fornesi foi coletado em novas localidades para as quais a espécie não havia sido registrada, de modo que sua distribuição é mais ampla do que o relatado anteriormente.

6) As variações nos cromossomos sexuais de 0 . flavescens, O. fornesi, 0. microtis e O. moojeni, devido à adição/deleção de heterocromatina constitutiva e inversão pericêntrica estão sendo descritas pela primeira vez na literatura. 
7) A banda $G$ de $O$. fornesi e $O$. stramineus está sendo apresentada pela primeira vez na literatura, assim como os dados de FISH telomérica.

8) Este trabalho reforça a importância de maiores esforços de coletas para conhecimento da biodiversidade brasileira e reitera a citogenética como uma ferramenta para diagnosticar as espécies de Oligoryzomys, uma vez que esse marcador é fundamental para a citotaxonomia do grupo, pois seus representantes possuem morfologia externa semelhante e de difícil distinção e algumas dessas espécies ocorrem em simpatria.

9) A presença de cromossomos supernumerários e polimorfismos de autossomos e cromossomos sexuais faz do gênero um excelente grupo de estudos de evolução cariotípica. 


\section{FIGURAS}

Figura 3.1 - Mapa do Brasil com as localidades amostradas e as espécies estudadas neste capítulo.

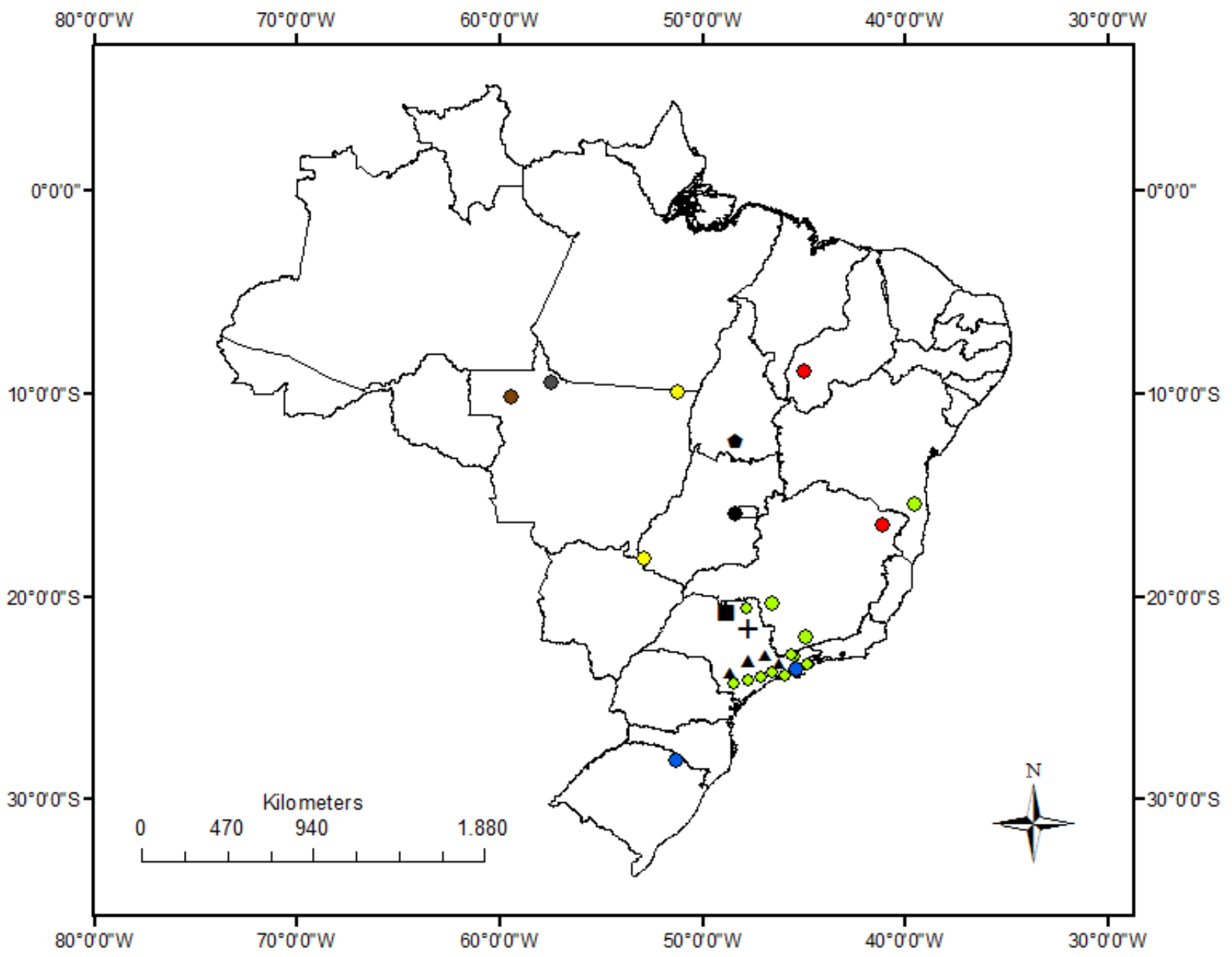

Legenda: O flavescens (azul), O. fornesi (amarelo), O. microtis (marrom), O. moojeni (círculo preto), $O$. nigripes (verde), Oligoryzomys sp. A (cinza), O. stramineus (vermelho), simpatria entre $O$. flavescens e $O$. nigripes (triângulo), simpatria entre $O$. fornesi e O. nigripes (cruz), simpatria entre O. flavescens, O. nigripes e O. fornesi (quadrado) e simpatria entre O. fornesi e O. moojeni (pentágono) (Tabela 3.2). 
Figura 3.2 - Cariótipo em coloração convencional de O. flavescens, $2 \mathrm{n}=65$, $\mathrm{NF}=66$, macho, proveniente da Floresta Nacional de Ipanema (SP).

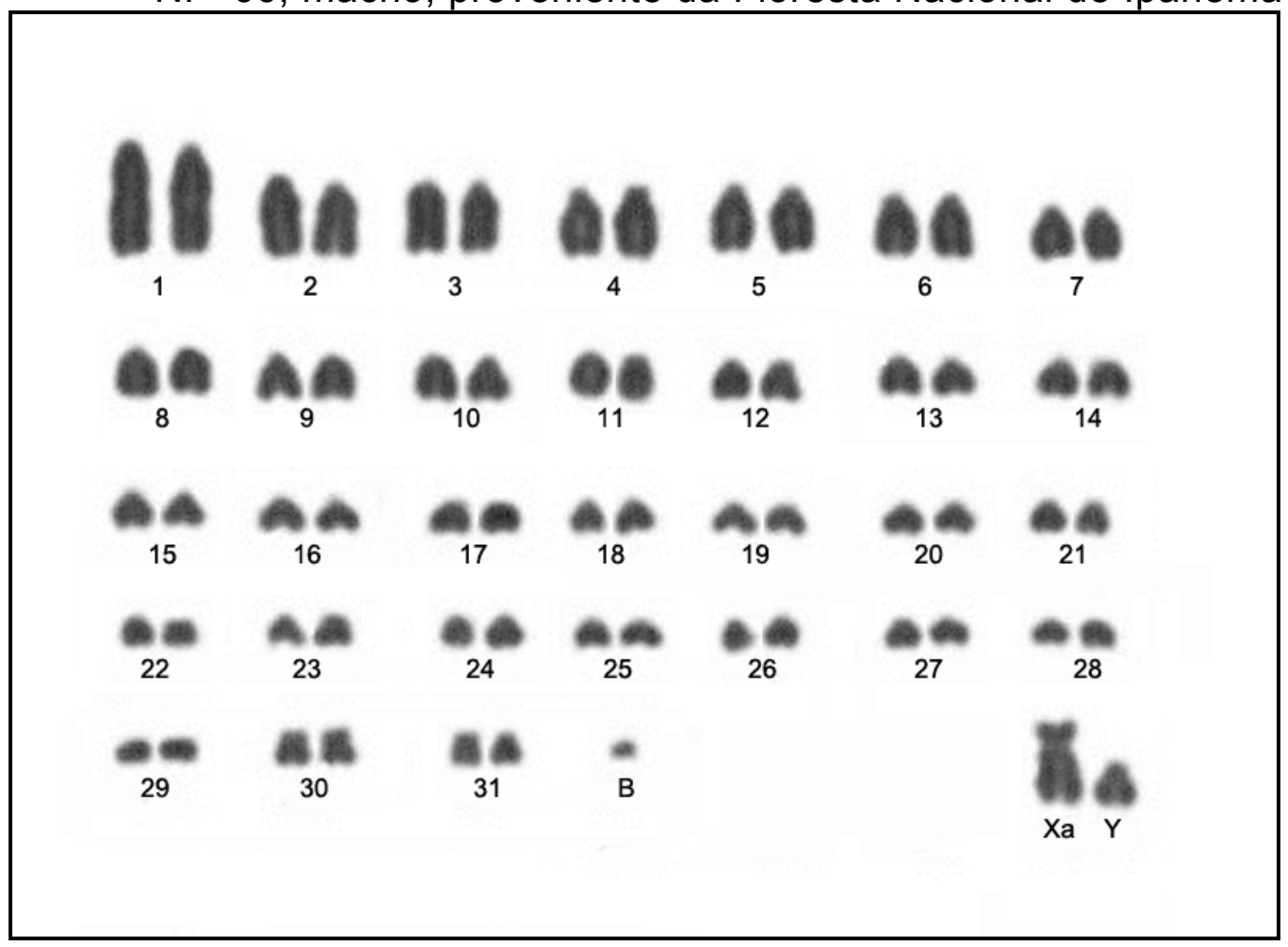

Figura 3.3 - Padrão de bandas $C(C B G)$ em O. flavescens, $2 n=64, N F=66$, macho, proveniente de Guará (SP).

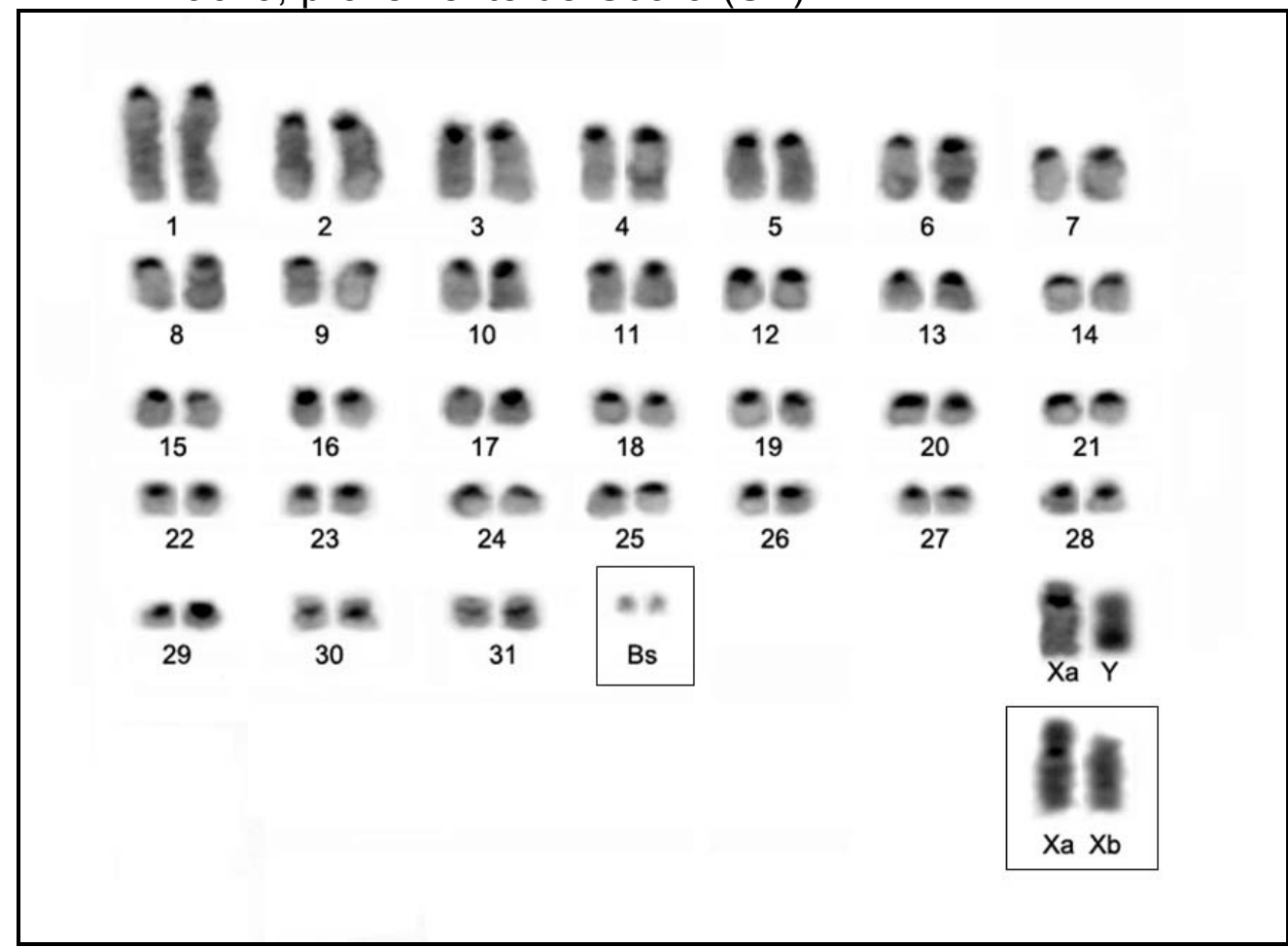

Em destaque, cromossomos supernumerários (Bs) e variação nos cromossomos sexuais de exemplares da Floresta Nacional de Ipanema (SP). 
Figura 3.4 - Padrão de bandas G (GTG) em O. flavescens, 2n=66, NF=66, macho, proveniente da Floresta Nacional de Ipanema (SP).

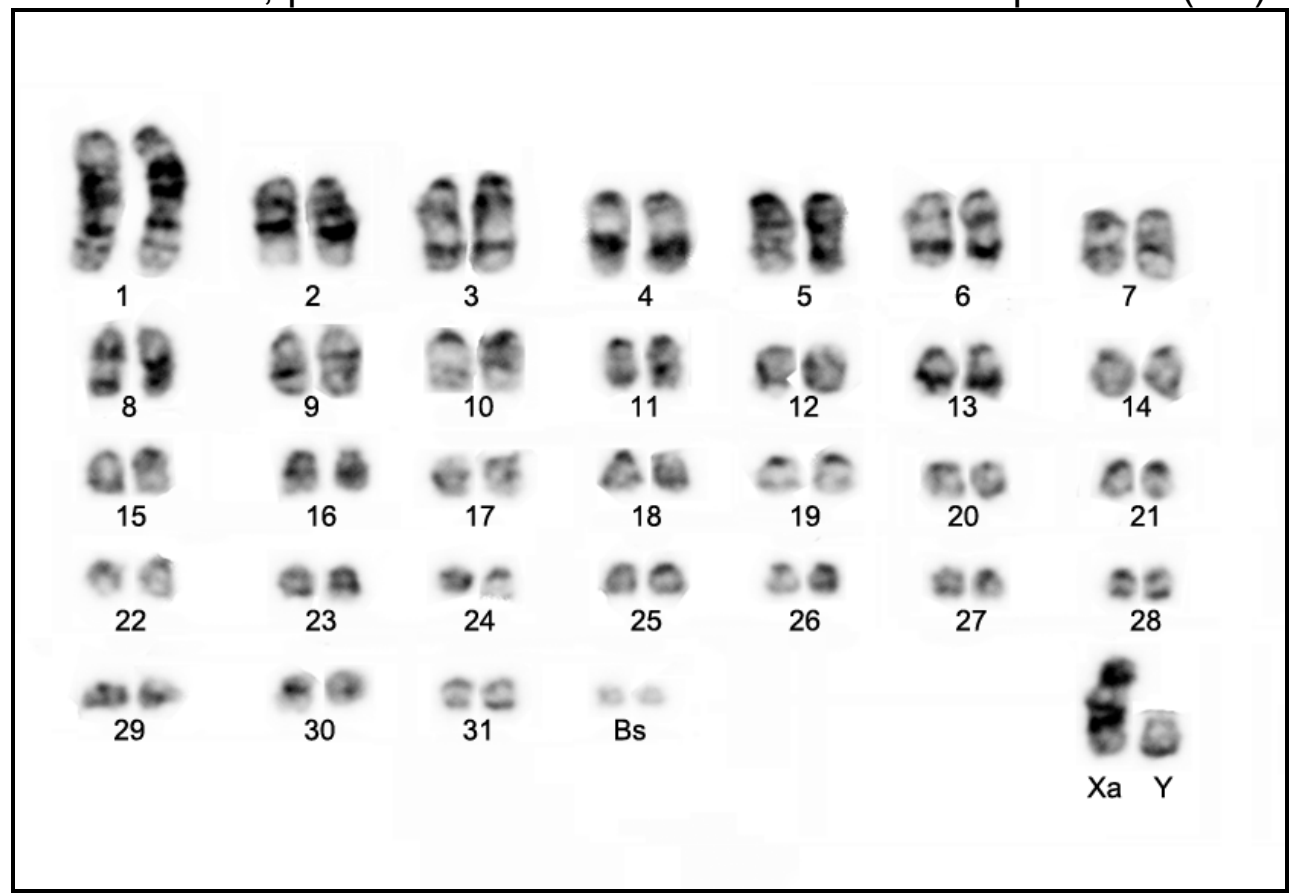

Figura 3.5 - Metáfase de 0 . flavescens, $2 \mathrm{n}=65, \mathrm{NF}=66$, macho, proveniente da Floresta Nacional de Ipanema (SP), com FISH telomérica evidenciando marcações nos telômeros.

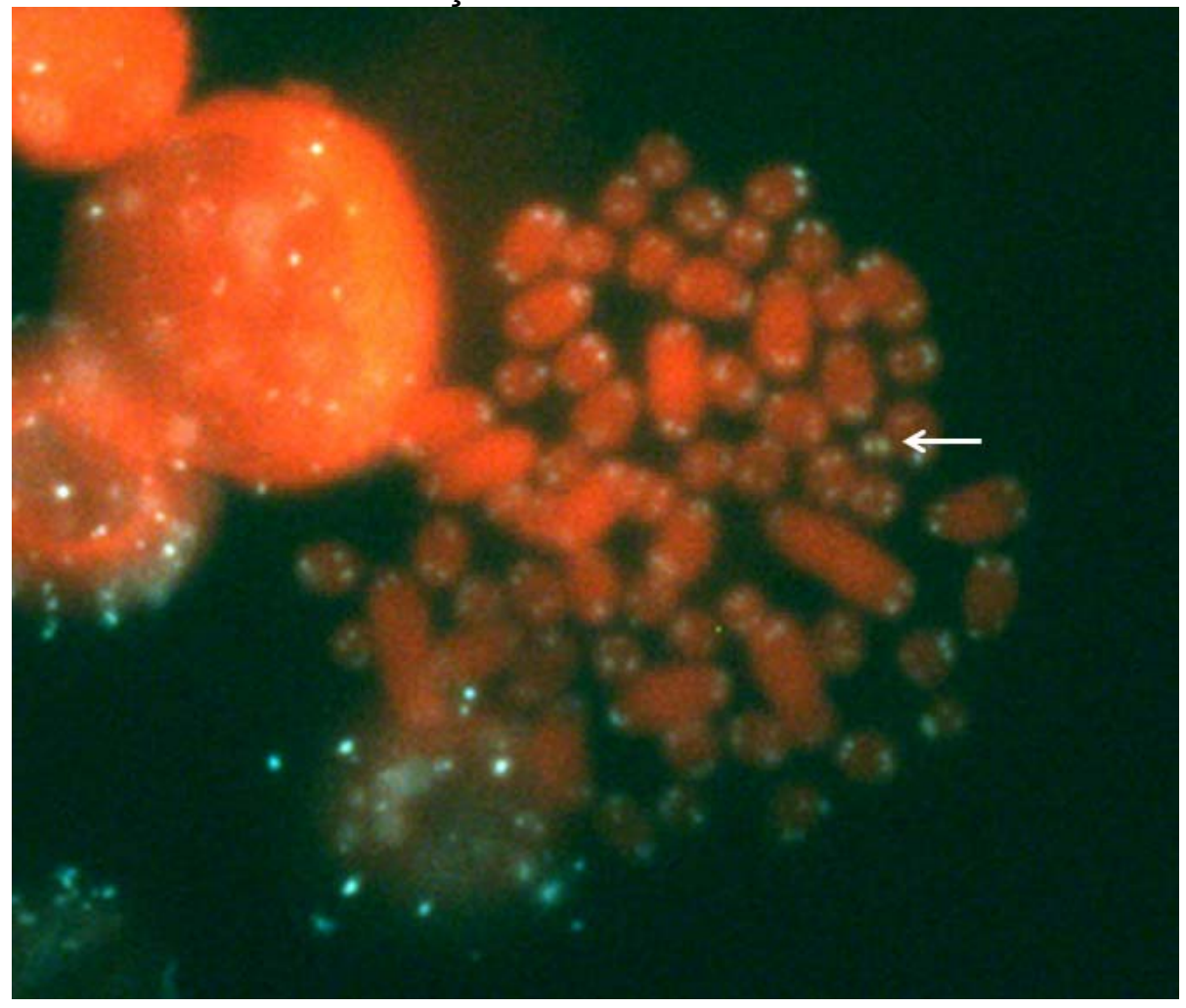

Em destaque, cromossomo B (seta). 
Figura 3.6 - Cariótipo em coloração convencional de 0 . fornesi, $2 \mathrm{n}=62, \mathrm{NF}=64$, macho, proveniente do Parque Nacional das Emas (GO).

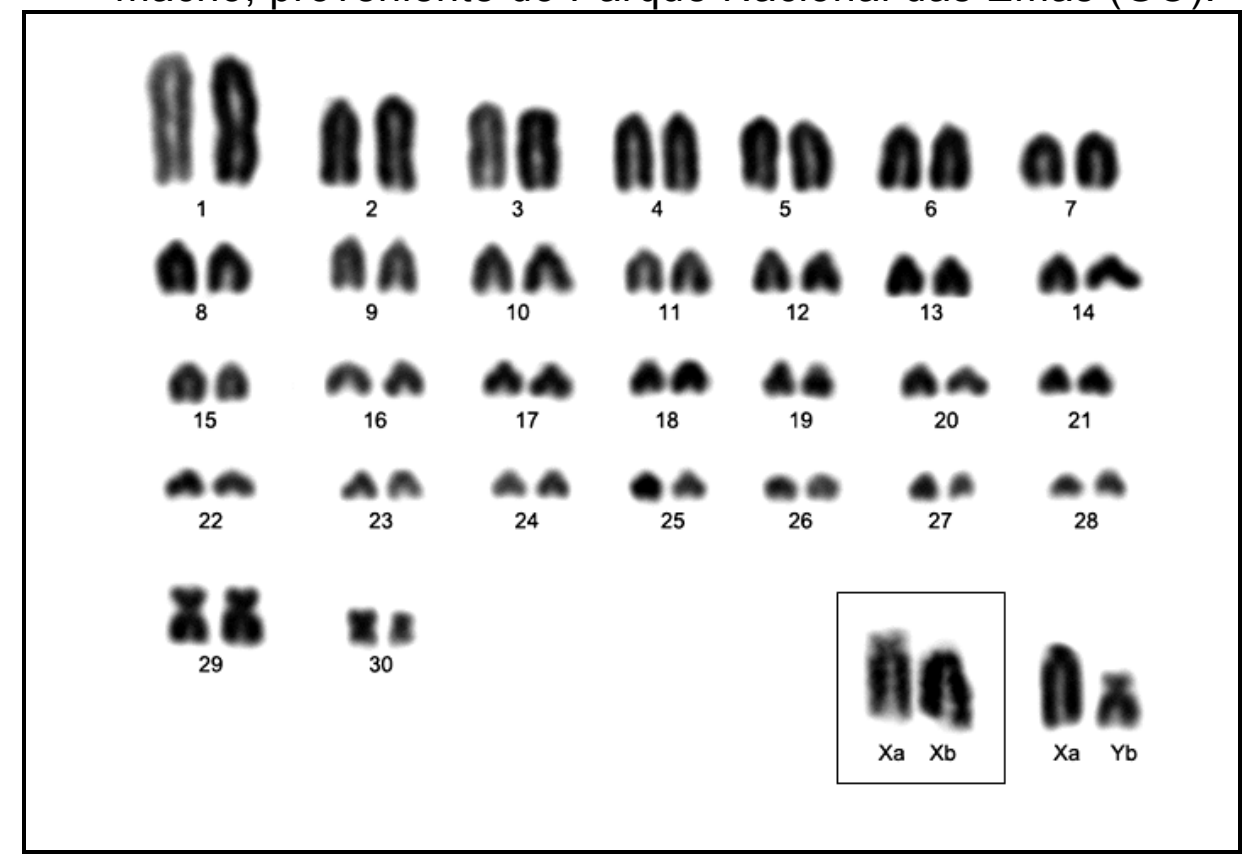

Em destaque, cromossomos $\mathrm{X}$ heteromórficos de uma fêmea proveniente de Vila Rica (MT).

Figura 3.7 - Padrão de bandas C (CBG) em O. fornesi, 2n=62, NF=64, macho, proveniente de Peixe (TO).

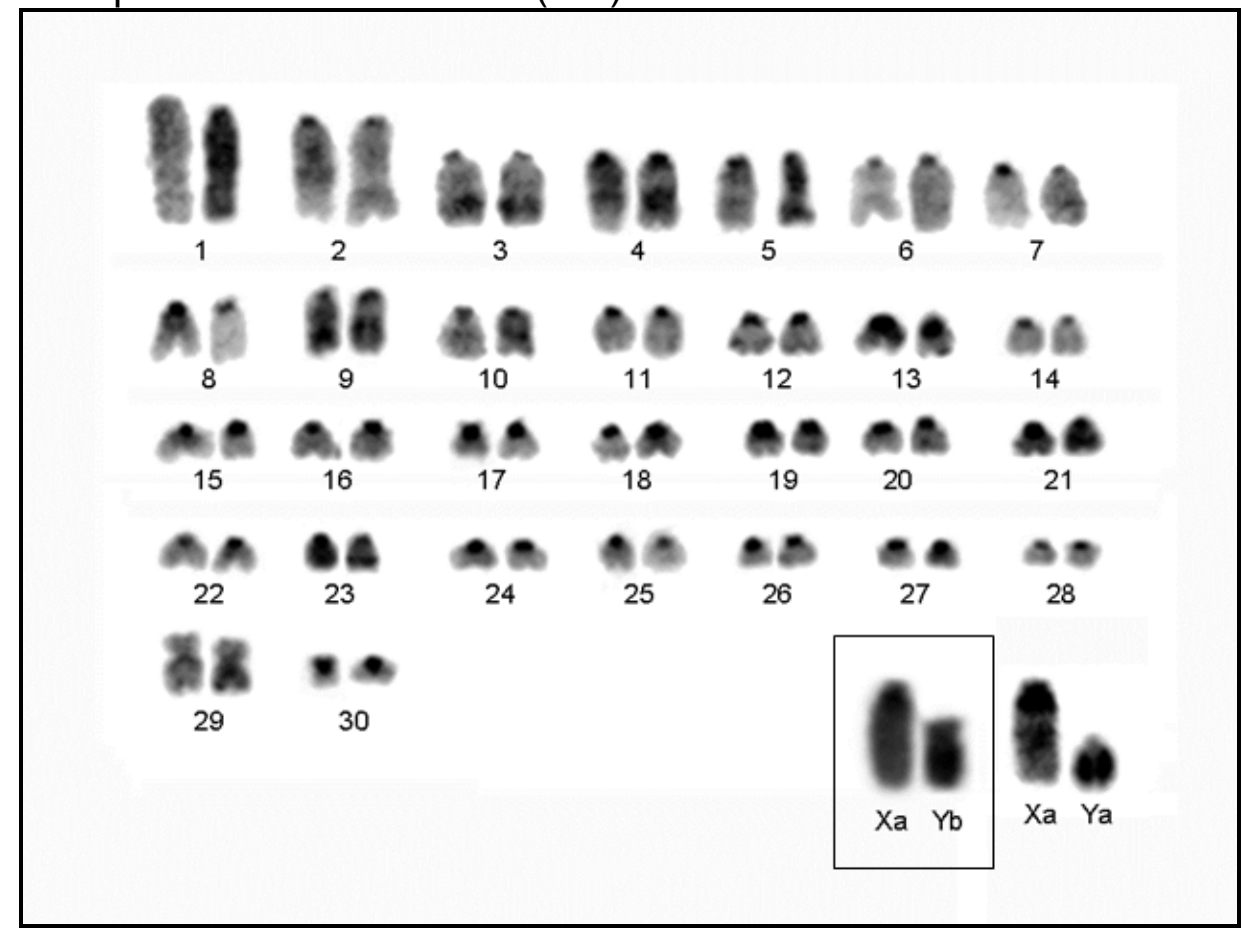

Em destaque, cromossomos sexuais de um exemplar macho proveniente do Parque Nacional das Emas (GO). 
Figura 3.8 - Padrão de bandas G (GTG) em O. fornesi, 2n=62, NF=64, macho, proveniente de Peixe (TO).

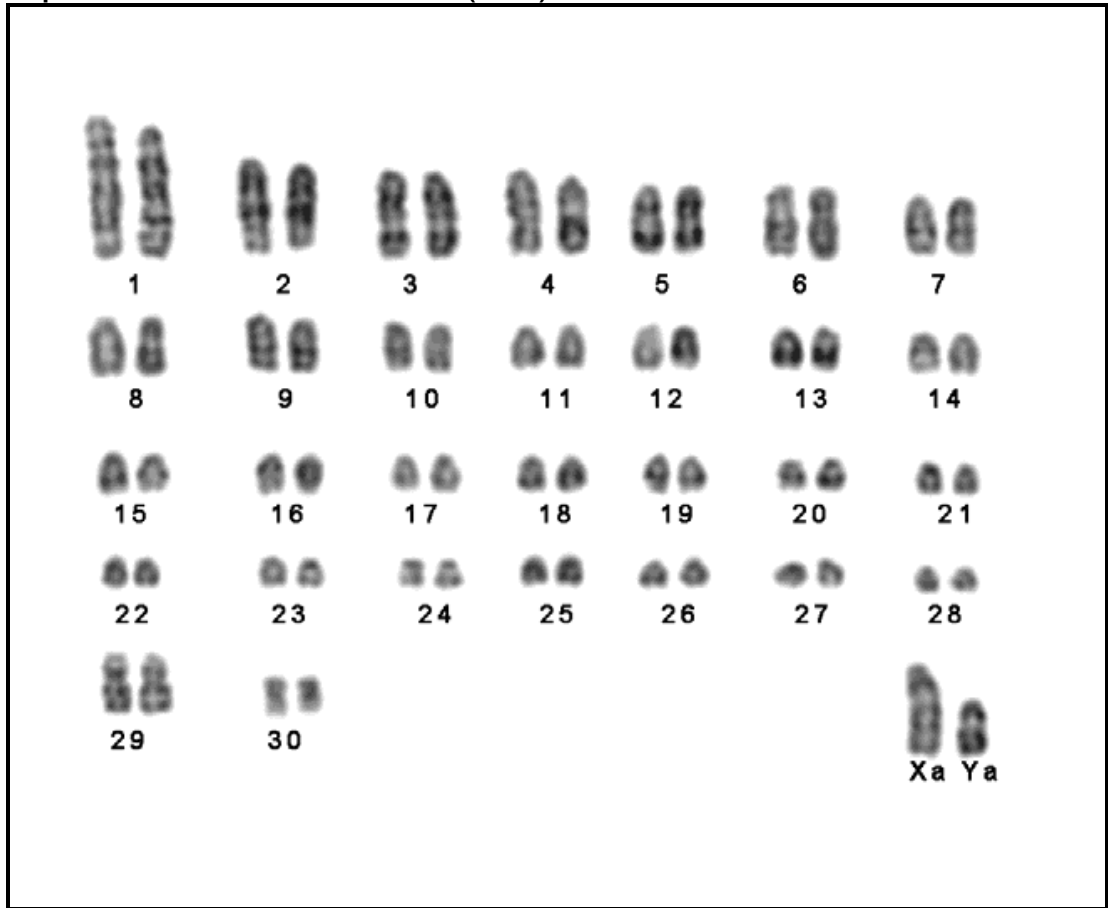

Figura 3.9 - Cariótipo em coloração convencional de 0 . microtis, $2 n=64, N F=64$, macho, proveniente de Aripuanã (MT).

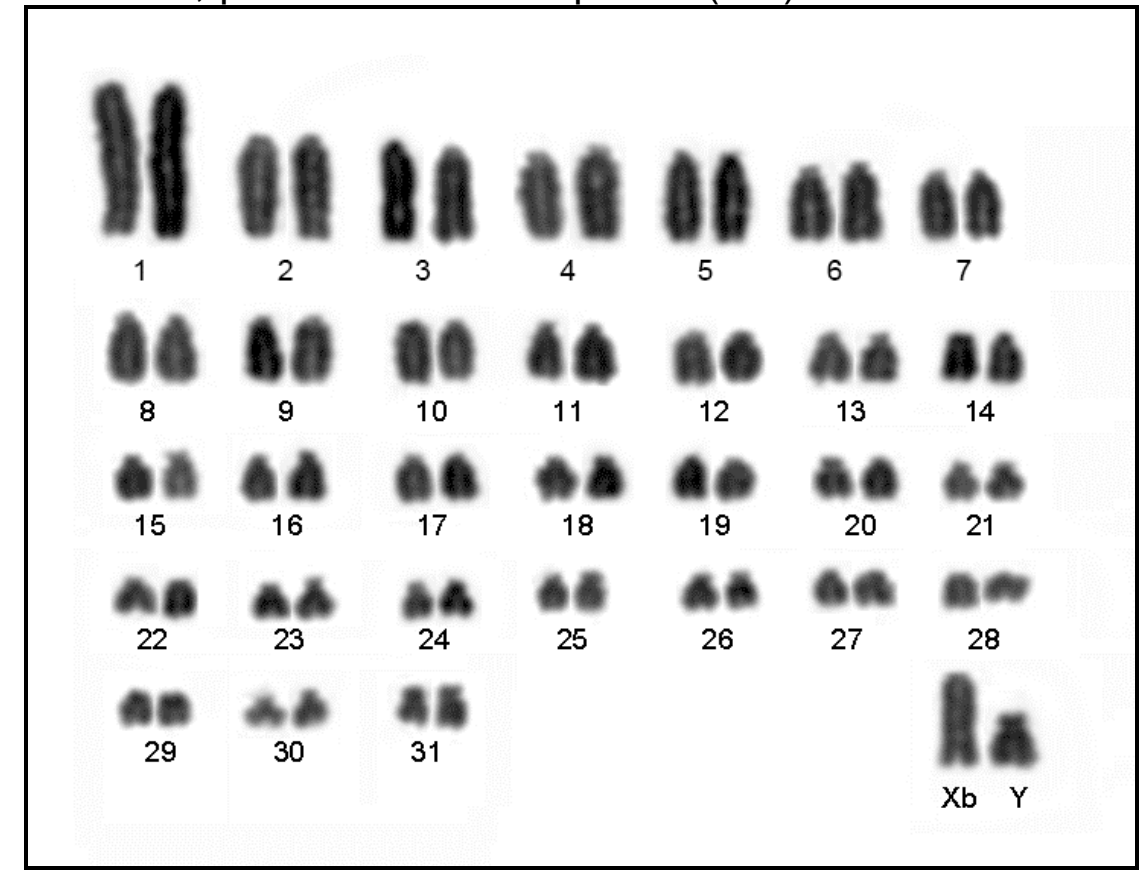


Figura 3.10 - Padrão de bandas $C(C B G)$ em O. microtis, $2 n=64, N F=64$, macho, proveniente de Aripuanã (MT).

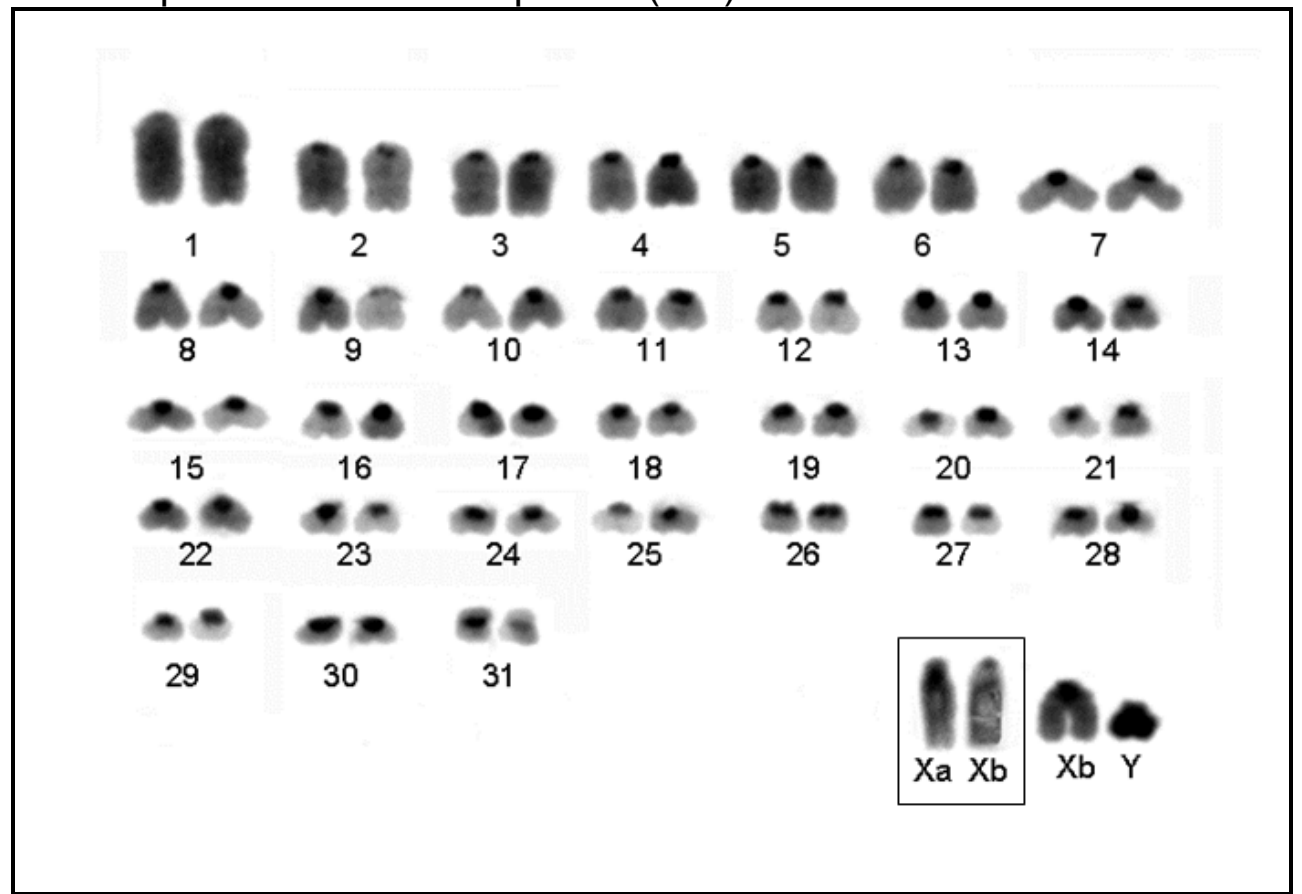

Em destaque, cromossomos sexuais heteromórficos de uma fêmea, da mesma localidade.

Figura 3.11 - Padrão de bandas G (GTG) em O. microtis, 2n=64, NF=64, fêmea, proveniente de Aripuanã (MT).

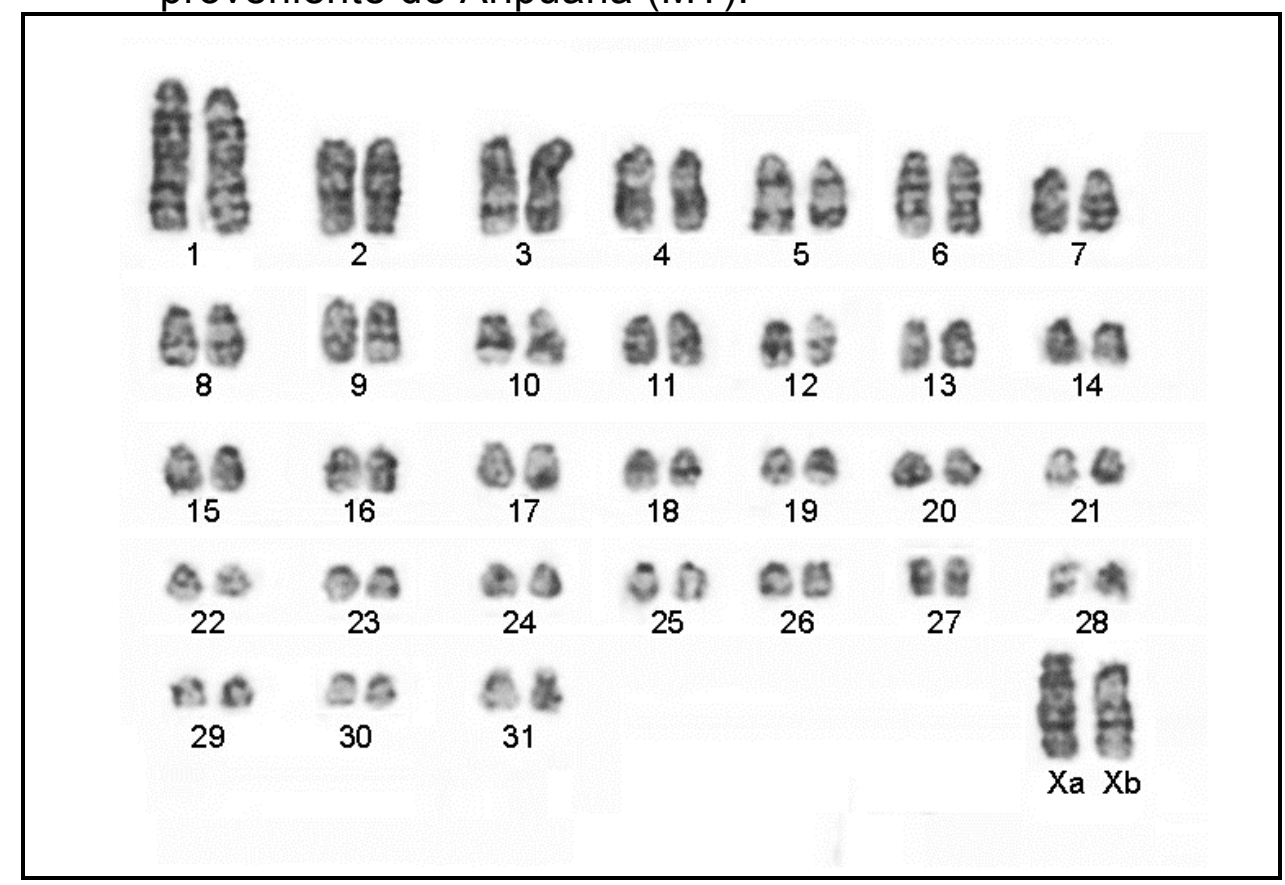


Figura 3.12 - Metáfase de 0 . microtis, $2 \mathrm{n}=64, \mathrm{NF}=64$, macho, proveniente de Aripuanã (MT) com FISH telomérica evidenciando marcações nos telômeros.

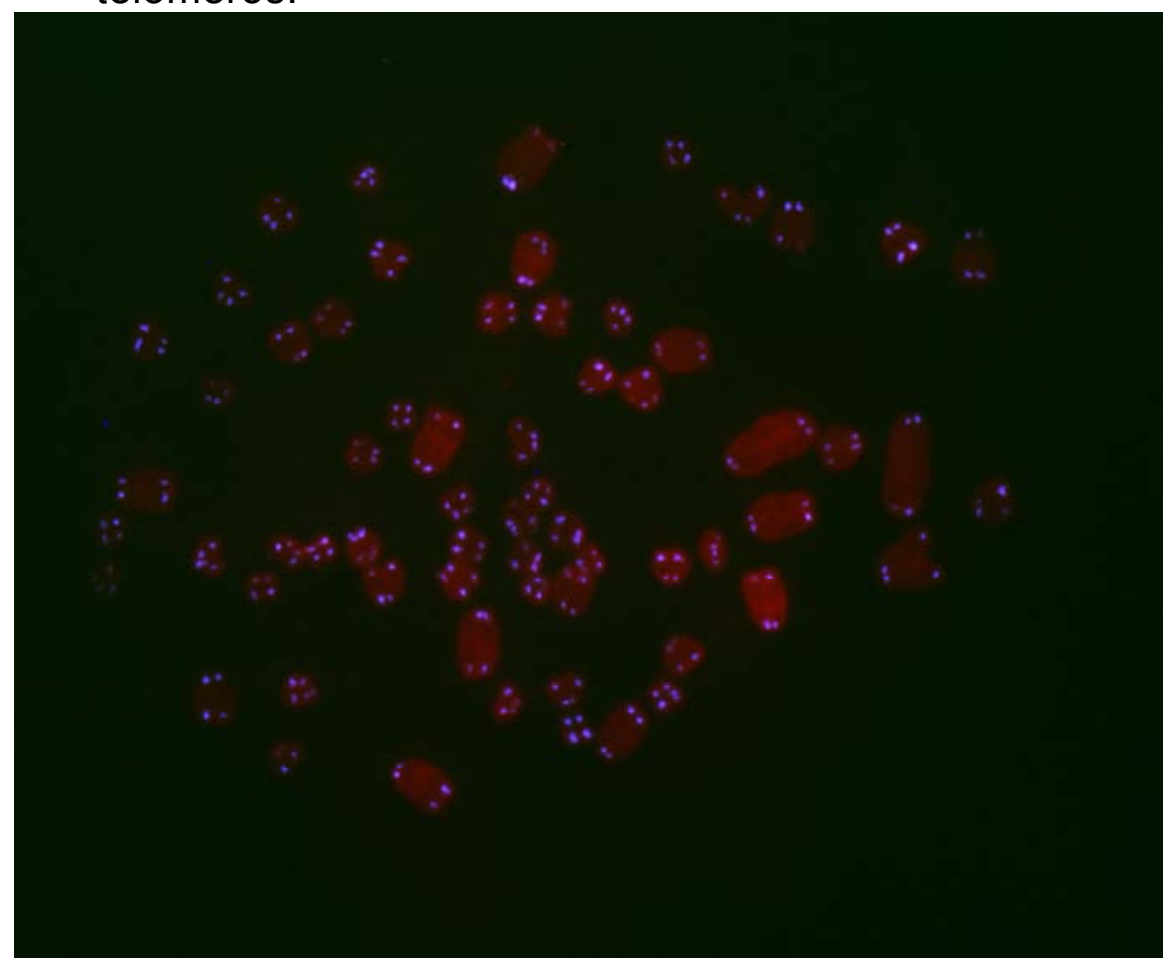

Figura 3.13 - Cariótipo em coloração convencional de 0 . moojeni, $2 \mathrm{n}=70$, $\mathrm{NF}=72$, fêmea, proveniente de Minaçu (GO).

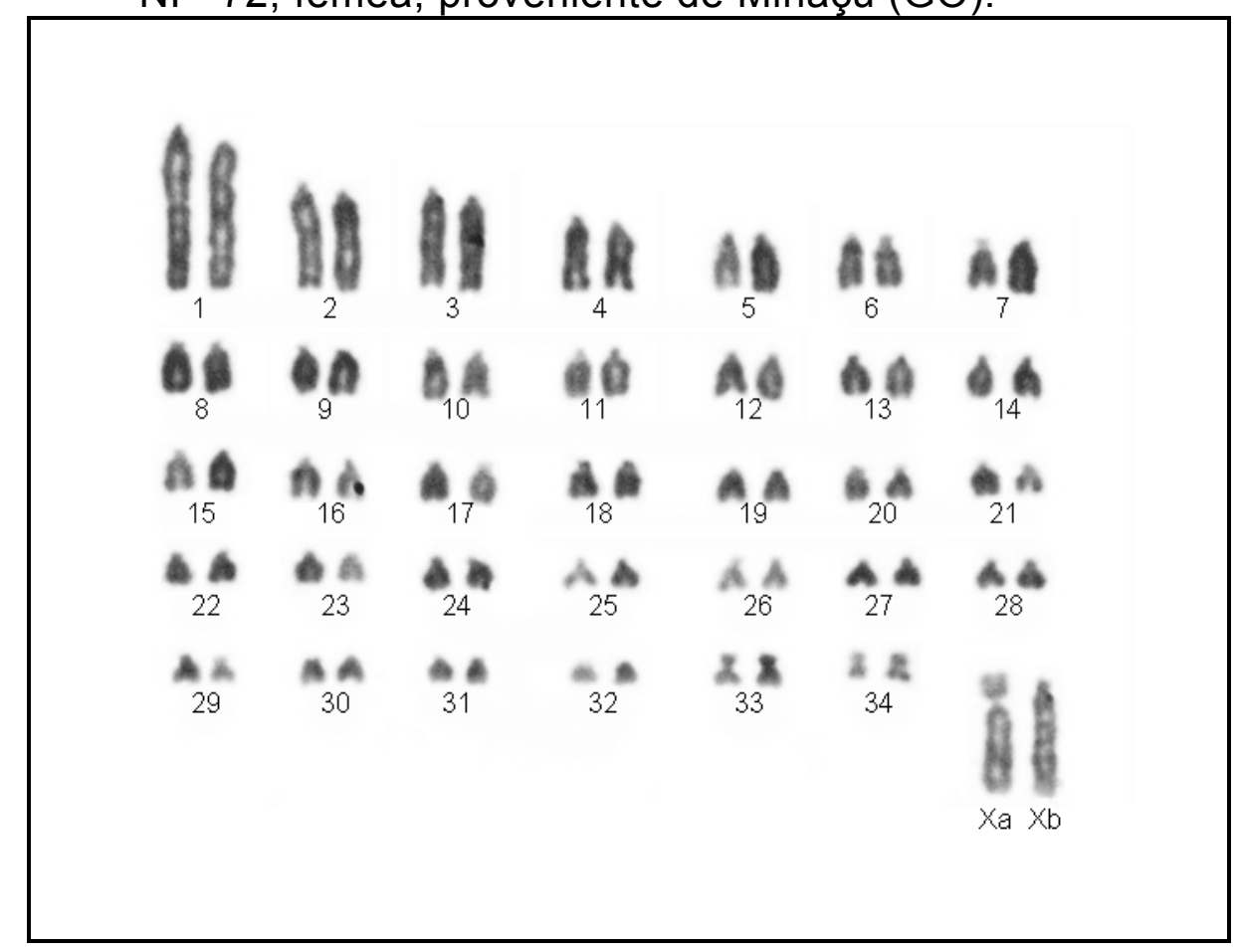


Figura 3.14 - Padrão de bandas $C(C B G)$ em O. moojeni, 2n=70, NF=72, macho, proveniente de Minaçu (GO).

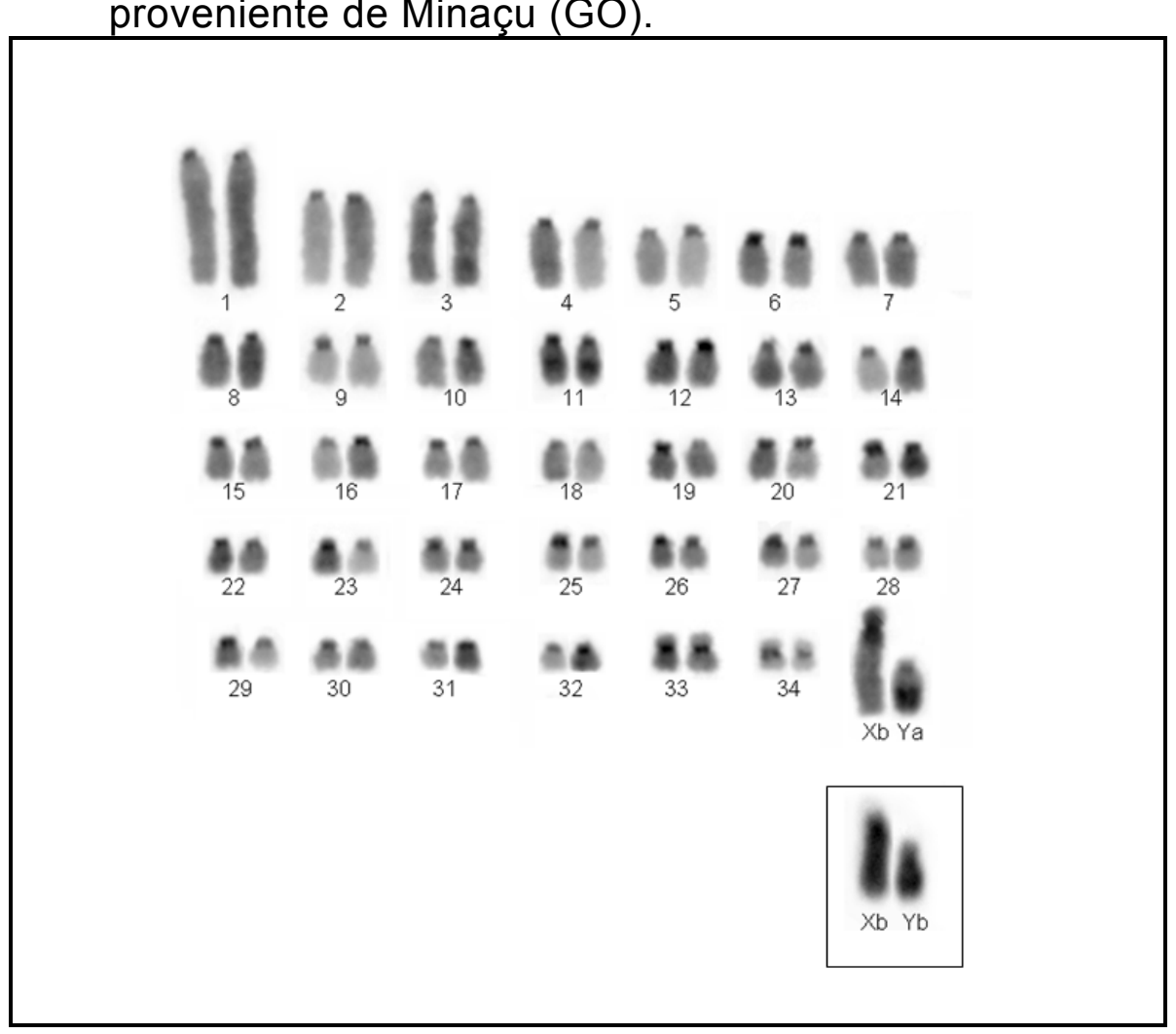

Em destaque, cromossomos sexuais de um exemplar macho, de Peixe (TO).

Figura 3.15 - Padrão de bandas G (GTG) em O. moojeni, 2n=70, NF=72, fêmea, proveniente de Minaçu (GO).

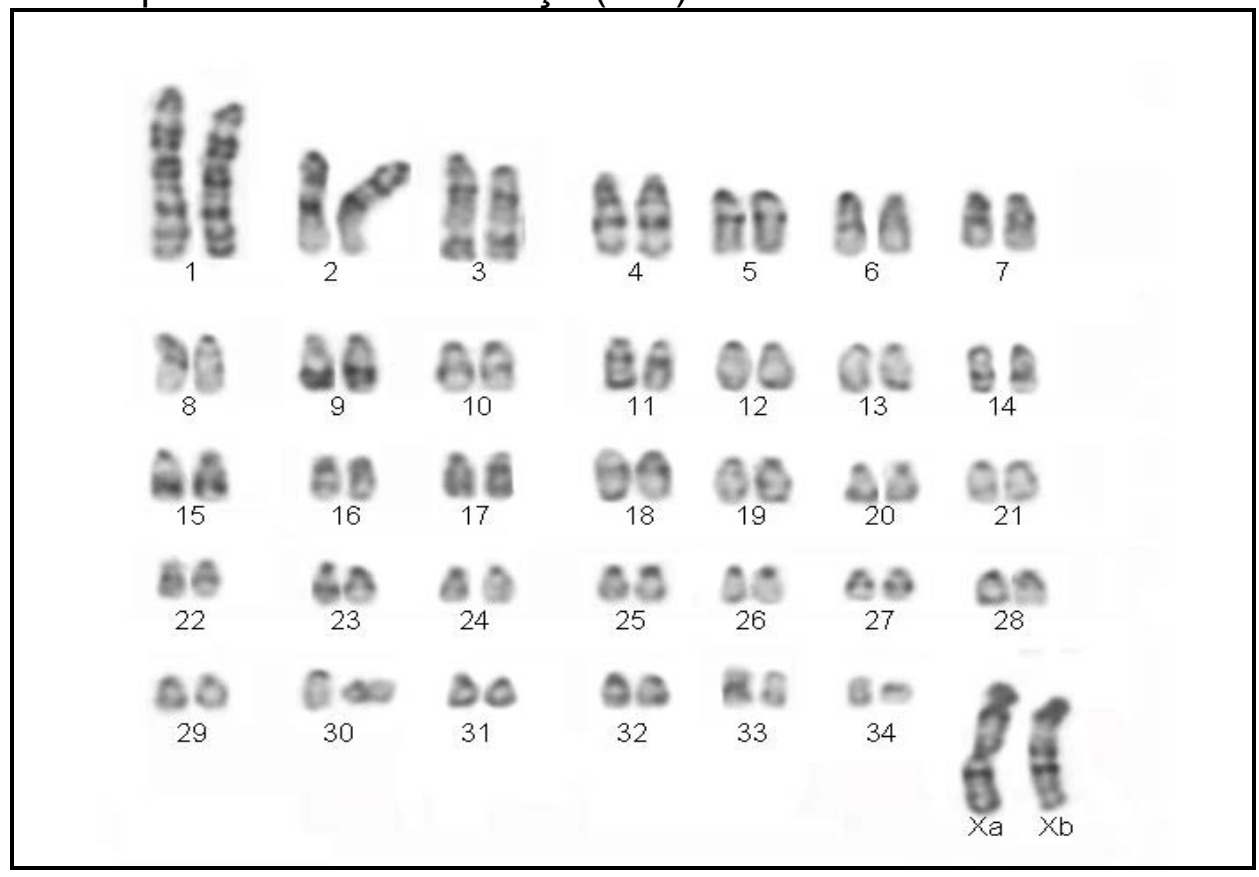


Figura 3.16 - Regiões organizadoras de nucléolo (RONs) em metáfase de 0. moojeni, fêmea, proveniente de Minaçu (GO). Observam-se oito marcações.

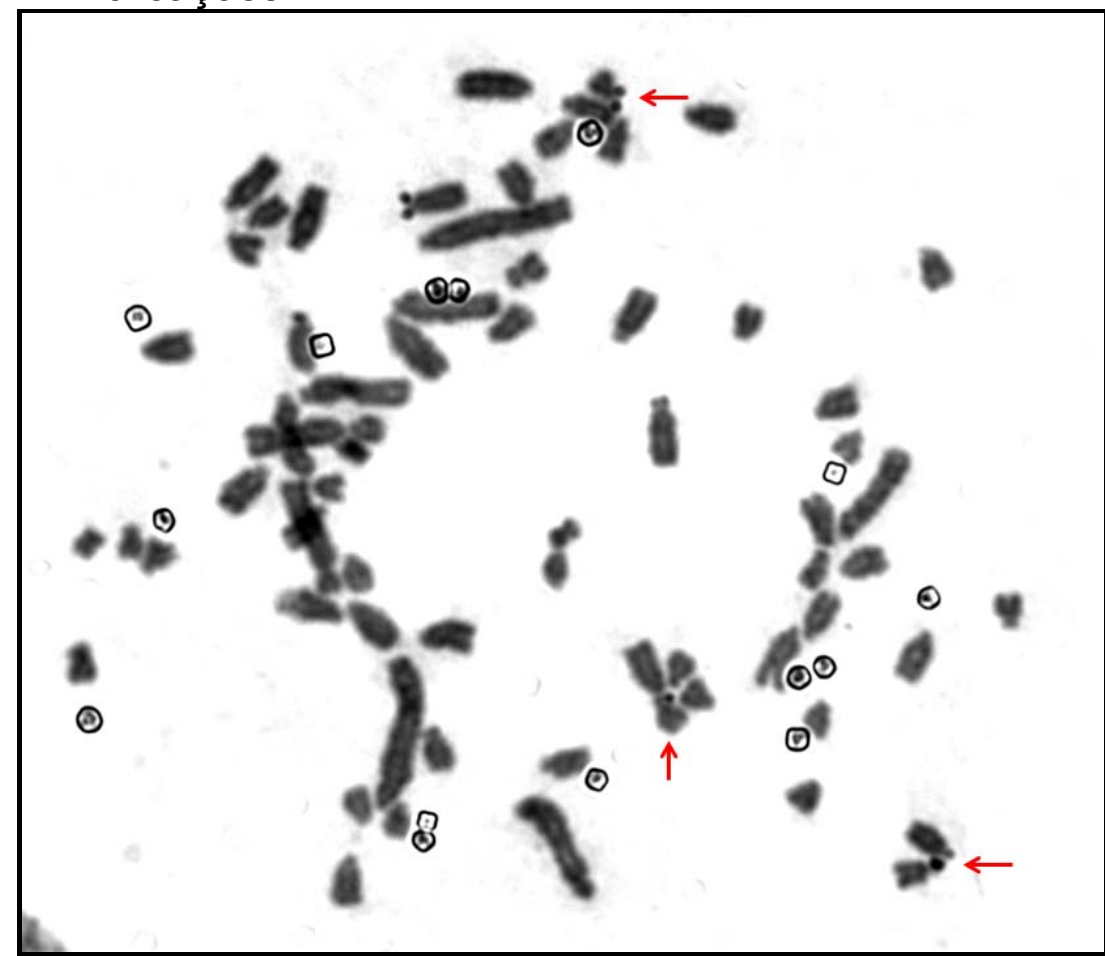

Setas indicam as associações encontradas. 
Figura 3.17 - Cariótipo em coloração convencional de O. nigripes, $2 \mathrm{n}=62$, $\mathrm{NF}=81$, macho, proveniente de São Joaquim da Barra (SP), que apresenta o par 2SM (homomórfico submetacêntrico), o par $3 \mathrm{H}$ (heteromórfico) e o par 8M (homomórfico metacêntrico).

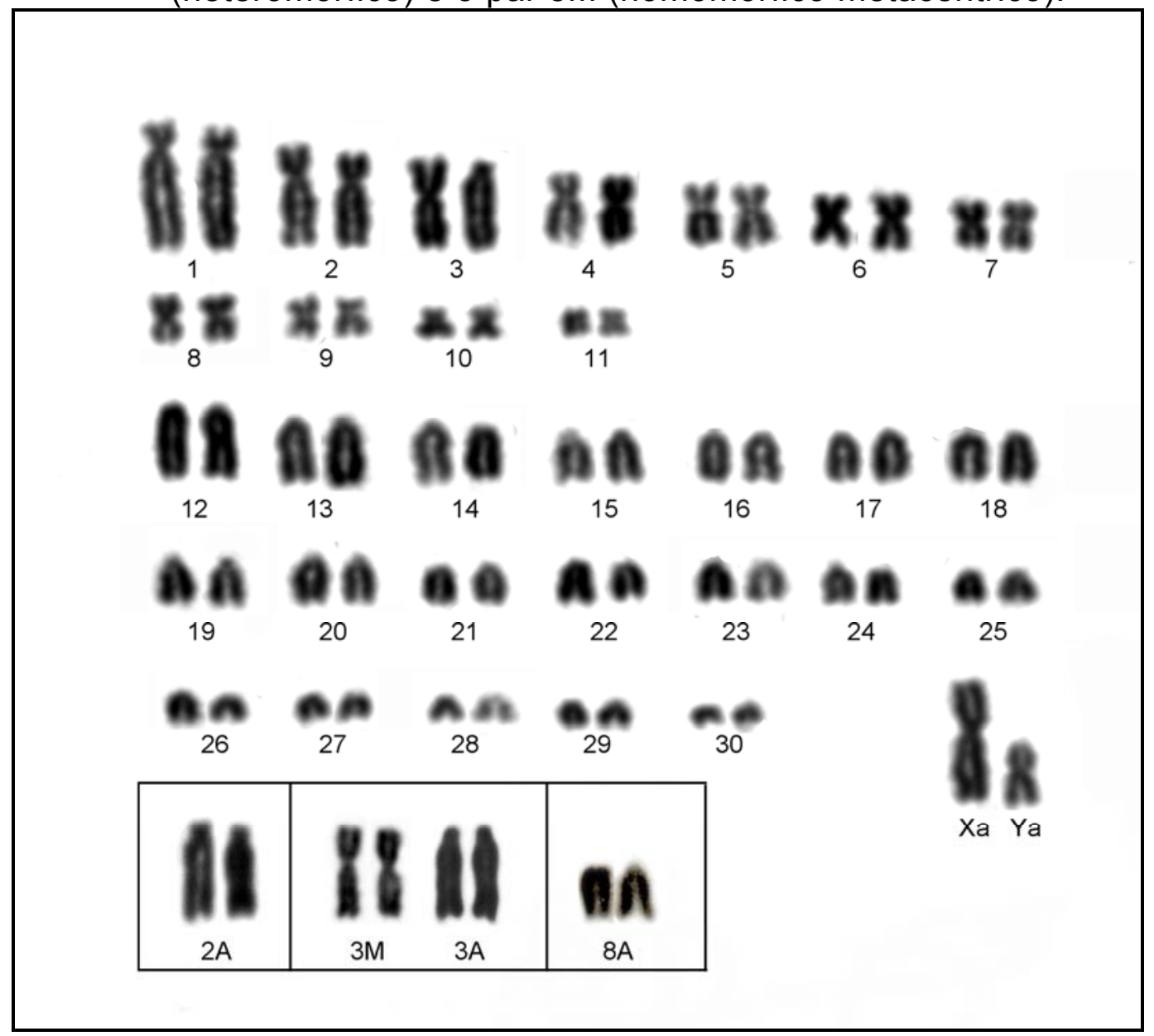

Em destaque, estão os outros polimorfismos/heteromosfismos encontrados nos pares autossômicos 2, 3 e 8: 2A (homomórfico acrocêntrico), 3M (homomórfico metacêntrico), 3A (homomórfico acrocêntrico) e 8A (homomórfico acrocêntrico). 
Figura 3.18 - Padrão de bandas C (CBG) em O. nigripes, 2n=62, NF=81, fêmea, proveniente da Floresta Nacional de Ipanema (SP).

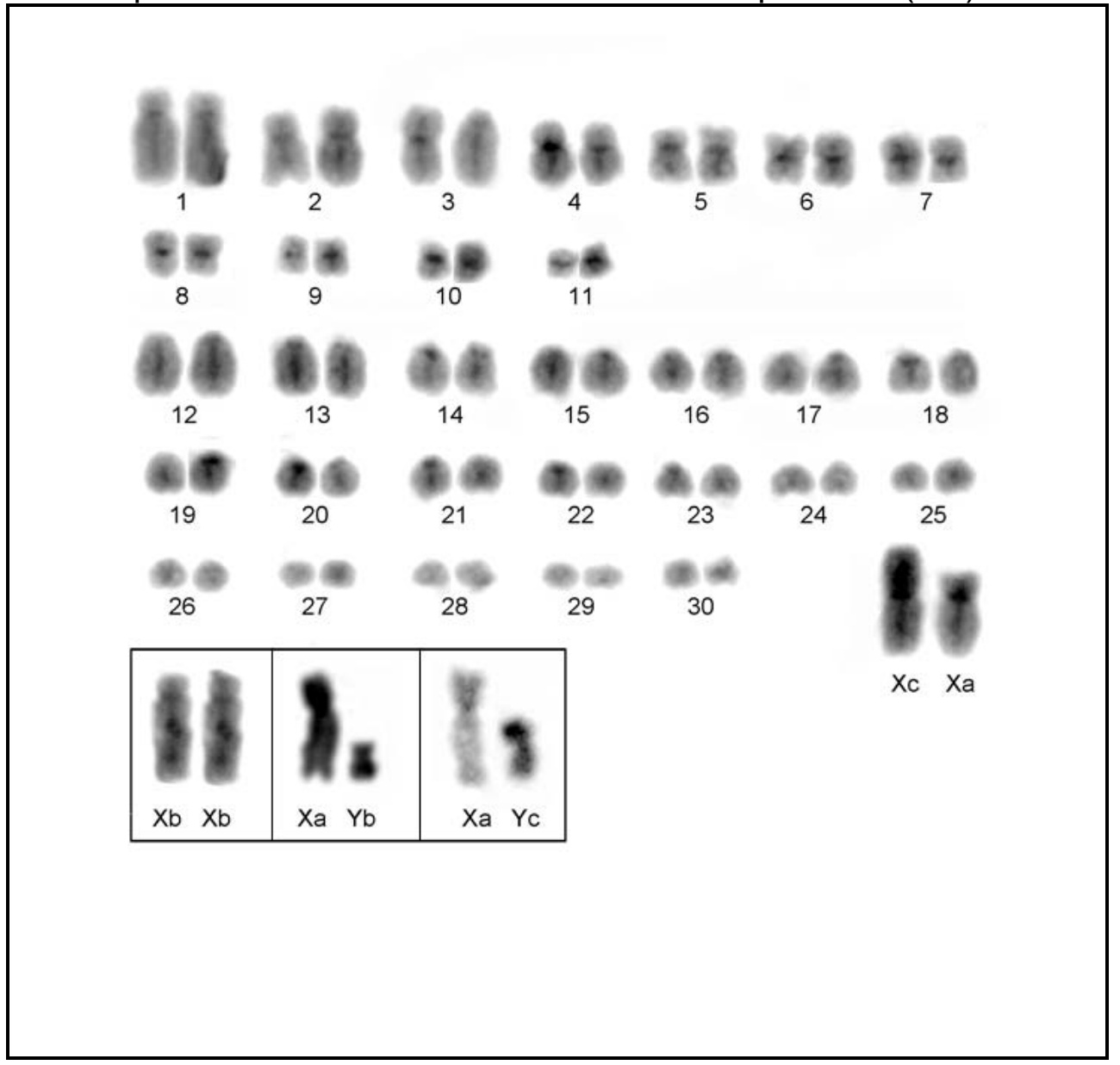

Em destaque, diferentes formas encontradas nos cromossomos sexuais desta espécie. 
Figura 3.19 - Padrão de bandas G (GTG) em O. nigripes, $2 n=62$, NF=81, fêmea, proveniente do Parque Estadual da Serra do Mar, núcleo Santa Virgínia (SP).

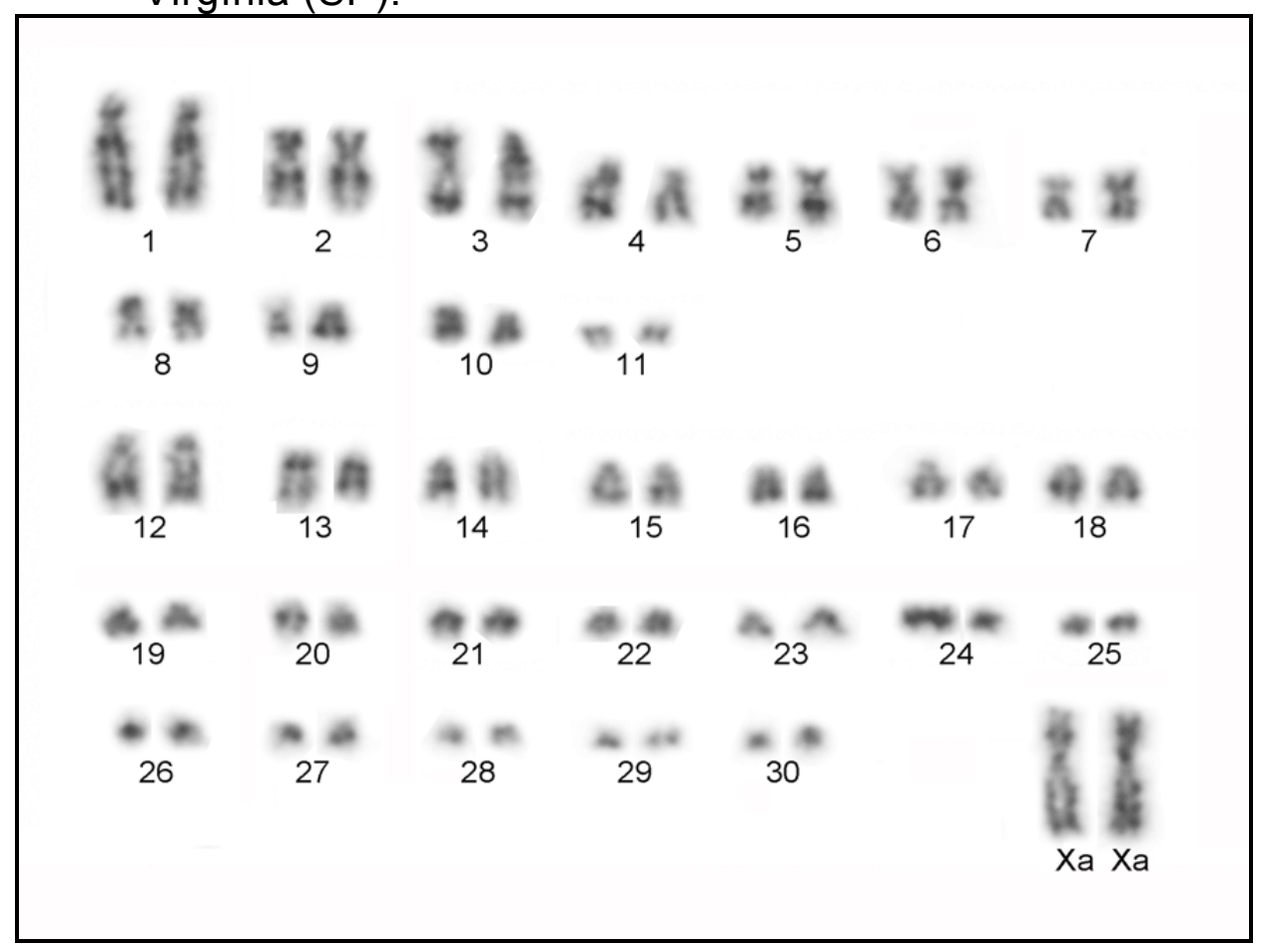


Figura 3.20 - Metáfases de O. nigripes com FISH telomérica evidenciando marcações nos telômeros.
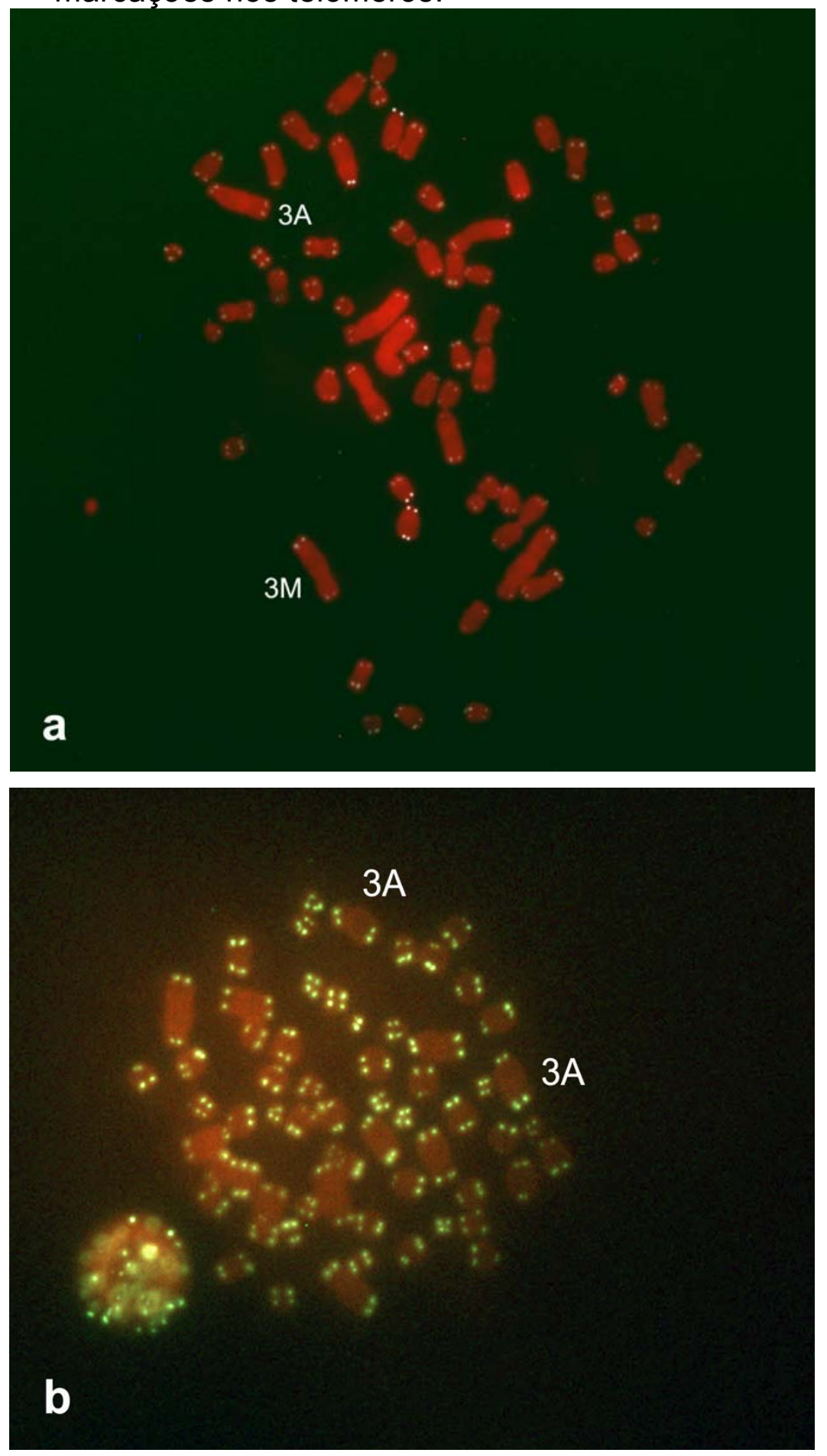

(a) $2 n=62, N F=81$ (par 3H), macho; (b) 2n=62, NF=80 (par 3A), fêmea. 
Figura 3.21 - Padrão de bandas C (CBG) em Oligoryzomys sp. $A, 2 n=70$, $\mathrm{NF}=72$, macho, proveniente de Apiacás (MT).

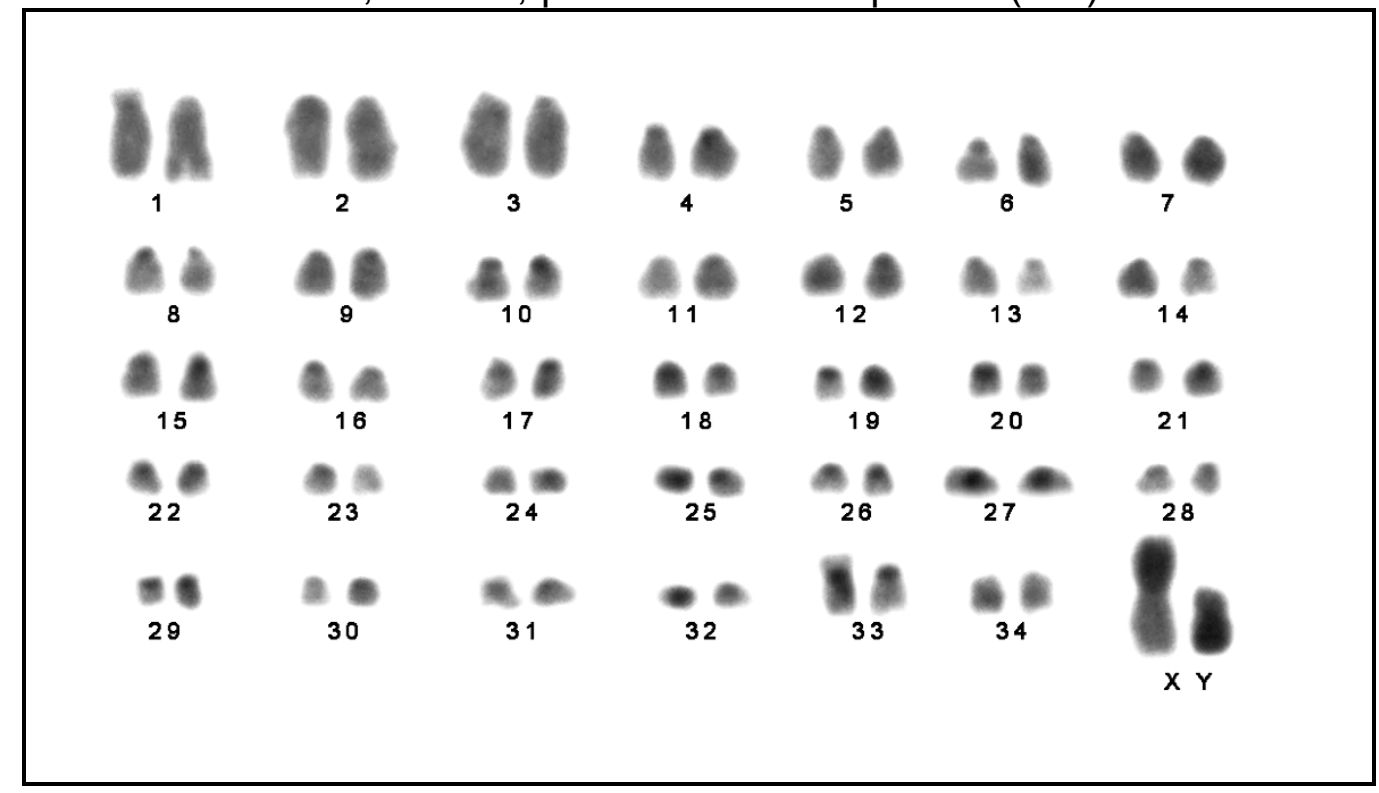

Figura 3.22 - Cariótipo em coloração convencional de O. stramineus, $2 \mathrm{n}=52$, $\mathrm{NF}=68$, macho, proveniente de Uruçuí-Una $(\mathrm{PI})$.

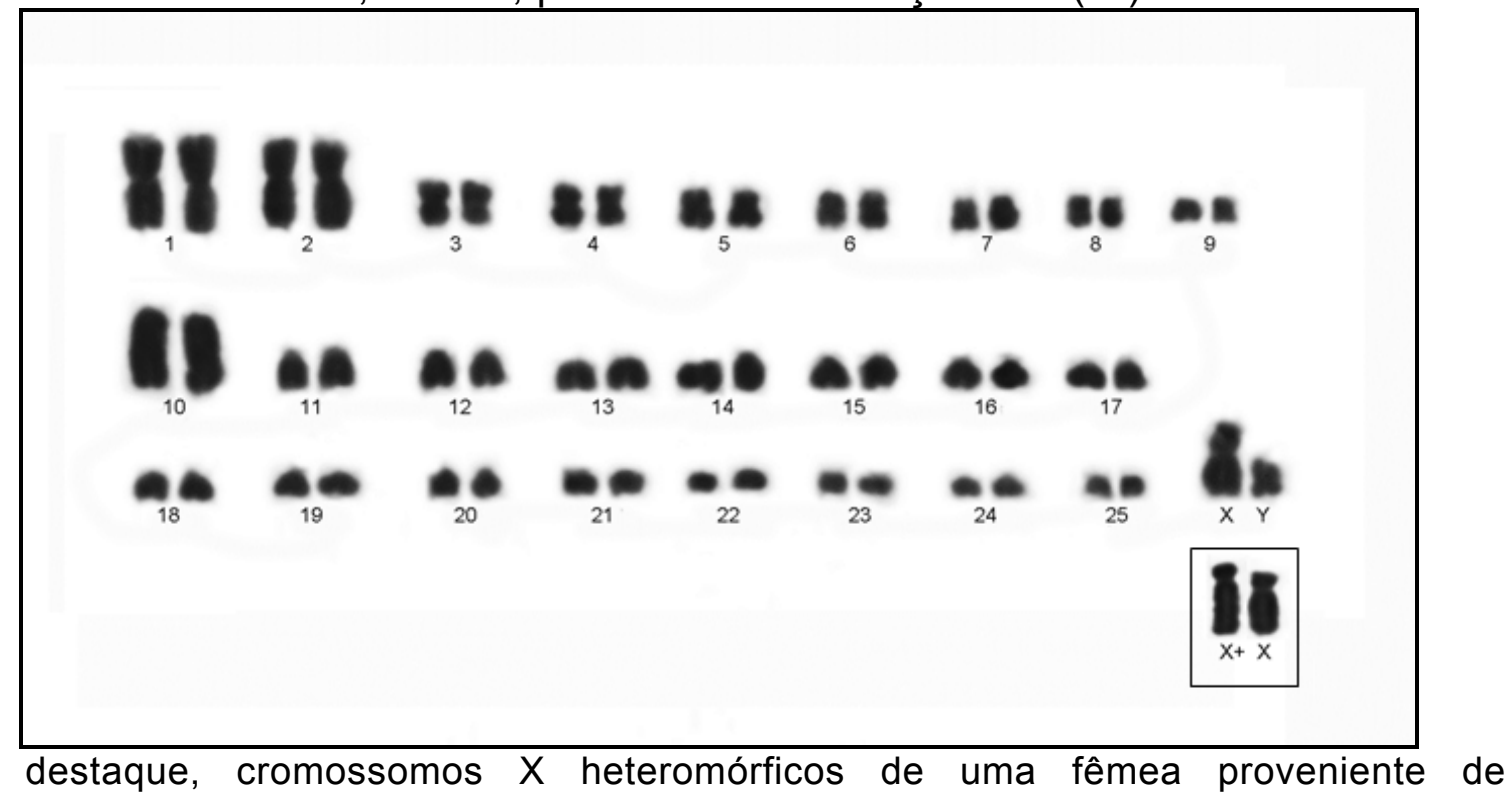

Jequitinhonha (MG). 
Figura 3.23 - Padrão de bandas $C(C B G)$ em O. stramineus, 2n=52, NF=68, macho, proveniente de Uruçuí-Una $(\mathrm{PI})$.

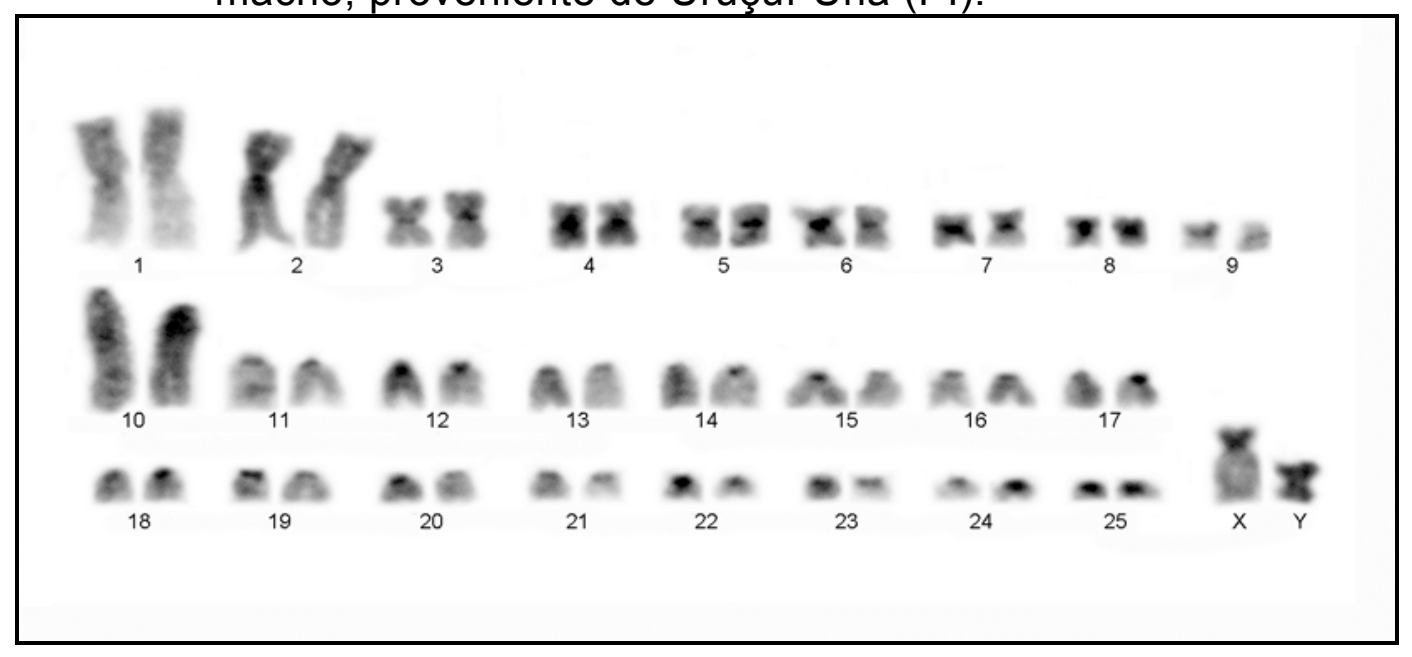

Figura 3.24 - Padrão de bandas $G(G T G)$ em O. stramineus, $2 n=52, N F=68$, fêmea, proveniente de Jequitinhonha (MG).

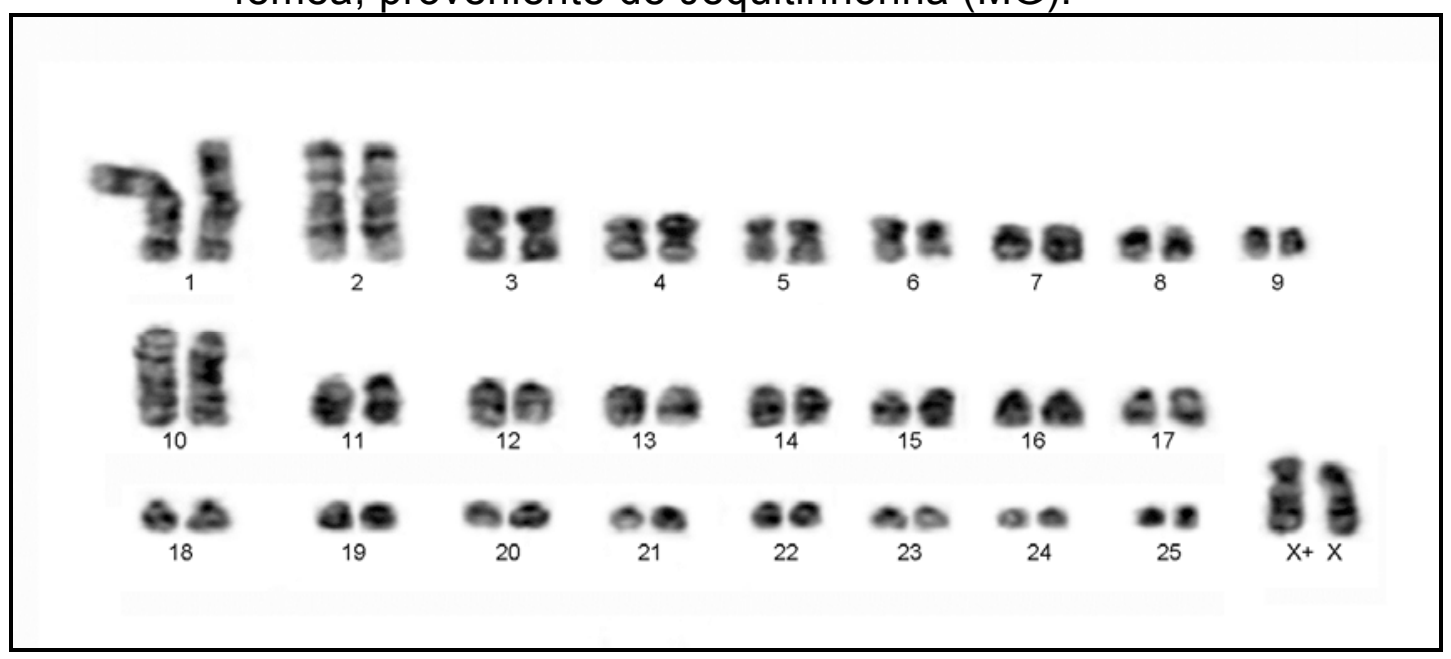


Figura 3.25 - Comparação dos padrões de bandas G (GTG) das espécies $O$. flavescens (OFL), O. fornesi (OFO), O. microtis (OMI), O. moojeni (OMO), O. nigripes (ONI), O. rupestris (ORU), Oligoryzomys sp. 2 (OSP) e O. stramineus (OST) (o padrão de bandas G de ORU e OSP foi retirado de Silva e Yonenaga-Yassuda, 1997).

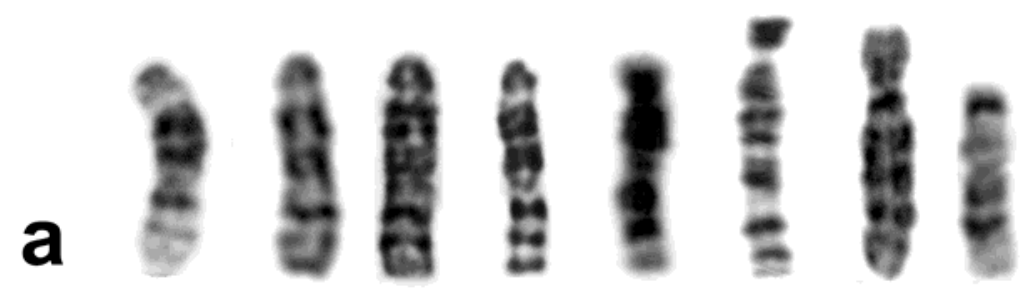

OFL 1 OFO 1 OMI 1 OMO 1 ONI 1 ORU 3 OSP 3 OST 2

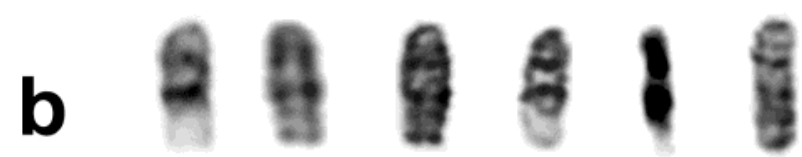

OFL 2 OFO 2 OMI 2 OMO 2 ONI 2 OST 10

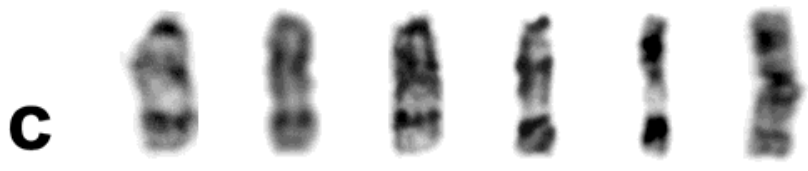

OFL 3 OFO 3 OMI 3 OMO 3 ONI 3 OST 1 
CAPÍTULO 4 Pintura cromossômica comparativa (Zoo-FISH) em Oligoryzomys (Rodentia, Sigmodontinae): homologias e rearranjos envolvidos na diferenciação cariotípica de cinco espécies do gênero 


\subsection{Resumo}

Oligoryzomys pertence à subfamília Sigmodontinae, tribo Oryzomyini, sendo o gênero com maior número de espécies dessa tribo. Os dados cromossômicos revelam alta variabilidade cariotípica de $2 n=44$ em Oligoryzomys sp. 2, a $2 \mathrm{n}=72$ em 0 . utiaritensis. O objetivo deste trabalho é investigar a presença de segmentos cromossômicos homólogos e blocos sintênicos entre as espécies de Oligoryzomys, usando pintura cromossômica, e inferir os rearranjos ocorridos durante a evolução cariotípica do gênero. Foram utilizadas 23 sondas cromossomo-específicas de Oligoryzomys moojeni, 2n=70 (OMO 1 a 8, 9/10, 11 a 13, 16, 17, 25 a 30, 33, 34 e X) que pintaram 29 segmentos autossômicos em O. fornesi (OFO) com $2 \mathrm{n}=62 ; 30$ segmentos em O. microtis (OMI) com $2 \mathrm{n}=64 ; 31$ em O. nigripes (ONI) com 2n=62; e 32 segmentos em O. rupestris (ORU) e Oligoryzomys sp. 2 (OSP), com $2 n=46$ e $2 n=44$, respectivamente. As sondas OMO 2, 3, 7, 8, 11, 12, 16, 17, 25, 26, 27, 29, 30 e 34 marcaram sempre um único segmento em todas as espécies. As sondas OMO 4 e OMO 5 mostraram a mesma associação sintênica, marcando duas regiões diferentes de um mesmo par acrocêntrico em todas as espécies. Especificamente em $O$. rupestris e Oligoryzomys sp. 2, um total de oito sondas pintaram onze segmentos no par 1 de ORU, enquanto nove sondas hibridaram 12 regiões do par 1 de OSP. A sonda OMO 6 pintou OSP 1p, um segmento proximal em OSP $2 q$ e todo par OSP 19; em ORU, a mesma sonda pintou um segmento proximal no par ORU $2 q$ e os pares acrocêntricos ORU 19 e ORU 20 inteiros. As hibridações com a sonda OMO $X$ mostraram sinais nos cromossomos $X$ e $Y$. Os resultados evidenciam a ocorrência de vários rearranjos cromossômicos que levaram à diferenciação cariotípica do gênero, tais como: inversões pericêntricas, fissão, fusão em tandem, fusão cêntrica e perda/inativação, ganho/ativação ou reposicionamento de centrômero.

Palavras-chave: Pintura cromossômica. Oligoryzomys. Sintenias. Evolução cariotípica. 


\subsection{Abstract}

Oligoryzomys belongs to the subfamily Sigmodontinae, tribe Oryzomyini, and presents a high number of species. Karyological data reveal diploid number ranging from $2 n=44$ in Oligoryzomys sp. 2 to $2 n=72$ in 0 . utiaritensis. The aim of this work is to investigate chromosome homologies among Oligoryzomys species using chromosome painting and also to infer the rearrangements that occurred during the karyotype evolution of the genus. For this proposal, 23 sets of whole chromosome probes from Oligoryzomys moojeni with 2n=70 (OMO 1-8, 9/10, 11 13, 16, 17, 25-30, 33, 34 and X) were hybridized on five Oligoryzomys species. The OMO probes painted 29 autossomic segments on O. fornesi (OFO) with $2 n=62 ; 30$ autossomic segments on $O$. microtis (OMI), $2 n=64 ; 31$ segments on $O$. nigripes $(\mathrm{ONI}), 2 \mathrm{n}=62 ; 32$ segments on $O$. rupestris $(\mathrm{ORU}), 2 \mathrm{n}=46$, and 32 on Oligoryzomys sp. 2 (OSP), 2n=44. The probes OMO 2, 3, 7, 8, 11, 12, 16, 17, 25, 26, 27, 29, 30 and 34 painted one segment, and probes OMO 4 and 5 painted two regions of the same pair in all species studied, showing a syntenic association. Specifically concerning $O$. rupestris and Oligoryzomys sp. 2, a total of 8 probes hybridized 11 segments on the largest pair of ORU 1 and 9 probes hybridized 12 segments on OSP 1. Besides, OMO 6 painted three segments in ORU, corresponding to proximal segment of ORU $2 q$, and the whole ORU 19 and 20. In OSP, the segment correspondent to the pair ORU 20 was homologous of OSP $1 \mathrm{p}$. OMO $X$ showed signals of hybridization in both chromosomes $\mathrm{X}$ and $\mathrm{Y}$. The results revealed that extensive chromosomal rearrangements, such as pericentric inversion, Robertsonian rearrangements and tandem fusion/fission, have driven differentiation among Oligoryzomys karyotypes, as well as loss/ inactivation, gain/activation or repositioning of centromeres.

Keywords: Chromosome painting. Oligoryzomys. Synteny. Chromosome evolution. 


\subsection{Introdução}

O gênero Oligoryzomys está inserido na subfamília Sigmodontinae, tribo Oryzomyini, sendo o mais especioso dessa tribo (WEKSLER; PERCEQUILLO, 2011). É considerado um gênero complexo do ponto de vista taxonômico, devido a distribuição abrangente e similaridade morfológica das espécies. Apesar das controvérsias, atualmente, são reconhecidas 22 espécies para o gênero (MUSSER; CARLETON, 2005; PARESQUE, 2010; WEKSLER; BONVICINO, 2005; WEKSLER; PERCEQUILLO, 2011; Tabela 1.3, Capítulo 1).

Abordagens multidisciplinares envolvendo dados de morfologia, ecologia, citogenética e filogenia molecular têm sido empregadas na tentativa de esclarecer a diversidade e as relações de parentesco entre os representantes do gênero.

Análises filogenéticas baseadas em sequências obtidas de genes nucleares e mitocondriais corroboram o monofiletismo do gênero, mas as relações entre as espécies ainda são controversas (GONZÁLEZ-ITTIG et al., 2010; MIRANDA et al., 2008; MYERS; LUNDRIGAN; TUCKER, 1995; PALMA et al., 2010).

Recentemente, Agrellos et al. (2012), usando sequência do citocromo-b e do íntron 7 do beta-fibrinogênio, recuperaram O. microtis como irmã das outras espécies de Oligoryzomys, e 0 . moojeni e 0 . utiaritensis em um clado mais derivado.

Com relação à citogenética, os dados cromossômicos revelaram uma grande amplitude no número diplóide, que pode variar de $2 \mathrm{n}=44$ em Oligoryzomys sp. 2 (SILVA; YONENAGA-YASSUDA, 1997) a $2 \mathrm{n}=72 \mathrm{em} O$. utiaritensis (AGRELLOS et al., 2012). Diversos rearranjos cromossômicos foram descritos, tais como inversões pericêntricas (detectadas em $O$. nigripes, $O$. stramineus, O. moojeni), polimorfismos de cromossomos sexuais (O. nigripes, $O$. flavescens, $O$. longicaudatus) e presença de supernumerários (O. flavescens) (ALMEIDA; YONENAGA-YASSUDA, 1991; BONVICINO; GEISE, 2006; GALLARDO; GONZÁLEZ, 1977; LIMA; BONVICINO; KASAHARA, 2003; PARESQUE et al., 2007; SBALQUEIRO et al., 1991). 
Silva e Yonenaga-Yassuda (1997) descreveram os cariótipos de $O$. rupestris $(2 n=46, N F=52)$ (referido na época como Oligoryzomys sp. 1) e Oligoryzomys sp. $2(2 n=44, N F=52)$, espécie ainda não descrita formalmente, e realizaram comparações utilizando informações de bandas $C, G, R$, localização de RONs e FISH com sondas teloméricas. Este estudo revelou que a diferença no número diplóide entre essas espécies foi devido à ocorrência de um evento de fusão cêntrica. As evidências que levaram a tal conclusão foram: (i) presença de um par acrocêntrico pequeno a mais em $O$. rupestris; (ii) diferença de tamanho do par 1 de ambas as espécies, sendo que esse par é acrocêntrico em O. rupestris e subtelocêntrico em Oligoryzomys sp. 2; (iii) presença de heterocromatina constitutiva na região pericentromérica do par 1 de 0 . rupestris e a ausência em Oligoryzomys sp. 2; (iv) presença de RON no par 1 somente de O. rupestris e (v) padrão similar de bandas $\mathrm{G}$ e $\mathrm{R}$ entre o braço longo do par 1 de ambas as espécies.

Os dados cromossômicos disponíveis na literatura levaram Mattevi e Andrades-Miranda (2006) a agruparem as espécies de Oligoryzomys em relação ao tamanho e morfologia do primeiro par autossômico, sendo: (1) grupo que possui o primeiro par acrocêntrico uma vez e meia maior que o par 2 ( $O$. rupestris, O. messorius, O. longicaudatus, O. moojeni, O. fornesi, O. flavescens); (2) grupo que possui o primeiro par com dois braços e uma vez e meia maior que o segundo par (O. magellanicus, O. microtis); e (3) grupo com os primeiros pares de tamanhos similares (O. stramineus, O. fulvescens, O. chacoensis, O. andinus, O. delicatus, O. destructor, O. nigripes).

Até o momento, os estudos realizados no gênero Oligoryzomys contemplam exclusivamente a variabilidade cromossômica intraespecífica, sendo escassos os estudos comparativos entre espécies. Essas informações são baseadas em coloração diferencial (bandas C, G e R), localização de RONs por impregnação de nitrato de prata e de sequências teloméricas por FISH.

O objetivo do presente capítulo é realizar uma comparação entre as espécies de Oligoryzomys, investigar as regiões de homologia, estabelecer os blocos sintênicos entre as espécies, por meio de pintura cromossômica com sondas espécie-específicas de 0 . moojeni $(2 \mathrm{n}=70)$, e inferir os rearranjos ocorridos durante a evolução cariotípica do gênero. Para isso, será utilizada a 
filogenia de Agrellos et al. (2012), como base para discussão dos resultados obtidos.

\subsection{Material e Métodos}

As sondas cromossomo-específicas da espécie Oligoryzomys moojeni $(2 n=70, N F=72)$ foram geradas por citometria de fluxo, no Departamento de Medicina Veterinária, Universidade de Cambridge (Inglaterra), a partir de cromossomos obtidos de cultura de fibroblastos de uma fêmea com heteromorfismo nos cromossomos sexuais, caracterizados como Xa e Xb (Figura 3.13 - Capítulo 3).

O isolamento dos cromossomos ocorreu de acordo com Yang et al. (1995; 2009). Para cada pico registrado pela citometria, cerca de 400 cromossomos foram separados. Os picos foram amplificados por DOP-PCR utilizando o primer 6MW (5' CCG ACT CGA GNN NNN NAT GTG G 3') (TELENIUS et al., 1992). Os produtos primários de PCR foram marcados com Biotina-16-dUTP (marcação indireta) ou FITC-12-dUTP (marcação direta) em uma segunda amplificação por DOP-PCR com o mesmo primer.

A hibridação in situ foi realizada segundo Yang et al. (1995), com modificações (ver Capítulo 2 para maiores detalhes).

As sondas de O. moojeni foram primeiramente hibridadas em metáfases da mesma espécie com o objetivo de tentar identificar cada pico gerado pela citometria. A identificação dos picos foi feita com base no padrão de bandas das metáfases fotografadas em DAPI, pela montagem dos cariótipos e pela sua posição no cariótipo de fluxo.

Depois de identificados, cada pico foi denominado pelo número do par cromossômico correspondente. Para facilitar a comparação, os números cromossômicos são antecedidos pela primeira letra do gênero e as duas primeiras letras da espécie (exemplo: OMO 1, OMO 2, OMO Xa, referem-se, respectivamente, aos cromossomos 1, 2 e Xa de O. moojeni).

Para as hibridações, sete espécies (incluindo O. moojeni) foram utilizadas (Tabela 4.1).

As metáfases de O. fornesi, O. microtis, O. moojeni, O. nigripes, 0. rupestris e Oligoryzomys sp. 2 foram obtidas a partir de cultura celular, segundo 
Freshney (1986), e as de O. flavescens, de medula óssea e baço, segundo Ford e Hamerton (1956).

Primeiramente, serão apresentados os resultados da citometria de fluxo de O. moojeni. Em seguida, serão mostrados os resultados das hibridações das sondas de O. moojeni nas outras espécies (Tabela 4.2). O padrão de hibridação foi indicado ao lado dos padrões de bandas $G$ de cada espécie, exceto para $O$. flavescens, cujas hibridações só foram realizadas com as sondas OMO Xa e OMO Xb.

Devido ao elevado número de sondas e enorme quantidade de imagens, apenas as principais figuras serão apresentadas.

Tabela 4.1 - Relação das espécies de Oligoryzomys estudadas no presente capítulo, com número de laboratório ou número de tombo no MZUSP (quando disponível), número diplóide $(2 n)$, número fundamental (NF), sexo, procedência e coordenadas.

\begin{tabular}{|c|c|c|c|c|c|c|}
\hline Espécie & Código & $2 n$ & NF & Sexo & Procedência & Coordenadas \\
\hline O. flavescens & ROD 21 & 66 & $66^{*}$ & $M$ & $\begin{array}{l}\text { Floresta Nac. } \\
\text { Ipanema, SP }\end{array}$ & $23^{\circ} 25^{\prime} \mathrm{S} ; 47^{\circ} 35^{\prime} \mathrm{O}$ \\
\hline O. fornesi & CIT 1477 & 62 & 64 & $M$ & Peixe, TO & $12^{\circ} 01^{\prime} \mathrm{S} ; 48^{\circ} 32^{\prime} \mathrm{O}$ \\
\hline O. microtis & $\begin{array}{l}\text { MZUSP } \\
29534\end{array}$ & 64 & 64 & $M$ & Aripuanã, MT & $10^{\circ} 10^{\prime} \mathrm{S} ; 59^{\circ} 27^{\prime} \mathrm{O}$ \\
\hline O. moojeni & CIT 2040 & 70 & 72 & $\bar{F}$ & Minaçu, GO & $13^{\circ} 55^{\prime} \mathrm{S} ; 48^{\circ} 22^{\prime} \mathrm{O}$ \\
\hline O. nigripes & $\mathrm{BIO} 797^{\mathrm{a}}$ & 62 & 81 & $\mathrm{M}$ & $\begin{array}{l}\text { Fazenda } \\
\text { Intervales, SP }\end{array}$ & $24^{\circ} 12^{\prime} \mathrm{S} ; 48^{\circ} 30^{\prime} \mathrm{O}$ \\
\hline O. rupestris & $\mathrm{BIO} 899^{\mathrm{b}}$ & 46 & 52 & $\mathrm{~F}$ & $\begin{array}{l}\text { Pico das } \\
\text { Almas, BA }\end{array}$ & $13^{\circ} 33^{\prime} \mathrm{S} ; 4^{\circ} 56^{\prime} \mathrm{O}$ \\
\hline Oligoryzomys sp. 2 & $\mathrm{BIO} 813^{\mathrm{b}}$ & 44 & 52 & $\mathrm{M}$ & $\begin{array}{l}\text { Serra do Cipó, } \\
\text { MG }\end{array}$ & $19^{\circ} 18^{\prime} \mathrm{S} ; 4^{\circ} 35^{\prime} \mathrm{O}$ \\
\hline
\end{tabular}

*Exemplar possui dois cromossomos supernumerários (Bs) e o NF não inclui esses cromossomos, por serem puntiformes; ${ }^{a}$ Exemplar analisado em Silva (1994); ${ }^{b}$ Exemplares analisados em Silva e Yonenaga-Yassuda (1997).

\subsection{Resultados}

\subsubsection{Citometria de fluxo de Oligoryzomys moojeni $(2 n=70, N F=72)$}

O cariótipo de O. moojeni, conforme descrito no Capítulo 3 (Figura 3.13), é composto por 32 pares acrocêntricos com variação gradual de tamanho (sendo que o par 1 é o maior do complemento) e dois pares de cromossomos com dois 
braços (pares 33 e 34). Há duas formas para o cromossomo X: um é submetacêntrico (Xa) e o outro, subtelocêntrico (Xb).

Foram registrados e isolados 30 picos a partir do cariótipo de fluxo de $O$. moojeni (Figura 4.1), dos quais 23 apresentaram sondas de cromossomos únicos (21 autossomos e os dois cromossomos $X$ heteromórficos - Xa e Xb), quatro picos apresentaram sondas contendo dois pares autossômicos cada e três picos, sondas com três ou quatro pares.

Foram identificados os picos correspondentes aos cromossomos X (Xa e $\mathrm{Xb}$ ) e os picos únicos correspondentes aos cromossomos OMO 1, 2, 3, 4, 5, 6, 7, $8,11,12,13,16,17,25,26,27,28,29,30,33$ e 34. Também foi possível a identificação de um dos picos duplos, que corresponde aos pares OMO 9 e 10 . Os picos restantes não puderam ser identificados, pois representam mais de um par cromossômico, que não foram separados pela citometria, devido à equivalência de tamanho.

As sondas OMO $\mathrm{Xa}$ e OMO $\mathrm{Xb}$ marcaram ambos os cromossomos $\mathrm{X}$ inteiros da fêmea e, no macho, o cromossomo $X$ inteiro e a região proximal do $Y$.

\subsubsection{Pintura cromossômica com as sondas OMO Xa e Xb de O. moojeni em $O$. flavescens $(2 n=66, N F=66)$}

Para O. flavescens, somente as sondas correspondentes ao $\mathrm{X}$ foram hibridadas, pois a hibridação in situ com sondas cromossômicas não se mostrou satisfatória em material de medula/baço. Foram observadas marcações no cromossomo $\mathrm{X}$ e no braço curto do cromossomo $\mathrm{Y}$.

\subsubsection{Pintura cromossômica com sondas de 0 . moojeni em 0 . fornesi $(2 n=62$, $N F=64)$}

As sondas cromossômicas correspondentes aos picos identificados foram hibridadas em metáfases de $O$. fornesi e marcaram 31 segmentos no total, sendo 29 segmentos autossômicos (Tabela 4.2, Figura 4.2).

Catorze sondas pintaram cromossomos inteiros: OMO 1, OMO 2, OMO 3, OMO 7, OMO 11, OMO 12, OMO 16, OMO 17, OMO 25, OMO 26, OMO 27 , OMO 28, OMO 29 e OMO 34 (Figura 4.3). 
Cinco sondas hibridaram mais de um par cromossômico: OMO 4, OMO 5 , OMO 6, OMO 13 e OMO 33 (Figura 4.4) e duas sondas (OMO 8 e OMO 30) marcaram braços cromossômicos inteiros. A sonda dupla, correspondente aos pares OMO 9 e 10, hibridou em um par acrocêntrico (OFO 9) e na região distal do par OFO 6 (Figura 4.4).

Finalmente, $\mathrm{OMO} \mathrm{Xb}$ marcou o cromossomo $\mathrm{X}$ inteiro e o braço curto do $\mathrm{Y}$ (Figura 4.4).

\subsubsection{Pintura cromossômica com sondas de O. moojeni em O. microtis $(2 n=64$, $N F=64)$}

No complemento de 0 . microtis, 32 regiões de homologia foram encontradas e destas, 30 regiões são autossômicas (Tabela 4.2, Figura 4.5).

Das 23 sondas utilizadas, 16 mostraram-se íntegras, marcando cromossomos inteiros: OMO 1, OMO 2, OMO 3, OMO 7, OMO 8, OMO 11, OMO 12, OMO 16, OMO 17, OMO 25, OMO 26, OMO 27, OMO 28, OMO 29, OMO 30 e OMO 34 (Figura 4.6).

Cinco sondas hibridaram mais de um par cromossômico: OMO 4, OMO 5 , OMO 6, OMO 13 e OMO 33 (Figura 4.7). A sonda correspondente aos pares OMO 9 e 10, marcou um par acrocêntrico médio (OMI 6) e a região distal do par OMI 4 (dado não mostrado).

OMO Xb hibridou o cromossomo OMI X e a região centromérica de OMI $\mathrm{Y}$, estendendo ao braço curto (Figura 4.8).

\subsubsection{Pintura cromossômica com sondas de 0 . moojeni em 0 . nigripes $(2 n=62$, $N F=81$ )}

Trinta e três segmentos homólogos foram encontrados após as hibridações das sondas de $O$. moojeni em metáfases de $O$. nigripes, sendo 31 correspondentes a regiões autossômicas (Tabela 4.2, Figura 4.9).

No total, 13 sondas hibridaram cromossomos inteiros de $O$. nigripes: OMO 2, OMO 3, OMO 7, OMO 11, OMO 12, OMO 17, OMO 25, OMO 26, OMO 27, OMO 28, OMO 29, OMO 33 e OMO 34 (Figura 4.10).

Cinco sondas hibridaram mais de um par cromossômico: OMO 1, OMO 4 , OMO 5, OMO 6 e OMO 13 (Figura 4.11). 
Três sondas marcaram exclusivamente braços cromossômicos inteiros no complemento de O. nigripes: OMO 16, OMO 8 e OMO 30 (Figura 4.12).

A sonda correspondente ao cromossomo $\mathrm{Xb}$ de OMO marcou $\mathrm{O}$ cromossomo $\mathrm{X}$ inteiro e o braço longo do $\mathrm{Y}$ de ONI (Figura 4.13).

\subsubsection{Pintura cromossômica com sondas de 0 . moojeni em 0 . rupestris $(2 n=46$, $N F=52)$}

As sondas cromossomo-específicas de O. moojeni foram hibridadas em metáfases de $O$. rupestris (ORU) e 33 segmentos homólogos foram observados, sendo 32 regiões autossômicas (Tabela 4.2, Figura 4.14).

As sondas OMO 8, OMO 11, OMO 12, OMO 17, OMO 29, OMO 30 e OMO 33 marcaram cromossomos inteiros (Figura 4.15).

Quatro sondas marcaram mais de um par cromossômico em ORU: OMO 6, OMO 9/10, OMO 13 e OMO 28.

Oito sondas hibridaram o maior par cromossômico de O. rupestris (ORU 1), formando 11 segmentos neste cromossomo: OMO 3, OMO 4, OMO 5, OMO 13, OMO 16, OMO 25, OMO 26 e OMO 34 (Figura 4.16). A sonda OMO 4 marcou três regiões distintas no par ORU 1 enquanto que OMO 5, marcou duas regiões (Figura 4.16).

O par ORU 2 foi hibridado por quatro sondas distintas: OMO 2, OMO 6, OMO 7 e OMO 27 (Figura 4.17). O par ORU 3, foi pintado pelas sondas OMO 1, OMO 9/10 e OMO 28 (Figura 4.18).

Como a amostra de $O$. rupestris era composta somente de fêmeas, as sondas OMO Xa e OMO Xb, marcaram ambos os cromossomos ORU $X$ inteiros (dado não mostrado).

\subsubsection{Pintura cromossômica com sondas de O. moojeni em Oligoryzomys sp. 2 $(2 n=44, N F=52)$}

As hibridações das sondas cromossomo-específicas de 0 . moojeni em Oligoryzomys sp. 2 mostraram 34 regiões de homologia, sendo 32 correspondentes a regiões autossômicas (Tabela 4.2, Figura 4.19).

Sete sondas hibridaram cromossomos inteiros, exibindo exatamente 0 mesmo padrão de marcação encontrado em O. rupestris: OMO 8, OMO 11, OMO 
12, OMO 17, OMO 29, OMO 30 e OMO 33 e quatro sondas marcaram mais de um par cromossômico: OMO 6, OMO 9/10, OMO 13 e OMO 28 (dados não mostrados).

Nove sondas hibridaram o par OSP 1 (o maior par do complemento): OMO 3, OMO 4, OMO 5, OMO 6, OMO 13, OMO 16, OMO 25, OMO 26 e OMO 34, de modo que 12 segmentos foram observados neste cromossomo (Figura 4.20).

O padrão de hibridação observado nos pares OSP 2 e OSP 3, foi o mesmo observado em ORU 2 e ORU 3, respectivamente, de modo que a mesma figura está sendo usada para ilustrar ambas as espécies: quatro sondas pintaram regiões diferentes de OSP 2 (OMO 2, OMO 6, OMO 7 e OMO 27) (ver Figura 4.17). Além disso, as sondas OMO 9/10, OMO 28 e OMO 1 marcaram o par OSP 3 (Figura 4.18).

Tanto a sonda OMO Xa quanto $\mathrm{Xb}$, hibridaram os cromossomos OSP $\mathrm{X} \mathrm{e}$ a região pericentromérica em OSP Y. 
Tabela 4.2 - Segmentos cromossômicos homólogos detectados entre as espécies $O$. fornesi (OFO), O. microtis (OMI), O. nigripes (ONI), $O$. rupestris (ORU) e Oligoryzomys sp. 2 (OSP) através da hibridação das sondas de $O$. moojeni (OMO). Tanto os segmentos autossômicos quanto os sexuais foram considerados.

\begin{tabular}{|c|c|c|c|c|c|}
\hline $\begin{array}{c}\text { Sondas } \\
\text { utilizadas }\end{array}$ & $\begin{array}{c}\text { OFO } \\
(2 n=62)\end{array}$ & $\begin{array}{c}\text { OMI } \\
(2 n=64)\end{array}$ & $\begin{array}{c}\text { ONI } \\
(2 n=62)\end{array}$ & $\begin{array}{c}\text { ORU } \\
(2 n=46)\end{array}$ & $\begin{array}{c}\text { OSP } \\
(2 n=44)\end{array}$ \\
\hline OMO 1 & 1 & 1 & $\begin{array}{l}1 \\
28\end{array}$ & $3 q$ & $3 q$ \\
\hline OMO 2 & 2 & 2 & 2 & $2 q$ (distal) & 2q (distal) \\
\hline OMO 3 & 3 & 3 & 3 & 1q (distal) & 1q (distal) \\
\hline OMO 4 & $\begin{array}{l}5 q \text { (proximal) } \\
17\end{array}$ & $\begin{array}{l}5 \mathrm{q} \text { (proximal) } \\
17 \\
26\end{array}$ & $\begin{array}{l}7 p \\
13 q \text { (proximal) } \\
17\end{array}$ & $\begin{array}{l}\text { 1q (3 } \\
\text { segmentos } \\
\text { intersticiais) }\end{array}$ & $\begin{array}{l}\text { 1q ( } 3 \text { segmentos } \\
\text { intersticiais) }\end{array}$ \\
\hline OMO 5 & $\begin{array}{l}5 q \text { (distal) } \\
18\end{array}$ & $\begin{array}{l}5 q \text { (distal) } \\
18\end{array}$ & $\begin{array}{l}13 q \text { (distal) } \\
16\end{array}$ & $\begin{array}{l}1 \mathrm{q}(2 \\
\text { segmentos } \\
\text { intersticiais) }\end{array}$ & $\begin{array}{l}\text { 1q (2 segmentos } \\
\text { intersticiais) }\end{array}$ \\
\hline OMO 6 & $\begin{array}{l}22 \\
23\end{array}$ & $\begin{array}{l}22 \\
23\end{array}$ & $\begin{array}{l}4 \\
25\end{array}$ & $\begin{array}{l}2 q \text { (proximal) } \\
19 \\
20\end{array}$ & $\begin{array}{l}1 p \\
2 q \text { (proximal) } \\
19\end{array}$ \\
\hline OMO 7 & 8 & 7 & 15 & $2 q$ (intersticial) & 2q (intersticial) \\
\hline OMO 8 & $29 q$ & 9 & $6 q$ & 4 & 4 \\
\hline OMO 9,10 & $\begin{array}{l}6 q \text { (distal) } \\
9\end{array}$ & $\begin{array}{l}4 q \text { (distal) } \\
6\end{array}$ & $\begin{array}{l}5 p \\
12 q \text { (distal) } \\
14\end{array}$ & $\begin{array}{l}3 p \\
12 \\
21\end{array}$ & $\begin{array}{l}3 p \\
12 \\
20\end{array}$ \\
\hline OMO 11 & 10 & 10 & 18 & 5 & 5 \\
\hline OMO 12 & 11 & 11 & 19 & 6 & 6 \\
\hline OMO 13 & $\begin{array}{l}19 \\
20 \\
21\end{array}$ & $\begin{array}{l}19 \\
20 \\
21\end{array}$ & $\begin{array}{l}22 \\
23 \\
24\end{array}$ & $\begin{array}{l}1 q \text { (intersticial) } \\
13 \\
14\end{array}$ & $\begin{array}{l}1 \mathrm{q} \text { (intersticial) } \\
13 \\
14\end{array}$ \\
\hline OMO 16 & 12 & 12 & $9 q$ & 1q (proximal) & 1q (proximal) \\
\hline OMO 17 & 13 & 13 & 21 & 9 & 9 \\
\hline OMO 25 & 14 & 14 & 20 & 1q (proximal) & 1q (proximal) \\
\hline OMO 26 & 15 & 15 & 26 & 1q (proximal) & 1q (proximal) \\
\hline OMO 27 & 16 & 16 & 27 & $2 p$ & $2 p$ \\
\hline OMO 28 & 24 & 24 & 29 & $\begin{array}{l}3 q \text { (proximal) } \\
17\end{array}$ & $\begin{array}{l}3 q \text { (proximal) } \\
17\end{array}$ \\
\hline OMO 29 & 25 & 25 & 30 & 15 & 15 \\
\hline OMO 30 & $29 p$ & 27 & $6 p$ & 16 & 16 \\
\hline OMO 33 & $\begin{array}{l}27 \\
28\end{array}$ & $\begin{array}{l}29 \\
30\end{array}$ & 10 & 18 & 18 \\
\hline OMO 34 & 26 & 28 & 11 & 1q (intersticial) & 1q (intersticial) \\
\hline OMO Xa e Xb & $\begin{array}{l}X \\
Y p \\
\end{array}$ & $\begin{array}{l}X \\
Y p \\
\end{array}$ & $\begin{array}{l}\mathrm{X} \\
\mathrm{Yq} \\
\end{array}$ & $\mathrm{X}$ & $\begin{array}{l}\mathrm{X} \\
\mathrm{Yq} \text { (proximal) }\end{array}$ \\
\hline Total & 31 segmentos & 32 segmentos & 33 segmentos & 33 segmentos & 34 segmentos \\
\hline
\end{tabular}




\subsection{Discussão}

O presente trabalho é inédito na literatura, pois aborda a evolução cromossômica através de sondas espécie-específicas de Oligoryzomys. Embora a pintura cromossômica seja uma técnica cada vez mais empregada nos estudos citogenéticos, esses dados ainda são escassos para os roedores Neotropicais.

$\mathrm{O}$ trabalho pioneiro de Zoo-FISH em roedores sigmodontinos foi realizado por Fagundes et al. (1997). Foram realizadas comparações em exemplares de Akodon cursor com $2 \mathrm{n}=14$ e $2 \mathrm{n}=15$ e A. montensis com $2 \mathrm{n}=24$, a partir da sonda do par 1 submetacêntrico de $A$. cursor (ACU) com $2 n=16$. Foi possível inferir homologia desse cromossomo com um dos braços do maior metacêntrico (ACU $1+3$ ) de exemplares com $2 n=14$ e 15 e com outros pares autossômicos de $A$. montensis.

Mais recentemente, Ventura et al. (2009) compararam os cariótipos de quatro espécies de Akodon e os resultados revelaram homologia completa entre os complementos de Akodon sp. n. $(2 \mathrm{n}=10)$, A. cursor $(2 \mathrm{n}=15)$, A. montensis $(2 n=24)$ e $A$. paranaensis $(2 n=44)$, evidenciando inúmeros rearranjos cromossômicos entre as espécies.

Nagamachi et al. (2013) estabeleceram padrões de homologias entre duas espécies da tribo Oryzomyini. A partir de sondas cromossômicas de Hylaeamys megacephalus $(2 n=54)$, foi estabelecido o mapa de homologias cromossômicas entre esta espécie e Cerradomys langguthi $(2 n=46)$ e o resultado mostrou a presença de inúmeros rearranjos cromossômicos.

A pintura cromossômica comparativa (Zoo-FISH) realizada neste trabalho a partir de sondas de 0 . moojeni $(2 n=70)$ nos complementos de O. fornesi $(2 n=62)$, O. microtis $(2 n=64), O$. nigripes $(2 n=62)$, O. rupestris $(2 n=46)$ e Oligoryzomys sp. $2(2 n=44)$, mostrou uma extensa reorganização genômica entre essas espécies.

No total, considerando os autossomos e os cromossomos sexuais, a hibridação das sondas de 0 . moojeni mostrou 31 regiões de homologia em $O$. fornesi, $32 \mathrm{em} 0$. microtis, $33 \mathrm{em}$ O. nigripes e 0 . rupestris e 34 regiões em Oligoryzomys sp. 2 (Tabela 4.2). 


\subsubsection{Sondas que permaneceram íntegras}

Em todas as espécies estudadas, a partir das 23 sondas cromossômicas obtidas, 14 produziram um único sinal de hibridação: OMO 2, OMO 3, OMO 7, OMO 8, OMO 11, OMO 12, OMO 16, OMO 17, OMO 25, OMO 26, OMO 27 , OMO 29, OMO 30 e OMO 34, mostrando que a sintenia desses cromossomos é conservada (Tabela 4.2).

Dessas 14 sondas, apenas quatro (OMO 11, OMO 12, OMO 17 e OMO 29) permaneceram intactas, ou seja, marcaram cromossomos inteiros e não apenas regiões cromossômicas, de modo que as sondas restantes encontram-se rearranjadas no genoma das outras espécies estudadas neste capítulo.

A discussão que se segue correlaciona os rearranjos detectados no presente trabalho a uma perspectiva evolutiva e, para tanto, foi utilizada como base a filogenia de Agrellos et al. (2012), que é a mais recente e inclui o maior número de espécies do gênero Oligoryzomys (Figura 4.21).

\subsubsection{Sondas que se mostraram rearranjadas e os mecanismos responsáveis por esses rearranjos}

Três sondas (OMO 1, OMO 28 e OMO 33) marcaram mais de um segmento em algumas espécies, mas permaneceram íntegras em outras (Tabela 4.2).

A sonda OMO 1 marcou somente um segmento em $O$. fornesi, O. microtis, O. rupestris e Oligoryzomys sp. 2. Entretanto, esta mesma sonda marcou dois segmentos em $O$. nigripes e, portanto, pode-se inferir, com base na filogenia da Figura 4.21, que ocorreu um evento de fissão nesse par.

A sonda OMO 28, que se apresentou íntegra em $O$. fornesi, O. microtis e O. nigripes, marcou duas regiões em O. rupestris e Oligoryzomys sp. 2, indicando um evento de fissão. Além disso, esta mesma sonda sofreu posterior fusão em tandem com os pares OMO 9/10 e OMO 1, compondo o par 3 de ORU e OSP (Tabela 4.2, Figura 4.18).

A sonda OMO 33, que corresponde a um par metacêntrico permaneceu íntegra em $O$. nigripes, pois marcou um par metacêntrico de mesmo tamanho. Contudo, em O. fornesi e O. microtis, a hibridação ocorreu envolvendo dois 
pares acrocêntricos pequenos, revelando a ocorrência de fusão cêntrica em $O$. nigripes e O. moojeni, considerando a filogenia apresentada na Figura 4.21. Esta mesma sonda marcou um par acrocêntrico em 0 . rupestris e Oligoryzomys sp. 2, mostrando a ocorrência de fusão em tandem ou, alternativamente, fusão cêntrica seguida de inversão pericêntrica, uma vez que estamos considerando O. microtis como irmã de todas as outras espécies de Oligoryzomys, de acordo com Agrellos et al. (2012) (Figura 4.21).

Quatro sondas mostraram-se rearranjadas, marcando mais de um segmento, nas cinco espécies estudadas (Tabela 4.2): OMO 4, OMO 5, OMO 6 e OMO 13.

A sonda OMO 4, marca três regiões em $O$. microtis, $O$. nigripes, $O$. rupestris e Oligoryzomys sp. 2 e duas regiões em $O$. fornesi. Considerando $O$. microtis como a espécie que divergiu mais cedo na filogenia do gênero, sugerese que, em $O$. fornesi, ocorreu um evento de fusão em tandem e em O. moojeni, no mínimo dois eventos (Figura 4.21).

Com relação à sonda OMO 5 , esta marcou dois segmentos em todas as espécies, indicando que houve fusão em tandem em 0 . moojeni, gerando o par OMO 5 (Figura 4.21).

Entretanto, a hipótese de que fusões em tandem geraram os pares OMO 4 e OMO 5 em O. moojeni só seria viável se um evento anterior de fissão no par 5 de O. microtis (que é marcado pelas sondas OMO 4 e OMO 5) tivesse ocorrido, mostrando que rearranjos complexos estão envolvidos na diferenciação cariotípica de Oligoryzomys.

A sonda OMO 6 hibrida dois pares acrocêntricos em $O$. fornesi e $O$. microtis, indicando a ocorrência de fusão em tandem desses pares em $O$. moojeni, que levou à formação do par OMO 6. Em O. nigripes, esta mesma sonda hibrida um par acrocêntrico e outro metacêntrico indicando também a ocorrência de inversão pericêntrica (Figura 4.21).

Já a sonda OMO 13, hibrida três regiões em todas as espécies, indicando no mínimo dois eventos de fusão em tandem em O. moojeni (Figura 4.21).

De acordo com King (1993), as fusões em tandem podem ser formadas pela fusão direta de centrômero/telômero e telômero/telômero, sem nenhuma perda cromossômica. Esse tipo de rearranjo ocorre principalmente em linhagens 
de espécies cujos cariótipos são compostos predominantemente por cromossomos acrocêntricos, como é o caso de Oligoryzomys.

Dois cromossomos acrocêntricos podem se fundir em tandem, produzindo um grande cromossomo com dois centrômeros. Entretanto, sabe-se que cromossomos dicêntricos são instáveis e propensos a quebras, devido às forças geradas pelos dois centrômeros ativos, que puxam o cromossomo para polos opostos da célula (CHOO, 1997). Para que esse rearranjo seja viável, uma das três condições deve ocorrer: (i) caso os centrômeros estejam fisicamente próximos, eles podem funcionar como uma estrutura monocêntrica; (ii) um dos centrômeros necessita ser eliminado por deleção; ou (iii) um dos centrômeros é inativado. De acordo com Choo (1997), a inativação de um dos centrômeros parece ser o mecanismo mais frequente que torna as fusões em tandem viáveis.

Ao contrário das fusões, as fissões que ocorrem ao longo do cromossomo (aquelas que não envolvem o centrômero), requerem ganho/ativação de um centrômero latente. A existência de centrômeros latentes foi postulada como um possível mecanismo de evolução cromossômica e sua ativação seria condicionada a dois mecanismos: mutações no DNA centromérico latente ou efeitos epigenéticos (CHOO, 1997).

Já no caso das fissões cêntricas (quebra na região centromérica de um cromossomo de dois braços), o centrômero se dividiria em duas partes funcionais dando origem a dois cromossomos acrocêntricos (CHOO, 1997).

A pintura cromossômica comparativa deste trabalho mostrou que tanto eventos de fissão quanto de fusão podem ter ocorrido ao longo da evolução cromossômica de Oligoryzomys. Entretanto, as hibridações com sondas teloméricas mostraram marcações exclusivas na região dos telômeros (Capítulo 3), sugerindo que, possivelmente, as regiões correspondentes ao telômero dos cromossomos rearranjados devam ter se perdido durante as inúmeras quebras cromossômicas (RUIZ-HERRERA et al., 2008).

\subsubsection{Associações específicas encontradas a partir da pintura cromossômica e a redução do número diplóide em 0 . rupestris e Oligoryzomys sp. 2}

As sondas OMO 4 e OMO 5 mostram a mesma associação sintênica em O. fornesi (OFO 5), O. microtis (OMI 5), O. nigripes (ONI 13), O. rupestris (ORU 
1q) e Oligoryzomys sp. 2 (OSP 1q) (Tabela 4.2; Figura 4.22); contudo, essa sintenia não se manteve em $O$. moojeni.

Enquanto em O. microtis, O. rupestris e Oligoryzomys sp. 2, as sondas OMO 8 e OMO 30 hibridaram em pares acrocêntricos, nas espécies $O$. fornesi e O. nigripes essas duas sondas marcam braços diferentes de um mesmo par cromossômico submetacêntrico: OFO 29 e ONI 4, respectivamente (Figura 4.23), sugerindo que rearranjos Robertsonianos devem ter ocorrido independentemente na história evolutiva de Oligoryzomys (Figura 4.21).

As fusões Robertsonianas são o tipo mais comum de rearranjo estrutural relatado em mamíferos (KING, 1993; ROMANENKO; VOLOBOUEV, 2012). Esse tipo de rearranjo envolve fusão de dois cromossomos acrocêntricos, resultando na formação de um cromossomo de dois braços, formando polimorfismos cromossômicos balanceados, na maioria dos casos (KING, 1993).

A hibridação das sondas cromossomo-específicas de O. moojeni mostrou praticamente o mesmo padrão entre as espécies $O$. rupestris e Oligoryzomys sp. 2, confirmando que ORU e OSP são espécies relacionadas, conforme descrito por Silva e Yonenaga-Yassuda (1997). O par 1 de ORU foi hibridado por oito sondas cromossômicas de OMO enquanto que nove sondas hibridaram o par 1 de OSP (Figuras 4.16 e 4.20). Já o par 2 de ORU e OSP, foi hibridado por quatro sondas (Figura 4.17) e o par 3 por três sondas (Figura 4.18), mostrando que eventos de fusão em tandem ocorreram durante a diferenciação cariotípica dessas espécies, proporcionando os menores números diplóides já descritos para o gênero (Figura 4.24).

Silva e Yonenaga-Yassuda (1997) realizaram medições cromossômicas nessas duas espécies e constataram que os três maiores pares representam aproximadamente $43 \%$ de todo o lote haplóide do cariótipo de ORU e OSP. De fato, o cariótipo dessas duas espécies é composto por macro e microcromossomos, diferentemente do padrão encontrado nas outras espécies de Oligoryzomys e até mesmo na maioria dos roedores orizominos. A pintura cromossômica do presente trabalho mostrou que rearranjos complexos estão envolvidos na diferenciação cariotípica de ORU e OSP com relação às outras espécies do gênero.

As hibridações em ORU e OSP indicam também a ocorrência de perda, inativação ou reposicionamento de centrômero, uma vez que a pintura 
cromossômica mostrou que eventos de fusão em tandem geraram os três maiores pares do cariótipo de O. rupestris e Oligoryzomys sp. 2 (Figura 4.24).

Silva e Yonenaga-Yassuda (1997) foram as primeiras a descreverem o cariótipo de $O$. rupestris e Oligoryzomys sp. 2. Através de técnicas citogenéticas clássicas (bandamento cromossômico, coloração das regiões organizadoras de nucléolo) e FISH com sondas teloméricas, as autoras evidenciaram que a diferença no número diplóide de ambas as espécies se deu por fusão cêntrica. No presente trabalho, a sonda OMO 6 marcou três regiões na espécie $O$. rupestris: ORU2q, ORU 19 e ORU 20 e três regiões em Oligoryzomys sp. 2: OSP $1 p$, OSP $2 q$ e OSP 19, corroborando a hipótese de que uma fusão Robertsoniana foi o evento responsável pela diferença dos números diplóides $2 n=44$ e $2 n=46$ (Figura 4.25).

$\mathrm{Na}$ literatura, alguns autores têm relacionado ambas as espécies como um mesmo táxon (O. rupestris) (BONVICINO; GEISE, 2006; PARESQUE, 2010), porém, as prerrogativas iniciais permanecem bastante consistentes, dado que $O$. rupestris e Oligoryzomys sp. 2 possuem distribuição disjunta (separadas por aproximadamente $800 \mathrm{~km}$ ao longo das montanhas do Espinhaço) e diferenças morfológicas (DE VIVO, comunicação pessoal; SILVA; YONENAGA-YASSUDA, 1997).

\subsubsection{Homologia do cromossomo $X$}

As sondas correspondentes aos dois cromossomos $\mathrm{X}$ de $\mathrm{O}$. moojeni marcou o cromossomo $X$ inteiro de todas as espécies estudadas (O. flavescens, O. fornesi, O. microtis, O. nigripes e Oligoryzomys sp. 2), corroborando o padrão observado de duas bandas escuras intersticiais gerados pela banda $G$ nestes cromossomos (Capítulo 3) e o conhecimento de que o cromossomo $\mathrm{X}$ de mamíferos é conservado.

Além disso, a hibridação de OMO X em O. flavescens (exemplar macho, com 2Bs) não evidenciou nenhuma marcação no cromossomo B. Alguns trabalhos utilizando sondas de cromossomos Bs mostram regiões de sintenia entre os supernumerários e os cromossomos sexuais (SILVA; YONENAGAYASSUDA, 2004). É provável que isso seja decorrente da natureza heterocromática desses cromossomos. 
Quando a sonda do cromossomo $\mathrm{X}$ de O. moojeni foi hibridada em metáfases de machos, houve marcação nos cromossomos $\mathrm{Y}$, na região não correspondente à heterocromatina constitutiva, que pode provavelmente estar relacionada à região pseudoautossômica (Figura 4.26). Caso semelhante foi descrito recentemente para outro roedor orizomino: a sonda correspondente ao cromossomo $\mathrm{X}$ de Holochilus brasiliensis mostrou homologia com o cromossomo $X$ inteiro e a região pseudoautossômica do $\mathrm{Y}$ de Pseudoryzomys simplex (MOREIRA et al., 2013).

Acosta et al. (2010) realizaram análises nos cromossomos sexuais de roedores da subfamília Arvicolinae utilizando pintura cromossômica. Os resultados revelaram que os cromossomos $\mathrm{X}$ e $\mathrm{Y}$ compartilham sequências específicas, uma vez que a sonda do cromossomo $X$ de Chionomys nivalis é homóloga à região eucromática do cromossomo $\mathrm{Y}$ de Microtus cabrerae e $M$. agrestis. Os autores sugeriram que as regiões de homologia compartilhadas entre o $\mathrm{X}$ e o $\mathrm{Y}$ podem representar a região pseudoautossômica. Entretanto, não foi possível correlacionar o comportamento sináptico/ assináptico à existência de homologia entre os cromossomos sexuais dessas espécies.

Dessa forma, os autores argumentam que a região de homologia entre $\circ \mathrm{X}$ e $\mathrm{Y}$, revelada pela pintura cromossômica, pode representar a região pseudoautossômica funcional (onde os eventos de crossing-over ocorrem) ou podem ser sequências homólogas onde não há emparelhamento, pois a existência de homologia não é uma exigência para que o emparelhamento ocorra (ACOSTA et al., 2010).

\subsubsection{Pintura cromossômica e a evolução cariotípica em Oligoryzomys}

A comparação dos padrões de bandas $G$ entre as espécies de Oligoryzomys (Capítulo 3) foi eficaz no estabelecimento de homologias apenas entre os maiores pares autossômicos e tais homologias foram, posteriormente, confirmadas pela pintura cromossômica deste capítulo.

A pintura cromossômica, por ser mais precisa, demonstrou a presença de um maior número de regiões sintênicas do que a comparação de bandas $G$ pode mostrar. Desse modo, fica clara a importância da associação entre as técnicas de citogenética clássica e molecular, para melhor caracterização dos cariótipos e 
para estudos de evolução cromossômica. Além disso, a comparação com dados de filogenia, publicados na literatura, foi importante para a correlação dos rearranjos observados.

Vários pontos puderam ser inferidos a partir dos dados de pintura cromossômica: primeiramente, a divisão das espécies com base na morfologia e tamanho do par 1, postulada por Mattevi e Andrades-Miranda (2006), não se mostrou eficiente, uma vez que o par 1 de O. rupestris e Oligoryzomys sp. 2 não é homólogo ao par 1 das outras espécies de Oligoryzomys. Além disso, observou-se que o par 1 de 0 . fornesi, O. microtis e O. moojeni corresponde ao par 1 e ao par 28 de O. nigripes.

A análise por citogenética convencional do gênero Oligoryzomys mostra que, na maioria das espécies, o cariótipo é predominantemente composto de pares acrocêntricos (ANDRADES-MIRANDA et al., 2001; ANISKIN; VOLOBOUEV, 1999; WEKSLER; BONVICINO, 2005; Capítulo 3). As hibridações mostraram que as sondas correspondentes aos pares de dois braços (OMO 33 e OMO 34) não estão conservadas nos cariótipos do gênero.

Estudos intraespecíficos em $O$. nigripes, realizados através de comparações de bandas $G$, mostraram que as variações encontradas no número fundamental são decorrentes de inversões pericêntricas nos pares 2, 3, 4 e 8 (ALMEIDA; YONENAGA-YASSUDA, 1991; PARESQUE et al., 2007). A comparação de bandas $G$ entre essa espécie e $O$. flavescens, $O$. fornesi, $O$. microtis, 0 . moojeni e 0 . stramineus, realizada no Capítulo 3 junto com os resultados de pintura cromossômica deste capítulo, corroboram estes dados e indicam que esta é a espécie que mais sofreu esse tipo de rearranjo.

Assim, poder-se-ia hipotetizar que seria mais parcimonioso que a forma homomórfica acrocêntrica encontrada nos pares 2 e 3 de 0 . nigripes $(N F=78)$ fosse uma condição ancestral, uma vez que está presente nessa forma em $O$. microtis e O. fornesi (espécies que divergiram mais cedo na filogenia), apesar de a frequência do par ONI 2 submetacêntrico ser superior na população. Paresque et al. (2007), através de estudos populacionais, sugeriram que o cariótipo primitivo de 0 . nigripes fosse $2 n=62, N F=80$ (par 2 submetacêntrico e par 3 acrocêntrico), baseados na hipótese de diferenciação dos orizominos na região dos Andes. 
Apesar de sua alta resolução, a pintura cromossômica não é eficaz na detecção de rearranjos intra-cromossômicos (como as inversões pericêntricas), pois grandes regiões de sintenia podem não reter as mesmas relações intracromossômicas (FERGUSON-SMITH; TRIFONOV, 2007). Além disso, a pintura também não é capaz de determinar a orientação de cada bloco sintênico nos cromossomos. Considerando a filogenia apresentada por Agrellos et al. (2012), teria ocorrido uma acentuada redução no número diplóide (em O. rupestris) seguida de aumento no clado composto por $O$. moojeni e $O$. utiaritensis (Figura 4.21).

Quando a filogenia de Agrellos et al. (2012) é correlacionada aos dados gerados por pintura cromossômica do presente capítulo, percebe-se que ocorreram vários eventos de fusão em tandem, uma vez que sondas únicas de O. moojeni marcaram duas ou mais regiões nas outras espécies (que divergiram mais cedo, segundo a filogenia).

No entanto, deve-se levar em consideração o fato de que nem todas as sondas de OMO foram utilizadas nos experimentos e que as relações de parentesco entre as espécies do gênero não estão resolvidas, visto que esta é a única filogenia em que $O$. moojeni aparece no clado mais derivado e, além disso, o valor de suporte nesse clado é baixo (Figuras 1.2 e 4.21 ).

Além disso, é importante que haja integração de dados morfológicos, moleculares e de citogenetica clássica e molecular para melhor caracterização das espécies e suas relações.

Os dados de Zoo-FISH podem ser usados para análises filogenéticas fazendo-se uma matriz de caracteres onde estariam contidos os rearranjos cromossômicos presentes nas diferentes espécies. Vários autores têm utilizado dados de pintura cromossômica para inferir relações filogenéticas em seus grupos de estudos (DE OLIVEIRA et al., 2002; FINOTELO et al., 2010; HASS; SBALQUEIRO; MULLER, 2008).

A pintura cromossômica no gênero Oligoryzomys mostrou que rearranjos complexos estão envolvidos na diferenciação dos genomas das espécies estudadas. Dessa forma, pode-se dizer que a evolução cromossômica em Oligoryzomys não ocorreu de forma linear (em um único sentido), de modo que houve aumento e redução do número diplóide ao longo do processo de especiação. As hibridações realizadas revelaram rearranjos do tipo inversões 
pericêntricas, Robertsonianos, fissão, fusão em tandem assim como perda, ganho, reposicionamento ou ativação/inativação de centrômero.

\subsection{Conclusões}

1) Estudos de evolução cromossômica em Oligoryzomys, a partir de pintura cromossômica comparativa, estão sendo apresentados pela primeira vez na literatura.

2) Os resultados revelaram uma complexa reorganização genômica envolvendo os cariótipos das cinco espécies estudadas, embora sequências teloméricas intersticiais não tenham sido detectadas.

3) A pintura cromossômica mostrou 31 regiões de homologia em $O$. fornesi, 32 em 0 . microtis, 33 em 0 . nigripes e 0 . rupestris e 34 regiões em Oligoryzomys sp. 2.

4) O. rupestris $(2 n=46)$ e Oligoryzomys sp. $2(2 n=44)$ são as espécies que possuem os cariótipos mais rearranjados, sendo que a fusão em tandem originou os três maiores pares no cariótipo dessas espécies.

5) Os dados de pintura cromossômica corroboram os dados prévios de que a fusão cêntrica é o evento responsável pela diferença no número diplóide de $O$. rupestris e Oligoryzomys sp. 2.

6) $O$ cromossomo $X$ de $O$. moojeni mostrou homologia entre o $X$ e $\circ \mathrm{Y}$ das outras espécies, revelando, possivelmente, a região pseudoautossômica.

7) Rearranjos complexos estão envolvidos na diferenciação cariotípica de Oligoryzomys, tais como: inversões pericêntricas, fissões, fusões em tandem, fusão cêntrica, perda/inativação, reposicionamento e ganho/ativação de centrômero. 


\section{FIGURAS}

Figura 4.1 - Cariótipo de fluxo de Oligoryzomys moojeni $(2 n=70)$.

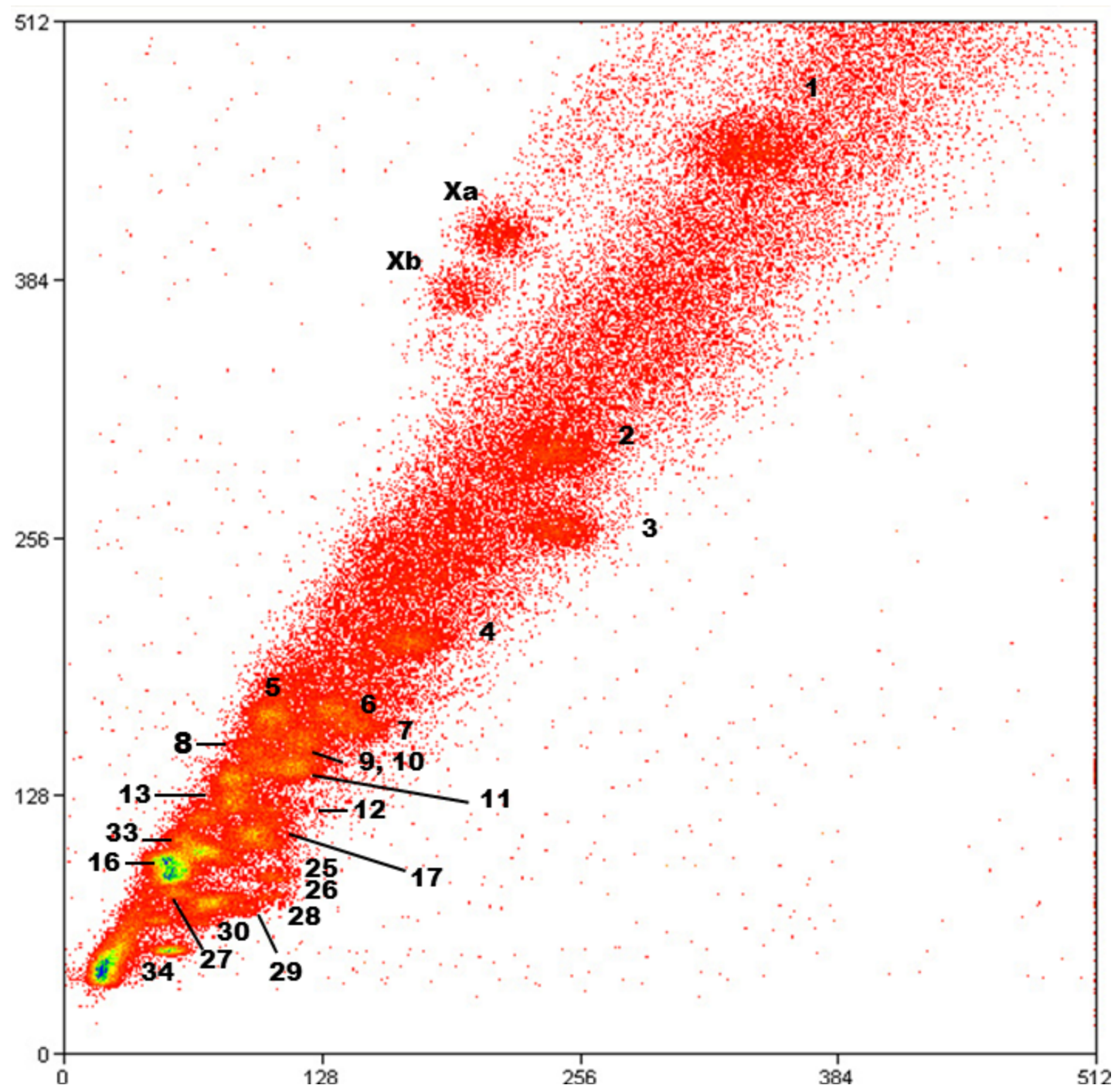

Os cromossomos foram separados de acordo com seu tamanho e proporção AT/CG e, em seguida, corados com Hoechst 33258 (ordenada) e Cromomicina A (abscissa). Os números cromossômicos foram destacados nos picos em que foram identificados. 
Figura 4.2 - Padrão de bandas $\mathrm{G}$ em $O$. fornesi $(2 \mathrm{n}=62)$.

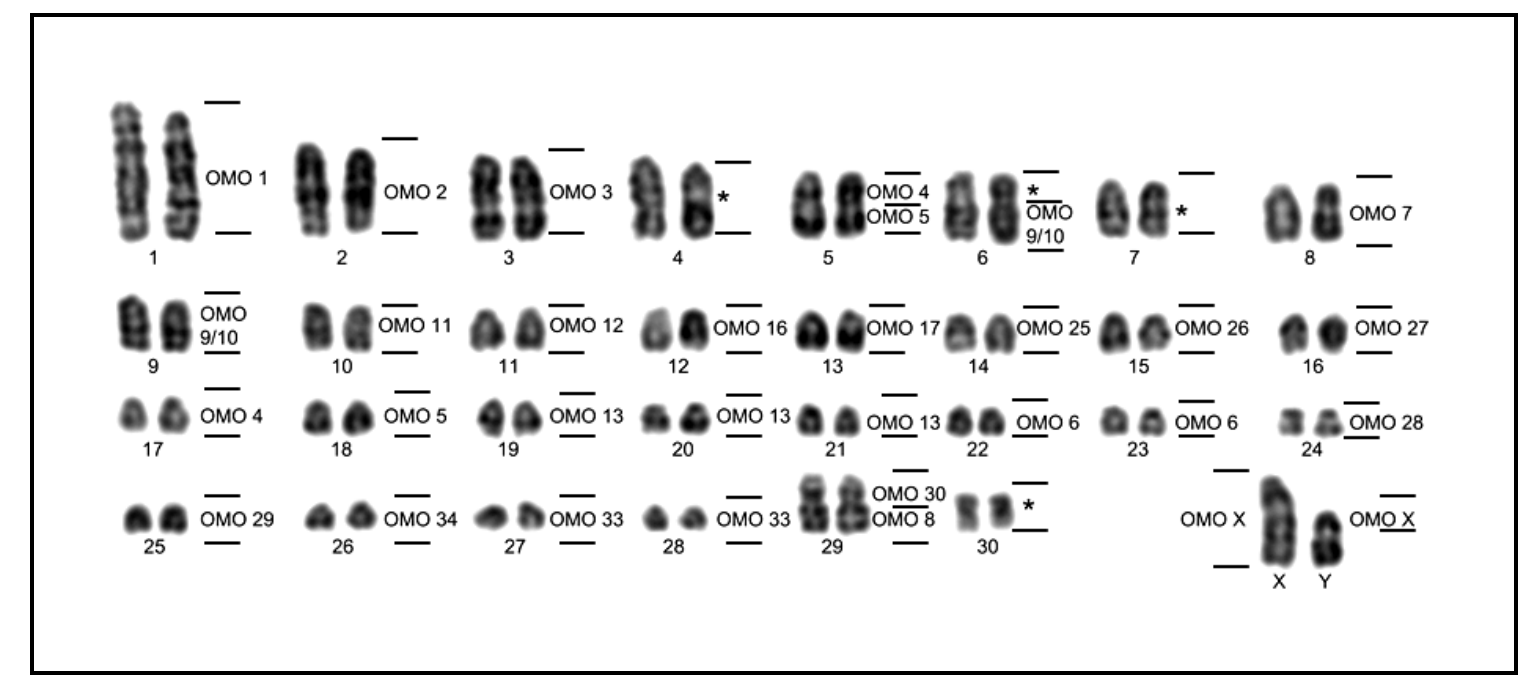

Os números das sondas de $O$. moojeni estão indicados ao lado dos respectivos cromossomos que pintaram. Asteriscos $\left({ }^{*}\right)$ indicam ausência de hibridação. 
Figura 4.3 - Algumas sondas de O. moojeni que marcam pares cromossômicos inteiros em $O$. fornesi $(2 n=62)$.

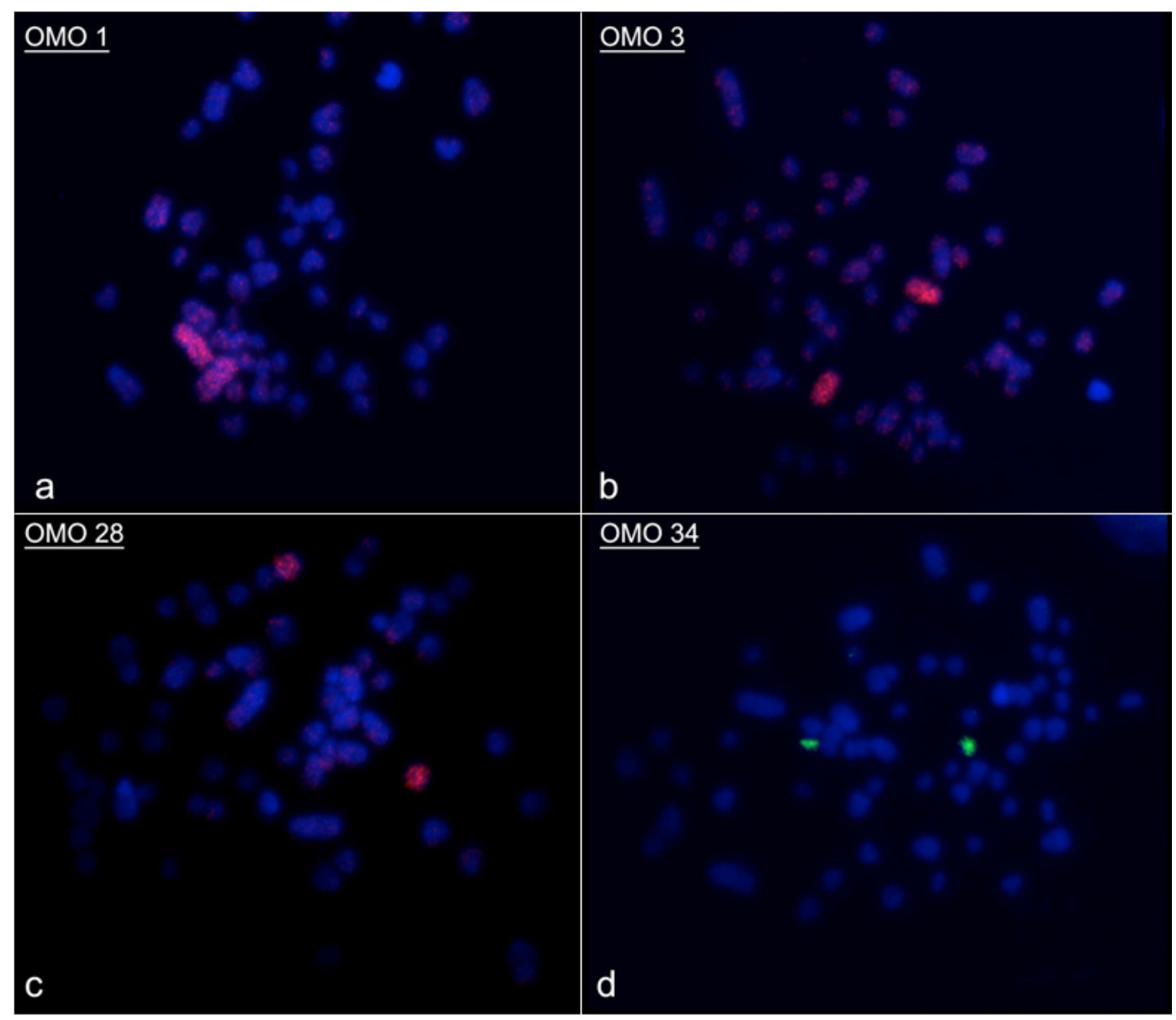

(a) OMO 1 marca o par OFO 1; (b) OMO 3 marca o par OFO 3; (c) OMO 28 marca o par OFO 24; e (d) OMO 34 marca o par OFO 26. 
Figura 4.4 - Algumas sondas de O. moojeni que marcam mais de um segmento em O. fornesi $(2 \mathrm{n}=62)$.

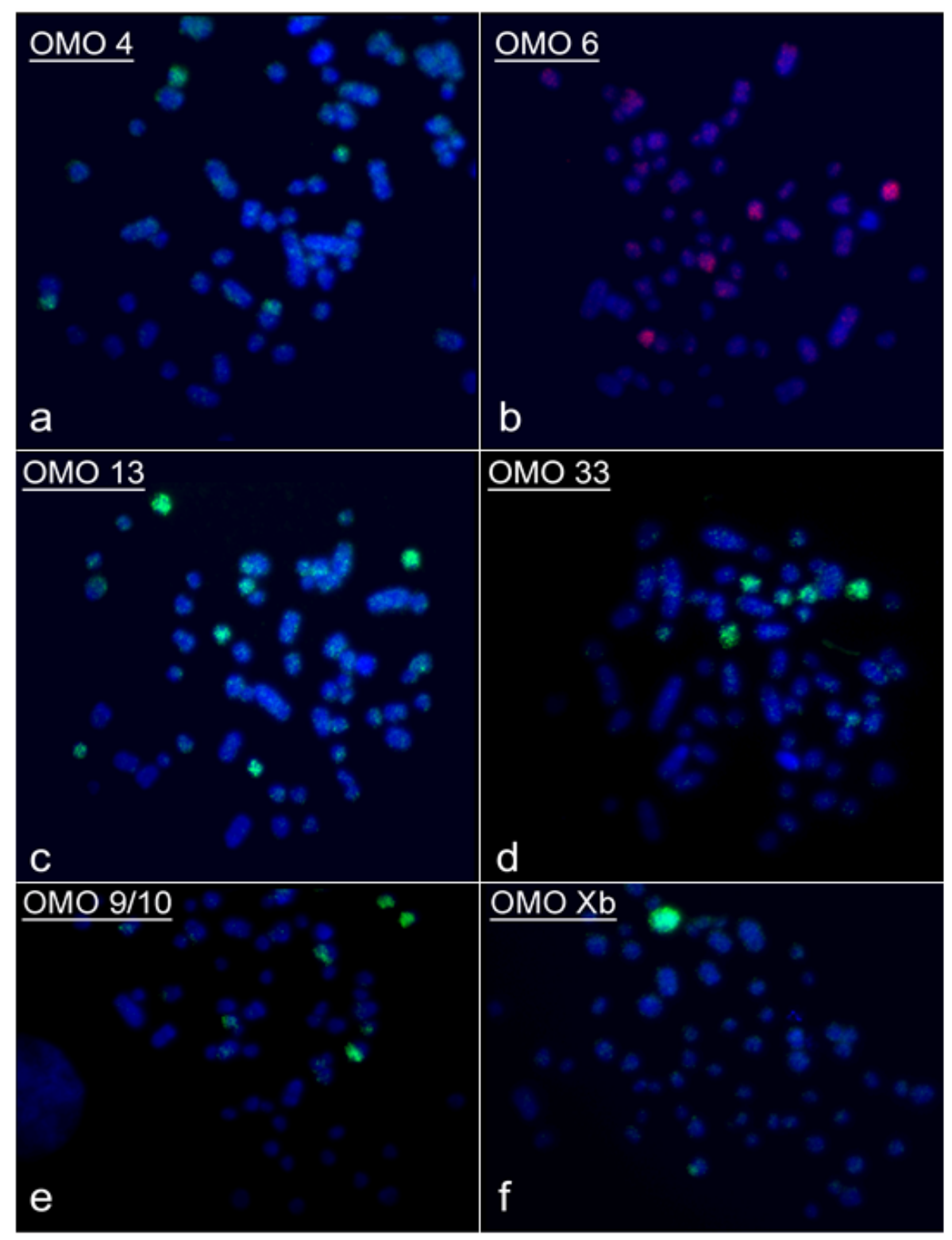

(a) OMO 4 hibrida os pares OFO 5q (proximal) e OFO 17; (b) OMO 6 hibrida os pares OFO 22 e OFO 23; (c) OMO 13 hibrida os pares OFO 19, OFO 20 e OFO 21; (d) OMO 33 hibrida os pares OFO 27 e OFO 28; (e) Sonda dupla de O. moojeni (OMO 9, 10) marca os pares OFO 6q (distal) e OFO 9; e (f) OMO Xb marca o cromossomo OFO X e OFO Yp. 
Figura 4.5 - Padrão de bandas $\mathrm{G}$ em O. microtis $(2 \mathrm{n}=64)$.

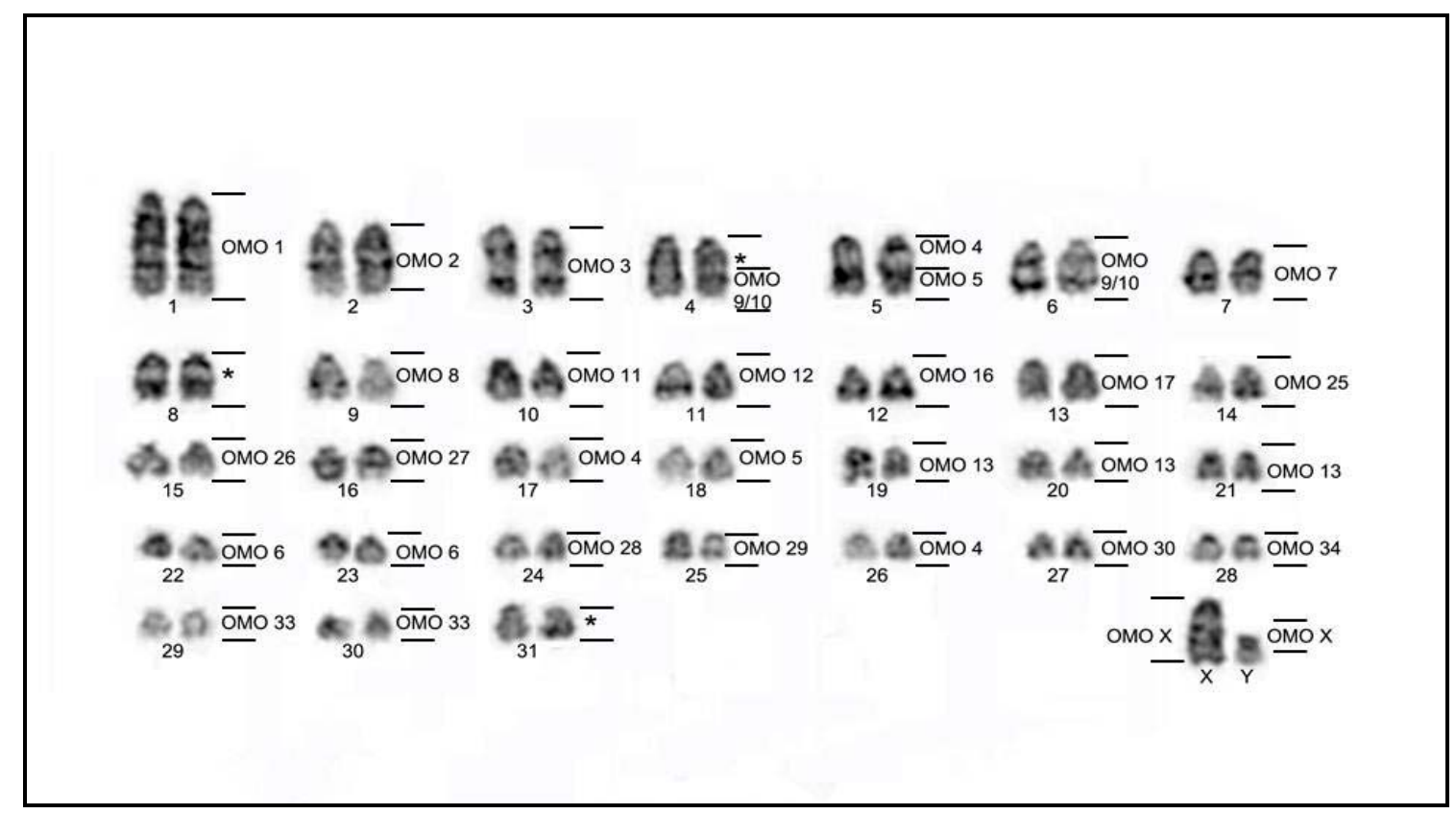

Os números das sondas de O. moojeni estão indicados ao lado dos respectivos cromossomos que pintaram. Asteriscos $\left({ }^{*}\right)$ indicam ausência de hibridação. 
Figura 4.6 - Algumas sondas de O. moojeni que hibridam pares cromossômicos inteiros em 0 . microtis $(2 \mathrm{n}=64)$.

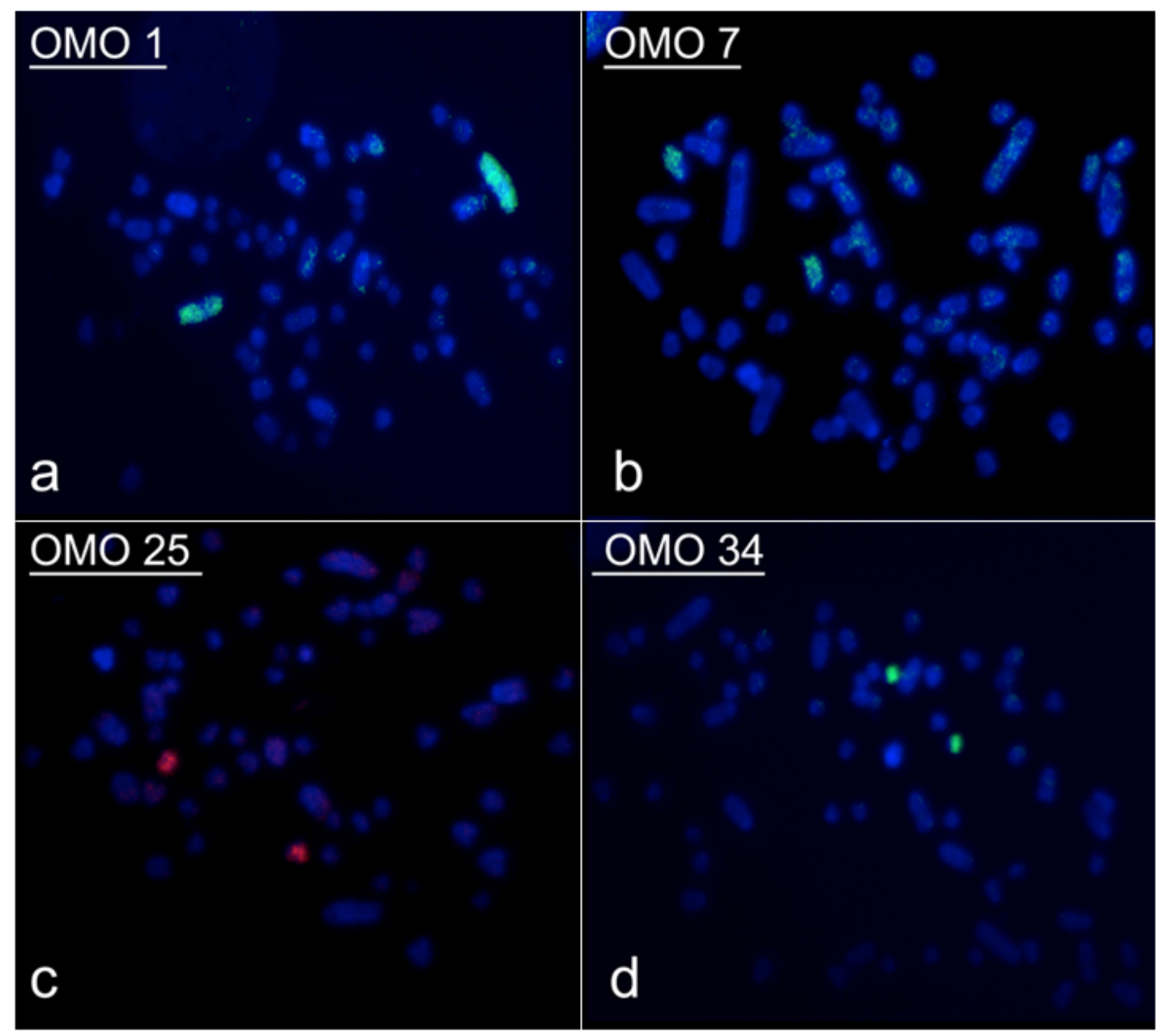

(a) OMO 1 hibrida o par OMI 1; (b) OMO 7 hibrida o par OMI 7; (c) OMO 25 hibrida o par OMI 14; e (d) OMO 34 hibrida o par OMI 28.

Figura 4.7 - Algumas sondas de O. moojeni que hibridam mais de um segmento em O. microtis $(2 \mathrm{n}=64)$.

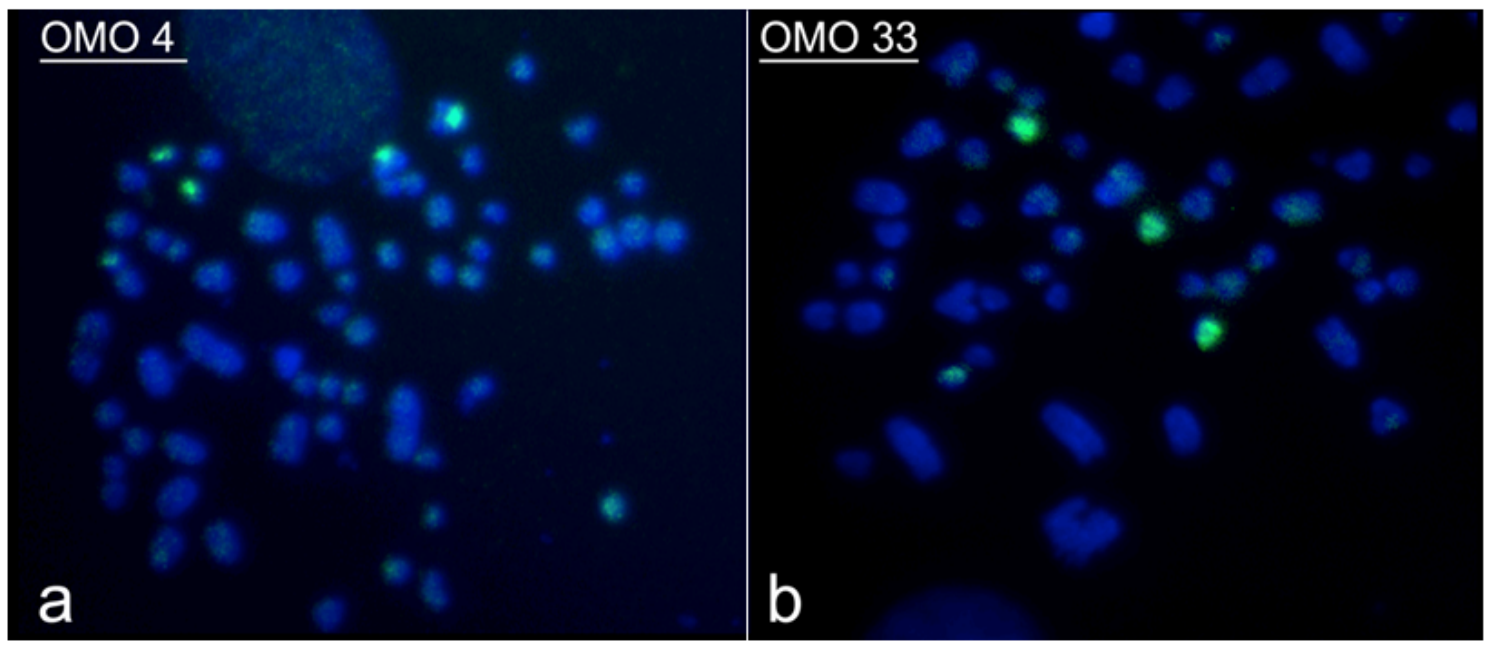

(a) OMO 4 hibrida os pares OMI 5q (proximal), OMI 17 e OMI 26; (b) OMO 33 hibrida os pares OMI 29 e OMI 30. 
Figura 4.8 - OMO Xb hibrida os cromossomos OMI X e OMI Yp.

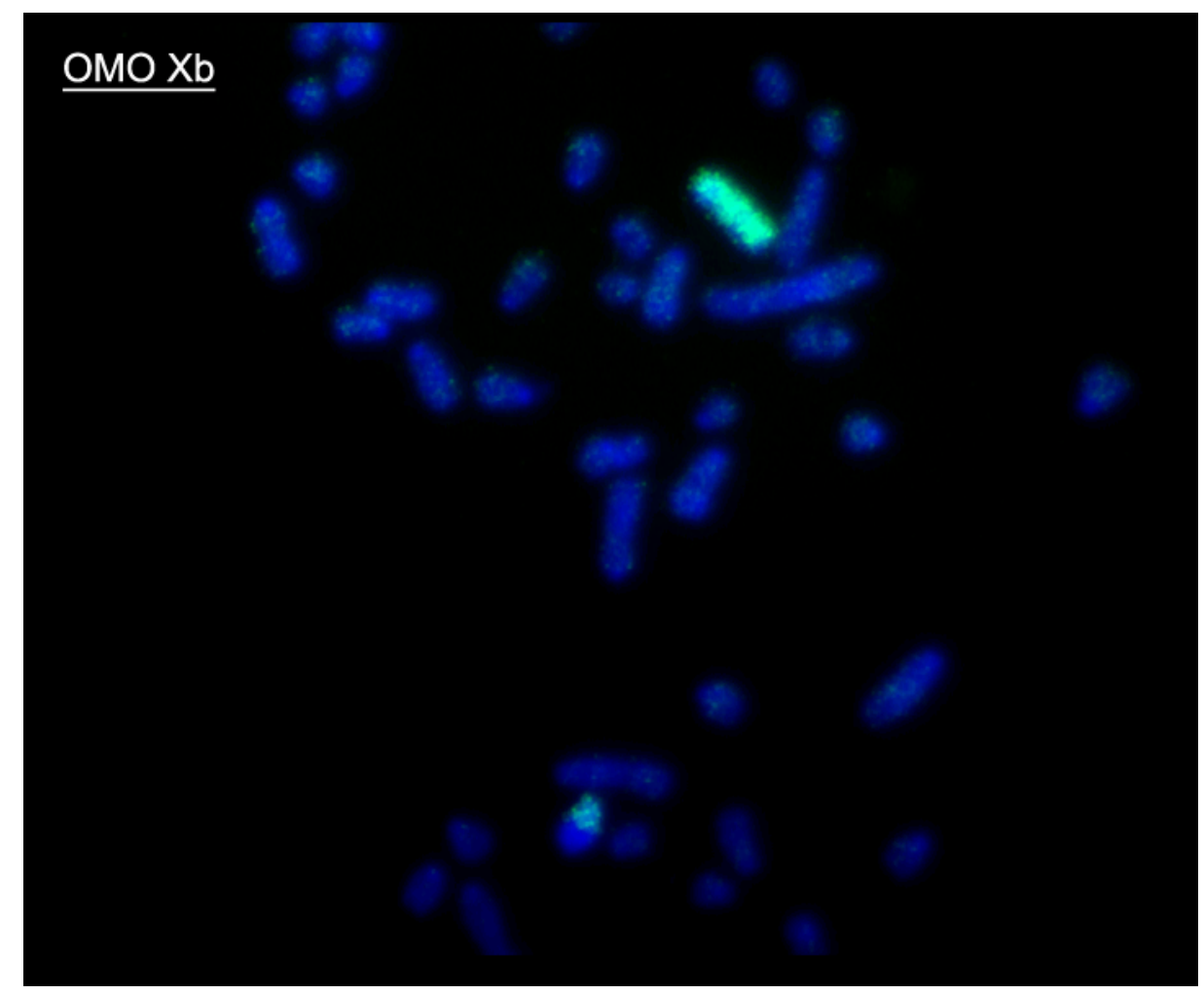

Figura 4.9 - Padrão de bandas $\mathrm{G}$ em O. nigripes $(2 \mathrm{n}=62)$.

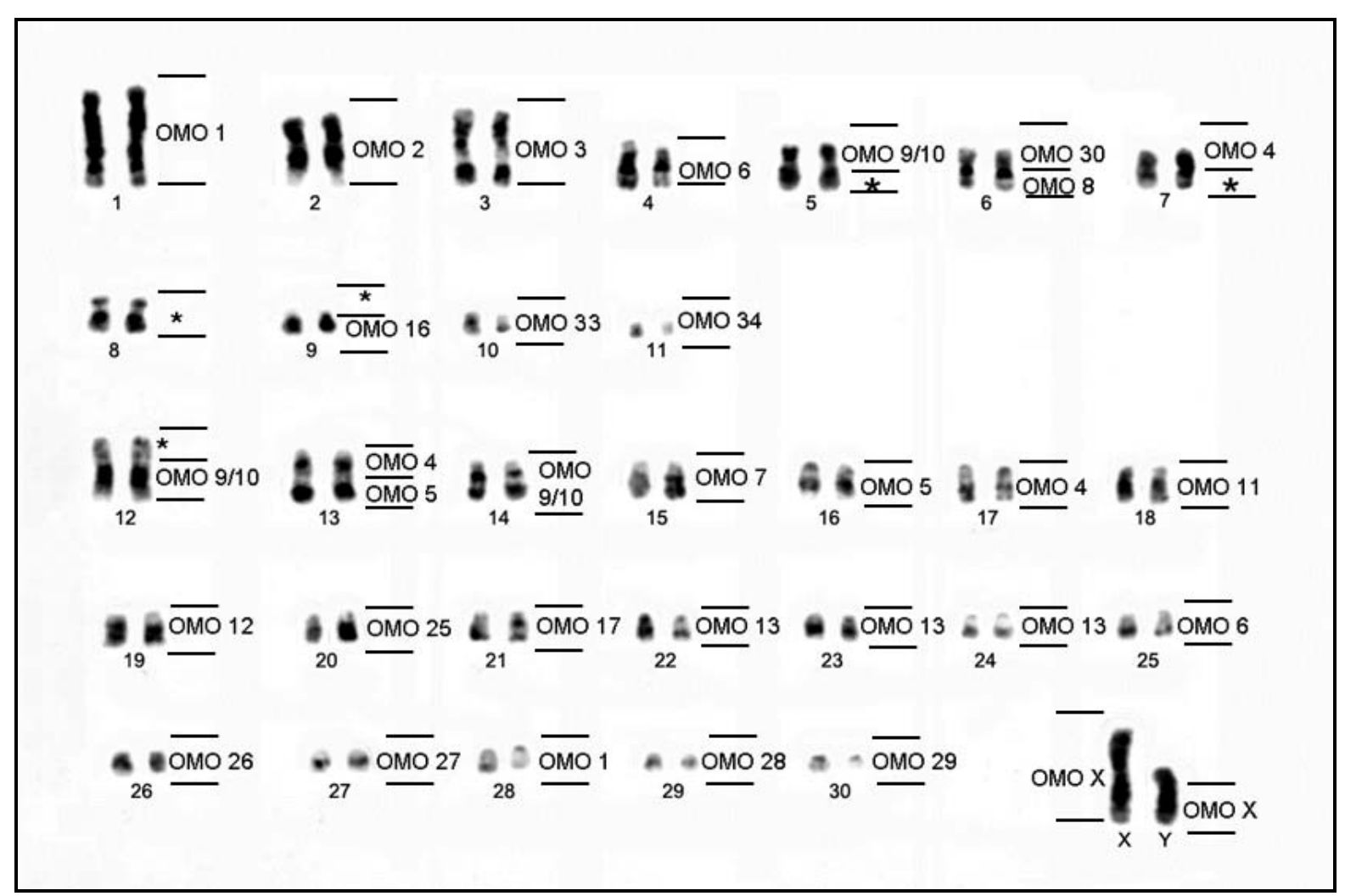

Os números das sondas de O. moojeni estão indicados ao lado dos respectivos cromossomos que pintaram. Asteriscos $\left(^{*}\right)$ indicam ausência de hibridação (cariótipo retirado de Silva, 1994). 
Figura 4.10 - Algumas sondas de 0 . moojeni que hibridam pares cromossômicos inteiros em O. nigripes $(2 n=62)$.

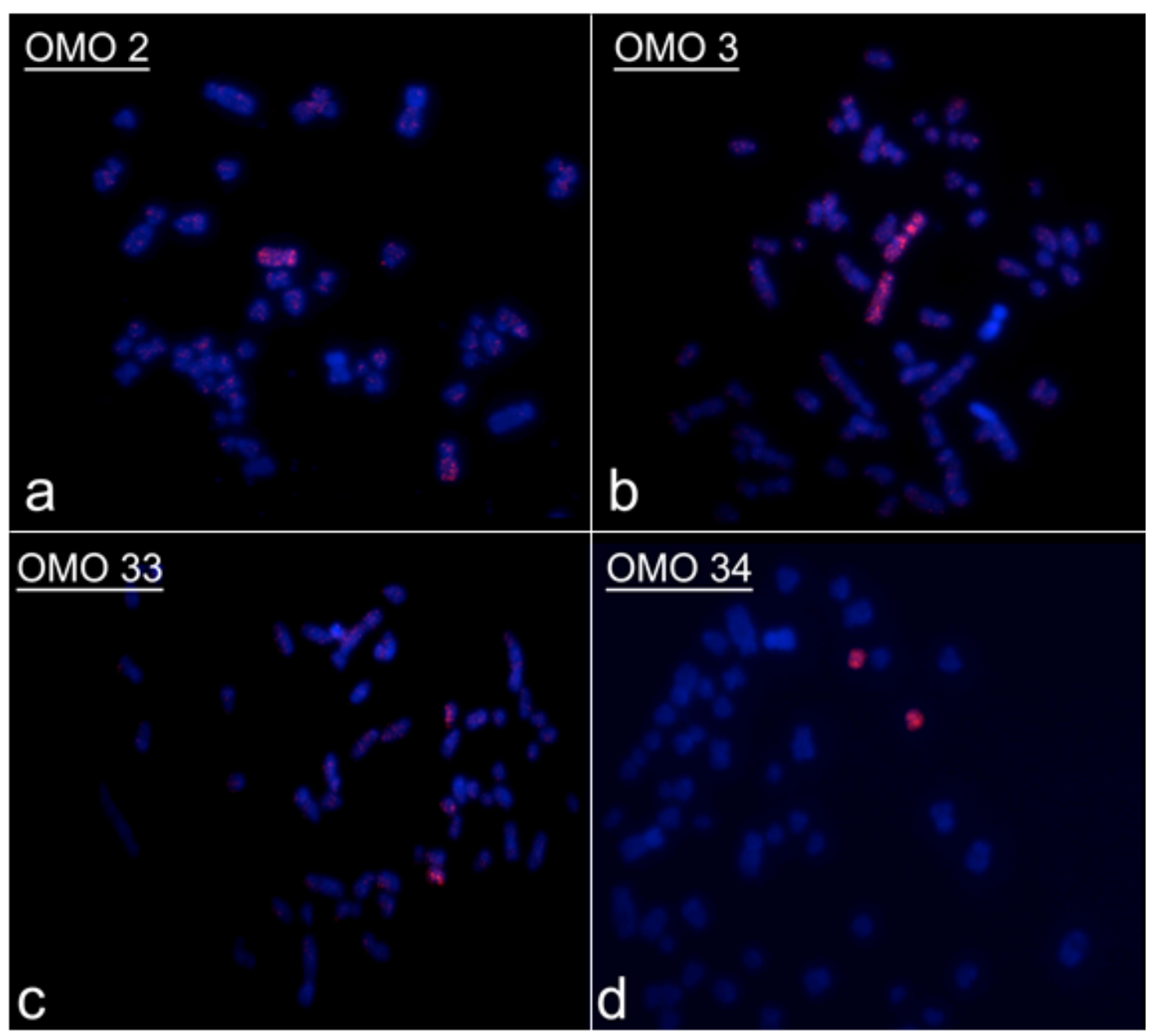

(a) OMO 2 hibrida o par ONI 2; (b) OMO 3 hibrida o par ONI 3; (c) OMO 33 hibrida o par ONI 10; e (d) OMO 34 hibrida o par ONI 11. 
Figura 4.11 - Algumas sondas de O. moojeni que hibridam mais de um segmento em $O$. nigripes $(2 \mathrm{n}=62)$.

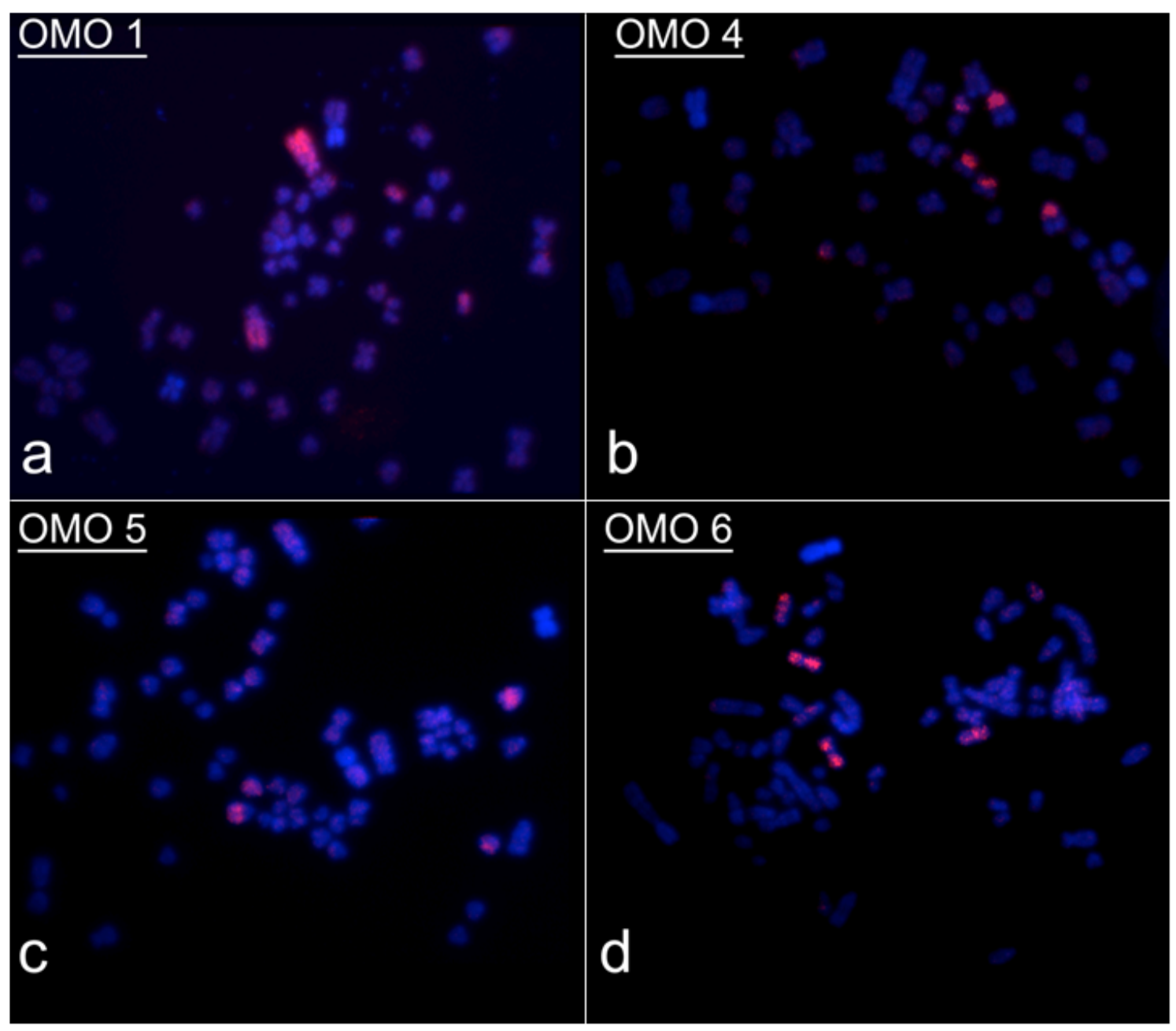

(a) OMO 1 hibrida os pares ONI 1 e ONI 28; (b) OMO 4 hibrida os pares ONI 7p, ONI 13q (proximal) e ONI 17; (c) OMO 5 hibrida os pares ONI 13q (distal) e ONI 16; e (d) OMO 6 hibrida os pares ONI 4 e ONI 25. 
Figura 4.12 - Sondas de O. moojeni que hibridam braços cromossômicos em 0 . nigripes $(2 \mathrm{n}=62)$.

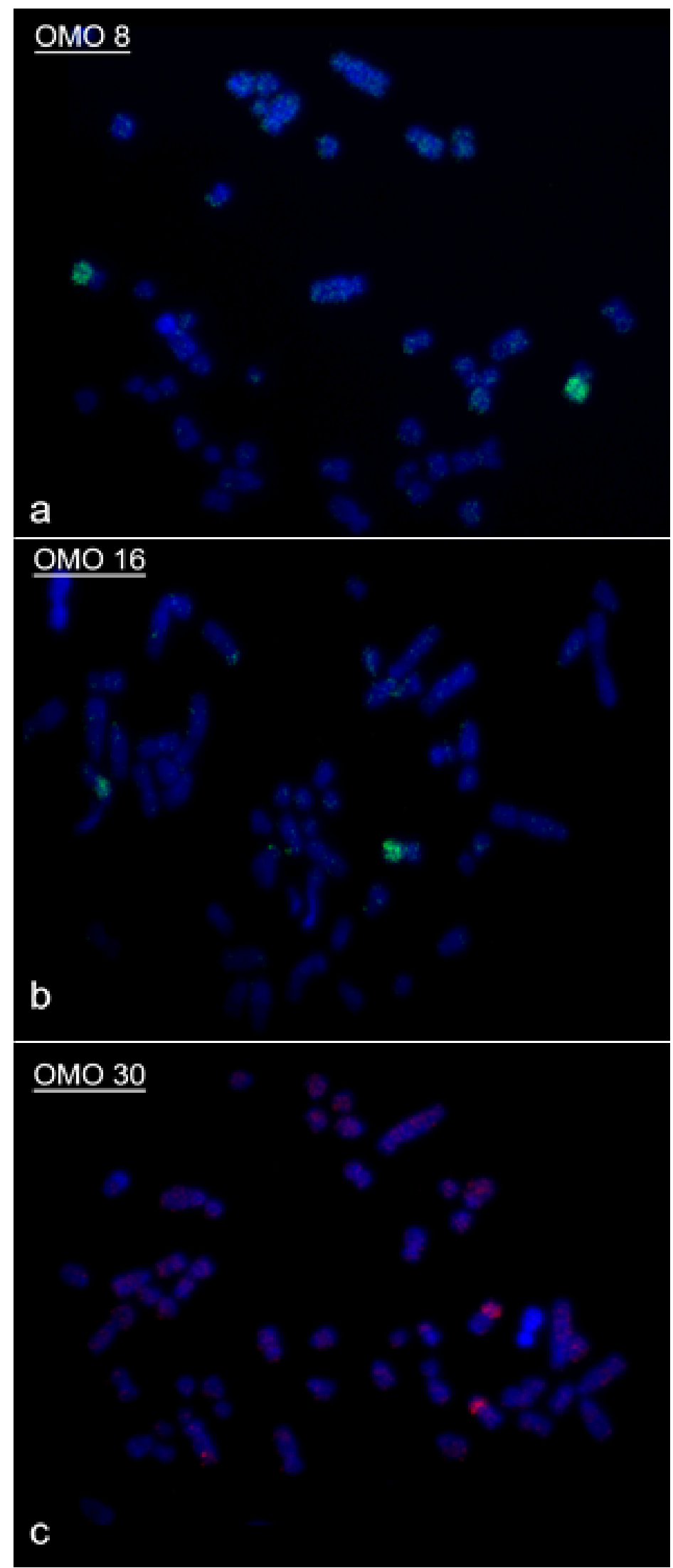

(a) OMO 8 hibrida ONI 6q; (b) OMO 16 hibrida ONI 9q; e (c) OMO 30 hibrida ONI 6p. 
Figura 4.13 - OMO Xb hibrida os cromossomos ONI X e ONI Yq.

\section{$\underline{\mathrm{OMO} X \mathrm{~b}}$}

Figura 4.14 - Padrão de bandas $\mathrm{G}$ em $O$. rupestris $(2 \mathrm{n}=46)$.

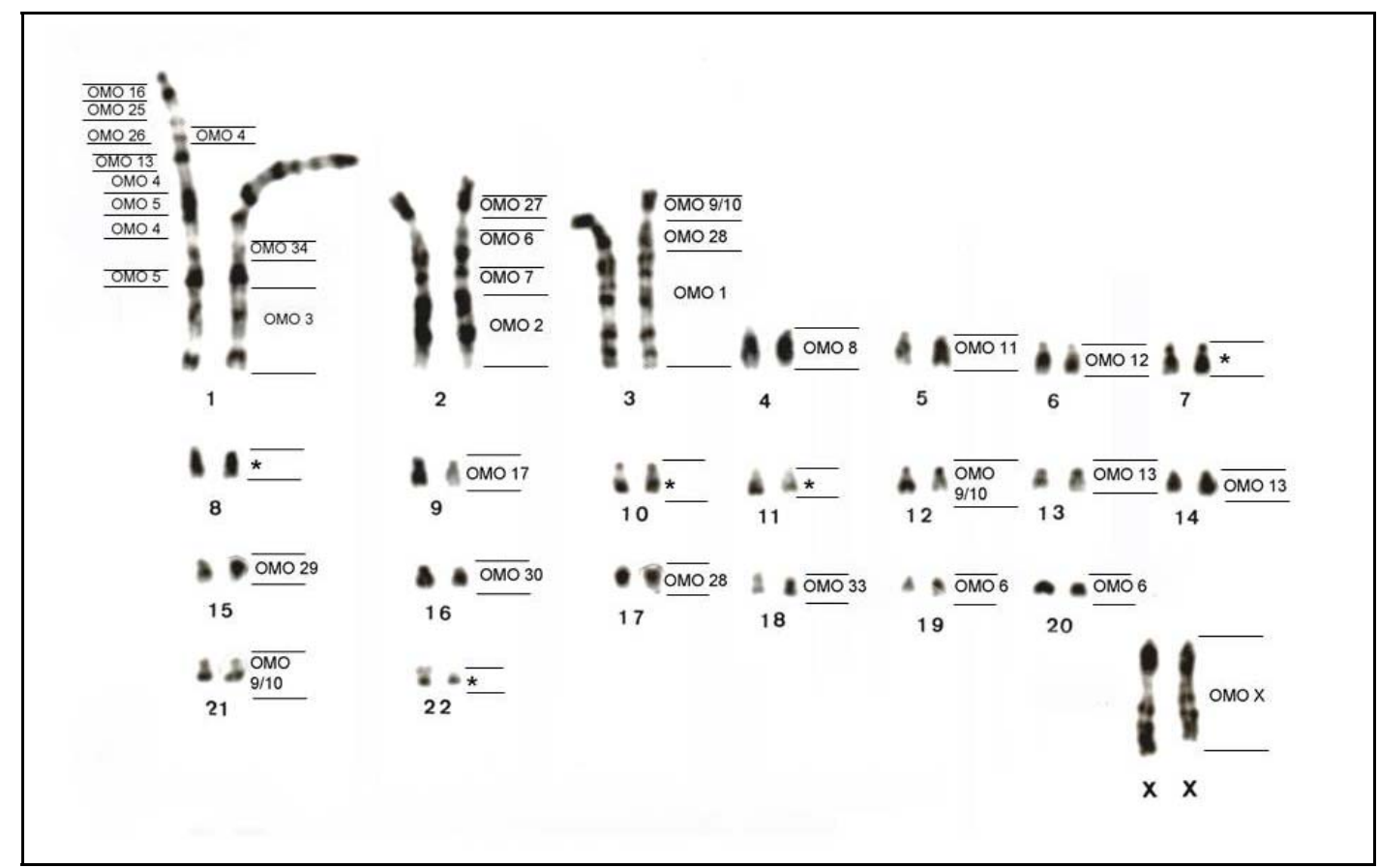

Os números das sondas de O. moojeni estão indicados ao lado dos respectivos cromossomos que pintaram. Asteriscos $\left(^{*}\right)$ indicam ausência de hibridação (cariótipo retirado de Silva e Yonenaga-Yassuda, 1997). 
Figura 4.15 - Algumas sondas de O. moojeni que hibridam pares cromossômicos inteiros em $O$. rupestris $(2 n=46)$.

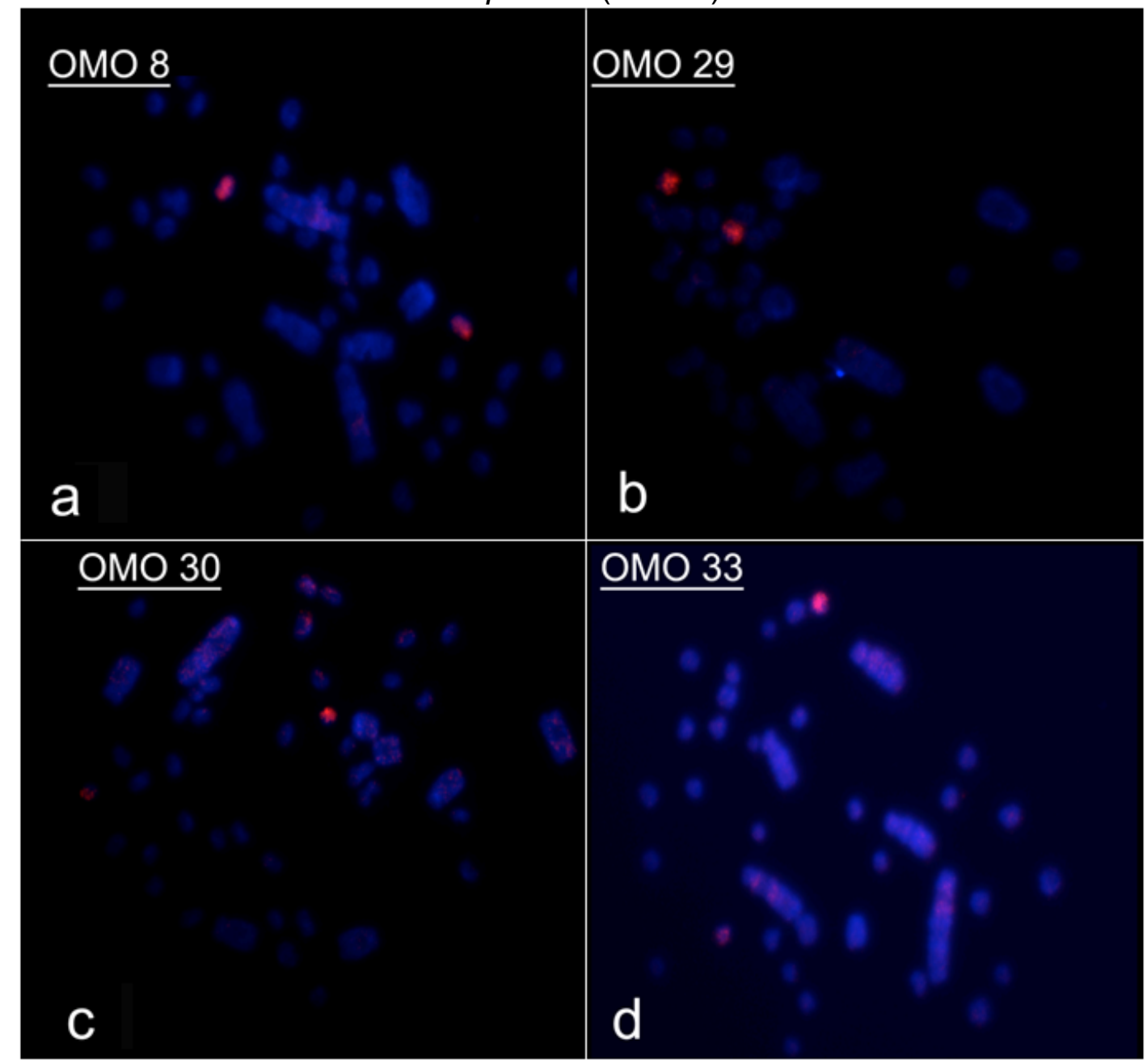

(a) OMO 8 hibrida o par ORU 4; (b) OMO 29 hibrida o par ORU 15; (c) OMO 30 hibrida o par ORU 16; e (d) OMO 33 hibrida o par ORU 18.

Figura 4.16 - Cromossomo 1 de O. rupestris hibridado por oito sondas diferentes de O. moojeni.

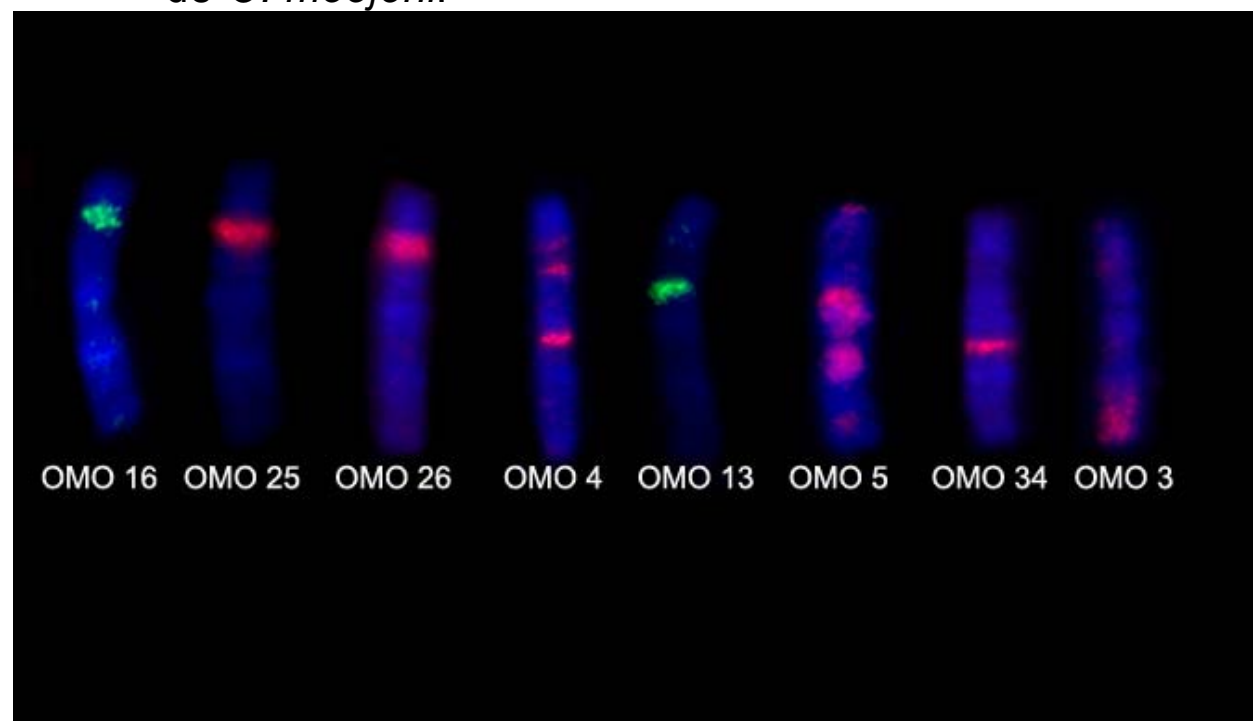


Figura 4.17 - Cromossomo 2 de O. rupestris e Oligoryzomys sp. 2 hibridado por quatro sondas diferentes de $O$. moojeni.

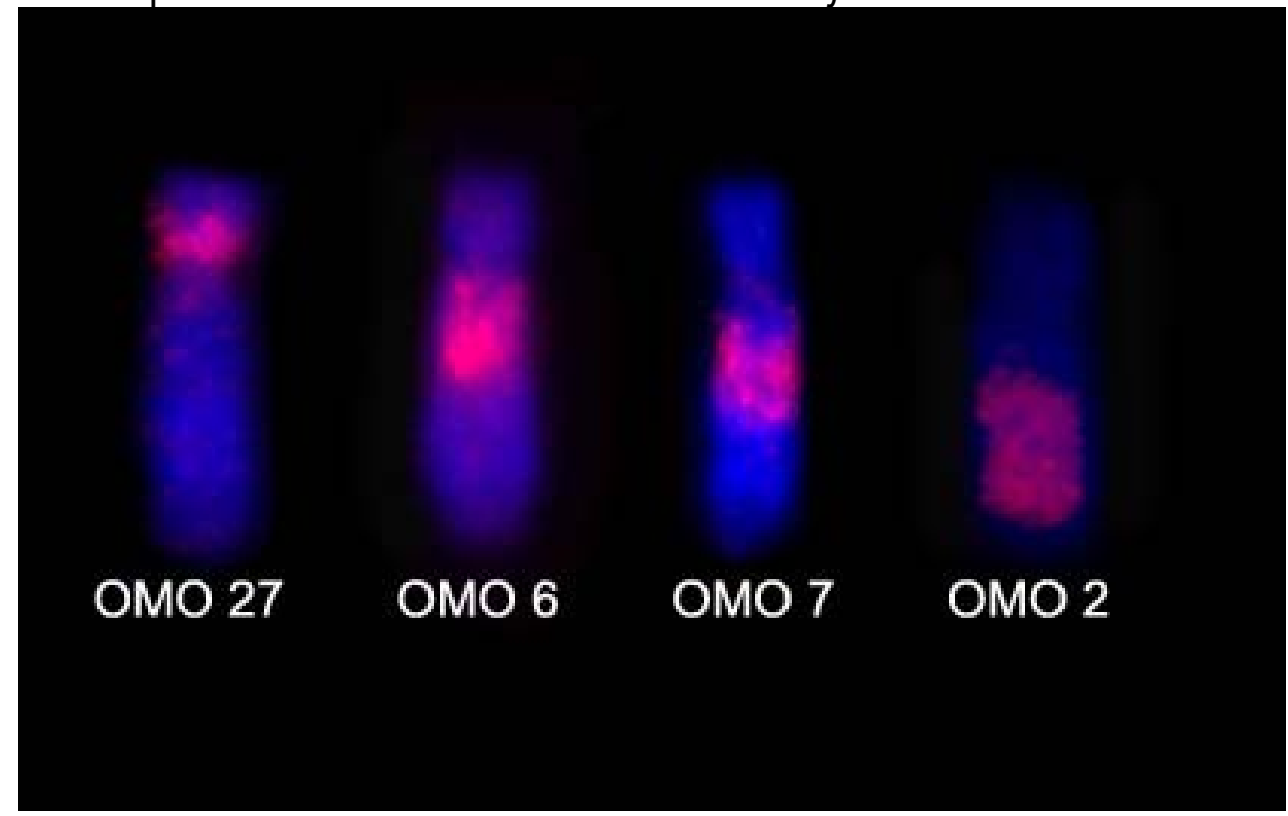

Figura 4.18 - Cromossomo 3 de O. rupestris e Oligoryzomys sp. 2 hibridado por três sondas diferentes de O. moojeni.

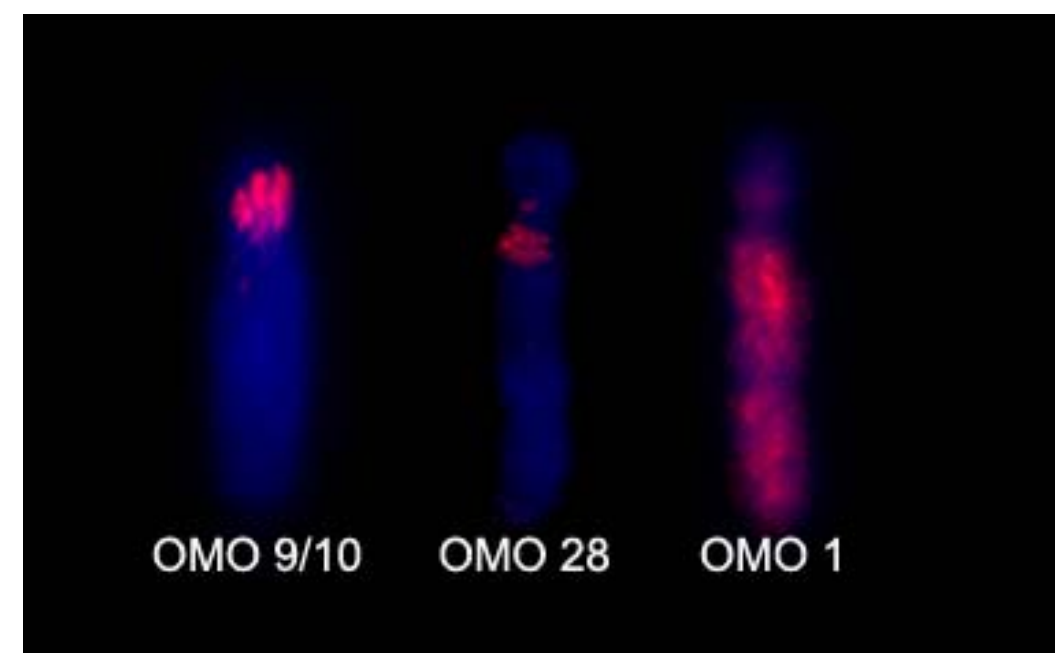


Figura 4.19 - Padrão de bandas G em Oligoryzomys sp. $2(2 n=44)$.

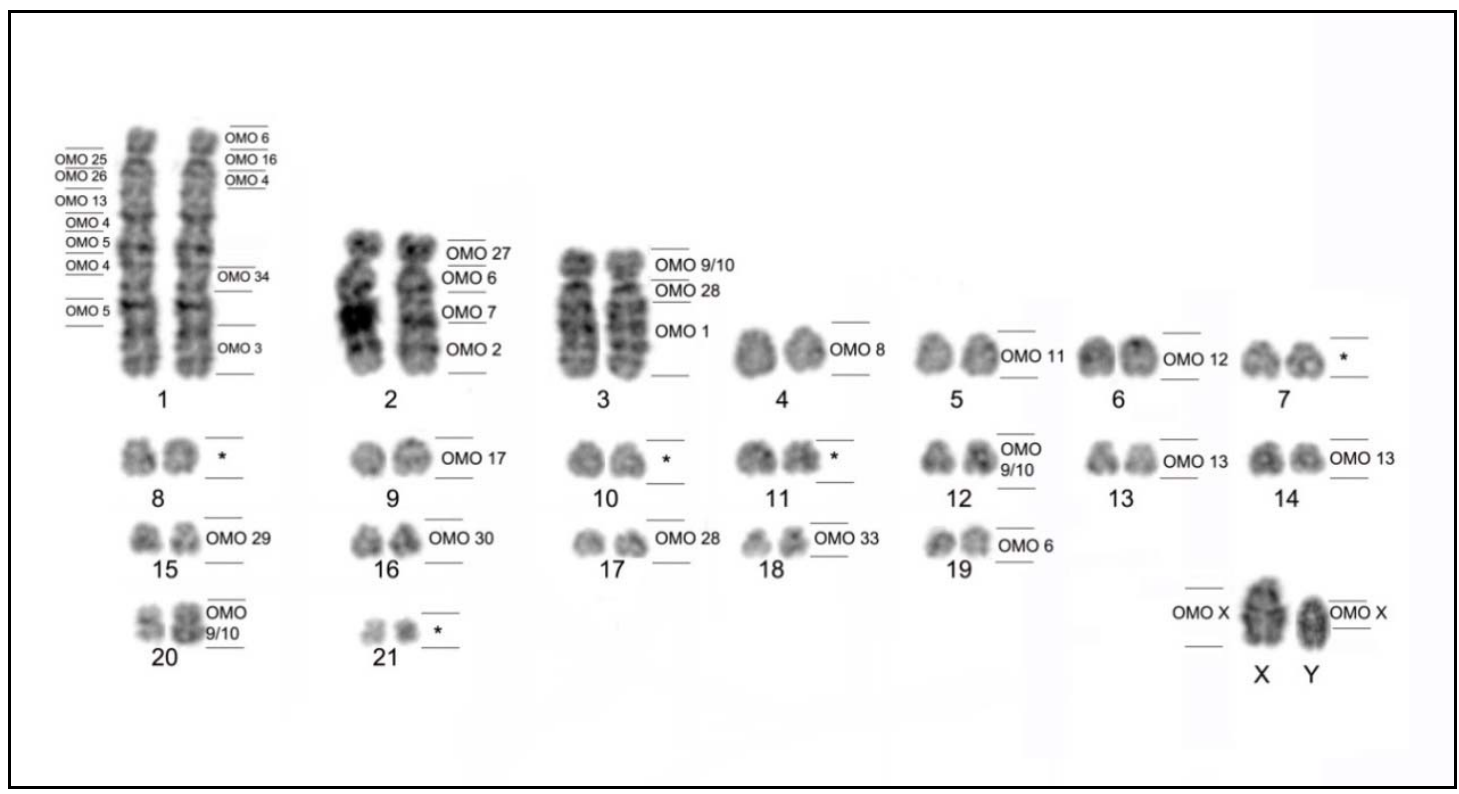

Os números das sondas de O. moojeni estão indicados ao lado dos respectivos cromossomos que pintaram. Asteriscos $\left(^{*}\right)$ indicam ausência de hibridação.

Figura 4.20 - Cromossomo 1 de Oligoryzomys sp. 2 hibridado por nove sondas diferentes de O. moojeni.

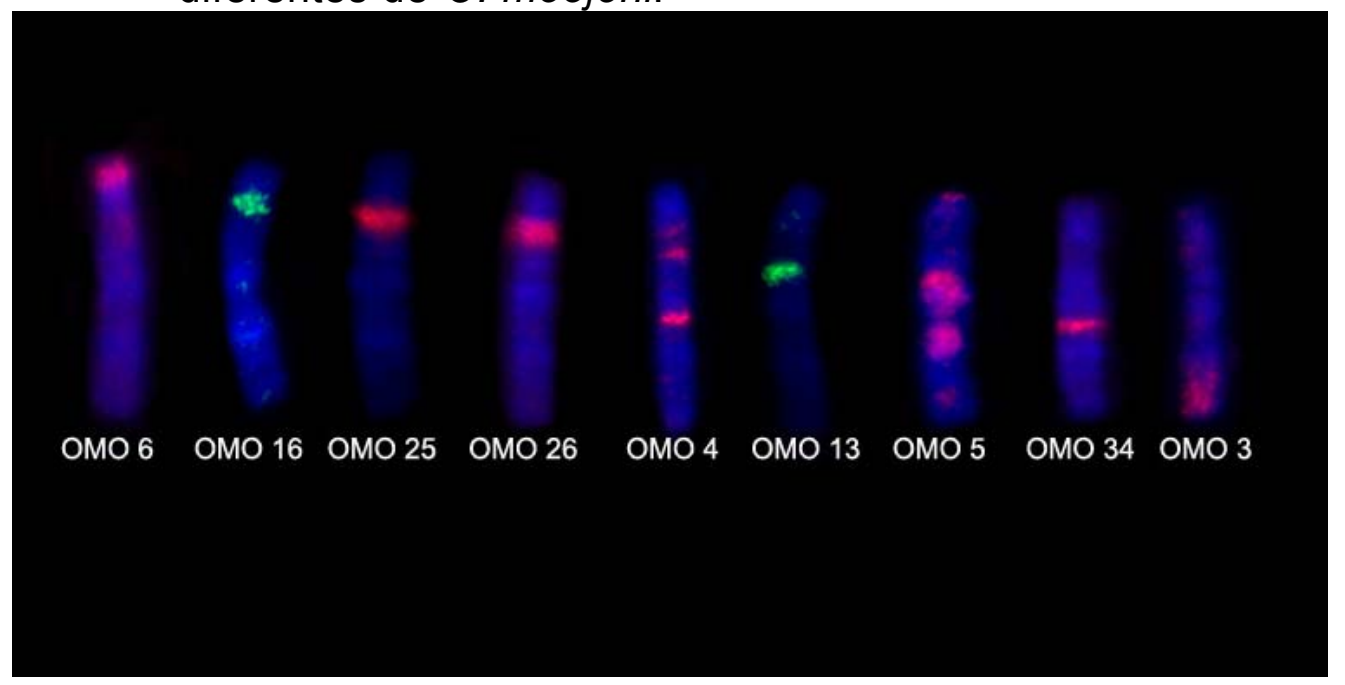


Figura 4.21 - Filogenia do gênero Oligoryzomys. As espécies em vermelho são aquelas cujas pinturas cromossômicas foram realizadas. A espécie Oligoryzomys sp. 2 não está representada na filogenia, pois não foi estudada por Agrellos et al. (2012).

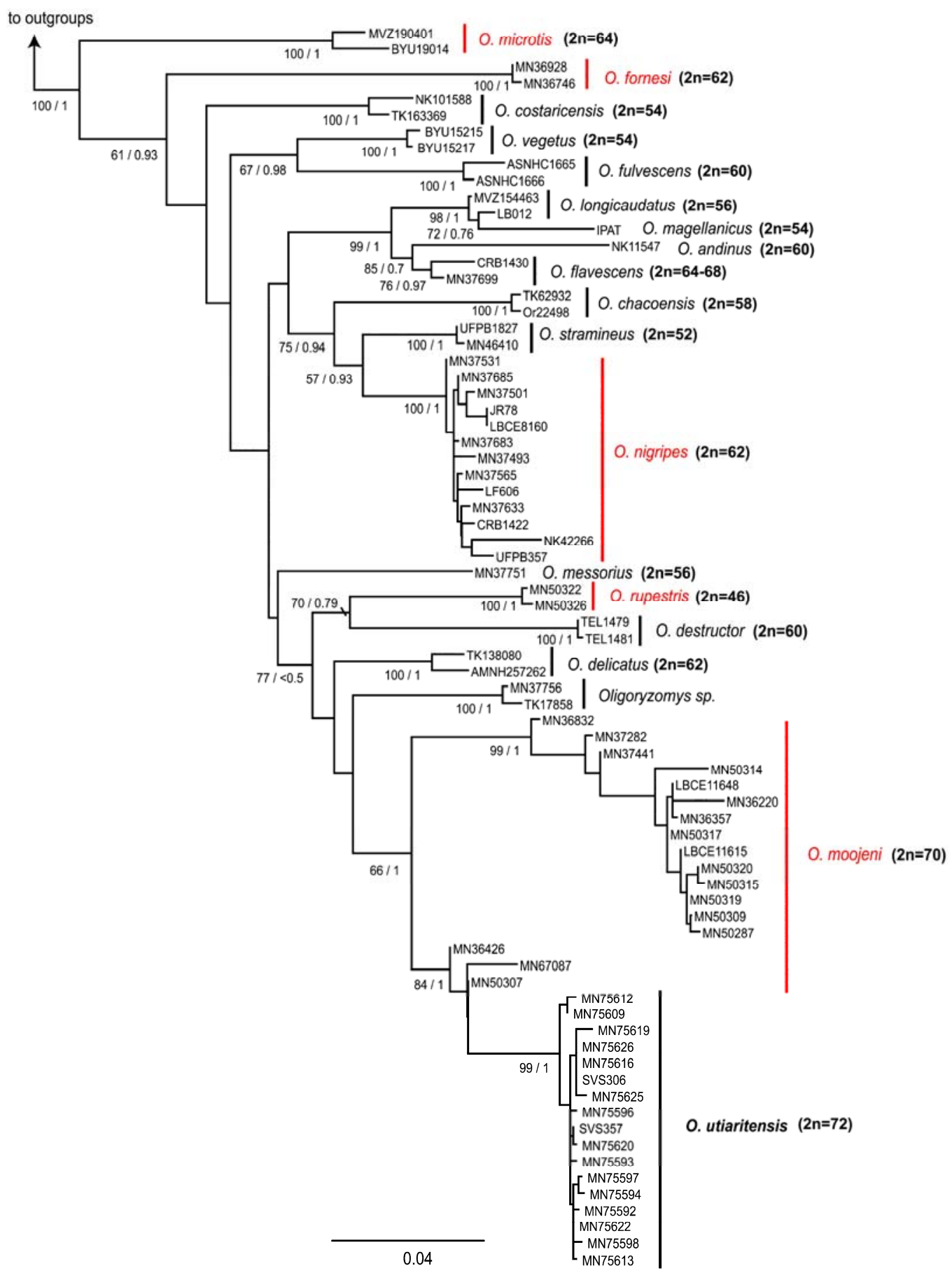

Fonte: Agrellos et al. (2012), com modificações. 
Figura 4.22 - Associação sintênica das sondas OMO 4 e OMO 5 em O. fornesi, O. microtis, 0 . nigripes, 0 . rupestris e Oligoryzomys sp. 2, respectivamente.

\section{OMO 4 OMO5}

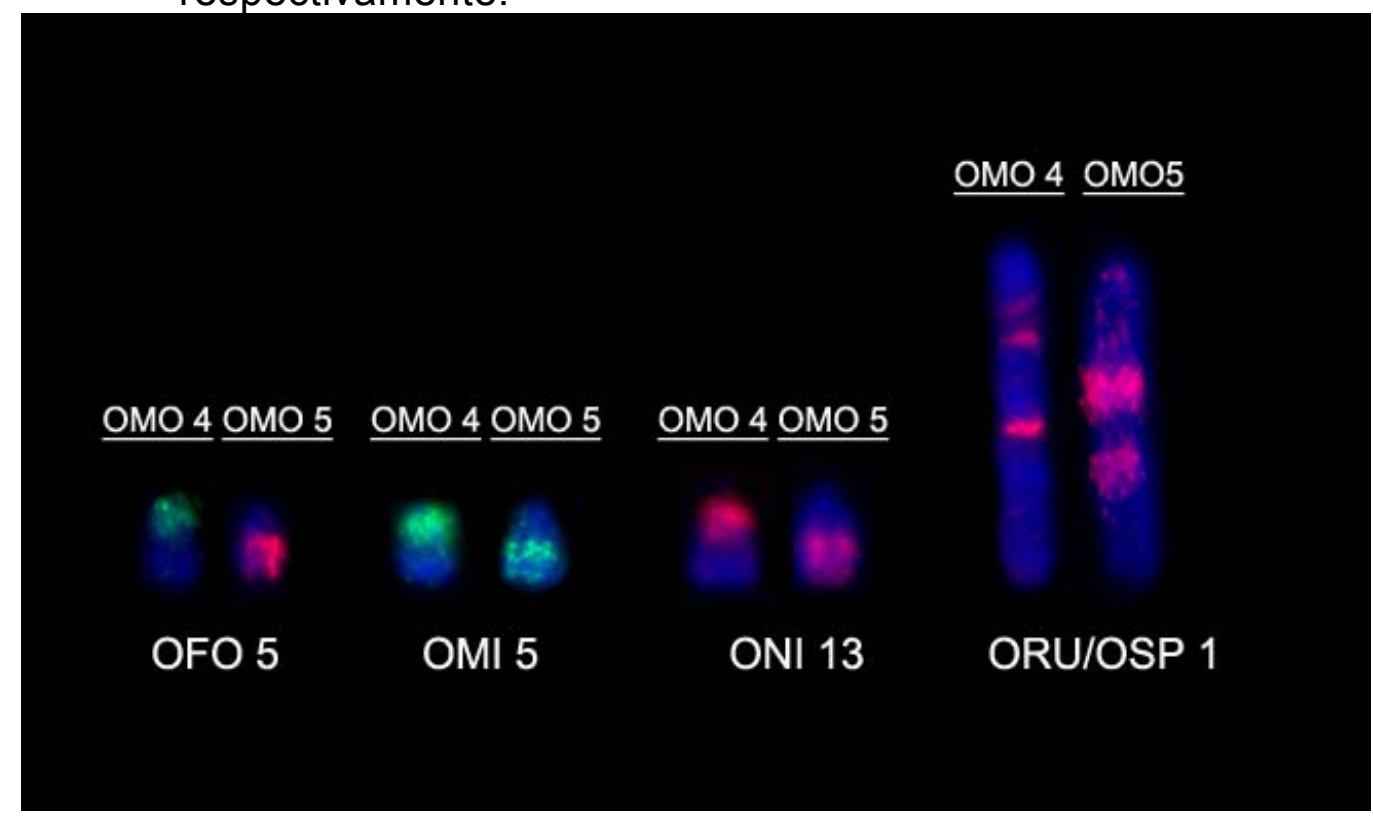

O par cromossômico marcado em cada espécie está identificado abaixo e a sonda utilizada está identificada na região superior.

Figura 4.23 - Associação das sondas OMO 30 e OMO 8 em O. fornesi e 0. nigripes, respectivamente.

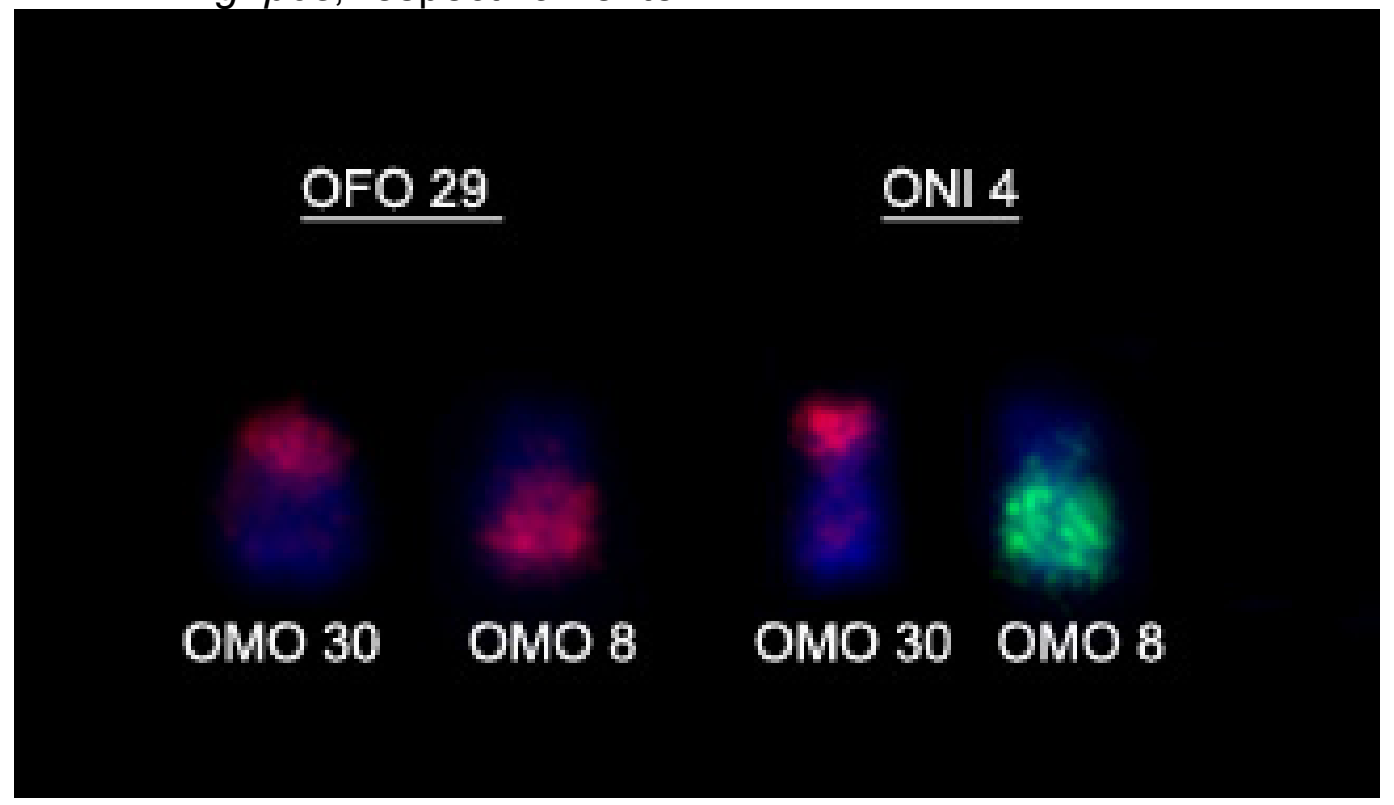

O par cromossômico marcado em cada espécie está identificado na região superior de cada par. Nas outras espécies as sondas OMO 30 e OMO 8 marcaram pares acrocêntricos distintos. 
Figura 4.24 - Idiograma dos cromossomos 1, 2 e 3 de (a) O. rupestris e (b) Oligoryzomys sp. 2.

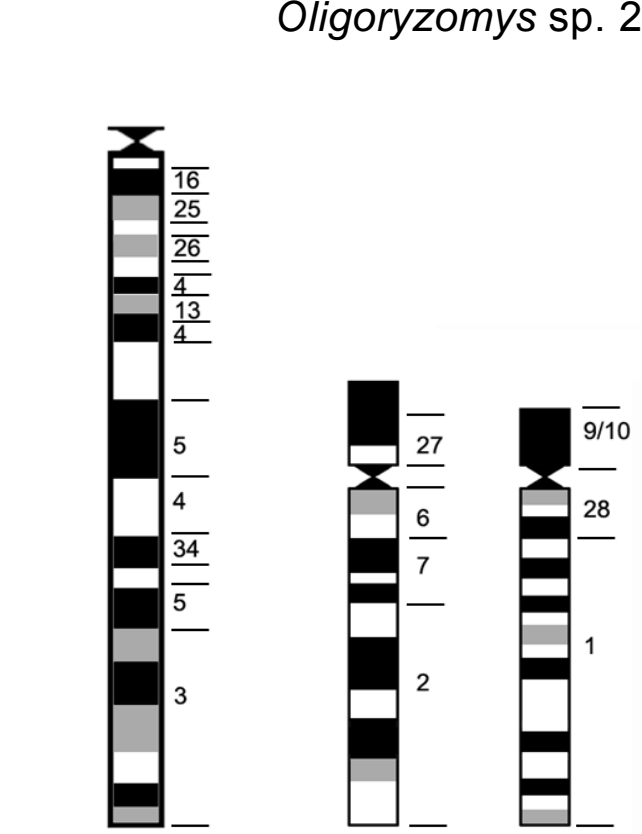

a

As sondas de OMO estão indicadas à direita de cada cromossomo.

Figura 4.25 - Hibridação da sonda OMO 6 em (a) O. rupestris e (b) Oligoryzomys sp. 2.

\section{OMO 6}
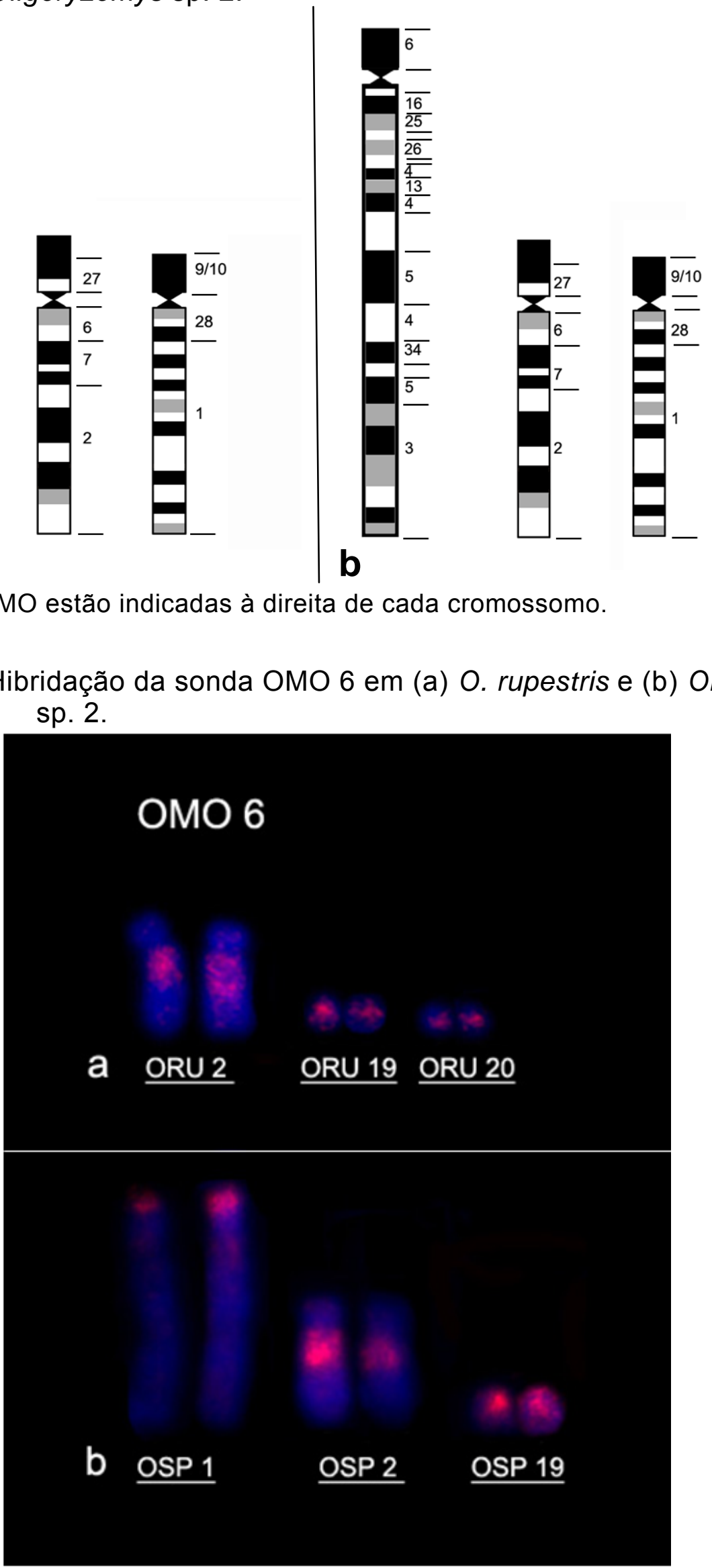
Figura 4.26 - Hibridação da sonda $O M O X$ nos cromossomos $Y$ de $O$. flavescens, 0 . fornesi, O. microtis, O. moojeni e O. nigripes.

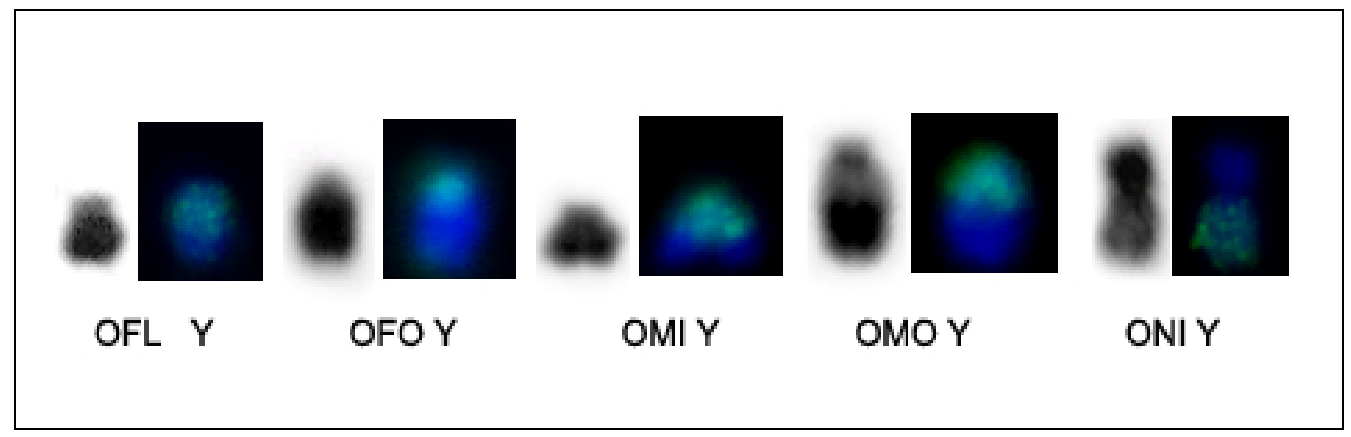

Notar que a hibridação não ocorre na região de heterocromatina constitutiva. 


\section{REFERÊNCIAS*}

ACOSTA, M. J.; ROMERO-FERNÁNDEZ, I.; SÁNCHEZ, A.; MARCHAL, J. A. Comparative analysis by chromosome painting of the sex chromosomes in Arvicolidae rodents. Cytogenet. Genome Res., v. 132, p. 47-54, 2010.

AGRELLOS, R.; BONVICINO, C. R.; ROSA, E. S. T.; MARQUES, A. A. R.; D'ANDREA, P. S.; WEKSLER, M. The taxonomic status of the Castelo dos Sonhos Hantavirus reservoir, Oligoryzomys utiaritensis Allen 1916 (Rodentia: Cricetidae: Sigmodontinae). Zootaxa, v. 3220, p. 1-28, 2012.

AGUILERA, M.; PÉREZ-ZAPATA, A.; MARTINO, A. Cytogenetics and karyosystematics of Oryzomys albigularis (Rodentia, Cricetidae) from Venezuela. Cytogenet. Cell Genet., v. 69, p. 44-49, 1995.

ALMEIDA, E. J. C.; YONENAGA-YASSUDA, Y. Robertsonian fusion, pericentric inversion and sex chromosome heteromorphisms in Oryzomys subflavus (Cricetidae, Rodentia). Caryologia, v. 38, p. 129-137, 1985.

ALMEIDA, E. J. C.; YONENAGA-YASSUDA, Y. Pericentric inversions and sex chromosome heteromorphisms in Oryzomys nigripes (Rodentia, Cricetidae). Caryologia, v. 44, p. 63-73, 1991.

ANDRADES-MIRANDA, J.; OLIVEIRA, L. F. B.; LIMA-ROSA, A. V.; NUNES A. P.; ZANCHIN N. I. T.; MATTEVI M. S. Chromosome studies of seven species of Oligoryzomys (Rodentia: Sigmodontinae) from Brazil. J. Mammal., v. 82, p. 1080-1091, 2001.

ANDRADES-MIRANDA, J.; ZANCHIN, N. I. T.; OLIVEIRA, L. F. B.; LANGGUTH, A. R.; MATTEVI, M. S. (T2AG3)n telomeric sequence hybridization indicating centric fusion rearrangements in the karyotype of the rodent Oryzomys subflavus. Genetica, v. 144, p. 11-16, 2002.

ANISKIN V. M.; VOLOBOUEV V. T. Comparative chromosome banding of two South-American species of rice rats of the genus Oligoryzomys (Rodentia, Sigmodontinae). Chromosome Res., v. 7, p. 557-562, 1999.

BELMAR-LUCERO, S.; GODOY, P.; FERRES, M.; VIAL, P.; PALMA, R. E. Range expansion of Oligoryzomys longicaudatus (Rodentia, Sigmodontinae) in Patagonian Chile, and first record of a Hantavirus in the region. Rev. Chil. Hist. Nat., v. 82, p. 265-275, 2009.

BONVICINO, C. R.; D'ANDREA, P. S.; BORODIN, P. M. Pericentric inversion in natural population of Oligoryzomys nigripes (Rodentia: Sigmodontinae). Genome, v. 44, p. 791-796, 2001.

\footnotetext{
* De acordo com: ASSOCIAÇÃO BRASILEIRA DE NORMAS TÉCNICAS. NBR 6023: informação e documentação: referências: elaboração. Rio de Janeiro, 2002.
} 
BONVICINO, C. R.; GEISE, L. Relevância dos estudos cariológicos na taxonomia de alguns gêneros de Oryzomyini (Rodentia, Sigmodontinae). In: FREITAS, T. R. O.; VIEIRA, E.; PACHECO, S.; CHRISTOFF, A. U. (Ed.). Mamíferos do Brasil: genética, sistemática, ecologia e conservação. São Carlos: Sociedade Brasileira de Genética, Suprema, 2006. p. 27-37.

BONVICINO, C. R.; MOREIRA, M. A. M. Molecular phylogeny of the genus Oryzomys (Rodentia, Sigmodontinae) based on cytochrome $b$ DNA sequences. Mol. Phylogenet. Evol., v. 18, p. 282-292, 2001.

BONVICINO, C. R.; OLIVEIRA, J. A.; D'ANDREA, P. S. Guia dos Roedores do Brasil com chaves para gêneros baseadas em caracteres externos. Rio de Janeiro: CCentro Pan-Americano de Febre Aftosa-OPAS/OMS, 2008. $120 \mathrm{p}$.

BONVICINO, C. R.; WEKSLER, M. A new species of Oligoryzomys (Rodentia, Sigmodontinae) from northeastern and central Brazil. $Z$. Saügetierkd., v. 63, p. 90-103, 1998.

BRUM-ZORRILLA, N.; FRONZA, T. G.; WAINBERG, R. Oryzomys flavescens and $O$. delticola chromosomes (Rodentia, Cricetidae) from Uruguay and Argentina. Caryologia, v. 41, p. 275-288, 1988.

CAMACHO, J. P. M. B Chromosomes. In: GREGORY, T. R. The evolution of the genome. USA: Elsevier Academic Press, 2005. Cap. 4, p.224-273.

CARLETON, M. D. Introduction to rodents. In: ANDERSON, S.; JONES, J. $\mathrm{K}$., Jr. (Ed.). Orders and families of recent mammals of the world. New York: John Wiley, 1984. p.255-288.

CARLETON, M. D.; MUSSER, G. G. Muroid Rodents. In: ANDERSON, S.; JONES, J. K., Jr. (Ed.). Orders and families of recent mammals of the world. New York: John Wiley, 1984. p. 289-379.

CARLETON, M. D.; MUSSER, G. G. Systematic studies of Oryzomyine rodents. (Muridae, Sigmodontinae): a sinopsis of Microryzomys. Bull. Am. Mus. Nat. Hist., v. 191, p. 1-83, 1989.

CARPENTER, W.; MASHIMA, T. Y.; RUPIPER, D. J. Exotic animal formulary. USA: Greystone Publications, 1996.

CHIARELLO, A. G.; AGUIAR, L. M. S.; CERQUEIRA, R.; MELO, F. R.; RODRIGUES, F.H.G.; SILVA, V.M.F. Mamíferos ameaçados de extinção no Brasil. In: MACHADO, A. B. M.; DRUMMOND, G. M.; PAGLIA, A. P. (Ed.). Livro vermelho da fauna brasileira ameaçada de extinção. Brasília, DF: MMA, 2008. Vol. 2, p. 681-874.

CHOO, K. H. A. The centromere. New York: Oxford University Press, 1997. $304 \mathrm{p}$. 
CHOWDHARY, B. P.; RAUDSEPP, T. Chromosome painting in farm, pet and wild animal species. Methods in Cell Science, v. 23, v. 37-55, 2001.

D'ELÍA, G. Phylogenetics of Sigmodontinae (Rodentia, Muroidea, Cricetidae), with special reference to the akodont group, and with additional comments on historical biogeography. Cladistics, v. 19, p. 307-323, 2003.

D'ElíA, G.; LUNA, L.; GONZALEZ, E. M.; PATTERSON, B. D. On the Sigmodontinae radiation (Rodentia, Cricetidae): an appraisal of phylogenetic position of Rhagomys. Mol. Phylogenet. Evol., v. 38, p. 558-564, 2006.

D'ElíA, G.; PARDINAS, U. F. J.; TETA, P.; PATTON, J. P. Definition and diagnosis of a new tribe of sigmodontinae rodents (Cricetidae: Sigmodontinae), and a revised classification of the subfamily. Gayana, v. 71, p. 187-194, 2007.

DE OLIVEIRA, E. H. C.; NEUSSER, M.; FIGUEIREDO, W. B.; NAGAMACHI, C.; PIECZARKA, J. C.; SBALQUEIRO, I. J.; WIENBERG, J.; MULLER, S. The phylogeny of howler monkeys (Alouatta, Platyrrhini): reconstruction by multicolor cross-species chromosome painting. Chromosome Res., v. 10, p. 669-683, 2002.

DE VIVO, M.; CARMIGNOTTO, A. P.; GREGORIN, R.; HINGST-ZAHER, E.; IACK-XIMENES, G. E., MIRETZKI, M.; PERCEQUILLO, A. R.; JR, M. M. R.; ROSSI, R. V.; TADDEI, V. A. Checklist dos mamíferos do estado de São Paulo, Brasil. Disponível em: <BiotaNeotropica11(1a):http://www.biotaneotropica.org.br/v11n1a/en/abstra ct?inventory+bn0071101a2011>. Acesso em: 25 mar. 2011.

DOBIGNY, G.; YANG, F. Comparative cytogenetics in the genomics era: cytogenomics comes of age. Chromosome Res., v. 16, p. 1-4, 2008.

EMMONS, L. E.; FEER, F. Neotropical rainforest mammals. A field guide. $2^{\text {nd }}$ ed. Chicago: University of Chicago, 1997. $184 \mathrm{p}$.

ESPINOSA, M. B.; REIG, O. A. Cytogenetics and karyosystematics of South American oryzomyine rodents (Cricetidae, Sigmodontinae). III. Banding karyotypes of Argentinian Oligoryzomys. Z. Säugetierkd., v. 56, p. 306-317, 1991.

FAGUNDES, V. Análises cromossômicas e dos complexos sinaptonêmicos em roedores brasileiros das famílias Cricetidae e Echimyidae. 1997. $194 \mathrm{f}$. Dissertação (Mestrado em Biologia) - Instituto de Biociências, Universidade de São Paulo, São Paulo, 1997.

FAGUNDES, V.; CHRISTOFF, A. U.; AMARO-GHILARD, R. C.; SCHEIBLER, D. R.; YONENAGA-YASSUDA, Y. Multiple interstitial ribosomal sites (NORs) in the Brazilian squirrel Sciurus aestuans ingrami (Rodentia, Sciuridae) with $2 n=40$. An overview of Sciurus cytogenetics. Genet. Mol. Biol., v. 26, p. 253-257, 2003. 
FAGUNDES, V.; CHRISTOFF, A. U.; YONENAGA-YASSUDA, Y. Extraordinary Chromosomal Polymorphism with 28 different karyotypes in the Neotropical species Akodon cursor (Muridae, Sigmodontinae), one of the smallest diploid number in rodents $(2 n=16,15$ and 14). Hereditas, $v$. 129, p. 263-274, 1998.

FAGUNDES, V.; SCALZI-MARTIN, J. M.; SIMS, K.; HOZIER, J.; YONENAGA-YASSUDA, Y. ZOO-FISH of a microdissection DNA library and G-banding patterns reveal the homeology between the Brazilian rodents Akodon cursor and A. montensis. Cytogenet. Cell Genet., v. 78, p. 224-228, 1997.

FERGUSON-SMITH, M.; TRIFONOV, V. Mammalian karyotype evolution. Nature Rev. Gen., v. 8, p. 950-962, 2007.

FERGUSON-SMITH, M. A.; YANG, F.; O'BRIEN, P. C. M. Comparative mapping using chromosome sorting and painting. ILAR J., v. 39, p. 68-76, 1998.

FERNANDES, F. A.; D'ANDREA, P. S.; BONVICINO, C. R. Oligoryzomys stramineus Bonvicino and Weksler, 1998 (Mammalia: Rodentia: Sigmodontinae): New records on northeastern Brazil. Checklist, v. 8, p. 184186, 2012.

FINOTELO, L. F. M.; AMARAL, P. J. S.; PIECZARKA, J. C.; DE OLIVEIRA, E. H. C.; PISSINATI, A.; NEUSSER, M.; MULLER, S.; NAGAMACHI, C.Y. Chromosome phylogeny of the subfamily Pitheciinae (Platyrrhini, Primates) by classic cytogenetics and chromosome painting. BMC Evol. Biol., v. 10, p. 2-9, 2010.

FORD, C. E.; HAMERTON, J. L. A colchicine hypotonic-citrate squash sequence for mammalian chromosome. Stain Technol., v. 31, p. 247-251, 1956.

FRANCĖS, J.; D’ELÍA, G. Oligoryzomys delticola es sinónimo de O. nigripes (Rodentia, Cricetidae, Sigmodontinae). Mastozool. Neotrop., v. 13, p. 123131, 2006.

FRESHNEY, R. I. Animal cell culture: a practical approach. Washington D.C: Oxford, 1986. 247 p.

GALLARDO, M.; GONZALEZ, L. A. Sex chromosome polymorphism in Oryzomys longicaudatus philippii (Rodentia, Cricetidae). Experientia, v. 30, p. 312-314, 1977.

GALLARDO, M. H.; PALMA, E. Systematics of Oryzomys longicaudatus (Rodentia: Muridae) in Chile. J. Mammal., v. 71, p. 333-342, 1990. 
GALLARDO, M. H.; PATTERSON, B. D. Chromosomal differences between two nominal subspecies of Oryzomys longicaudatus Bennett. Mammal. Chrom. Newsl., v. 25, p. 49-53, 1985.

GARDNER, A. L.; PATTON, J. L. Karyotypic variation in Oryzomyini rodents (Cricetidae) with comments on chromosomal evolution in the Neotropical cricetine complex. Occ. Pap. Mus. Zool., v. 49, p. 1-48, 1976.

GONZALEZ-ITTIG, R. E.; SALAZAR-BRAVO, J.; BARQUEZ, R. M.; GARDENAL, C. N. Phylogenetic relationships among species of the genus Oligoryzomys (Rodentia, Cricetidae) from Central and South America. Zool. Scripta, v. 39, p. 511-526, 2010.

GRAPHODATSKY, A. S.; TRIFONOV, V. A.; STANYON, R. The genome diversity and karyotype evolution of mammals. Mol. Cytogenet., v. 4, p. 2238, 2011.

GUERRA, M. Hibridização in situ: princípios básicos. In: FISH, conceitos e aplicações na citogenética. Ribeirão Preto: Sociedade Brasileira de Genética, 2005. p. 1-32.

HAIDUK, M. W.; BICKHAM, J.; SCHMIDLY, D. J. Karyotypes of six species of Oryzomys from Mexico and Central America. J. Mammal., v. 60, p. 610615, 1979.

HASS, I; SBALQUEIRO, I. J.; MULLER, S. Chromosomal phylogeny of four Akodontini species (Rodentia, Cricetidae) from Southern Brazil established by ZOO-FISH using Mus musculus (Muridae) painting probes. Chromosome Res., v. 16, p. 75-88, 2008.

HOOPER, E. T.; MUSSER, G. G. The glans pênis in Neotropical cricetines (family Muridae) with comments on classification of Muroid rodents. Misc. Publ. Mus. Zool. Univ. Mich., v. 123, p. 1-57, 1964.

HOWELL, W. M.; BLACK, D. A. Controlled silver-staining of nucleous organizer regions with a protective colloidal developer: a 1-step method. Experientia, v. 36, p. 1014-1015, 1980.

INTERNATIONAL UNION FOR CONSERVATION OF NATURE (IUCN). 2012. IUCN Red List of Threatened Species. Version 2012.2. Disponivel em: <www.iucnredlist.org> Acesso em: 18 mar. 2013.

JONES, R. N.; REES, H. B Chromosomes. New York: Academic Press, 1982. 266p.

KASAHARA, S. Introdução à pesquisa em citogenética de vertebrados. Ribeirão Preto: Sociedade Brasileira de Genética, 2009. 160 p. 
KASAHARA, S.; YONENAGA-YASSUDA, Y. Sex-chromosome variability in Zygodontomys lasiurus (Rodentia, Cricetidae). Cytologia, v. 48, p. 569-576, 1983.

KING, M. Species evolution the role of chromosome change. Great Britain: Cambridge University Press, 1993. 336 p.

LEE, C.; SASI, R.; LIN, C. C. Interstitial localization of telomeric DNA sequences in the Indian muntjac chromosomes: further evidence for tandem fusions in the karyotypic evolution of the Asian muntjacs. Cytogenet. Cell Genet., v. 63, p. 156-159, 1993.

LEVAN, A.; FREDGA, K.; SANDBERG, A. Nomenclature for centromeric position on chromosomes. Hereditas, v. 52, p. 201-220, 1964.

LIMA, J. F. S.; BONVICINO, C.; KASAHARA, S. A new karyotype of Oligoryzomys (Sigmodontinae, Rodentia) from central Brazil. Hereditas, v. 139, p. 1-6, 2003.

MATTEVI, M. S.; ANDRADES-MIRANDA, J. Estudos citogenéticos nos roedores da tribo Oryzomyini. In: FREITAS, T. R. O.; VIEIRA, E.; PACHECO, S.; CHRISTOFF, A. U. (Ed.). Mamíferos do Brasil: genética, sistemática, ecologia e conservação. São Carlos: Sociedade Brasileira de Genética, Suprema. 2006. p. 107-137.

METCALF, C. J.; ELDRIDGE, M. D. B.; JOHNSTON, P. G. Mapping the distribution of the telomeric sequence $\left(T_{2} A_{3}\right)_{n}$ in the $2 n=14$ ancestral marsupial complement and in the macropodines (Marsupialia: Macropodidae) by fluorescence in situ hybridization. Chromosome Res., v. 12, p. 405-414, 2004.

MEYNE, J.; BAKER, R. J.; HOBART, H. H.; HSU, T. C.; RYDER, O. A.; WARD, O. G.; WILEY, J. E.; WURSTER-HILL, D. H.; YATES, T. L.; MOYZIZ, R. K. Distribuition of non-telomeric sites of the (TTAGGG) n telomeric sequence in vertebrate chromosomes. Chromosoma, v. 99, p. 310, 1990.

MIRANDA, G. B.; OLIVEIRA, L. F. B.; ANDRADES-MIRANDA, J.; LANGGUTH, A.; CALLEGARI-JACQUES, S. M.; MATTEVI, M. Phylogenetic and phylogeographic patterns in Sigmodontine rodents of the genus Oligoryzomys. J. Hered., v. 100, p. 309-321, 2008.

MOREIRA, C. N.; DI-NIZO, C. B.; SILVA, M. J. J.; YONENAGA-YASSUDA, Y.; VENTURA, K. A remarkable autosomal heteromorphism in Pseudoryzomys simplex 2n=56, $\mathrm{FNa}=54-55$ (Rodentia, Sigmodontinae). Genet. Mol. Biol., 2013. In press. 
MORESCALCHI, M. A.; SCHEMPP, W.; CONSIGLIERE, S.; BIGONI, F.; WIENBERG, J.; STANYON, R. Mapping chromosomal homology between humans and the black-handed spider monkey by fluorescence in situ hybridization. Chromosome Res., v. 5, p. 527-536, 1997.

MUSSER, G. G.; CARLETON, M. D. Family Muridae. In: WILSON, D. E.; REEDER, D. M. Mammal species of the world: a taxonomic and geographic reference. $2^{\text {nd }}$ ed. Washington: Smithsonian Institution Press, 1993. p. 501755.

MUSSER, G. G.; CARLETON, M. D. Superfamily Muroidea. In: WILSON, D. E.; REEDER, D. M. Mammals species of the world. $3^{\text {rd }}$ ed. Baltimore: The Johns Hopkins University Press, 2005. Vol. 2, p. 955-1186.

MYERS, P.; CARLETON, M. D. The species of Oryzomys (Oligoryzomys) in Paraguay and the identity of Azara's "rat sixième ou rat à tarse noir". Misc. Publ. Mus. Zool. Univ. Mich., v. 161, p. 1-41, 1981.

MYERS, P.; LUNDRIGAN, B.; TUCKER, P. K. Molecular phylogenetics of Oryzomyine Rodents: The genus Oligoryzomys. Mol. Phylogenet. Evol., v. 4, p. 372-382, 1995.

NAGAMACHI, C. Y.; PIECZARKA, J. C.; O'BRIEN, P. C. M.; PINTO, J. A.; MALCHER, S. M.; PEREIRA, A. L.; RISSINO, J. D.; MENDES-OLIVEIRA, A. C.; ROSSI, R. V.; FERGUSON-SMITH, M. A. FISH with whole chromosome and telomeric probes demonstrates huge karyotypic reorganization with ITS between two species of Oryzomyini (Sigmodontinae, Rodentia): Hylaeamys megacephalus probes on Cerradomys langguthi karyotype. Chromosome Res., v. 2, p. 107-119, 2013.

NOWAK, R. M. Walker's mammals of the World. $5^{\text {th }}$ ed. Baltimore: John Hopkins University, 1991. Vol. 2, 1629 p.

OSGOOD, W. H. The mammals of Chile. Field Museum of Natural History, 1943. Vol. 30, 268 p. (Zoological series).

PAGNOZZI, J. M.; SILVA, M.J.J.; YONENAGA-YASSUDA,Y. Intraespecific variation in the distribution of the interstitial telomeric (TTAGGG)n sequences in Micoureus demerarae (Marsupialia: Didelphidae). Chromosome Res., v. 8, p. 585-591, 2000.

PAIVA, C. R.; NASCIMENTO, J.; SILVA, A. P. Z.; BERNARDE, P. S.; ANANIAS, F. Karyotypes and Ag-NORs in Phyllomedusa camba De La Riva, 1999 and P. rhodei Mertens, 1926 (Anura, Hylidae, Phyllomedusinae): cytotaxonomic considerations. Ital. J. Zool., v. 77, p. 116-121, 2010. 
PALMA, R. E.; RIVERA-MILLA, E.; SALAZAR-BRAVO, J.; TORRESPEREZ, F.; PARDIÑAS, U. F. J.; MARQUET, P. A.; SPOTORNO, A. E.; MEYNARD, A. P.; YATES, T. L. Phylogeography of Oligoryzomys longicaudatus (Rodentia: Sigmodontinae) in temperate South America. J. Mammal., v. 86, p. 191-200, 2005.

PALMA, R. E.; RODRIGUEZ-SERRANO, E.; RIVERA-MILLA, E.; HERNANDEZ, C. E.; SALAZAR-BRAVO, J.; CARMA, M. I.; BELMARLUCERO, S.; GUTIERREZ-TAPIA, P.; ZEBALLOS, H.; YATES, T. L. Phylogenetic relationships of the pigmy rice rats of the genus Oligoryzomys Bangs, 1900 (Rodentia, Sigmodontinae). Zool. J. Linnean Soc., v. 160, p. 551-566, 2010.

PARESQUE, R. Identidade das espécies de Oligoryzomys (Rodentia: Sigmodontinae) do Cerrado e Mata Atlântica. 2004. 136 f. Dissertação (Mestrado em Ciências Biológicas). Universidade Federal do Espírito Santo, Espírito Santo, 2004.

PARESQUE, R. Diversificação das espécies do gênero Oligoryzomys Bangs 1900 (Rodentia, Cricetidae) na região neotropical. 2010. 326 f. Tese (Doutorado em Biologia Genética) - Instituto de Biociências, Universidade de São Paulo, São Paulo, 2010.

PARESQUE, R.; SILVA, M. J. J.; YONENAGA-YASSUDA, Y.; FAGUNDES, V. Karyological geographic variation of Oligoryzomys nigripes Olfers, 1818 (Rodentia, Cricetidae) from Brazil. Genet. Mol. Biol., v. 30, p. 43-53, 2007.

PATTON, J. L. Comparative genomics and the role of chromosomal rearrangements in species divergence: a paradigm revisited. Mastozool. Neotrop., v. 11, p. 147-150, 2004.

PATTON, J. L.; DA SILVA, M. N. F.; MALCOLM, J. R. Mammals of the Rio Juruá and the evolutionary and ecological diversification of Amazonia. Bull. Am. Mus. Nat. Hist., v. 244, p. 1-305, 2000.

PELLEGRINO, K. C. M.; RODRIGUES, M. T.; YONENAGA-YASSUDA, Y. Chromosomal evolution in the Brazilian lizards of genus Leposoma (Squamata, Gymnophthalmidae) from Amazon and Atlantic rain forests: banding patterns and FISH of telomeric sequences. Hereditas, v. 131, p. 1521, 1999.

PEPPERS, J. A.; WIGGINS, L. E.; BAKER, R. J. Nature of B chromosomes in the harvest mouse Reithrodontomys megalotis by fluorescence in situ hybridization (FISH). Chromosome Res., v. 5, p. 475-479, 1997.

PERCEQUILLO, A. R.; WEKSLER, M.; COSTA, L. P. A new genus and species of rodent from the Brazilian Atlantic Forest (Rodentia: Cricetidae: Sigmodontinae: Oryzomyini), with comments on oryzomyine biogeography. Zool. J. Linnean Soc., v. 161, p. 357-390, 2011. 
PEREIRA, N. P.; VENTURA, K.; JUNIOR, M. C. S.; SILVA, D. M.; YONENAGA-YASSUDA, Y.; PELLEGRINO, K. C. M. Karyotype characterization and nucleolar organizer regions of marsupial species (Didelphidae) from areas of Cerrado and Atlantic Forest in Brazil. Genet. Mol. Biol., v. 31, p. 887-892, 2008.

PERINI, M. B.; WEIMER, T. A.; CALLEGARI-JACQUES, S. M.; MATTEVI, M. S. Biochemical polymorphisms and genetic relationships in Rodents of the genera Oryzomys and Oligoryzomys (Sigmodontinae) from Brazil. Biochem. Genet., v. 42, p. 317-329, 2004.

PIECZARKA, J. C.; NAGAMACHI, C. Y. Pintura cromossômica como instrumento para estudos filogenéticos em primatas. In: GUERRA, M. FISH, conceitos e aplicações na citogenética. Ribeirão Preto: Sociedade Brasileira de Genética, 2005. Cap. 5, p. 115-132.

PINE, R. H.; TIMM, R. M.; WEKSLER, M. A newly recognized clade of transAndean Oryzomyini (Rodentia: Cricetidae), with description of a new genus. J. Mammal., v. 93, p. 851-870, 2012.

RASBAND, W. S. ImageJ. US National Institutes of Health, Bethesda, Maryland, USA. Disponível em: <http://imagej.nih.gov/ij/>. Acesso em: 08 out. 2011.

REIG, O. A. A new fossil genus of South America cricetid rodents allied to Wiedomys, with an assessment of the Sigmodontinae. J. Zool., v. 192, p. 257-281, 1980.

REIG, O. A. Distribuição geográfica e história evolutiva dos roedores muroideos sulamericanos (Cricetidae: Sigmodontinae). Rev. Bras. Genet., v. 6, p. 333-365, 1984.

REIG, O. A. Diversity patterns and differentiation of high Andean rodents. In: VUILLEUMIER, F.; MONASTERIO, M. (Ed.). High altitude tropical biogeography. New York: Oxford University Press, 1986. p. 404-439.

RICHARD, F.; LOMBARD, M.; DUTRILLAUX, B. ZOO-FISH suggests a complete homology between human and Capuchin Monkey (Platyrrhini) euchromatin. Genomics, v. 36, p. 417-423, 1996.

RICHARD, F.; MESSAOUD, C.; BONNET-GARNIER, A.; LOMBARD, M.; DUTRILLAUX, B. Highly conserved chromosomes in an Asian squirrel as demonstrated by ZOO-FISH with human probes. Chromosome Res., v. 17, p. 597-603, 2003.

RIESEBERG, L. H. Chromosomal rearrangements and speciation. Trends Ecol. Evol., v. 16, p. 351-358, 2001.

RIESEBERG, L. H.; LIVINGSTONE, K. Chromosomal speciation in Primates. Science, v. 300, p. 267-268, 2003. 
ROMANENKO, S. A.; PERELMAN, P. L.; SERDUKOVA, N. A.; TRIFINOV, V.; BILTUEVA, L. S.; WANG, J.; LI, T.; NIE, W.; O’BRIEN, P. C. M.; VOLOBOUEV, V. T.; STANYON, R.; FERGUSON-SMITH, M. A.; YANG, F.; GRAPHODATSKY, A. S. Reciprocal chromosome painting between three laboratory rodent species. Mamm. Genome, v. 17, p. 1183-1192, 2006.

ROMANENKO, S. A.; PERELMAN, P. L.; TRIFONOV, V. A.; GRAPHODATSKY, A. S. Chromosomal evolution in Rodentia. Heredity, v. 108, p. 4-16, 2012.

RUIZ-HERRERA, A.; GARCÍA, F.; AZZALIN, C.; GIULOTTO, E.; EGOZCUE, J.; PONSÀ, M.; GARCIA, M. Distribution of intrachromosomal telomeric sequences (ITS) on Macaca fascicularis (primates) chromosomes and their implication for chromosome evolution. Hum. Genet., v. 110, p. 578-586, 2002.

RUIZ-HERRERA, A.; NERGADZE, S. G.; SANTAGOSTINO, M; GIULOTTO, $E$. Telomeric repeats far from the ends: mechanisms of origin and role in evolution. Cytogenet. Genome Res., v. 122, p. 219-228, 2008.

SBALQUEIRO, I. J.; MATTEVI M. S.; OLIVEIRA L. F. B.; SOLANO M. J. V. B chromosome system in populations of Oryzomys flavescens (Rodentia, Cricetidae) from southern Brazil. Acta Theriol., v. 36, p. 193-199, 1991.

SCACCHETTI, P. C.; PANSONATO-ALVES, J. C.; UTSUNOMIA, R.; OLIVEIRA, C.; FORESTI, F. Karyotypic diversity in four species of the genus Gymnotus Linnaeus, 1758 (Teleostei, Gymnotiformes, Gymnotidae): physical mapping of ribosomal genes and telomeric sequences. Comparative cytogenetics, v. 5, p. 223-235, 2011.

SCHERTHAN, H.; CREMER, T.; ARNASON, U.; HEINZ-ULRICH, W.; LIMADE-FARIA, A.; FRÖNICKE, L. Comparative chromosome painting discloses homologous segments in distantly related mammals. Nature Genetics, v. 6, p. 342-347, 1994.

SCHWARZACHER, T.; HESLOP-HARRISON, P. Practical in situ hybridization. New York: Springer-Verlag New York Inc., 2000. 203 p.

SEABRIGHT, M. A rapid being technique for human chromosomes. Lancet, v. 2, p. 971-972, 1971.

SILVA, M. J. J. Estudos cromossômicos e de complexos sinaptonêmicos em roedores brasileiros da Tribo Oryzomyini (Cricetidae, Rodentia). 1994. 168 f. Dissertação (Mestrado em Biologia). - Instituto de Biociências, Universidade de São Paulo, São Paulo, 1994. 
SILVA, M. J. J. Estudos dos processos de diferenciação cariotipica, baseados em citogenética convencional e molecular, em quatro gêneros de roedores brasileiros. 1999. $141 \mathrm{f}$. Tese (Doutorado em Biologia/ Genética) Instituto de Biociências, Universidade de São Paulo, São Paulo, 1999.

SILVA, M. J. J.; YONENAGA-YASSUDA, Y. New karyotypes of two related species of Oligoryzomys genus (Cricetidae, Rodentia) involving centric fusion with loss of NORs and distribution of telomeric (TTAGGG)n sequences. Hereditas, v. 127, p. 217-229, 1997.

SILVA, M. J. J.; YONENAGA-YASSUDA, Y. Heterogeneity and meiotic behaviour of $B$ and sex chromosomes, banding patterns and localization of (TTAGGG)n sequences by FISH, in the Neotropical water rat Nectomys (Rodentia, Cricetidae). Chromosome Res., v. 6, p. 445-462, 1998.

SILVA, M. J. J.; YONENAGA-YASSUDA, Y. B chromosomes in Brazilian rodents. Cytogenet. Genome Res., v. 106, p. 257-263. 2004.

SMITH, M. F.; PATTON, J. L. Phylogenetics relationships and the radiation of Sigmodontinae Rodents in South America: evidence from cytocrome b. J. Mammal. Evol., v. 6, p. 89-128, 1999.

STEPPAN, S. J.; ADKINS, R. M.; ANDERSON, J. Phylogeny and divergence-date estimates of rapid radiations in muroid rodents based on multiple nuclear genes. Systc. Biol., v. 53, p. 533-553, 2004.

STITOU, S.; GUARDIA, R. D.; JIMÉNEZ, R.; BURGOS, M. Inactive ribosomal cistrons are spread throughout the B chromosomes of Rattus rattus (Rodentia, Muridae). Implications for their origin and evolution. Chromosome Res., v. 8, p. 305-311, 2000.

SUMNER, A. T. A simple technique for demonstrating centromeric heterocromatin. Exp. Cell Res., v. 75, p. 304-306, 1972.

SVARTMAN, M. American marsupials chromosomes: why study them? Genet. Mol. Biol., v. 32, p. 675-687, 2009.

SVARTMAN, M.; ALMEIDA, E. J. C. Sex chromosomes polymorphisms in Oryzomys aff. subflavus (Cricetidae, Rodentia) from Central Brazil. Caryologia, v. 45, p. 313-324, 1992.

SWIER, V. J.; BRADLEY, R. D.; RENS, W.; ELDER, R. J.; BAKER, R. J. Patterns of chromosomal evolution in Sigmodon, evidence from whole chromosome paints. Cytogenet. Genome Res., v. 125, p. 54-66, 2009.

TEleniUS, H.; PELMEAR, A. H.; TUNNAClifFE, A.; CARTER, N. P.; BEHMEL, A.; FERGUSON-SMITH, M. A.; NORDENSKJÖLD, M.; PFRAGNER, R.; PONDER, B. A. J. Cytogenetic Analysis by Chromosome Painting using DOP-PCR amplified flow-sorted chromosomes. Genes Chromosomes Canc., v. 4, p. 257-263, 1992. 
TRIFONOV, V. A.; DEMENTYEVA, P. V.; BEKLEMISHEVA, V. R.; YUDKIN, D. V.; VOROBIEVA, N. V.; GRAPHODATSKY, A. S. Supernumerary Chromosomes, Segmental Duplications, and Evolution. Russ. J. Genet., v. 46, p. 1094-1096, 2010.

VENTURA, K.; O'BRIEN, P. C. M.; YONENAGA-YASSUDA, Y.; FERGUSON-SMITH, M. A. Chromosome homologies of the highly rearranged karyotypes of four Akodon species (Rodentia, Cricetidae) resolved by reciprocal chromosome painting: the evolution of the lowest diploid number in rodents. Chromosome Res., v. 17, p. 1063-1078, 2009.

VENTURA, K.; SATO-KUWABARA, Y.; FAGUNDES, V.; GEISE, L.; LEITE, Y. L. R.; COSTA, L. P.; SILVA, M. J. J.; YONENAGA-YASSUDA, Y.; RODRIGUES, M. T. Phylogeographic structure and karyotypic diversity of the Brazilian Shrew Mouse (Blarinomys breviceps, Sigmodontinae) in the Atlantic Forest. Cytogenet. Genome Res., v. 138, p. 19-30, 2012.

VENTURA, K.; SILVA, M. J. J.; FAGUNDES, V.; PARDINI, R.; YONENAGAYASSUDA, Y. An undescribed karyotype for Thaptomys $(2 n=50)$ and the mechanism of differentiation from Thaptomys nigrita $(2 n=52)$ evidenced by FISH and Ag-NORs. Caryologia, v. 57, p. 89-97, 2004.

VIEGAS-PEQUIGNOT, E.; DUTRILLAUX, B.; MAGDELENAT, H.; COPPEYMOISAN, M. Mapping of the single-copy DNA sequences on human chromosomes by in situ hybridization with biotinylated probes: Enhancement of detection sensitivity by intensified-fluorescence digital imaging microscopy. Genetics, v. 86, p. 582-586, 1989.

VIEIRA, M. Seasonal niche dynamics in coexisting rodents of the Brazilian Cerrado. Stud. Neotrop. Fauna E., v. 28, p. 7-15, 2003.

VILELA, R. V.; MACHADO, T.; VENTURA, K.; FAGUNDES, K.; SILVA, M. J. J.; YONENAGA-YASSUDA, Y. The taxonomic status of the endangered thin-spined porcupine, Chaetomys subspinosus (Olfers, 1818), based on molecular and karyologic data. BMC Evol. Biol., v. 9, p. 1-17, 2009.

VUJOSEVIC, M.; BLAGOJEVIC, J. B chromosomes in populations of mammals. Cytogenet. Genome Res., v. 106, p. 247-256, 2004.

WEKSLER, M. Revisão sistemática do grupo de espécies nitidus do gênero Oryzomys (Rodentia: Sigmodontinae). 1996. 210 f. Dissertação (Mestrado em Ciências Biológias - Zoologia) - Museu Nacional, Universidade Federal do Rio de Janeiro, Rio de Janeiro, 1996.

WEKSLER, M. Phylogeny of Neotropical oryzomyine rodents (Muridae: Sigmodontinae) based on the nuclear IRBP exon. Mol. Phylogent. Evol., v. 29, p. 331-349, 2003. 
WEKSLER, M.; BONVICINO, C. R. Taxonomy of pigmy rice rats genus Oligoryzomys Bangs, 1900 (Rodentia, Sigmodontinae) of the Brazilian cerrado, with the description of two new species. Arquivos do Museu Nacional Rio de Janeiro, v. 63, p. 113-130, 2005.

WEKSLER, M.; PERCEQUILLO, A. R. Key to the genera of the tribe Oryzomyini (Rodentia: Cricetidae: Sigmodontinae). Mastozool. Neotrop., v. 18, p. 281-292, 2011.

WEKSLER, M.; PERCEQUILLO, A. R.; VOSS, R. S. Ten new genera of Oryzomyine Rodents (Cricetidae: Sigmodontinae). American Museum Novitates, v. 3537, p. 1-29, 2006.

WIENBERG, J.; JAUCH, A.; STANYON, R.; CREMER, T. Molecular Cytotaxonomy of primates by chromosomal in situ suppression hybridization. Genomics, v. 8, p. 347-350, 1990.

WILEY, J. E.; MEYNE, J.; LITTLE, M. L.; STOUT, J. C. Intersticial hybridization sites of the (TTAGGG) $)_{n}$ telomeric sequence on the chromosomes of some North American hylid frogs. Cytogenet. Cell Genet., v. 61, p. 55-57, 1992.

WOOD, A. E. Are there rodent suborders? Syst. Zool., v. 7, p. 169-173, 1958.

YANG, F.; CARTER, N. P.; SHI, L.; FERGUSON-SMITH, M. A. A comparative study of karyotype of muntjacs by chromosome painting. Chromosoma., v. 103, p. 642-652, 1995.

YANG, F.; GRAPHODATSKY, A. S. Animal probes and ZOO-FISH. In: LIEHR, T. (Ed.). Fluorescence in situ hybridization (FISH) - Application Guide. Berlin: Springer-Verlag Heidelberg. 2009. Cap. 29, p. 323-347.

YANG, F.; TRIFONOV, V.; NG, B. L.; KOSYAKOVA, N.; CARTER, N. P. Generation of paint probes by flow-sorted and microdissected chromosomes. In: LIEHR, T. (Ed.). Fluorescence In Situ Hybridization (FISH) - Application Guide. Berlin: Springer-Verlag Berlin Heidelberg, 2009. p. 35-52.

YONENAGA, Y. Polimorfismos cromossômicos em roedores brasileiros. 1972. Tese (Doutorado em Ciências) - Instituto de Biociências, Universidade de São Paulo, São Paulo, 1972.

YONENAGA-YASSUDA, Y.; SOUZA, M. J.; KASAHARA, S.; L'ABBATE, M.; $\mathrm{CHU}, \mathrm{H}$. T. Supernumerary system in Proechimys iheringi iheringi (Rodentia, Echimyidae), from the state of São Paulo, Brazil. Caryologia, v. 38, p. 179-194, 1985.

ZAKIAN, V. A. Telomeres: beginning to understand the end. Science, v. 270, p. 1601-1606, 1995. 